\title{
Hydrogen Generation in TRU Waste Transportation Packages
}

\author{
B. L. Anderson, M. K. Sheaffer, L. E. Fischer
}

\section{March 27, 2000}

Lawrence

Livermore

National

Laboratory 


\section{DISCLAIMER}

This document was prepared as an account of work sponsored by an agency of the United States Government. Neither the United States Government nor the University of California nor any of their employees, makes any warranty, express or implied, or assumes any legal liability or responsibility for the accuracy, completeness, or usefulness of any information, apparatus, product, or process disclosed, or represents that its use would not infringe privately owned rights. Reference herein to any specific commercial product, process, or service by trade name, trademark, manufacturer, or otherwise, does not necessarily constitute or imply its endorsement, recommendation, or favoring by the United States Government or the University of California. The views and opinions of authors expressed herein do not necessarily state or reflect those of the United States Government or the University of California, and shall not be used for advertising or product endorsement purposes.

This work was performed under the auspices of the U. S. Department of Energy by the University of California, Lawrence Livermore National Laboratory under Contract No. W-7405-Eng-48.

This report has been reproduced directly from the best available copy.

Available electronically at http://www.doc.gov/bridge

Available for a processing fee to U.S. Department of Energy

And its contractors in paper from

U.S. Department of Energy

Office of Scientific and Technical Information

P.O. Box 62

Oak Ridge, TN 37831-0062

Telephone: (865) 576-8401

Facsimile: (865) 576-5728

E-mail: reports@adonis.osti.gov

Available for the sale to the public from

U.S. Department of Commerce

National Technical Information Service

5285 Port Royal Road

Springfield, VA 22161

Telephone: (800) 553-6847

Facsimile: (703) 605-6900

E-mail: orders@ntis.fedworld.gov

Online ordering: http://www.ntis.gov/ordering.htm

OR

Lawrence Livermore National Laboratory

Technical Information Department's Digital Library

http://www.llnl.gov/tid/Library.html 


\section{Hydrogen Generation in TRU Waste Transportation Packages}

Manuscript date: January 31, 2000

Publication date:

Prepared by:

B.L. Anderson

M.K. Sheaffer

L.E. Fischer

Lawrence Livermore National Laboratory

7000 East Avenue

Livermore, CA 94550

Prepared for

Office of Nuclear Material Safety and Safeguards

Spent Fuel Project Office

U.S. Nuclear Regulatory Commission

Washington, DC 20555-0001

NRC Job Code A0291 


\begin{abstract}
This document addresses hydrogen generation in TRU waste transportation packages. The potential sources of hydrogen generation are summarized with a special emphasis on radiolysis. After defining various TRU wastes according to groupings of material types, bounding radiolytic G-values are established for each waste type. Analytical methodologies are developed for prediction of hydrogen gas concentrations for various packaging configurations in which hydrogen generation is due to radiolysis. Representative examples are presented to illustrate how analytical procedures can be used to estimate the hydrogen concentration as a function of time. Methodologies and examples are also provided to show how the time to reach a flammable hydrogen concentration in the innermost confinement layer can be estimated. Finally, general guidelines for limiting the hydrogen generation in the payload and hydrogen accumulation in the innermost confinement layer are described.
\end{abstract}




\section{CONTENTS}

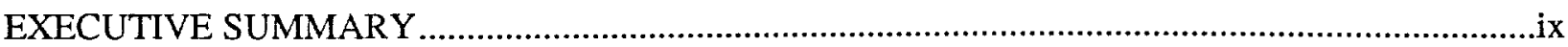

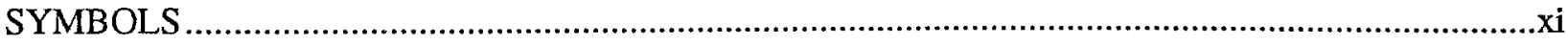

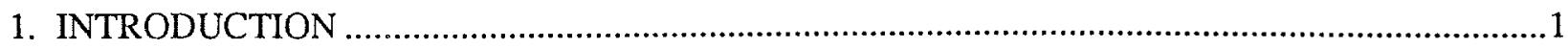

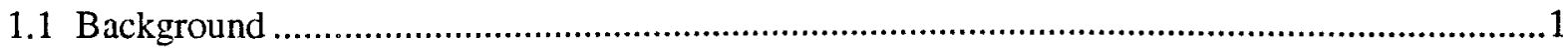

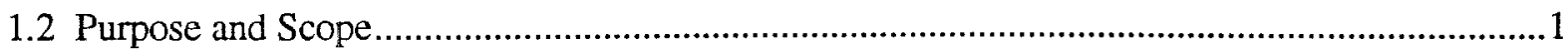

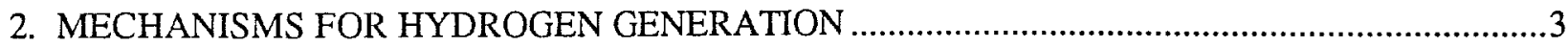

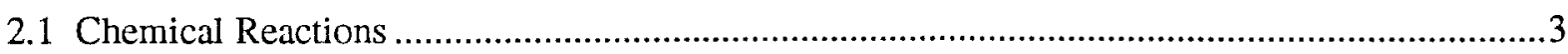

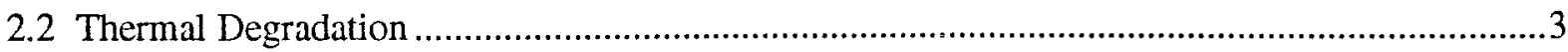

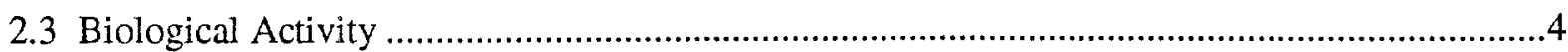

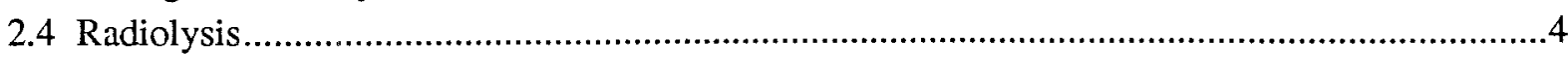

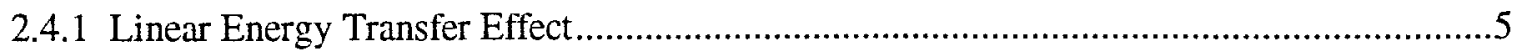

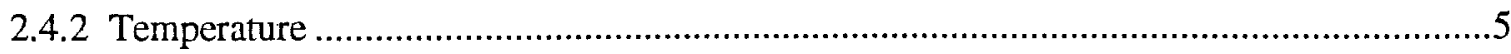

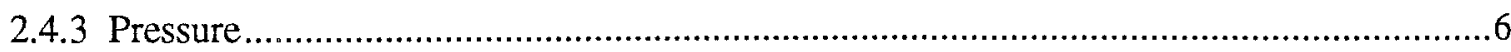

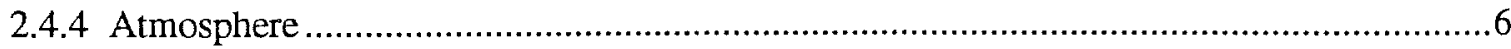

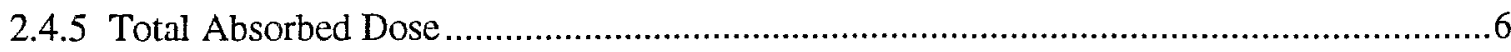

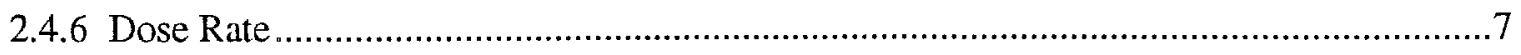

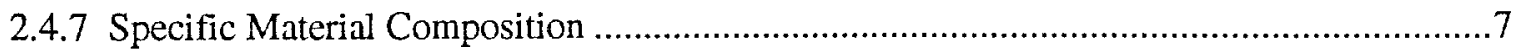

2.4.8 Fraction of Energy Absorbed by a Material ............................................................

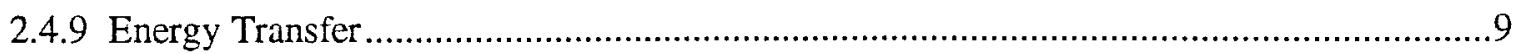

3. HYDROGEN GENERATION RATES IN TRANSURANIC WASTE........................................11

3.1 Radiolysis of Water and Other Materials Commonly in TRU Waste ......................................11

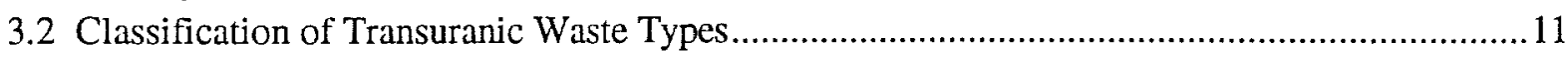

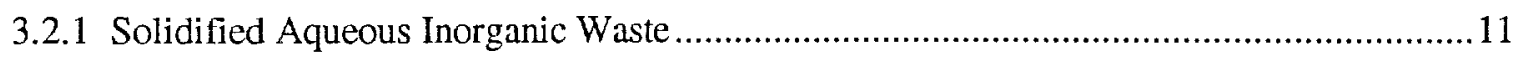

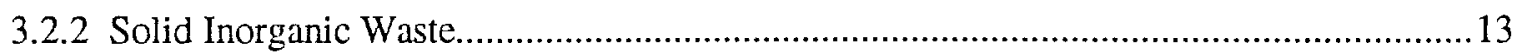

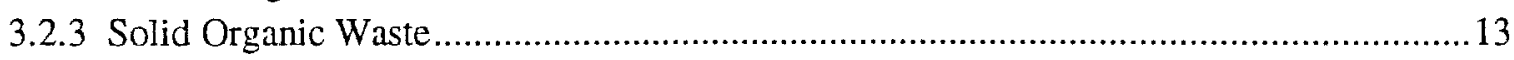

3.3 Effective Radiolytic G Values for Various Waste Types .................................................15

3.3.1 Effective G-Value for a General Mixture of Materials.................................................. 15

3.3.2 Effective G Values for Solidified Aqueous Inorganic Waste .........................................17

3.3.3 Effective G Values for Solid Inorganic Waste ............................................................22

3.3.4 Effective G Values for Solid Organic Waste ............................................................23

3.3.5 Summary of the Effective G Values for Various Waste Types When the Radionuclides

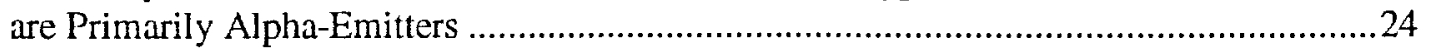

4 CALCULATION OF HYDROGEN CONCENTRATION FOR VARIOUS PACKAGING

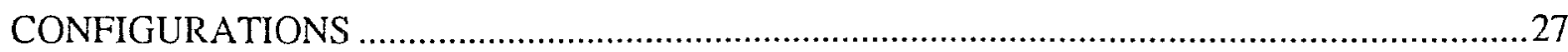

4.1 Modeling Hydrogen Concentration in TRU Waste Transportation Containers ........................27

4.1.1 Diffusion of Hydrogen Through Leak Paths..............................................................27

4.1.2 Permeation of Hydrogen Through Packaging Materials .............................................29

4.2 Hydrogen Gas Concentration for Various Packaging Configurations ......................................30

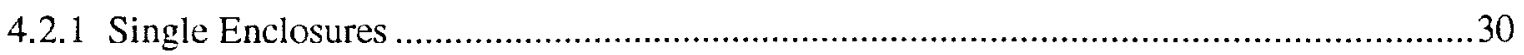




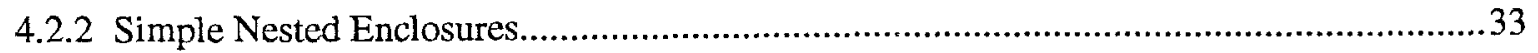

4.3 Pressures in Transuranic Waste Transportation Packages .....................................................42

4.3.1 Pressure in a Single Rigid Non-Leaking Enclosure ..................................................42

4.3.2 Pressure in a Single Rigid Leaking Enclosure ............................................................43

4.4 Time to Reach the Lower Flammability Limit for Hydrogen in Transuranic Waste

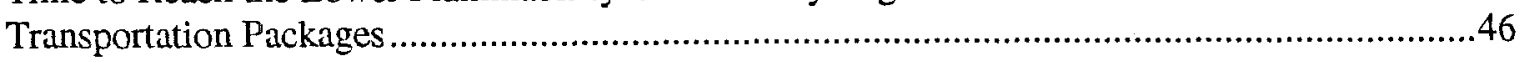

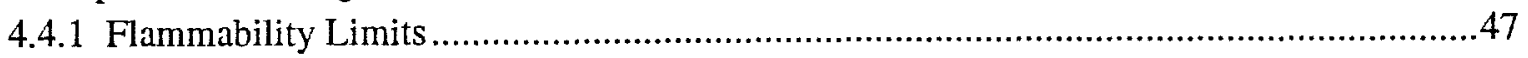

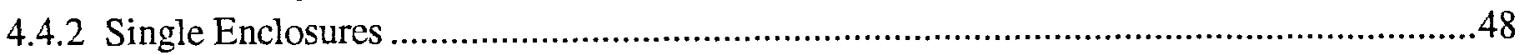

4.4.3 Simple Nested Enclosures..................................................................................49

5. CONTROL OF HYDROGEN IN TRANSURANIC WASTE TRANSPORTATION

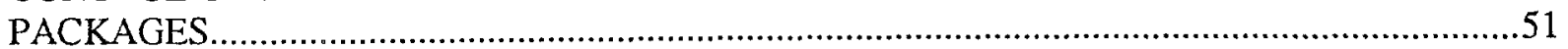

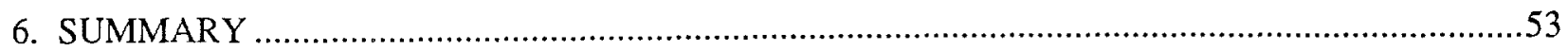

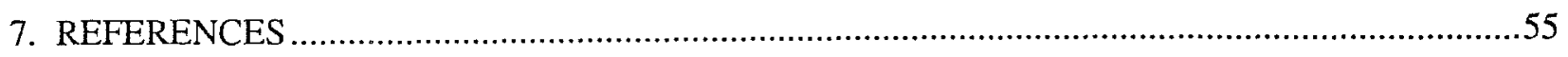

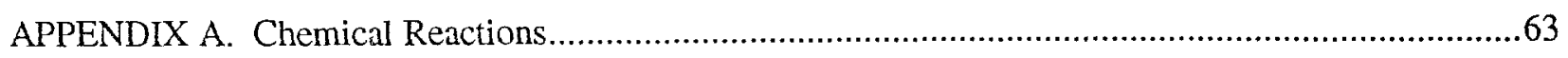

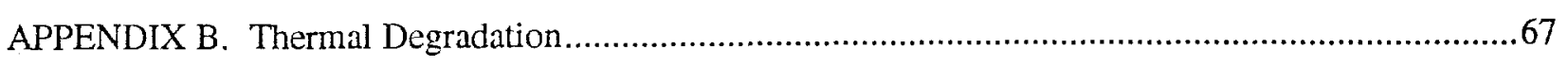

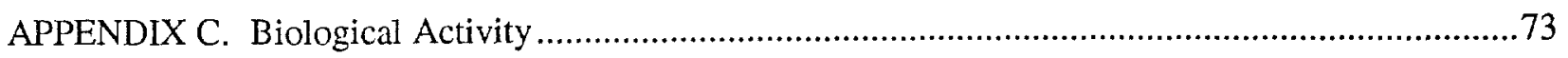

APPENDIX D. Radiolytic G-values for Various Materials ..............................................................75

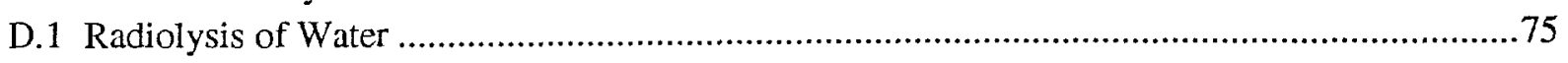

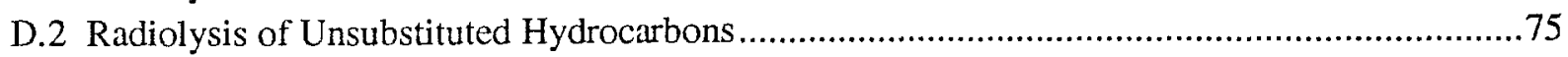

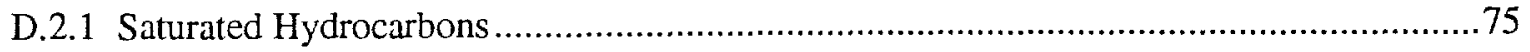

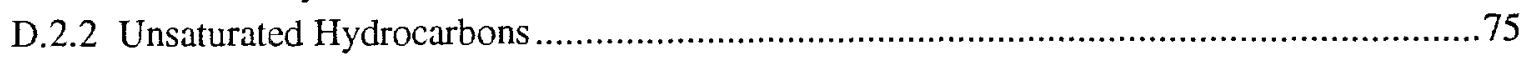

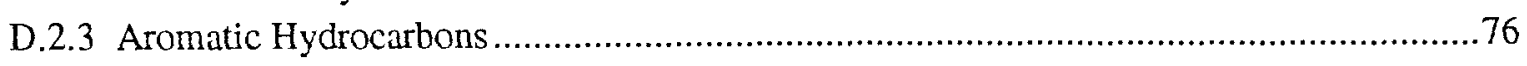

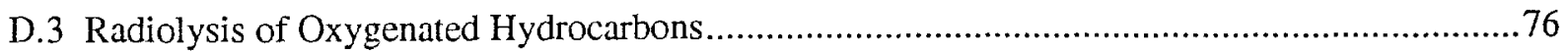

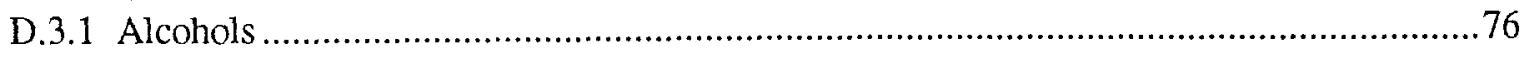

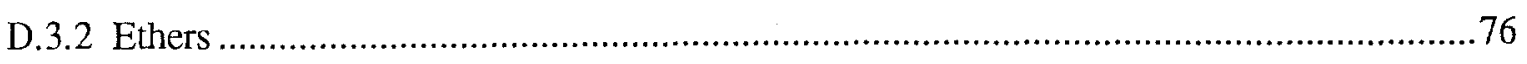

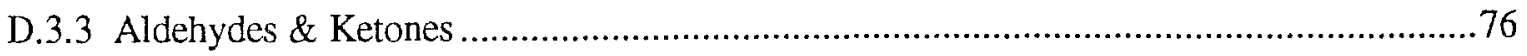

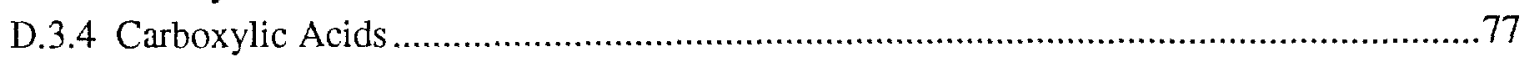

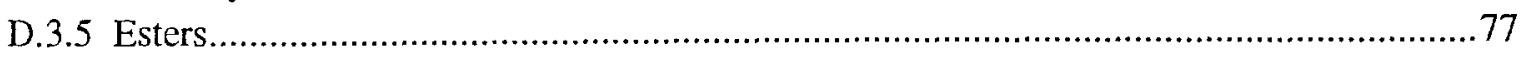

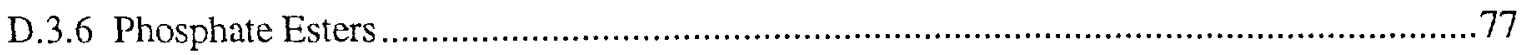

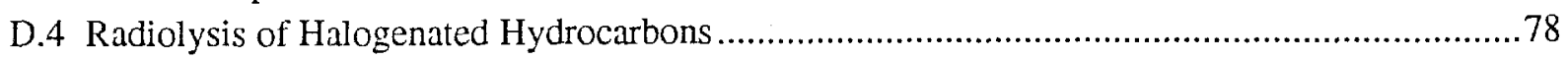

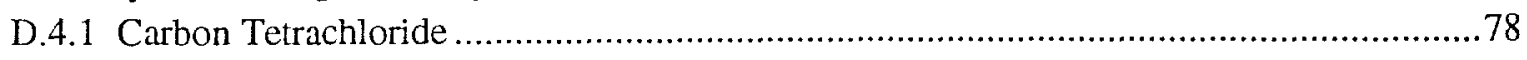

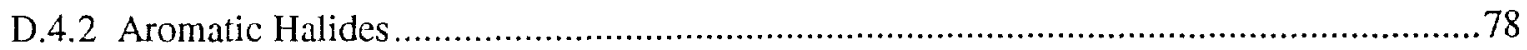

D.4.3 Miscellaneous Halogenated Hydrocarbons ............................................................. 78

D.5 Radiolysis of Organic Nitrogen Compounds ..............................................................78

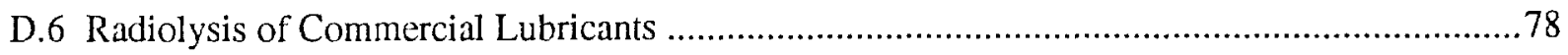

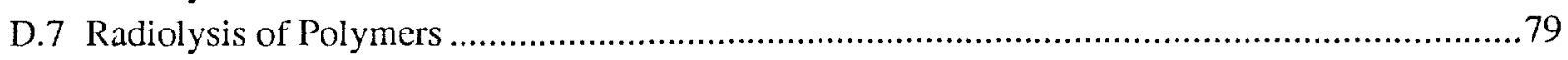

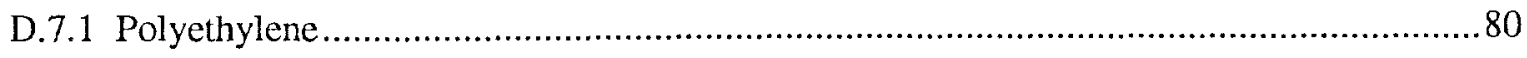

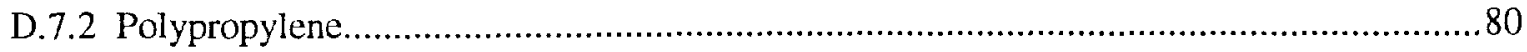

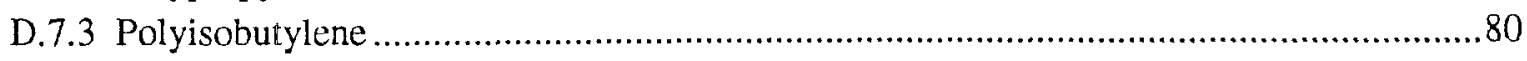

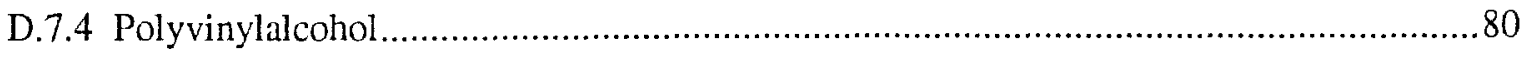

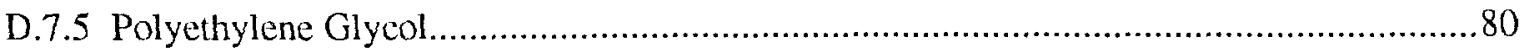




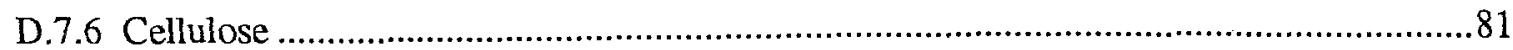

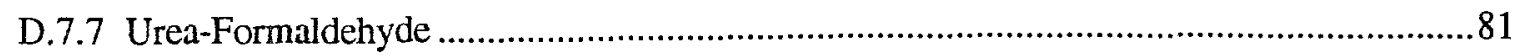

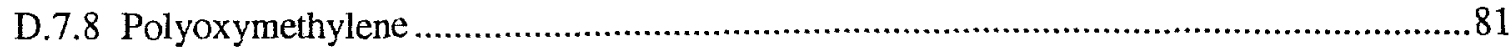

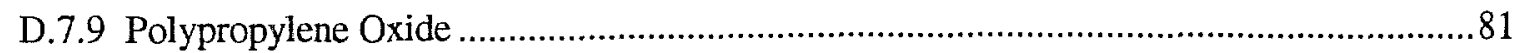

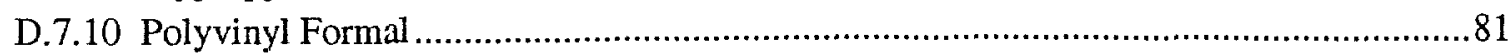

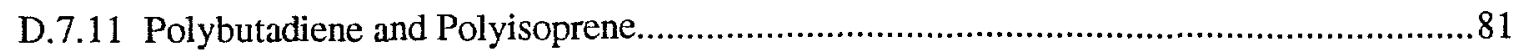

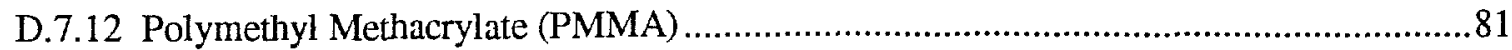

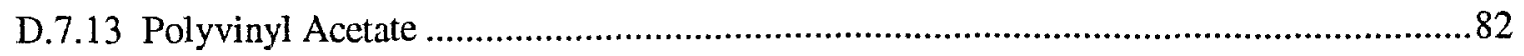

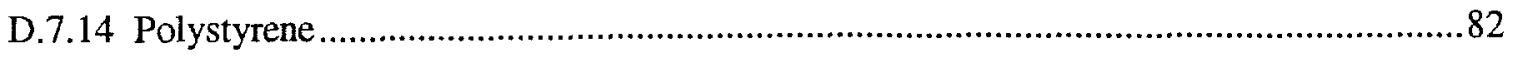

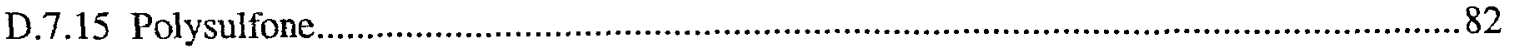

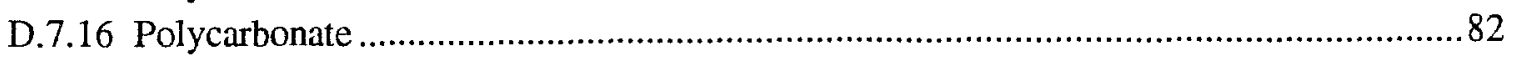

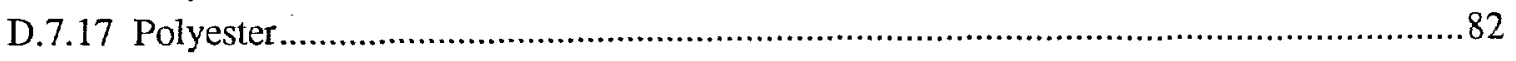

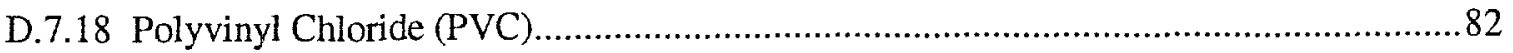

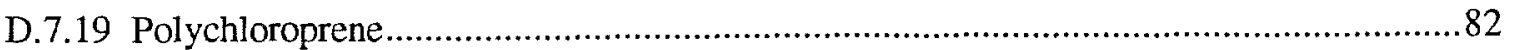

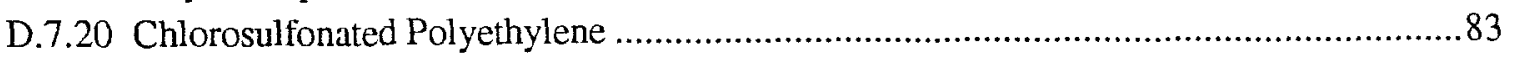

D.7.21 Polytetrafluoroethylene (PTFE) and Polychlorotrifluoroethylene .............................83

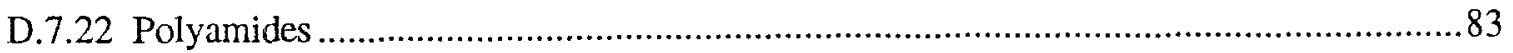

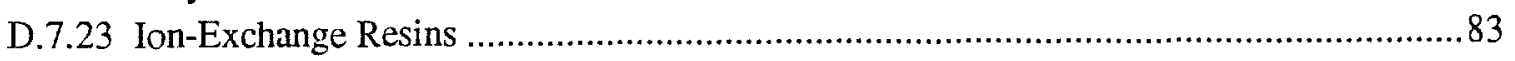

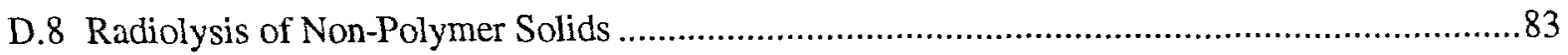

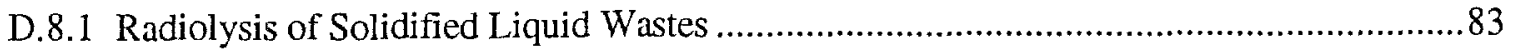

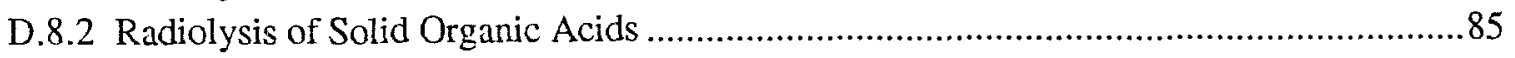

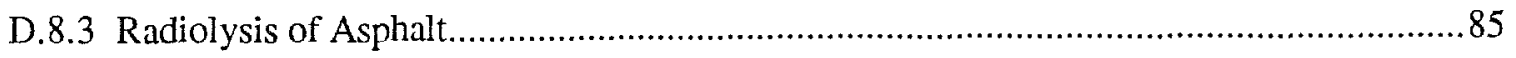

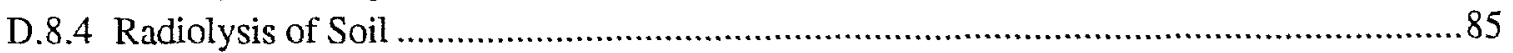

D.8.5 Radiolysis of Dry, Solid Inorganic Materials ........................................................ 85

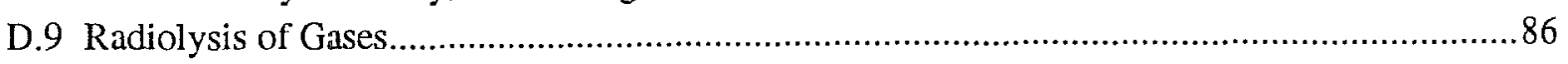

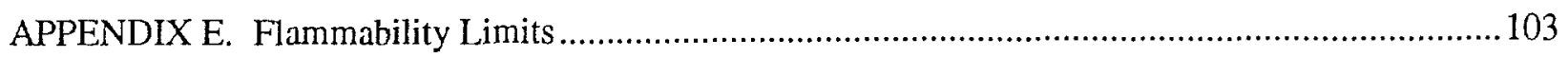

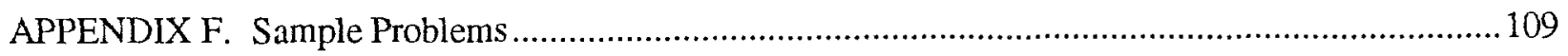




\section{TABLES}

Table 3.1 Summary of Bounding Radiolytic G Values for Hydrogen and Flammable-Gas

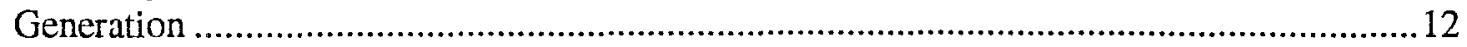

Table 3.2 Examples of Materials Acceptable in Solidified Aqueous Inorganic Wastes ......................13

Table 3.3 Examples of Materials Acceptable in Solid Inorganic Wastes ..........................................14

Table 3.4 Examples of Material Acceptable in Solid Organic Waste.............................................14

Table 3.5 Coefficients for Calculation of Effective G(gas) for Solidified Aqueous Inorganic

Absorbed Waste ....................................................................................................... 18

Table 3.6 Coefficients for Calculation of Effective G(gas) for Solidified Aqueous Inorganic

Particulate Waste .....................................................................................................20

Table 3.7 Coefficients for Calculation of Effective G(gas) for Solidified Aqueous Inorganic

Particulate Waste .........................................................................................................2 21

Table 3.8 Coefficients for Calculation of Effective G(gas) for Solidified Aqueous Inorganic

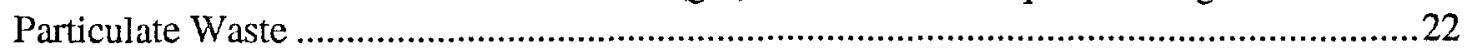

Table 3.9 Coefficients for Calculation of Effective G(gas) for Solid Organic Waste..........................24

Table 3.10 Effective Radiolytic G Values for the Various Waste Types at $298 \mathrm{~K}$ when the Waste Contains Radionuclides that are Predominantly Alpha-Emitting ..............................25

Table 3.11 Activation Energies for Bounding G Value Materials .....................................................25

Table B.1 Vacuum Outgassing of Some Common Polymers at 298 K (Parker Seals 1992) ....................68

Table B.2 Maximum Continuous Service Temperatures (MCST) for Common Plastics

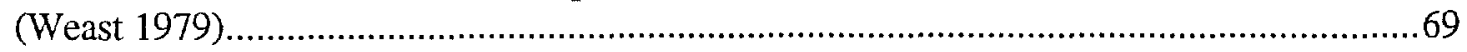

Table B.3 Various Thermal Degradation Results for Polymers .....................................................70

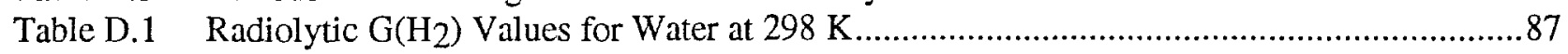

Table D.2 Radiolytic G Values for Saturated Hydrocarbons at $298 \mathrm{~K}$.............................................8

Table D.3 Radiolytic G Values for Unsaturated Hydrocarbons at $298 \mathrm{~K}$.........................................89

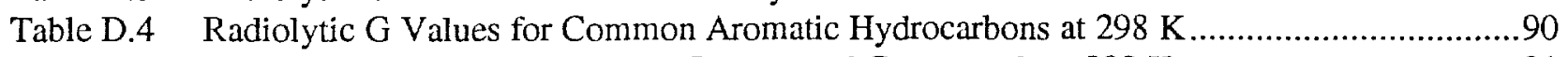

Table D.5a Radiolytic G Values for Various Oxygenated Compounds at $298 \mathrm{~K}$...............................91

Table D.5b Radiolytic G Values for Various Oxygenated Compounds at 298 K ...............................92

Table D.5c Radiolytic G Values for Various Oxygenated Compounds at $298 \mathrm{~K}$................................93

Table D.6 Radiolytic G Values for Halogenated Hydrocarbons at $298 \mathrm{~K}$.......................................94

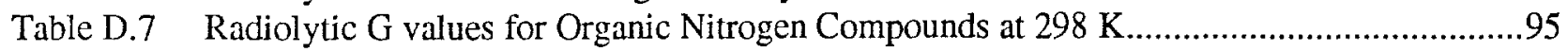

Table D.8 Radiolytic G Values for Common Commercial Lubricants at 298 K.................................96

Table D.9 Radiation Resistance of Some Common Polymers at $298 \mathrm{~K}$..........................................97

Table D.10 Expected Relative G(flam gas) Values for Structurally Related Polymers Containing Only Carbon, Hydrogen, Nitrogen, and Oxygen ...........................................................98

Table D.11 Summary of Maximum G Values for Various Classes of Polymers at $298 \mathrm{Ka}$..................99

Table D.12 G(gas) Values for Miscellaneous Commercial Plastics .................................................100

Table D.13 Summary of Radiolysis Experiments on Cements at $298 \mathrm{~K}$.......................................... 101

Table E.1 Lower and Upper Flammability Limits for Common Gases and Vapors ..........................103 


\section{EXECUTIVE SUMMARY}

An analysis of hydrogen generation in transportation packages for transuranic (TRU) waste materials is necessary to ensure that the packages do not accumulate an unsafe concentration of hydrogen (or other flammable) gas. As a result of safety considerations related to flammability, the concentration of hydrogen in the transportation package is limited to a level below the lower flammability limit. (Appendix E gives the lower flammability limit for common gases and vapors.) Mechanisms for hydrogen generation in transportation packages include (1) chemical reaction, (2) thermal degradation, (3) biological activity, and (4) radiolysis. The focus of this report is on radiolytic hydrogen generation, with general information provided on hydrogen generation via chemical reaction, thermal degradation, and biological activity.

Chemical reactions are capable of producing large quantities of hydrogen, but the contents of TRU waste transportation packages are typically controlled to limit any reaction among the contents or reactions between the contents and the packaging that would produce significant quantities of hydrogen or other gases. If chemical reactions that generate hydrogen (or other flammable gases) are expected to occur in the TRU waste transportation package, these gas sources should be included in an analysis of the flammable gas levels and pressures in the containment vessel(s) and related confinement barriers. Examples of chemical reactions that generate hydrogen are listed in Appendix A.

Thermal degradation of packaging materials or content constituents can be a source of flammable gaseous species if the temperature of the material is above its maximum continuous service temperature. Species released due to thermal degradation of organic materials are typically carbon dioxide, carbon monoxide, and small amounts of low molecular weight flammable species, but usually do not include significant amounts of hydrogen gas. For TRU wastes at temperatures up to $250 \cdot \mathrm{F}$, no significant thermal degradation is expected to occur in most materials, however, some out-gassing is expected from materials that have a maximum continuous service temperature below $250 \cdot \mathrm{F}$. These materials include nylon, polyethylene, polystyrene, polyvinylchloride, and epoxy. The species released from these materials at temperatures up to $250 \cdot \mathrm{F}$ include solvents, plasticizers, and other low molecular weight flammable materials. Although the gases released from thermal degradation of materials below $250 \cdot \mathrm{F}$ are not expected to include significant hydrogen or other flammable species, the gases that are determined to be released should be included in an analysis of the flammable gas levels and the pressures in the containment vessel(s) and the related confinement barriers. A general discussion concerning thermal degradation is presented in Appendix B.

Biological generation of hydrogen (or other gas) requires biologically contaminated waste and the nutrients and conditions conducive to biological growth within the transportation package. The nutrient and environmental conditions in TRU waste transportation packages are typically not sufficient to sustain biological growth. However, when chemical reactions are expected to occur, thermal degradation of materials is expected to occur, or it is suspected that the TRU waste has biological contamination, tests may need to be performed to estimate the expected hydrogen generation under normal and hypothetical accident transportation conditions. A general discussion of biologically generated gases in TRU waste transportation packages is in Appendix C.

Radiolytic generation of hydrogen occurs when ionizing radiation (e.g., $\alpha, \beta$, or $\gamma$ ) interacts with hydrogenous materials. The metric for hydrogen generation from a particular material undergoing radiolysis is the G-value, which has units of molecules of gaseous hydrogen product per $100 \mathrm{eV}$ of radioactive decay energy absorbed. Appendix D provides information concerning G-values for various hydrogenous materials commonly present in TRU waste. This report defines waste types according to 
waste form, packaging, and limits on G-values for waste constituents. The three general waste types considered are: (1) solidified aqueous inorganic absorbed waste, (2) solid inorganic waste, and (3) solid organic waste. Solidified aqueous inorganic waste has two sub-categories: (1) solidified aqueous inorganic particulate waste, and (2) solidified aqueous inorganic concreted waste. Solid inorganic waste also has two subcategories: (1) solid inorganic waste in plastic, and (2) solid inorganic waste in cans. For each waste type, an effective bounding G-value is determined by consideration of (a) the material in the waste with the bounding G-value, (b) energy transfer or energy partitioning, (c) waste geometry, and (d) the packaging materials and configuration. For TRU wastes that contain nuclides that are predominantly alpha-emitters, the bounding $\mathrm{G}\left(\mathrm{H}_{2}\right)$ values are as follows for the various waste types:

\begin{tabular}{lc}
\hline Waste Type & $\begin{array}{c}\mathbf{G}\left(\mathbf{H}_{2}\right) \\
\left.\text { [molecules } \mathrm{H}_{2} / 100 \mathrm{eV}\right]\end{array}$ \\
\hline Solidified Aqueous Inorganic Absorbed Waste & 1.6 \\
Solidified Aqueous Inorganic Particulate Waste & 1.6 \\
Solidified Aqueous Inorganic Concreted Waste & 0.5 \\
Solid Inorganic Waste in Plastic & 2.1 \\
Solid Inorganic Waste in Cans & 0 \\
Solid Organic Waste & 4.1 \\
\hline
\end{tabular}

For TRU wastes that contain nuclides that are significant beta and/or gamma emitters, the procedure for determination of the bounding G-value for the waste material is covered in the body of this report.

Equations are developed that allow prediction of the hydrogen concentration as a function of time for simple nested enclosures and for packages containing multiple contents packaged within multiple nested confinement layers. The inputs to these equations include the bounding effective $\mathrm{G}\left(\mathrm{H}_{2}\right)$-value for the contents, the $\mathrm{G}\left(\mathrm{H}_{2}\right)$-values for the packaging material(s), the void volume in the containment vessel and in the confinement layers (when applicable), the temperature when the package was sealed, the temperature of the package during transport, and the contents decay heat. Example calculations of the hydrogen concentration as a function of time for various contents in various packaging configurations are provided in Appendix F.

For TRU waste packages that have hydrogen-generating contents, the time it takes to reached the lower flammability limit in the containment vessel or other confined volume within the package must be known to appropriately evaluate the potential for a flammable gas mixture to occur during transportation. Equations are developed that allow calculation of the time it takes to reach a given hydrogen concentration (typically the lower flammability limit, i.e. 5 volume percent hydrogen in air) within a given confinement volume. Finally, general guidelines for limiting the hydrogen generation and accumulation in TRU waste transportation packages are discussed. 


\section{SYMBOLS}

\begin{tabular}{|c|c|}
\hline$A_{N}$ & Avagadro's number [6.023 $\times 10^{23}$ molecules/gmol] \\
\hline As & cross-sectional area of leakage hole $\left[\mathrm{cm}^{2}\right]$ \\
\hline $\mathrm{C}_{\mathrm{A}}$ & flammable gas concentration of gases escaping container $\left[\mathrm{gmol} / \mathrm{cm}^{3}\right]$ \\
\hline $\mathrm{C}_{\mathrm{A} 0}$ & concentration of flammable gases in the radiolytically generated gases $\left[\mathrm{gmole} / \mathrm{cm}^{3}\right.$ ] \\
\hline $\mathrm{C}_{\mathrm{H} 2 \text {,in }}$ & hydrogen concentration inside the confinement barrier [mole $\mathrm{H}_{2} / \mathrm{cm}^{3}$ ] \\
\hline $\mathrm{C}_{\mathrm{H} 2 \text {, out }}$ & hydrogen concentration outside the confinement barrier [mole $\mathrm{H}_{2} / \mathrm{cm}^{3}$ ] \\
\hline $\mathrm{d}$ & effective diameter of leakage hole $[\mathrm{cm}]$ \\
\hline $\mathrm{dt}$ & time differential $[s]$ \\
\hline $\mathrm{dC}_{\mathrm{A}} / \mathrm{dt}$ & time rate of change of $\mathrm{C}_{\mathrm{A}}\left[\mathrm{gmol} / \mathrm{cm}^{3} \cdot \mathrm{s}\right]$ \\
\hline $\mathrm{dC}_{\mathrm{H} 2} / \mathrm{dx}$ & hydrogen concentration gradient [mole $\mathrm{H}_{2} / \mathrm{cm}^{4}$ ] \\
\hline $\mathrm{D}_{\mathrm{H}}$ & decay heat absorbed by radiolytic materials $[\mathrm{eV} / \mathrm{s}]$ \\
\hline $\mathrm{D}_{\mathrm{H} 2}$ & coefficient for hydrogen diffusion in air $\left[\mathrm{cm}^{2} / \mathrm{s}\right]$ \\
\hline $\mathrm{E}$ & $=\mathrm{T}_{3} / \mathrm{n}_{3}$ \\
\hline $\mathrm{E}_{\mathrm{P}}$ & activation energy for permeation $[\mathrm{kcal} / \mathrm{gmol}]$ \\
\hline $\mathrm{F}_{\mathrm{c}}$ & coefficient continuum flow $\left[\mathrm{cm}^{3} / \mathrm{s} \cdot \mathrm{atm}\right]$ \\
\hline $\mathrm{F}_{\mathrm{L}, \mathrm{MIX}}$ & flammability limit of a gas mixture in air [volume percent flammable gas] \\
\hline $\mathrm{F}_{\mathrm{m}}$ & coefficient for molecular flow $\left[\mathrm{cm}^{3} / \mathrm{s} \cdot \mathrm{atm}\right]$ \\
\hline$F_{M}$ & fraction of energy absorbed by material $\mathrm{M}$ \\
\hline$F_{M, \alpha}$ & fraction of alpha energy absorbed by material $M$ \\
\hline $\mathrm{F}_{\mathrm{M}, \beta}$ & fraction of beta energy absorbed by material $\mathrm{M}$ \\
\hline $\mathrm{F}_{\mathrm{M}, \gamma}$ & fraction of gamma energy absorbed by material $\mathrm{M}$ \\
\hline $\mathrm{F}_{\mathrm{P}}$ & fraction of energy emerging from radioactive particles \\
\hline$F_{P, \alpha}$ & fraction of alpha energy emerging radioactive particles \\
\hline $\mathrm{F}_{\mathrm{P}, \beta}$ & fraction of beta energy emerging from radioactive particles \\
\hline $\mathrm{F}_{\mathrm{P}, \gamma}$ & fraction of gamma energy emerging from radioactive particles \\
\hline $\mathrm{F}_{\text {plastic }, \alpha}$ & fraction of alpha energy absorbed by plastic \\
\hline$F_{\text {water, } \alpha}$ & fraction of alpha energy absorbed by water \\
\hline
\end{tabular}




\begin{tabular}{|c|c|}
\hline $\mathrm{G}_{\text {eff }}$ & effective radiolytic G-value for a mixture of materials [molecules $/ 100 \mathrm{eV}$ ] \\
\hline $\mathrm{G}_{\mathrm{eff}, \alpha}$ & $\begin{array}{l}\text { effective radiolytic G-value for a mixture of materials when the radioisotopes are } \\
\text { predominantly alpha-emitting [molecules } / 100 \mathrm{eV} \text { ] }\end{array}$ \\
\hline$G_{\text {eff }, \beta}$ & $\begin{array}{l}\text { effective radiolytic } \mathrm{G} \text {-value for a mixture of materials when the radioisotopes are } \\
\text { predominantly beta-emitting [molecules } / 100 \mathrm{eV} \text { ] }\end{array}$ \\
\hline $\mathrm{G}_{\mathrm{eff}, \gamma}$ & $\begin{array}{l}\text { effective radiolytic } G \text {-value for a mixture of materials when the radioisotopes are } \\
\text { predominantly gamma-emitting [molecules } / 100 \mathrm{eV} \text { ] }\end{array}$ \\
\hline G(flam gas) & radiolytic G-value for flammable gas generation [molecules $/ 100 \mathrm{eV}$ ] \\
\hline G(net gas) & radiolytic G-value for net gas generation [molecules $/ 100 \mathrm{eV}$ ] \\
\hline $\mathrm{G}\left(\mathrm{H}_{2}\right)$ & radiolytic G-value for hydrogen generation [molecules/100 eV] \\
\hline $\mathrm{G}(\mathrm{HCl})$ & radiolytic G-value for $\mathrm{HCl}$ gas generation [molecules $/ 100 \mathrm{eV}$ ] \\
\hline $\mathrm{G}_{\mathrm{M}}$ & maximum G-value for material $\mathrm{M}$ [molecules $/ 100 \mathrm{eV}$ ] \\
\hline $\mathrm{G}_{\mathrm{M}, \boldsymbol{\alpha}}$ & maximum G-value for material $\mathrm{M}$ due to alpha irradiation [molecules $/ 100 \mathrm{eV}$ ] \\
\hline $\mathrm{G}_{\mathrm{M}, \beta}$ & maximum G-value for material $\mathrm{M}$ due to beta irradiation [molecules $/ 100 \mathrm{eV}$ ] \\
\hline $\mathrm{G}_{\mathrm{M}, \gamma}$ & maximum G-value for material $\mathrm{M}$ due to gamma irradiation [molecules/100 eV] \\
\hline G(plastic) & radiolytic G-value for plastic [molecules $/ 100 \mathrm{eV}$ ] \\
\hline G(water) & radiolytic G-value for water [molecules/100 eV] \\
\hline h & height of cylinder $[\mathrm{cm}]$ \\
\hline $\mathrm{n}$ & number of gas moles [gmol] \\
\hline $\mathrm{n}_{0}$ & number of gas moles when the container was sealed [gmol] \\
\hline $\mathrm{n}_{\text {flam gas }}$ & number of moles of flammable gas [gmol] \\
\hline $\mathrm{n}_{\mathrm{H} 2,1}$ & number of hydrogen moles within enclosure \#1 [gmol] \\
\hline $\mathrm{n}_{\mathrm{H} 2,2}$ & number of hydrogen moles within enclosure \#2 [gmol] \\
\hline $\mathrm{n}_{\text {net gas }}$ & net number of moles of gas [gmol] \\
\hline$n_{0,1}$ & initial number of gas moles within enclosure \#1 [gmol] \\
\hline $\mathrm{n}_{0,2}$ & initial number of gas moles within enclosure $\# 2$ [gmol] \\
\hline $\mathrm{n}_{1}$ & number of gas moles within enclosure \#1 [gmol] \\
\hline $\mathrm{n}_{2}$ & number of gas moles within enclosure \#2 [gmol] \\
\hline $\mathrm{n}_{3}$ & number of gas moles within enclosure \#3 [gmol] \\
\hline $\mathrm{p}_{\mathrm{i}}$ & proportion of gas " $\mathrm{i}$ " in a gas mixture \\
\hline
\end{tabular}




\begin{tabular}{|c|c|}
\hline$P$ & gas pressure [atm] \\
\hline$P_{0}$ & pressure when container was sealed [atm] \\
\hline$P_{1}$ & gas pressure at position " 1 " [atm] \\
\hline $\mathrm{P}_{2}$ & gas pressure at position " 2 " [atm] \\
\hline $\mathrm{P}_{\mathrm{a}}$ & average pressure [atm] \\
\hline$P_{d}$ & downstream pressure [atm] \\
\hline$P_{F}$ & fraction of particles that reach plastic packaging material \\
\hline$P_{P}$ & permeability $\left[\mathrm{mole} \cdot \mathrm{cm} / \mathrm{s} \cdot \mathrm{cm}^{2} \cdot \mathrm{mmHg}\right]$ \\
\hline$P_{s s}$ & steady-state pressure [atm] \\
\hline$P_{u}$ & container pressure or upstream pressure [atm] \\
\hline$P_{u, 0}$ & container pressure or upstream pressure at time $=0[\mathrm{~atm}]$ \\
\hline$Q$ & volumetric rate of radiolytically-generated gas $\left[\mathrm{cm}^{3} / \mathrm{s}\right]$ \\
\hline $\mathrm{t}$ & time [seconds] \\
\hline$t_{C}$ & thickness of confinement barrier $[\mathrm{cm}]$ \\
\hline$t_{R}$ & range of particles in material $[\mathrm{cm}]$ \\
\hline $\mathbf{t}_{5 \%}$ & time to reach 5 volume percent hydrogen [s] \\
\hline $\mathrm{T}$ & gas temperature $[\mathrm{K}]$ \\
\hline $\mathrm{T}_{0}$ & temperature when container was sealed $[\mathrm{K}]$ \\
\hline $\mathrm{T}_{1}$ & effective hydrogen transport rate through barrier \#1 [mole $\mathrm{H}_{2} / \mathrm{s} \cdot$ mole fraction] \\
\hline $\mathrm{T}_{2}$ & effective hydrogen transport rate through barrier $\# 2$ [mole $\mathrm{H}_{2} / \mathrm{s} \cdot \mathrm{mole}$ fraction] \\
\hline $\mathrm{T}_{3}$ & effective hydrogen transport rate through barrier $\# 3$ [mole $\mathrm{H}_{2} / \mathrm{s}$ mole fraction] \\
\hline $\mathrm{T}_{\mathrm{D}}$ & hydrogen transport rate [mole $\mathrm{H}_{2} / \mathrm{s} \cdot$ mole fraction] \\
\hline $\mathrm{T}_{\text {eff }}$ & effective hydrogen transport rate [mole $\mathrm{H}_{2} / \mathrm{s}$.mole fraction] \\
\hline$r$ & radius of cylinder $[\mathrm{cm}]$ \\
\hline $\mathrm{R}$ & gas law constant $\left[82.05 \mathrm{~atm} \cdot \mathrm{cm}^{3} / \mathrm{gmol} \cdot \mathrm{K}\right]$ \\
\hline $\mathrm{R}_{\mathrm{M}}$ & molar hydrogen generation rate $\left[\mathrm{gmol} \mathrm{H}_{2} / \mathrm{s}\right]$ \\
\hline $\mathrm{V}$ & container void volume $\left[\mathrm{cm}^{3}\right]$ \\
\hline $\mathrm{x}_{\mathrm{H} 2, \mathrm{in}}$ & hydrogen mole fraction inside the confinement barrier \\
\hline $\mathrm{x}_{\mathrm{H} 2 \text {,out }}$ & hydrogen mole fraction outside the confinement barrier \\
\hline
\end{tabular}




$\begin{array}{ll}\mathrm{X} & \text { mole fraction hydrogen } \\ \mathrm{X}_{\mathrm{a}} & \text { ambient hydrogen mole fraction } \\ \mathrm{X}_{\mathrm{H}_{2}} & \text { mole fraction hydrogen } \\ \mathrm{X}_{1} & \text { mole fraction hydrogen in enclosure } \# 1 \\ \mathrm{X}_{2} & \text { mole fraction hydrogen in enclosure } \# 2 \\ \mathrm{X}_{3} & \text { mole fraction hydrogen in enclosure \#3 } \\ \alpha & \text { fraction of G(net gas) equivalent to G(flam gas) } \\ \lambda_{\alpha} & \text { fraction of decay energy due to alpha decay } \\ \lambda_{\beta} & \text { fraction of decay energy due to beta decay } \\ \lambda_{\gamma} & \text { fraction of decay energy due to gamma decay } \\ \rho_{\mathrm{M}} & \text { gas molar density at } \mathrm{P}_{\mathrm{u}} \text { [gmol/cm } 3 \text { ] }\end{array}$




\section{HYDROGEN GENERATION IN TRU WASTE TRANSPORTATION PACKAGES}

\section{INTRODUCTION}

\subsection{Background}

Packages for transporting certain quantities and types of radioactive material are designed and constructed to meet the requirements of Title 10, Code of Federal Regulations, Part 71 (10 CFR Part 71). An evaluation that demonstrates compliance with this regulation is submitted to the U.S. Nuclear Regulatory Commission (NRC) in the application for package approval.

One concern in the evaluation of packages to transport transuranic (TRU) waste is the production of hydrogen and other flammable gases. Regulations in 10 CFR 71.43(d) specify that no significant chemical, galvanic, or other reaction may occur among packaging components, among package contents, or between the packaging and the package contents. The effects of radiation must also be considered.

For the purposes of this report, TRU waste is considered to be radioactive waste that (1) is subject to the requirements of 10 CFR Part 71, (2) contains nuclides with an atomic number greater than 92, and (3) is not considered high-level waste, as defined by 10 CFR 60.2. Other documents (U.S. EPA, 40 CFR Part 191; DOE Order 5820.2A) have specified alternative definitions, including limits on half-life and specific activity, which are not significant for transportation evaluations. The majority of radionuclides in TRU waste decay by alpha (and gamma) emission, but some nuclides (and their progeny) are beta or beta-gamma emitters.

TRU waste usually consists of transuranic nuclides mixed with plastics, metal, glass, paper, salts, absorbents, oxides, filters, filter media, cloth, concrete and other waste materials. Typical waste includes contaminated clothing, paper, tools, and similar items. Most TRU waste exists in solid form, but liquids and sludges are also encountered. Some liquids are solidified, and some sludges dewatered, prior to transport.

\subsection{Purpose and Scope}

The purpose of this report is to provide information on the production of hydrogen and other flammable gases in transportation packages for TRU waste. Section 2 discusses the various mechanisms of gas production and provides general guidelines for assessing their importance. Radiolysis is usually the most significant mechanism for gas generation in TRU waste. Section 3 discusses radiolysis in detail and provides information on generation rates in various organic and inorganic wastes. Based on these rates, Section 4 discusses the calculation of gas concentration as a function of time and decay heat for various TRU contents and packaging configurations in order to determine the time at which the flammability limit is reached. Section 5 presents information concerning the control of hydrogen gas generation. An extensive list of references is presented in Section 7.

Because hydrogen is the most significant flammable gas produced in TRU waste transportation packages, this report focuses primarily on the generation of hydrogen. Situations in which other flammable gases should be considered, however, are noted as appropriate.

This report provides information that may be used by NRC staff to evaluate the potential for hydrogen generation in transportation packages, and describes an acceptable method to demonstrate that flammable concentrations of hydrogen will not occur within packages during transport. Control of hydrogen in 
1. Introduction

transuranic waste transportation packages by active intervention, i.e., use of hydrogen recombiners, hydrogen getters, periodic venting, inerting, etc., is not within the scope of this report. 


\section{MECHANISMS FOR HYDROGEN GENERATION}

Mechanisms for hydrogen gas generation in transuranic waste transportation packages include (1) chemical reactions, (2) thermal degradation, (3) biological activity, and (4) radiolysis. In general, hydrogen generated by chemical reactions in transportation packages can be avoided. Thermal effects generate significant amounts of flammable gases only if polymers or other organics within the package undergo thermal degradation. Biological generation of gases occurs only if the contents are sufficiently contaminated before loading and the contents have sufficient substrate to support biological growth. This section briefly discusses the first three mechanisms and their potential contribution to the total hydrogen generation rate in a transportation package. Radiolysis, which is generally the most important mechanism for hydrogen (and flammable gas) generation, is introduced in this section and discussed in detail in Section 3.

\subsection{Chemical Reactions}

For TRU wastes that are dewatered, solidified, or concreted, the hydrogen production due to chemical reaction should be minimal as long as the content constituents and materials of packaging are chosen so that there will be no significant chemical, galvanic, or other reaction among the packaging components, among the package contents, or between the packaging components and the package contents (10 CFR 71.43(d)). For contents that include water, organic materials (e.g., sludges), or mixtures of potentially reactive species, the rate of hydrogen generation from chemical reaction should be determined and the related consequences analyzed in the safety evaluation of the transportation package. Appendix A provides a summary of some common types of chemical reactions that can lead to hydrogen generation.

\subsection{Thermal Degradation}

Thermal degradation of organic materials in TRU waste transportation packages is usually not a significant source of hydrogen or other flammable gas generation for waste temperatures below $\sim 250^{\circ} \mathrm{F}$. The major constituents released when an organic material undergoes thermal degradation are carbon dioxide and carbon monoxide, and small amounts of low molecular-weight flammable species.

Therefore, gases generated due to thermal degradation can contribute to the total pressure but typically do not contribute significantly to the inventory of flammable species in the containment vessel. For TRU wastes that are above $250^{\circ} \mathrm{F}$, tests may be needed to determine the amount of gas, both flammable and nonflammable, which will be released during transportation.

Although TRU waste contents at lower temperatures are not expected to have significant thermal degradation, some small amounts of off-gassing can occur for materials that have maximum continuous service temperatures below $250^{\circ} \mathrm{F}$ (e.g., nylon, polyethylene, polystyrene, polyvinylchloride, and epoxy). The constituents of this off-gassing can be released solvents, plasticizers, and other low molecular weight flammable materials. Neither off-gassing nor thermal degradation of organic materials releases significant quantities of hydrogen gas. Although TRU waste materials below about $250^{\circ} \mathrm{F}$ are not expected to release significant quantities of flammable materials, it is important to estimate the rate of accumulation of these materials in the containment vessel (along with the rate due to other mechanisms, including hydrogen generation during storage before transportation) to verify that a flammable mixture will not be formed during transportation.

Appendix B provides general information the thermal degradation of TRU wastes (including the maximum continuous service temperature and results from thermal degradation experiments for various plastics). 


\subsection{Biological Activity}

Gas generation in TRU waste due to biological activity is not expected for the vast majority of TRU waste forms because of the sub-optimal or hostile environment, which is typically characterized by (1) lack of water, (2) lack of appropriate carbon substrate (nutrients), (3) low phosphorus levels, (4) high $\mathrm{pH}$, and (5) significant radiation fields.

The carbon chains in polymeric materials, such as cellulose-based materials and plastics, can serve as carbon substrates for certain types of microbes. However, the rate of biological degradation of these cellulose-based materials is typically very slow even in optimal environments and would not be expected to contribute a significant amount of gas in most TRU wastes during transportation.

Aerobic biological activity does not result in the production of flammable gases; carbon dioxide and water vapor are the major products. However, in addition to nonflammable gases, anaerobic organisms can produce hydrogen and methane. Therefore, for TRU waste materials that are suspected of containing viable organisms and sufficient nutrients to sustain biological growth even at low levels (e.g., contaminated wet soil, contaminated wet resin beads, etc.), tests should be performed to determine the gas generation rate for both flammable and nonflammable species. Nonflammable gas generation usually influences only the containment vessel pressure, but the potential flammability hazard needs to be analyzed when flammable gases are generated. Appendix $\mathrm{C}$ provides general information on the potential for biologically-generated gas in TRU waste.

\subsection{Radiolysis}

Radiolysis is the decomposition of a material as a result of exposure to radiation. This radiation may include alpha particles, beta particles, or gamma rays from radioactive isotope decay. When a material is subject to ionizing radiation of sufficient energy, chemical bonds may be broken. This breaking of bonds produces excited species, such as ions and radicals. The species produced by ionizing radiation will, in general, be the same in a particular material regardless of the type or energy of the ionizing radiation. Reactions between excited species and between the excited species and other nearby material may produce molecules, including gases, not initially present in the system. Of particular interest for the safety analysis of transportation packages is the rate of gas generation, especially the rate of hydrogen and other flammable gas generation.

Alpha particles, which consist of two protons and two neutrons, lose energy principally by interactions with electrons. These interactions may lead to excitation and ionization of atoms and molecules. Liberated electrons also interact with other atoms and molecules in the material. An alpha particle loses only a small amount of its energy in each interaction. As a consequence, alpha particles slow down gradually as a result of a large number of small energy losses and travel in nearly a straight trajectory.

Beta particles are fast electrons emitted by radioactive nuclei. The energies of beta particles range from zero to a maximum value dependent upon the parent nucleus. Beta particles lose energy predominately through interactions with electrons, may lose a large amount of their energy in a single interaction, and may be deflected through a large angle.

Many nuclei decay by alpha or beta decay to an excited level of the daughter nucleus, which then transitions to the ground state by gamma (photon) emission. These gammas, which have a maximum energy of a few $\mathrm{MeV}$, usually interact with atomic electrons by either the photoelectric effect or Compton effect. In the photoelectric effect, which predominates for low-energy gammas and high-atomic-number materials, the gamma energy is completely absorbed. In the Compton effect, which predominates for 
high-energy gamma and low-atomic-number materials, the gamma is scattered with a reduced energy. Compton interactions in water predominant from approximately $30 \mathrm{keV}$ to $20 \mathrm{MeV}$.

\section{Radiolytic G-Values}

Regardless of the type of ionizing radiation causing the radiolysis, the measure of radiolytic gas generation is the $G$ value. $G$ values have units of number of gas molecules produced per $100 \mathrm{eV}$ of radiation energy absorbed. Factors affecting radiolytic gas generation from the interaction of alpha, beta or gamma radiation with matter include: (1) the linear energy transfer (LET), (2) the irradiation environment (e.g., pressure, temperature, $\mathrm{pH}$, and gases present), (3) the absorbed dose, (4) the dose rate, (5) the material composition, (6) the range of the incident radiation, (7) the configuration of the radioactive material relative to the material undergoing radiolysis, and (8) energy transfer considerations. Radiolytic G-values for various materials are discussed in detail later in this report and in Appendix D.

\subsubsection{Linear Energy Transfer Effect}

Differences in $G$ values for a material irradiated by different types of radiation are ascribed to the way in which energy is lost in matter. Linear energy transfer (LET) is the energy loss per unit length of an ionizing particle traveling through a material. An average LET is calculated by dividing the initial energy of a particle by its range in the material.

Although differences in radiolysis products have been found for materials subject to different types of radiation, these differences are relatively small, and for the purposes of this document, bounding radiolytic $\mathrm{G}$ values are presented to enable bounding estimates of the flammable gas generation rates. Typically, alpha-radiolysis of a material will yield the bounding $\mathrm{G}$ values for gas generation.

\subsubsection{Temperature}

Most chemical reaction rates depend on temperature. The rate constant, $\mathrm{k}$, can be described using the Arrhenius law: $k=A \exp \left(-E_{a} / R T\right)$, where $E_{a}$ is the activation energy, $A$ is the pre-exponential factor, $R$ is the gas law constant, and $\mathrm{T}$ is the absolute temperature. The activation energy is the energy necessary to initiate the reaction.

The activation energy for radiolytic gas generation in most materials appears to be less than or equal to $3 \mathrm{kcal} / \mathrm{gmol}$, which results in a weak temperature dependence (NRC Docket No. 71-9218, Aug. 11, 1999). $E_{a}$ for polyvinylchloride (PVC) is $-3 \mathrm{kcal} / \mathrm{gmol}$, and $\mathrm{E}_{\mathrm{a}}$ for polyethylene is about $0.8 \mathrm{kcal} / \mathrm{gmol}$. Alpha radiolysis data for cellulosics indicate that the $\mathrm{E}_{\mathrm{a}}$ for radiolysis is about $1-2 \mathrm{kcal} / \mathrm{gmol}$ (Kosiewicz 1981; Zerwech 1979). The temperature dependence of $\mathrm{G}\left(\mathrm{H}_{2}\right)$, which is the radiolytic $\mathrm{G}$ value for hydrogen generation, in liquid n-hexane and neopentane corresponds to an activation energy of $\sim 3$ $\mathrm{kcal} / \mathrm{gmol}$ (Bolt and Carroll 1963). The radiolysis of water has been found to be temperatureindependent, and therefore has an apparent activation energy of $0 \mathrm{kcal} / \mathrm{gmol}$.

The relationship between the rate constants $k_{1}$ and $k_{2}$ at two different temperatures $T_{1}$ and $T_{2}$ is given by:

$$
\ln \left(\frac{\mathrm{k}_{2}}{\mathrm{k}_{1}}\right)=\left(\frac{\mathrm{E}_{\mathrm{a}}}{\mathrm{R}}\right)\left(\frac{\mathrm{T}_{2}-\mathrm{T}_{1}}{\mathrm{~T}_{2} \mathrm{~T}_{1}}\right) .
$$

The G-value at a temperature $T_{2}$ can be calculated from a known G-value at a temperature $T_{1}$ : 


$$
\left.\mathrm{G}_{\mathrm{T}_{2}}=\mathrm{G}_{\mathrm{T}_{1}} \exp \left[\left(\frac{\mathrm{E}_{\mathrm{a}}}{\mathrm{R}}\right) \frac{\mathrm{T}_{2}-\mathrm{T}_{1}}{\mathrm{~T}_{2} \mathrm{~T}_{1}}\right)\right] .
$$

For example, with an activation energy of $3 \mathrm{kcal} / \mathrm{gmol}$, the radiolytic gas generation at $328 \mathrm{~K}\left(131^{\circ} \mathrm{F}\right)$ is approximately 1.6 times the gas generation rate at $298 \mathrm{~K}\left(77^{\circ} \mathrm{F}\right)$.

Although, an activation energy of $3 \mathrm{kcal} / \mathrm{gmol}$ is usually bounding for purposes of estimating the radiolytic gas generation rates for TRU waste packages containing polymeric materials, special cases may exist where polymers are present that have higher activation energies. Although the value of $E_{a}=3$ $\mathrm{kcal} / \mathrm{gmol}$ is usually conservative mixtures of materials commonly found in TRU waste, it is important to verify through literature sources or experiment that the activation energy of $E_{a}=3 \mathrm{kcal} / \mathrm{gmol}$ is bounding for the particular waste under consideration.

\subsubsection{Pressure}

As pressure increases due to the formation of gaseous radiolysis products, the effective $G$ value may be slightly reduced due to radiolytic back reactions involving the radiolysis products. These back reactions, and the fact that radiolytically generated gases can remain dissolved, are the reasons that radiolysis experiments conducted in a vacuum measure more gas generation than do experiments conducted at ambient or elevated pressure. The analyses presented in this document for radiolytic gas generation neglect the effect of pressure (radiolytic back-reactions) and employ the bounding $G$ values measured.

\subsubsection{Atmosphere}

Measured total gas $\mathrm{G}$ values often depend on the atmosphere in which the irradiation occurs, especially the presence or absence of oxygen. Many polymers will be oxidized rather than crosslink when subject to irradiation in the presence of oxygen (Makhlis 1975). As a result of this radiation-enhanced oxidation, oxygen may be depleted from the containment vessel. Additionally, various thermal, chemical, and radiolytic oxidation processes that tend to deplete oxygen levels can occur in TRU waste materials, the packaging materials, and the waste containers. Vapors of organic volatile compounds may also be present that can influence the radiolysis products and other reactions among the contents and container.

Although the atmosphere inside the transportation package can alter the amount, and to a lesser degree the type, of radiolysis products, for the overwhelming majority of compounds the yield of radiolysis gases is largest when the experiments are conducted in vacuum. Therefore, for the purposes of this document, the $\mathrm{G}$ values used are typically those obtained from experiments conducted in vacuum.

\subsubsection{Total Absorbed Dose}

As irradiation of a material proceeds, the measured $G$ value may decrease with increasing absorbed dose if the radiolysis products are more stable to irradiation than the parent material. Conversely, radiolysis of plastics such as PVC, in which additives are used to achieve stability, could result in higher $G$ values with increasing absorbed dose as the additives are consumed.

Radiolysis of many common plastics results in a release of hydrogen from saturated carbon-carbon bonds, increasing the amount of unsaturated carbon-carbon bonds. Since unsaturated hydrocarbon liquids have much lower $\mathrm{G}\left(\mathrm{H}_{2}\right)$ values than related saturated hydrocarbon liquids, as a saturated hydrocarbon undergoes radiolysis and more unsaturated carbon-carbon bonds are formed, the $\mathrm{G}\left(\mathrm{H}_{2}\right)$ value will decrease with absorbed dose. This decrease in $\mathrm{G}$ values with absorbed dose has been termed a "matrixdepletion" effect. To avoid this complication of differences in absorbed dose effects and to ensure 
conservatism in the results, $G$ values are often expressed as initial $G$ values or as the $G$ values extrapolated to near zero absorbed dose.

\subsubsection{Dose Rate}

In a number of experiments, the $G$ values for specific materials were independent of dose rate for the dose rate ranges studied (e.g., Bibler 1976; Chapiro 1962). Others (O'Donnell and Sangster 1970), however, others have found that $G$ values may exhibit a non-linear dependence on dose rate. These observed non-linearities may be due to radiation-initiated chain reactions.

Some apparent dose rate effects may be caused by an increase in the material's temperature. Since the major portion of the absorbed radiation energy is converted to heat, at high dose rates the temperature of the material could rise significantly. At high localized temperatures, reaction pathways different from those occurring at low dose rates may dominate (Schnabel 1981).

Physical dose-rate effects have been observed for numerous materials subject to gamma radiation. Most of these experiments were performed in oxygen-containing environments in an effort to simulate accelerated aging. Physical dose rate effects depended on material type, aging conditions, sample geometry, and the degradation parameter being monitored. In general, more degradation was produced for a given total dose as the dose rate was lowered. Diffusion-limited oxidation processes were shown to be the cause of such effects. When the oxidation processes in a material consume dissolved oxygen faster than it can be replenished from the atmosphere surrounding the material (from diffusion), a heavily oxidized layer of material is formed near the sample surface, and oxygen depletion may occur in the sample interior. As the dose rate is reduced, however, oxidation of the sample interior increases due to the longer times available for the diffusion processes.

The dose rate effects leading to sample oxidation depend on the range of the radiation. For alpha radiation, the reaction will be dose-rate independent if the oxygen can easily diffuse to a depth equal to the range of the alpha particles. Likewise, the physical dose-rate effects can be minimized in gamma radiolysis experiments by using thin film samples (Bonzon 1986).

Chemical dose-rate effects involving the interactions between radiation and thermal degradation have been reported for polyethylene and PVC irradiated in the presence of oxygen (Gillen et al. 1982). These experiments showed that the most severe mechanical degradation occurred when radiation was combined with elevated temperature. The reported degradation was much greater than the sum of the damage caused by separate exposure to radiation and to the elevated temperature. This effect was attributed to an oxidation mechanism, in which peroxides initially formed by the radiation were decomposed. The magnitude of these effects could be reduced by removing any oxygen before the irradiated materials were heated.

\subsubsection{Specific Material Composition}

Many of the radiolysis experiments reported in the literature were performed using pure polymeric materials. However, commercial plastics differ from the pure polymers because they contain large fractions of various additives, such as stabilizers and plasticizers. These additives can significantly influence the amount and species of gases generated by thermal degradation and radiolysis.

Liquid plasticizers are added to polymers such as PVC or cellulose esters to increase flexibility. These compounds typically have low volatility, but may be emitted from the polymer upon heating. Plasticizers in PVC commonly comprise about $30-40 \%$ of the total material. Most of the plasticizers are combustible, and lower the flame resistance and softening points of the polymer products (Deanin 1972). 
Stabilizers are added to the polymer to increase resistance to heat, ultraviolet light, or other forms of degradation. Most plastics contain antioxidants, which may eventually be consumed by reaction with oxygen. The use of antioxidants can improve the radiation resistance of the base polymer. Inorganic fillers are also usually effective in increasing radiation resistance by dilution of the base polymer (Georgia Institute of Technology/EPRI NP-2129 1981).

The polymers in TRU waste are typically commercial materials, containing plasticizers and stabilizers that can affect radiolytic gas production in terms of the gas composition and the amount of gas. For this reason, maximum $G$ values measured for commercial materials provide more realistic upper bounds for radiolytic gas generation than do the $G$ values measured for pure polymers.

\subsubsection{Fraction of Energy Absorbed by a Material}

Factors affecting the fraction of energy absorbed by a material include the range of the radiation, the distribution of radioactive contaminants, and, in the case of alpha radiolysis, the particle size of the radioactive alpha-source and the source-target geometry.

\subsubsection{Radiation Effectiveness Range}

Knowledge of the range of radiation in TRU waste materials is important in comparing alpha with gamma or beta radiolysis experiments on specific materials, and in estimating the gas generation rates expected in TRU waste containers. The range of $5.5 \mathrm{MeV}$ alpha particles in dry air at 1 atmosphere is about $4.2 \mathrm{~cm}$ (Cember 1978). When the air is humidified or has other vapors, the range of an alpha particle decreases. The range of alpha particles in plastics, cellulosics, or water (all having a mass density of approximately $1 \mathrm{~g} / \mathrm{cm}^{3}$ ) is estimated as $5 \times 10^{-3} \mathrm{~cm}$. Based on these data and the fact that the range of gamma radiation in a given material is very much greater than the range of alpha particles, it can be concluded that: (1) for low density materials (materials with a density of about $1 \mathrm{~g} / \mathrm{cm}^{3}$ ) less than about $5 \times 10^{-3} \mathrm{~cm}(-2 \mathrm{mils})$ thick, both alpha particles and gamma rays can penetrate completely through the material; (2) materials more than about $4 \mathrm{~cm}$ away from all alpha-emitting radionuclides should not experience any alpha radiolysis; and (3) radiolysis of gases or vapors within $4 \mathrm{~cm}$ of alpha-emitting radionuclides will occur unless the alpha particles are first absorbed by other materials.

\subsubsection{Distribution of Radioactive Contaminants}

The distribution of radioactive contaminants in a TRU waste container can affect the rate of radiolytic gas generation, especially if the materials are heterogeneous. If the materials irradiated with alpha particles are heterogeneous, the dose absorbed may be a fraction of the alpha dose emitted. Some possible distributions of alpha-emitting radionuclides include the following: (1) all alpha sources are located in the interior of metal pieces; (2) all alpha sources are located on the exterior of metal pieces (i.e., surface contamination); or (3) all alpha sources are uniformly distributed in the waste. The rate of radiolytic gas generation will be different for the three cases. In case (1), no radiolytic gas will be generated because the alpha particles will only interact with the metal as a result of their short range in the material (assuming no water or organic content). In case (2), about one-half of the alpha particles will be absorbed by the metal creating no radiolytic gas, and the other half of the alpha particle emitted will interact with the waste surrounding the metal pieces and produce radiolytic gas proportional to the effective radiolytic $G$ value of the surrounding material. In case (3), gas will be generated at a rate equal to the weighted average radiolytic $G$ value for the waste materials. An upper-bound estimate of the quantity of radiolytic gas generated from a mixture of materials can be calculated by assuming that all emitted alpha energy is absorbed by the material in the waste mixture having the highest $G$ value. 


\subsubsection{Particle Size of the Contaminant}

The plutonium contaminants in TRU wastes are typically in particle form as plutonium dioxide or hydroxides, but may sometimes be in the form of plutonium nitrate from solution in nitric acid. If the plutonium is in particle form, some of the alpha particles will interact with the plutonium or oxygen atoms within the particle in the process known as self absorption, rather than with the surrounding waste material. The fraction of alpha particle energy escaping from $\mathrm{PuO}_{2}$ particles as a function of particle radius and initial energy has been calculated (NRC Docket No. 71-9218, Aug. 11, 1999; VanDevender 1984; Cowell 1984; Ziegler et al. 1985).

Self absorption is most likely the reason behind the observation that the measured $\mathrm{G}\left(\mathrm{H}_{2}\right)$ value for ${ }^{238} \mathrm{Pu}$ dissolved in nitric acid is about 2.5 times the $\mathrm{G}\left(\mathrm{H}_{2}\right)$ value for $2 \mu \mathrm{m}$ particles of the oxide (Bibler 1979). Similarly, the gas generation rate obtained from particulate-contaminated waste may be less than the rate predicted using the maximum $G$ values and the total activity of the waste.

Because of uncertainties in measuring particle size distributions of radioactive particles, the uncertainties in ensuring that particle size distributions remain constant when subject to transportation-induced forces, and the marginal benefit of alpha self absorption (only about $20 \%$ for $4.5 \mu \mathrm{m}$ radius particles ), selfabsorption arguments may be difficult to justify for transportation of TRU waste. As a conservative approach, this document assumes that all alpha energy escapes plutonium particles that have radii less than about $0.5 \mathrm{~cm}$.

\subsubsection{Energy Transfer}

The energy absorbed at one location on a large molecule may damage a more susceptible site elsewhere on the molecule. This concept of energy transfer from the location where energy is absorbed to the chemical bond that is broken illustrates that the major products of radiolysis are influenced by the molecular structure. Certain structures, such as aromatic rings, seem to absorb ionizing radiation and dissipate it as heat in the form of molecular vibrations and other nondestructive relaxation mechanisms. Systems containing these structures undergo less decomposition than would be expected (O'Donnell and Sangster 1970).

When a homogeneous mixture of two compounds is irradiated, the yields of the different radiolysis products often are directly proportional to the yields from the pure components and their relative proportions in the mixture. This behavior is observed when each component degrades independently of another. However, for some mixtures, energy transfer can occur among the components in the mixture. In a two-component mixture in which one component can transfer energy to the second component, the second component may absorb more energy and be decomposed more rapidly than predicted by its proportion in the mixture. 
2. Mechanisms for Hydrogen Generation 


\section{HYDROGEN GENERATION RATES IN TRANSURANIC WASTE}

This section discusses radiolytic gas generation rates in transuranic waste. Section 3.1 presents a summary of bounding values of experimentally measured $\mathrm{G}$ values for radiolysis of water and common TRU waste materials. Section 3.2 classifies TRU waste into three general waste types (and several subtypes) based on waste materials and packaging configurations. The use of these general waste types simplifies the selection of bounding $\mathrm{G}$ values. It eliminates the need to determine the detailed composition of the waste and to know the $G$ value for each constituent in the waste material. Section 3.3 discusses a method to calculate the gas generation rates (determine an effective $G$ value) for each general waste sub-type. Appendix D provides additional details regarding the radiolytic G-value for various materials.

\subsection{Radiolysis of Water and Other Materials Commonly in TRU Waste}

This section discusses experimentally measured $G$ values for water and common TRU waste materials. Although this information is not intended to be an exhaustive listing of all experiments or address every material, it presents sufficient data for estimating reasonable bounding values of $G$ for various materials or material groups typically present in TRU waste.

A summary of the reasonable bounding $\mathrm{G}\left(\mathrm{H}_{2}\right)$ and $\mathrm{G}$ (flam gas) values for material groups typically found in TRU waste are listed in Table 3.1. Although materials not identified in this report may be found to exceed the reasonable bounding $G$ values listed for a particular material grouping, the values listed are generally representative of materials that are commonly present in TRU waste. The $G$ values for polymers listed in Table 3.1 correspond to radiolysis of commercial materials.

\subsection{Classification of Transuranic Waste Types}

For the purposes of this report, TRU wastes are categorized into three general waste types, with several sub-types, based on the waste materials present and packaging configurations. The use of these general waste types simplifies the selection of bounding $G$ values. It eliminates the need to determine the detailed composition of the waste and to know the $\mathrm{G}$ value for each waste material.

The three general waste types are (1) Solidified Aqueous Inorganic Waste, (2) Solid Inorganic Waste, and (3) Solid Organic Waste.

\subsubsection{Solidified Aqueous Inorganic Waste}

This waste type includes soil and concreted or sludge wastes that do not contain more than trace amounts ( $<1$ weight percent) of organic materials (with the exception of organic packaging materials), in which the waste mixture is homogeneous. 
Table 3.1 Summary of Bounding Radiolytic G Values for Hydrogen and Flammable-Gas Generation

\begin{tabular}{|c|c|c|}
\hline Material & $\begin{array}{l}\text { Bounding } \mathrm{G}\left(\mathrm{H}_{2}\right) \\
{\left[\mathrm{H}_{2} \text { molecules } / 100 \mathrm{eV}\right]}\end{array}$ & $\begin{array}{l}\text { Bounding G(flam gas) } \\
\text { [gas molecules } / 100 \mathrm{eV} \text { ] }\end{array}$ \\
\hline Water & 1.6 & 1.6 \\
\hline \multicolumn{3}{|l|}{ Hydrocarbons: } \\
\hline Saturated Hydrocarbons & 9.0 & 10.2 \\
\hline Unsaturated Hydrocarbons & 3.0 & 3.0 \\
\hline Aromatic Hydrocarbons & 0.6 & 0.6 \\
\hline \multicolumn{3}{|l|}{ Oxygenated Compounds: } \\
\hline Methanol Gas & 10.8 & 11.1 \\
\hline Alcohols (liquid) & 5.4 & 6.1 \\
\hline Ethers & 3.6 & 3.8 \\
\hline Aldehydes \& Ketones & 1.5 & 3.5 \\
\hline Carboxylic Acids & 0.8 & 4.4 \\
\hline Esters & 1.0 & 3.0 \\
\hline Phosphate Esters & 2.3 & 2.4 \\
\hline Halogenated Hydrocarbons: & 0.8 & 0.8 \\
\hline Organic Nitrogen Compounds: & 6.35 & 6.35 \\
\hline Commercial Lubricants: & 2.8 & 2.9 \\
\hline \multicolumn{3}{|l|}{ Polymers: } \\
\hline $\begin{array}{l}\text { Saturated Hydrocarbon } \\
\text { Polymers }\end{array}$ & 4.0 & 4.1 \\
\hline Alcohol Polymers & 3.5 & 3.5 \\
\hline $\begin{array}{l}\text { Unsaturated Hydrocarbon } \\
\text { Polymers }\end{array}$ & 0.7 & 0.9 \\
\hline Ester Polymers & 0.9 & 1.4 \\
\hline Aromatic Polymers & 0.3 & 0.3 \\
\hline $\begin{array}{l}\text { Halogen-Containing } \\
\text { Polymers }\end{array}$ & 0.7 & 0.8 \\
\hline Ion-Exchange Resins & 1.7 & 1.7 \\
\hline \multicolumn{3}{|l|}{ Non-Polymer Solids: } \\
\hline $\begin{array}{l}\text { Solidified Aqueous } \\
\text { Sludges }\end{array}$ & $\begin{array}{c}0.43 \\
\text { (no experiments) }\end{array}$ & $\begin{array}{c}0.43 \\
\text { (no experiments) }\end{array}$ \\
\hline Concretes & 0.6 & 0.6 \\
\hline Absorbed Liquids & depends on liquid and solid & depends on liquid and solid \\
\hline Solid Organic Acids & 2.3 & 2.6 \\
\hline Asphalt & 1.3 & 1.3 \\
\hline Soil & $\begin{array}{c}0.15(\mathrm{w} / 5 \% \text { water }) \\
0.37(\mathrm{w} / 25.5 \% \text { water \& } \\
\cdot 46.4 \% \text { organic content })\end{array}$ & $\begin{array}{c}0.15(w / 5 \% \text { water }) \\
0.37(w / \cdot 25.5 \% \text { water } \& \\
\cdot 46.4 \% \text { organic content })\end{array}$ \\
\hline Dry, Solid, Inorganics & 0 & 0 \\
\hline Gases: & 0 & 0 \\
\hline
\end{tabular}


The three sub-categories of Solidified Aqueous Inorganic Waste include:

- Solidified Aqueous Inorganic Absorbed Waste-Absorbed, adsorbed, or solidified inorganic liquids (nuclides may be in solution and energy transfer may occur between the liquid and the inorganic binder). For this waste sub-type, any inorganic absorbents or solidification agents can be used.

- Solidified Aqueous Inorganic Particulate Waste-Soils, solidified particulates, or sludges formed from precipitates. Since the sludges are formed by precipitating the radionuclides from solution, the radionuclides should be in the form of particulates. For this waste sub-type, experimental data indicate (NRC Docket No. 71-9218, Aug. 11, 1999) that energy transfer can occur between many of the materials and water, and therefore it is assumed that all the available energy is absorbed by the water.

- Solidified Aqueous Inorganic Concreted Waste-Concreted inorganic particulate waste having a maximum of 30 weight percent unbound water. Experimental data for this waste sub-type indicate that energy transfer does not occur between the cement and the bound or the unbound water, and that the effective G-value for the bound water is close to zero.

Examples of materials acceptable in all three types of Solidified Aqueous Inorganic Wastes are listed in Table 3.2 .

Table 3.2 Examples of Materials Acceptable in Solidified Aqueous Inorganic Wastes

\begin{tabular}{llll}
\hline Alumna cement & Concrete & Inorganic acids & Sand \\
Aquaset/Petroset & Diatomite & Inorganic filter media & Salts \\
Aqueous sludges & Envirostone & Inorganic insulation & Slag \\
Aqueous solutions & Iron hydroxide & Metals & Soil \\
Ash & Florco & Nitrates & Soot \\
Calcium carbonate & Fire brick & Oil-dry & Steel \\
Celite & Glass & Perlite & Vermiculite \\
Clay & Grit & Portland cement & Water \\
\hline
\end{tabular}

\subsubsection{Solid Inorganic Waste}

This waste type includes surface-contaminated inorganic materials, such as glass, metal, ceramics, and fiberglass. The waste materials must be dry and free of oil, grease, or other organics except for trace quantities ( $<1$ weight percent). Solid Inorganic Waste has two subdivisions:

- Solid Inorganic Waste in Plastic - Solid inorganic materials packaged in organic materials; and

- Solid Inorganic Waste in Cans-Solid inorganic materials packaged in metal cans.

Examples of materials acceptable in both types of Solid Inorganic Waste are listed in Table 3.3.

\subsubsection{Solid Organic Waste}

This waste type includes surface-contaminated solid organic materials, such as plastics, paper, cloth, Plexiglas, and Benelex. The materials can contain absorbed water, commercial greases, oils, or organic 
liquids having sufficiently low G-values. Cemented organic process solids are included in this waste type.

In this report, the surface-contaminated organic wastes and their organic packaging are assumed to absorb $100 \%$ of the available alpha decay energy. The only gas generated by inorganic materials (which are permitted in this waste type) would be oxygen, which would tend to be consumed by oxidation of the plastic packaging materials. Therefore, any inorganic materials present are considered to generate no gas.

Based on experimentally measured G-values, solid organic materials with the following structural groups are acceptable in this waste type: aromatic rings, unsaturated $\mathrm{C}-\mathrm{C}$ bonds, and $\mathrm{C}-\mathrm{N}$ triple bonds. Materials for which the $\mathrm{G}$-value at room temperature for flammable gas could be greater than 4.1 are limited to trace quantities (less than $1 \%$ by weight). These materials include cellulose nitrate, polyvinyl formate, polyoxymethylene, and poly(olefin sulfones) (based on current data). Other polymers containing ether functional groups may also have high $\mathrm{G}$ (flammable gas) values.

Examples of materials acceptable in Solid Organic Waste are listed in Table 3.4.

Table 3.3 Examples of Materials Acceptable in Solid Inorganic Wastes

\begin{tabular}{lll}
\hline Asbestos & Grit & Nitrates \\
Ash & Inorganic filter media & Portland cement \\
Clays & Inorganic insulation & Salts \\
Concrete (surface-contaminated only) & Inorganic resins & Sand \\
Firebrick & Metals & Slag \\
Florco & Metallic oxides & Soil \\
Glass & Molds \& crucibles (e.g., ceramic, & Soot \\
& graphite) & \\
\hline
\end{tabular}

Table 3.4 Examples of Material Acceptable in Solid Organic Waste

\begin{tabular}{lll}
\hline Aniline-formaldehyde & Phenol-formaldehyde & Polystyrene \\
Any solid inorganic material & Phenolic resin & Polysulfone \\
Asphalt & Polyamide & Polytetrafluoroethylene \\
Bakelite & Polybutadine & Polyurethane \\
Cellulose & Polycarbonate & Polyvinyl acetate \\
Cellulose acetate butyrate & Polychloroprene & Polyvinyl alcohol \\
Cellulose proprionate & Polychlorotrifluoroethylene & Polyvinyl chloride \\
Cellulose acetate & Polyester & Polyvinylidene chloride \\
Chlorinated polyether & Polyethylene & Rubber \\
Chlorosulfonated polyethylene & Polyethylene glycol & Rubber hydrochloride \\
Detergent (solid) & Polyimide & Sand \\
Melamine-formaldehyde & Polyisobutylene & Soil \\
Oil & Polyisoprene & Tributyl phosphate \\
Organic acids (solid) & Polymethyl methacrylate & Urea-formaldehyde \\
\hline
\end{tabular}


Organic filter media

Organic insulation

Organic resins
Polyphenyl methacrylate

Polypropylene
Water (absorbed)

Waxes or greases

\subsection{Effective Radiolytic G Values for Various Waste Types}

This section discusses a method to calculate gas generation rates (determine an effective $G$ value) for each general waste sub-type.

\subsubsection{Effective G-Value for a General Mixture of Materials}

The effective radiolytic $G$ value for a mixture of materials can be expressed as the sum of the $G$ values for the materials present with some weighting factors for the energy absorbed:

$$
\mathrm{G}_{\text {eff }}=\sum_{\mathrm{M}}\left[\left(\mathrm{F}_{\mathrm{p}} \mathrm{xF} \mathrm{F}_{\mathrm{M}}\right) \times \mathrm{G}_{\mathrm{M}}\right]
$$

where: $F_{\mathrm{P}}$ is the fraction of energy emerging from the radioactive particles;

$\mathrm{F}_{\mathrm{M}}$ is the fraction of energy absorbed by material $\mathrm{M}$; and

$G_{M}$ is the maximum $G$ value for material $M$.

Determination of separate $G$ values for alpha, beta, and gamma radiation may be necessary when the waste emits significant amounts of gamma and beta radiation in addition to alpha radiation:

$$
\begin{aligned}
& G_{\text {eff }, \alpha}=\sum_{M}\left[\left(F_{P, \alpha} \times F_{M, \alpha}\right) x G_{M, \alpha}\right] \\
& G_{e f f, \beta}=\sum_{M}\left[\left(F_{P, \beta} \times F_{M, \beta}\right) \times G_{M, \beta}\right], \text { and } \\
& G_{e f f, \gamma}=\sum_{M}\left[\left(F_{P, \gamma} x F_{M, \gamma}\right) \times G_{M, \gamma}\right],
\end{aligned}
$$

where the terms in Equations 3.2, 3.3, and 3.4 are defined according to Equation 3.1, with the subscripts $\alpha, \beta$, and $\gamma$ denoting the radiation that produces the radiolysis.

The effective $G$ value for a waste material that contains radioactive nuclei that emit alpha, beta, and gamma radiation is:

$$
\mathrm{G}_{\text {eff }}=\lambda_{\alpha} \mathrm{G}_{\text {eff, }, \alpha}+\lambda_{\beta} \mathrm{G}_{\text {eff. } \beta}+\lambda_{\gamma} \mathrm{G}_{\mathrm{eff}, \gamma}
$$

where: $\lambda_{\alpha}$ is the fraction of the decay energy due to alpha decay;

$\lambda_{\beta}$ is the fraction of the decay energy due to beta decay; and

$\lambda_{\gamma}$ is the fraction of the decay energy due to gamma decay. 


\subsubsection{Fraction of Decay Energy Available for Radiolysis-Range of Radiation}

The fraction of decay energy available for radiolysis depends on the range of the radiation, the sizes of the radioactive particles, the density of the waste, and the waste configuration.

The fraction of alpha energy emerging from radioactive particles, $F_{P, \alpha}$, depends on the size of the particles. For alpha irradiation, the absorbed dose for waste materials is applicable only to the mass of the waste within the range of the alpha particles. Although plutonium oxalate calcined at $1000^{\circ} \mathrm{C}$ has been shown to have a particle size distribution such that a maximum of $82 \%$ of the alpha radiation energy escapes the particles as a result of self-absorption (NRC Docket No. 71-9218, Aug. 11, 1999), other TRU waste such as HEPA filters may include smaller radioactive particles that exhibit smaller amounts of alpha self-absorption. Since determination of particle size distributions is difficult and particle size distributions may not remain constant under transportation-induced forces, this report conservatively assumes that $F_{P, \alpha}=1=0$. If the particle size distribution of the radioactive particles in the TRU waste is known, and it can be justified that the particle size distribution will not change during loading and transportation, then $F_{P, \alpha}$ may be less than 1.0. The range of alpha particles with energies between 4 and 8 $\mathrm{MeV}$ in low density materials can be estimated by the following equation (Liverhant 1960):

Range $_{\alpha}(\mathrm{cm})=[(1.24 *$ Particle Energy $(\mathrm{MeV}))-2.62]\left(\frac{1.2 \times 10^{-3} \mathrm{~g} / \mathrm{cm}^{3}}{\text { Density }}\right)$.

For a density of plastics and paper of approximately $1 \mathrm{~g} / \mathrm{cm}^{3}$, the range of a $5.14 \mathrm{MeV}$ alpha particle $(239 \mathrm{Pu})$ is $4.6 \times 10^{-3} \mathrm{~cm}$, and the range of a $5.59 \mathrm{MeV}$ alpha particle $(238 \mathrm{Pu})$ is $5.2 \times 10^{-3} \mathrm{~cm}$. The range of a $5.59 \mathrm{MeV}$ alpha particle in air is about $4.3 \mathrm{~cm}$. Therefore, any waste material within about $4.3 \mathrm{~cm}$ of an alpha source could potentially receive alpha radiation. However, once an alpha particle strikes a material with a mass density of about $1 \mathrm{~g} / \mathrm{cm}^{3}$, its range in that material would only be about $4.6 \times 10^{-3} \mathrm{~cm}$.

The range of beta particles is more difficult to calculate than the range of alpha particles. The path of a beta particle is very irregular and not as straight as that of heavy charged particles. A practical range, also called extrapolated range, for beta particles with energies up to $3 \mathrm{MeV}$ can be estimated by the following equation (Liverhant 1960):

Range $_{\beta}\left(\mathrm{gram} / \mathrm{cm}^{2}\right)=0.546 *$ Particle Energy $(\mathrm{MeV})-0.108$.

For beta-emitting nuclides in TRU waste, the energies are typically 1 to $3 \mathrm{MeV}$. The range of a $1 \mathrm{MeV}$ beta particle is $0.438 \mathrm{~g} / \mathrm{cm}^{2}$, and the range of a $3 \mathrm{MeV}$ beta particle is $1.53 \mathrm{~g} / \mathrm{cm}^{2}$. In air $\left(\rho=1.2 \times 10^{-3}\right.$ $\mathrm{g} / \mathrm{cm}^{3}$ ), the range of a $1 \mathrm{MeV}$ beta particle is about $365 \mathrm{~cm}$ and the range of a $3 \mathrm{MeV}$ beta particle is about $1275 \mathrm{~cm}$. In material with a mass density of $1 \mathrm{~g} / \mathrm{cm}^{3}$, the range of a $1 \mathrm{MeV}$ beta particle is about $0.44 \mathrm{~cm}$ and the range for a $3 \mathrm{MeV}$ beta particle is about $1.53 \mathrm{~cm}$. From a practical standpoint, the range of beta particles from radioactive decay is typically much larger than that of alphas, and $\mathrm{F}_{\mathrm{P}, \beta}$ may be assumed to be 1.0

Therefore, with $F_{P, \alpha}=F_{P, \beta}=F_{P, \gamma}=1$, the effective $G$ value becomes:

$$
\mathrm{G}_{\mathrm{eff}}=\lambda_{\alpha} \sum_{\mathrm{M}}\left[\mathrm{F}_{\mathrm{M}, \alpha} \mathrm{x} \mathrm{G}_{\mathrm{M}, \alpha}\right]+\lambda_{\beta} \sum_{\mathrm{M}}\left[\mathrm{F}_{\mathrm{M}, \beta} \mathrm{x} \mathrm{G}_{\mathrm{M}, \beta}\right]+\lambda_{\gamma} \sum_{\mathrm{M}}\left[\mathrm{F}_{\mathrm{M}, \gamma} \times \mathrm{G}_{\mathrm{M}, \gamma}\right] \text {. }
$$

In many instances, detailed information concerning the radionuclides and their concentrations in a waste material may be unavailable, and determination of the separate decay fractions $\left(\lambda_{\alpha}, \lambda_{\beta}\right.$, and $\left.\lambda_{\gamma}\right)$ may not be possible. For most waste types and waste configurations, a conservative approach is to assume that all decay energy is in the form of alpha decay, but the conservatism of this approach needs to be justified. 
Assuming all the radiation is in the form of alpha decay is usually conservative since the energy from the alpha decay will be deposited in waste material within the innermost confinement volume, and the innermost confinement volume is the region that typically has the highest concentration of hydrogen at any given time.

\subsubsection{Fraction of Decay Energy Absorbed by Different Materials}

The fraction of alpha energy absorbed by material $\mathrm{M}, \mathrm{F}_{\mathrm{M}, \alpha}$, is assumed to be1.0 since the range of alpha particles is small and the region of energy deposition is well defined.

The fraction of beta and gamma energy absorbed by material $M, F_{M, \beta}$ and $F_{M, \gamma}$, respectively, depends on the energy (and range) of the beta particles and gamma rays and needs to be calculated on a case-by-case basis for the particular nuclides, waste materials, and packaging configuration in question. As a bounding approach, which typically yields very conservative results, $\mathrm{F}_{\mathrm{M}, \beta}$ and $\mathrm{F}_{\mathrm{M}, \gamma}$ may be chosen as 1.0.

\subsubsection{Effective G Values for Solidified Aqueous Inorganic Waste}

Solidified Aqueous Inorganic Waste includes soil and cemented or sludge wastes with no more than trace amounts ( $<1$ weight $\%$ ) of organic materials (with the exception of organic packaging materials). The materials must be well mixed with radionuclides dispersed homogeneously throughout the solidified or solid mass. The Solidified Aqueous Inorganic Waste mass is typically placed inside one or more plastic bags before it is placed inside the containment vessel.

Water is the only compound allowed in the solidified aqueous inorganic waste mass ( $>1$ weight \%) that can radiolytically generate hydrogen. However, since the Solid Aqueous Inorganic Waste mass is generally wrapped in one or more layers of plastic (typically polyethylene or polyvinylchloride), radiation that escapes the waste mass can cause radiolysis in the polymeric confinement layers (i.e., plastic bags and drum liners).

The bounding $\mathrm{G}\left(\mathrm{H}_{2}\right)$ value for material in the Solidified Aqueous Inorganic Waste mass is 1.6, based on the alpha-radiolysis of water. (The bounding $\mathrm{G}\left(\mathrm{H}_{2}\right)$ value for the gamma-radiolysis of water has been shown to be about 0.5 , see Appendix D.) The bounding $\mathrm{G}\left(\mathrm{H}_{2}\right)$ value for hydrogen generation for the plastic bag confinement layers is 4.1 based on the radiolysis of polyethylene. The bounding $\mathrm{G}(\mathrm{HCl})$ value for the plastic confinement layers is 0.7 due to the possible radiolysis of polyvinylchloride. Polymeric confinement materials that have a $\mathrm{G}\left(\mathrm{H}_{2}\right)$ value greater than 4.1 or a $\mathrm{G}(\mathrm{HCl})$ greater than 0.7 are not covered by the following analysis.

The typical organic packaging materials used to confine the solidified contents are plastic bags. For waste materials that emit alpha and beta particles, only a fraction of the alpha and beta radiation produced within the solidified mass reaches the organic packaging materials because of absorption of a majority of the radiation within the solidified mass. Since the range of alpha particles in water is only about $5 \times 10^{-3}$ $\mathrm{cm}$, the fraction of alpha particles that can reach the plastic packaging material can come only from the outer $5 \times 10^{-3} \mathrm{~cm}$ layer of material. Similarly, since the range of beta particles in water is generally 1.53 $\mathrm{cm}$ or less, the fraction of beta particles that can reach the plastic packaging material can come only from the outer $1.53 \mathrm{~cm}$ layer of material. In general, the fraction of radiation produced in the solidified mass that can reach the plastic packaging material is calculated by dividing the volume of the waste mass into the product of the bulk mass surface area and the average range of the radiation in the material.

Therefore, for solidified waste materials with a cylindrical shape, the fraction of alpha or beta particles that can reach the plastic packaging materials is:

$\mathrm{P}_{\mathrm{F}}=\frac{2 \mathrm{t}_{\mathrm{R}}(\mathrm{r}+\mathrm{h})}{\mathrm{rh}}$ 
where: $P_{F}$ is the particle fraction that can reach the plastic packaging materials;

$t_{R}$ is the range of the particles in the waste material $[\mathrm{cm}]$;

$r$ is the radius of the cylinder $[\mathrm{cm}]$; and

$\mathrm{h}$ is the height of the cylinder [cm].

For example, a waste mass with an approximate volume of one gallon (with a radius of $7.62 \mathrm{~cm}(3.0 \mathrm{in}$.) and a height of $20.32 \mathrm{~cm}\left(8.0\right.$ in.)) has a $P_{F}=1.8 \times 10^{-3}$ for alpha particles and a $P_{F}=0.55$ for beta particles. Since the amount of material inserted into the product can is typically one gallon or more, these $\mathrm{P}_{\mathrm{F}}$ values are considered conservative for most cases.

For gamma-emitting wastes, most of the gamma rays will escape the solidified mass. As a result of the penetrating nature of gamma rays and to a lesser extent beta particles, most of the gamma ray and beta particle energy would also penetrate through the plastic bags and only a very small fraction of the total gamma ray and beta particle energy deposited in the bags. This small fraction of gamma ray and beta particle energy deposited may be calculated, or conservatively, the fraction of beta and gamma decay energy that escapes the solidified waste and is deposited in the polymeric confinement layers (e.g., plastic bags that are usually polyethylene or polyvinylchloride) can be assumed to be 1.0 .

\subsubsection{Effective G Value for Solidified Aqueous Inorganic Absorbed Waste}

Solidified Aqueous Inorganic Absorbed Waste may include any inorganic absorbents or solidification agents. The radionuclides may be present as particles or in solution encapsulated by the solidification materials. Because of the possibility of energy transfer between these inorganic materials and water, the fraction of available energy absorbed by the water is assumed to be 1.0 .

For Solidified Aqueous Inorganic Absorbed Waste, the coefficients used in Equation 3.5 are summarized in Table 3.5.

Table 3.5 Coefficients for Calculation of Effective G(gas) for Solidified Aqueous Inorganic Absorbed Waste

\begin{tabular}{|c|c|c|c|c|c|}
\hline Coefficient & Value & Coefficient & Value & Coefficient & Value \\
\hline$F_{P, \alpha}$ & $1.0 \mathrm{a}$ & $F_{\text {water, } \alpha}$ & $1.0^{b}$ & $F_{\text {plastic, } \alpha}$ & $1.8 \times 10^{-3} \mathrm{~d}$ \\
\hline$F_{P, \beta}$ & 1.0 & $F_{\text {water, } \beta}$ & 1.0 & $F_{\text {plastic, } \beta}$ & $0.55 \mathrm{e}$ \\
\hline $\mathrm{FP}_{\mathrm{P}, \gamma}$ & 1.0 & $F_{\text {water, } \gamma}$ & $1.0 \mathrm{c}$ & Fplastic, $\gamma$ & TBD $\mathrm{f}$ \\
\hline $\begin{array}{l}\text { a A value }<1.0 \text { n } \\
\text { b Due to energy } \\
\text { c A value of } 1.0 \\
\text { d Valid estimate } \\
\text { e Valid estimate } \\
\text { f A calculated va }\end{array}$ & $\begin{array}{l}\text { e justifiable for } \\
\text { er, all the alpha } \\
\text { servative; a calo } \\
\text { organic solids w } \\
\text { organic solids w } \\
\text { ess than } 1.0 \text { may }\end{array}$ & $\begin{array}{l}\text { es that have diam } \\
y \text { is assumed to b } \\
\text { yalue less than } \\
\text { urface area to vo } \\
\text { urface area to vo } \\
\text { tified. }\end{array}$ & $\begin{array}{l}\text { What remain gre } \\
\text { rbed by the wa } \\
\text { y be justifiabl } \\
\text { ratio }<1.3 \text { (mi } \\
\text { ratio }<1.3 \text { (mir }\end{array}$ & $\begin{array}{l}1 \text { gallon, see } S \\
1 \text { gallon, see } S\end{array}$ & $\begin{array}{l}3.2) \text {. } \\
3.2) \text {. }\end{array}$ \\
\hline
\end{tabular}

Using the coefficients in Table 3.5, the effective radiolytic G value for Solidified Aqueous Inorganic Absorbed Waste is: 


$$
\begin{aligned}
\mathrm{G}_{\text {Solidified Aqueous Inorganic Absorbed Waste }}= & \lambda_{\alpha}\left[\left(1.8 \times 10^{-3}\right)\left(\mathrm{G}_{\text {plastic, } \alpha}\right)+(1.0)\left(\mathrm{G}_{\text {water }, \alpha}\right)\right] \\
& +\lambda_{\beta}\left[(0.55)\left(\mathrm{G}_{\text {plastic, }, \beta}\right)+(1.0)\left(\mathrm{G}_{\text {water, }, \beta}\right)\right] \\
& +\lambda_{\gamma}\left[\left(\mathrm{F}_{\text {plastic, } \gamma}\right)\left(\mathrm{G}_{\text {plastic }, \gamma}\right)+\left(\mathrm{F}_{\text {water }, \gamma}\right)\left(\mathrm{G}_{\text {water, }, \gamma}\right)\right] .
\end{aligned}
$$

Since $G_{M, \alpha}$ is typically greater than $G_{M, \beta}$ or $G_{M, \gamma}$, and for many materials $G_{M, \beta}$ and $G_{M, \gamma}$ values are limited or unavailable, a simple conservative approach is to assume all the $G$-values for a given material (M) are equal to $\mathrm{G}_{\mathrm{M}, \alpha}$.

For Solidified Aqueous Inorganic Absorbed Waste that contains predominantly alpha-emitting radionuclides (i.e., $\lambda_{\alpha}=1.0, \lambda_{\beta}=0$, and $\lambda_{\gamma}=0$ in Equation 3.10 ), the effective radiolytic $G$ value is given by:

$$
\begin{aligned}
\mathrm{G}_{\text {Solid Aqueous Inorganic Absorbed Waste, } \alpha} & =\sum_{\mathrm{M}}\left[\left(\mathrm{F}_{\mathrm{M}, \alpha} \times \mathrm{XG}_{\mathrm{M}, \alpha}\right) \times \mathrm{F}_{\mathrm{P}, \alpha}\right] \\
& =\left[\left(1.8 \times 10^{-3}\right)\left(\mathrm{G}_{\mathrm{phastic,} \alpha}\right)\right](1.0)+\left[(1.0)\left(\mathrm{G}_{\text {water }, \alpha}\right)\right](1.0)
\end{aligned}
$$

Using $\mathrm{G}_{\text {plastic, } \alpha}\left(\mathrm{H}_{2}\right)=4.1, \mathrm{G}_{\text {plastic }}$ (gas)=4.1 (based on the radiolysis of polyethylene), and $\mathrm{G}_{\text {plastic }}(\mathrm{HCl})=0.7$ (based on the radiolysis of polyvinylchloride), and $G_{\text {water, } \alpha}\left(H_{2}\right)=1.6$ (based on the $\alpha$-radiolysis of water), $\mathrm{G}_{\text {water }}$ (gas) $=2.4$ (assuming that oxygen and hydrogen are released as a result of water radiolysis) in Equation 3.11, the effective $\mathrm{G}$ values for potentially flammable gas $\left(\mathrm{H}_{2}\right), \mathrm{HCl}$, and net gas for Solidified Aqueous Inorganic Absorbed Waste that contains predominately alpha-emitting radionuclides can be estimated as:

$\mathrm{G}\left(\mathrm{H}_{2}\right)=\left[\left(1.8 \times 10^{-3}\right)(4.1)+(1.0)(1.6)\right](1.0)=1.6$

$\mathrm{G}(\mathrm{HCl})=\left[\left(1.8 \times 10^{-3}\right)(0.7)\right](1.0)=1.08 \times 10^{-3}=0$

$\mathrm{G}($ net gas $)=\left[\left(1.8 \times 10^{-3}\right)(4.1)+(1.0)(2.4)\right](1.0)=2.4$.

Note that the contributions to the effective $G$ values from the radiolysis of the polymeric confinement layers are negligible for Solidified Aqueous Inorganic Absorbed Waste that contains predominantly alpha-emitting radionuclides.

\subsubsection{Effective G Value for Solidified Aqueous Inorganic Particulate Waste}

For Solidified Aqueous Inorganic Particulate Waste, which contains solidified particulates, soil or sludges, energy transfer can occur between many of the materials and water. All of the waste decay energy is assumed to be absorbed by the water. The only alpha particles emitted from the waste that can interact with the plastic confinement layer(s) originate from a thin layer near the outer surface of the waste mass. The coefficients used in Equation 3.5 for Solidified Aqueous Inorganic Particulate Waste are the same as those used for Solidified Aqueous Inorganic Absorbed waste, and are summarized in Table 3.6. 
3. Hydrogen Generation Rates in Transuranic Waste

Table 3.6 Coefficients for Calculation of Effective G(gas) for Solidified Aqueous Inorganic Particulate Waste

\begin{tabular}{lc|lc|lc}
\hline Coefficient & \multicolumn{1}{c|}{ Value } & Coefficient & Value & Coefficient & Value \\
\hline $\mathrm{F}_{\mathrm{P}, \alpha}$ & $1.0^{\mathrm{a}}$ & $\mathrm{F}_{\text {water }, \alpha}$ & $1.0^{\mathrm{b}}$ & $\mathrm{F}_{\text {plastic, } \alpha}$ & $1.8 \times 10^{-3 \mathrm{~d}}$ \\
$\mathrm{~F}_{\mathrm{P}, \beta}$ & 1.0 & $\mathrm{~F}_{\text {water }, \beta}$ & 1.0 & $\mathrm{~F}_{\text {plastic }, \beta}$ & $0.55 \mathrm{e}$ \\
$\mathrm{F}_{\mathrm{P}, \gamma}$ & 1.0 & $\mathrm{~F}_{\text {water }, \gamma}$ & $1.0^{\mathrm{c}}$ & $\mathrm{F}_{\text {plastic, } \gamma}$ & TBD \\
\hline
\end{tabular}

a A value $<1.0$ may be justifiable for particles that have diameters that remain greater than $\sim 10 \mu \mathrm{m}$.

b Due to energy transfer, all the alpha energy is assumed to be absorbed by the water.

c A value of 1.0 is conservative; a calculated value less than 1.0 may be justifiable.

d Valid estimate for inorganic solids with a surface area to volume ratio $<1.3$ (min. volume 1 gallon, see Sec. 3.3 .2 ).

e Valid estimate for inorganic solids with a surface area to volume ratio < 1.3 (min. volume 1 gallon, see Sec. 3.3.2).

f A calculated value less than 1.0 may be justifiable.

Substituting the coefficients in Table 3.6 into Equation 3.5, the effective radiolytic G value for Solidified Aqueous Inorganic Particulate Waste is obtained:

$$
\begin{aligned}
\mathrm{G}_{\text {Solidified Aqueous Inorganic Particulate Waste }}= & \lambda_{\alpha}\left[\left(1.8 \times 10^{-3}\right)(\mathrm{G} \text { (plastic) })+(1.0)(\mathrm{G}(\text { water }))\right] \\
& +\lambda_{\beta}[(0.55)(\mathrm{G} \text { (plastic) })+(1.0)(\mathrm{G}(\text { water }))] \\
& \left.+\lambda_{\gamma}\left[\left(\mathrm{F}_{\text {plastic }, \gamma}\right)(\mathrm{G} \text { (plastic })\right)+\left(\mathrm{F}_{\text {water }, \gamma}\right)(\mathrm{G}(\text { water }))\right] .
\end{aligned}
$$

The effective $G$ value for Solidified Aqueous Inorganic Particulate Waste that contains predominantly alpha-emitting radionuclides (i.e. $\lambda_{\beta}=\lambda_{\gamma}=0$ in Equation 3.15) is given by:

$$
\begin{aligned}
\mathrm{G}_{\text {Solidified Aqueous Inorganic Particulate Waste, } \alpha} & =\sum_{\mathrm{M}}\left[\left(\mathrm{F}_{\mathrm{M}} \times \mathrm{GG}_{\mathrm{M}}\right) \mathrm{xF}_{\mathrm{P}}\right] \\
& =\left\{\left[\left(1.8 \times 10^{-3}\right)(\mathrm{G}(\text { plastic }))\right]+[(1.0)(\mathrm{G}(\text { water }))]\right\}(1.0) .
\end{aligned}
$$

Using $\mathrm{G}_{\text {plastic, } \alpha}\left(\mathrm{H}_{2}\right)=4.1, \mathrm{G}_{\text {plastic }}$ (gas)=4.1 (based on the radiolysis of polyethylene), and $\mathrm{G}_{\text {plastic }}$ $(\mathrm{HCl})=0.7$ (based on the radiolysis of polyvinylchloride), and $\mathrm{G}_{\mathrm{water}, \alpha}\left(\mathrm{H}_{2}\right)=1.6$ (based on the $\alpha$-radiolysis of water), $G_{w a t e r}$ (gas)=2.4 (assuming oxygen and hydrogen are released from the radiolysis of water) in Equation 3.16, the effective $\mathrm{G}$ values for potentially flammable gas $\left(\mathrm{H}_{2}\right), \mathrm{HCl}$, and net gas for Solidified Aqueous Inorganic Particulate Waste that contains predominately alpha-emitting radionuclides can be estimated as:

$\mathrm{G}\left(\mathrm{H}_{2}\right)=\left[\left(1.8 \times 10^{-3}\right)(4.1)+(1.0)(1.6)\right](1.0)=1.6$

$\mathrm{G}(\mathrm{HCl})=\left[\left(1.8 \times 10^{-3}\right)(0.7)\right](1.0)=1.08 \times 10^{-3}=0$

$\mathrm{G}($ net gas $)=\left[\left(1.8 \times 10^{-3}\right)(4.1)+(1.0)(2.4)\right](1.0)=2.4$.

Note that the contributions to the effective $G$ values from the radiolysis of the polymeric confinement layers are negligible for Solidified Aqueous Inorganic Particulate Waste. 


\subsubsection{Effective G Values for Solidified Aqueous Inorganic Concreted Waste}

For Solidified Aqueous Inorganic Concreted Waste, which contains concreted inorganic particulate waste, energy transfer does not occur between the cement and the bound or unbound water (NRC Docket No. 71-9218, Aug. 11, 1999), and the G value for the bound water (water of hydration) is close to zero. The unbound water content of the cured concrete is limited to $30 \%$ by weight. For Solidified Aqueous Inorganic Concreted Waste, therefore, only $30 \%$ of the decay energy available is absorbed by the water. However, the only alpha decay energy that can interact with the plastic confinement layer(s) surrounding the Solidified Aqueous Inorganic Concreted Waste mass originate from a thin layer near the outer surface of the waste mass. The coefficients used in Equation 3.5 for Solidified Aqueous Inorganic Concreted Waste are summarized in Table 3.7.

Table 3.7 Coefficients for Calculation of Effective G(gas) for Solidified Aqueous Inorganic Particulate Waste

\begin{tabular}{|c|c|c|c|c|c|}
\hline Coefficient & Value & Coefficient & Value & Coefficient & Value \\
\hline$F_{P, \alpha}$ & $1.0^{\mathrm{a}}$ & $\mathrm{F}_{\text {water }, \alpha}$ & $0.3 b$ & $F_{\text {plastic, } \alpha}$ & $1.8 \times 10^{-3} \mathrm{e}$ \\
\hline$F_{P, \beta}$ & 1.0 & $F_{\text {water, } \beta}$ & $0.3 \mathrm{c}$ & $F_{\text {plastic, } \beta}$ & $0.55 \mathrm{f}$ \\
\hline $\mathrm{F}_{\mathrm{P}, \gamma}$ & 1.0 & $F_{\text {water, } \gamma}$ & $0.3 \mathrm{~d}$ & $\mathrm{~F}_{\text {plastic, } \gamma} \gamma$ & $1.0 \mathrm{~g}$ \\
\hline \multicolumn{6}{|c|}{ A value $<1.0$ may be justifiable for particles that have diameters that remain greater than $\sim 10 \mu \mathrm{m}$. } \\
\hline \multicolumn{6}{|c|}{$\begin{array}{l}\text { Due to lack of energy transfer, the fraction of decay energy that can interact with the water is limited to the fraction of free water, whic } \\
\text { is limited to } 30 \% \text {. }\end{array}$} \\
\hline \multicolumn{6}{|c|}{ c A value of 0.3 is conservative; a calculated value less than 0.3 may be justifiable. } \\
\hline \multicolumn{6}{|c|}{ d A value of 0.3 is conservative; a calculated value less than 0.3 may be justifiable. } \\
\hline \multicolumn{6}{|c|}{ e A value of 0.3 is conservative; a calculated value less than 0.3 may be justifiable. } \\
\hline \multicolumn{6}{|c|}{ f Valid estimate for inorganic solids with a surface area to volume ratio $<1.3$ (min. volume 1 gallon, see Sec. 3.3.2). } \\
\hline
\end{tabular}

Using the coefficients in Table 3.7 in Equation 3.5, the effective radiolytic G value for Solidified Aqueous Inorganic Concreted Waste is obtained:

$$
\begin{aligned}
\mathrm{G}_{\text {Solidified Aqueous Inorganic Concreted } \text { Waste }=} & \lambda_{\alpha}\left[\left(1.8 \times 10^{-3}\right)(\mathrm{G}(\text { plastic }))+(0.3)(\mathrm{G}(\text { water }))\right] \\
& +\lambda_{\beta}[(\leq 0.55)(\mathrm{G}(\text { plastic }))+(\leq 0.3)(\mathrm{G}(\text { water }))] \\
& +\lambda_{\gamma}\left[\left(\mathrm{F}_{\text {plastic }, \gamma}\right)(\mathrm{G}(\text { plastic }))+(\leq 0.3)(\mathrm{G}(\text { water }))\right] .
\end{aligned}
$$

The effective $G$ value for Solidified Aqueous Inorganic Concreted Waste that contains predominantly alpha-emitting radionuclides (i.e. $\lambda_{\beta}=\lambda_{\gamma}=0$ in Equation 3.20 ) is given by:

$$
\begin{aligned}
\mathrm{G}_{\text {Solidiried Aqueous Inorganic Concreted waste, } \alpha} & =\sum_{\mathrm{M}}\left[\left(\mathrm{F}_{\mathrm{M}} \times \mathrm{G}_{\mathrm{M}}\right) \mathrm{xF}_{\mathrm{P}}\right] \\
& \left.=\left\{\left(1.8 \times 10^{-3}\right)(\mathrm{G}(\text { plastic }))\right]+[(0.30)(\mathrm{G}(\text { water }))]\right\}(1.0) .
\end{aligned}
$$

Using $\mathrm{G}_{\text {plastic, } \alpha}\left(\mathrm{H}_{2}\right)=4.1, \mathrm{G}_{\text {plastic }}$ (gas)=4.1 (based on the radiolysis of polyethylene), and $\mathrm{G}_{\text {plastic }}$ $(\mathrm{HCl})=0.7$ (based on the radiolysis of polyvinylchloride), and $\mathrm{G}_{\text {water, } \alpha}\left(\mathrm{H}_{2}\right)=1.6$ (based on the $\alpha$-radiolysis of water), $\mathrm{G}_{\text {water }}$ (gas)=2.4 (assuming oxygen and hydrogen are released from the radiolysis of water) in Equation 3.21, the effective $\mathrm{G}$ values for potentially flammable gas $\left(\mathrm{H}_{2}\right), \mathrm{HCl}$, and net gas for Solidified 
Aqueous Inorganic Concreted Waste that contains predominately alpha-emitting radionuclides can be estimated as:

$$
\begin{aligned}
& \mathrm{G}\left(\mathrm{H}_{2}\right)=\left[\left(1.8 \times 10^{-3}\right)(4.1)+(0.3)(1.6)\right](1.0)=0.49 \\
& \mathrm{G}(\mathrm{HCl})=\left[\left(1.8 \times 10^{-3}\right)(0.7)\right](1.0)=1.08 \times 10^{-3}=0
\end{aligned}
$$

$\mathrm{G}($ net gas $)=\left[\left(1.8 \times 10^{-3}\right)(4.1)+(0.30)(2.4)\right](1.0)=0.73$.

\subsubsection{Effective G Values for Solid Inorganic Waste}

Solid Inorganic Waste includes surface-contaminated solid inorganic materials, such as glass, metal, ceramics, and fiberglass. The waste materials must be dry and free of oil, grease, or other organics except for trace quantities (less than $1 \%$ by weight). The waste may be placed inside plastic bags (Solid Inorganic Waste in Plastic) or metal cans (Solid Inorganic Waste in Cans), and then in drums that have a rigid high-density polyethylene liner or other approved container.

No materials in Solid Inorganic Waste can radiolytically generate hydrogen. For Solid Inorganic Waste in Plastic, radiation that escapes the waste mass can cause radiation in the polymeric packaging (confinement layers). For Solid Inorganic Waste in Cans, gamma radiation that escapes the waste mass and penetrates the metal can could potentially cause radiolysis in any water or organic material (e.g., polymeric drum liner) that is outside the metal can confinement layer. However, any radiolysis that occurs due to gamma radiation that escapes the metal can is expected to be very low.

On average, the surface-contaminated inorganic waste will absorb half of the alpha decay energy escaping from the surface contamination. It is assumed that the other half of the decay energy is absorbed by the packaging materials. The inorganic materials are considered to generate no gas by radiolysis. For Solid Inorganic Waste in Plastic with polymeric confinement around the solid inorganic material, the polymeric material cannot have a $\mathrm{G}\left(\mathrm{H}_{2}\right)$ value that exceeds 4.1 (based on polyethylene) or a $\mathrm{G}(\mathrm{HCl}$ ) value that exceeds 0.7 (based on PVC).

\subsubsection{Effective G Values for Solid Inorganic Waste in Plastic}

For Solid Inorganic Waste in Plastic, the coefficients used in Equation 3.5 to determine the effective Gvalue are summarized in Table 3.8 .

Table 3.8 Coefficients for Calculation of Effective G(gas) for Solidified Aqueous Inorganic Particulate Waste

\begin{tabular}{lclclc}
\hline Coefficient & Value & Coefficient & Value & Coefficient & Value \\
\hline $\mathrm{F}_{\mathrm{P}, \alpha}$ & $1.0^{\mathrm{a}}$ & $\mathrm{F}_{\text {water, } \alpha}$ & $0^{\mathrm{b}}$ & $\mathrm{F}_{\text {plastic, } \alpha}$ & $0.5^{\mathrm{e}}$ \\
$\mathrm{F}_{\mathrm{P}, \beta}$ & 1.0 & $\mathrm{~F}_{\text {water, } \beta}$ & $0^{\mathrm{c}}$ & $\mathrm{F}_{\text {plastic, } \beta}$ & $0.5^{\mathrm{f}}$ \\
$\mathrm{F}_{\mathrm{P}, \gamma}$ & 1.0 & $\mathrm{~F}_{\text {water }, \gamma}$ & $0^{\mathrm{d}}$ & $\mathrm{F}_{\text {plastic, } \gamma}$ & $0.5 \mathrm{~g}$ \\
\hline
\end{tabular}

a A value $<1.0$ may be justifiable for particles that have diameters that remain greater than $-10 \mu \mathrm{m}$.

b No water or organics are allowed in Solid Inorganic Waste in Plastic.

c No water or organics are allowed in Solid Inorganic Waste in Plastic.

e No water or organics are allowed in Solid Inorganic Waste in Plastic.

e Half of the decay energy from the surface contamination can interact with the packaging (e.g., plastic bags).

f Half of the decay energy from the surface contamination can interact with the packaging (e.g., plastic bags); a value less than 0.5 may be justifiable. 
g Half of the decay energy from the surface contarnination can interact with the packaging (e.g., plastic bags); a value less than 0.5 may be justifiable.

Using the coefficients from Table 3.8 in Equation 3.5, the effective radiolytic G value for Solid Inorganic Waste in Plastic is:

$$
\begin{aligned}
\mathrm{G}_{\text {Solid Inorganic Waste in Pastic }}= & \lambda_{\alpha}[(0.5)(\mathrm{G}(\text { plastic }))] \\
& +\lambda_{\beta}[(\leq 0.5)(G(\text { plastic }))] \\
& +\lambda_{\gamma}[(\leq 0.5)(G(\text { plastic }))] .
\end{aligned}
$$

The effective $G$ value for Solid Inorganic Waste in Plastic which contains radionuclides that are predominantly alpha-emitters (i.e. $\lambda_{\beta}=\lambda_{\gamma}=0$ in Equation 3.25 ) is given by:

$$
\mathrm{G}_{\text {Solid Inorganic Waste in Pastic, } \alpha}=\sum_{\mathrm{M}}\left[\left(\mathrm{F}_{\mathrm{M}} \mathrm{xG}_{\mathrm{M}}\right) \mathrm{xF}_{\mathrm{P}}\right]=[(0.5)(\mathrm{G} \text { (plastic) })] \text {. }
$$

Using $G_{\text {plastic, } \alpha}\left(\mathrm{H}_{2}\right)=4.1, G_{\text {plastic }}$ (net gas)=4.1(based on the radiolysis of polyethylene), and $G_{\text {plastic }}$ $(\mathrm{HCl})=0.7$ (based on the radiolysis of polyvinylchloride) in Equation 3.26, the effective $\mathrm{G}$ values for potentially flammable gas $\left(\mathrm{H}_{2}\right), \mathrm{HCl}$, and net gas for Solid Inorganic Waste that contains predominately alpha-emitting radionuclides can be estimated as:

$\mathrm{G}\left(\mathrm{H}_{2}\right)=[(0.5)(4.1)](1.0)=2.1$

$\mathrm{G}(\mathrm{HCl})=[(0.5)(0.7)](1.0)=0.35$

$\mathrm{G}($ net gas $)=[(0.5)(4.1)](1.0)=2.1$.

\subsubsection{Effective $\mathrm{G}$ values for Solid Inorganic Waste in Cans}

The effective $G$ values for Solid Inorganic Waste in Cans are equal to zero for radioisotopes that are predominantly alpha-emitters since there is no water, plastic, or other organics (above $1 \%$ by weight), and the inorganic materials and metal containers generate no gas from radiolysis (i.e., $F_{w a t e r, ~}=0$ and Flastic, $\alpha=0$ )=

For Solid Inorganic Waste in Cans that contains significant quantities of gamma-emitting radionuclides, the polymeric confinement layers and the polyethylene drum liners (if applicable) outside the metal confinement cans may undergo radiolysis as a result of the penetrating gamma radiation. If significant gamma radiation penetrates the metal can, an analysis should be performed to determine the resultant radiolytic gas generation.

\subsubsection{Effective G Values for Solid Organic Waste}

Solid Organic Waste includes surface-contaminated solid organic materials, such as plastics, paper, cloth, Plexiglas, and Menelex. The materials may contain absorbed water, commercial greases, oils or organic liquids having sufficiently low $G$ values. Cemented organic process solids are also included in this category. Solid organic materials with $\mathrm{G}\left(\mathrm{H}_{2}\right)$ values less than 4.1 are also acceptable (e.g., aromatic rings, unsaturated $\mathrm{C}-\mathrm{C}$ bonds, and $\mathrm{C}-\mathrm{N}$ triple bonds). In Solid Organic Waste, radiolysis can occur in any water or organic materials present. 
The surface-contaminated organic waste or their organic packaging is assumed to absorb $100 \%$ of the available decay energy. The only gas generated by inorganic materials is oxygen, which would tend to oxidize the plastic packaging materials. Therefore, any inorganic materials present are considered to generate no gas by radiolysis.

Radiolysis of the solid organic materials (typically plastic) bounds the radiolytic gas generation for Solid Organic Waste. For Solid Organic Waste, the coefficients used in Equation 3.5 to determine the effective G-value are summarized in Table 3.9.

Table 3.9 Coefficients for Calculation of Effective G(gas) for Solid Organic Waste

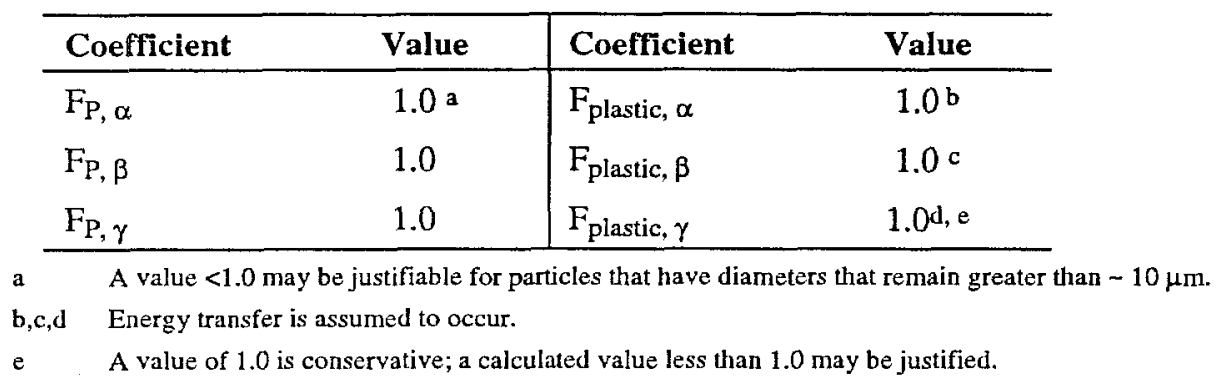

Using the coefficients from Table 3.9 in Equation 3.5, the effective radiolytic $\mathrm{G}$ value for Solid Organic Waste is:

$$
\begin{aligned}
\mathrm{G}_{\text {Solid Organic } \mathrm{W}_{\text {aste }}=} & \lambda_{\alpha}\left[(1.0)\left(\mathrm{G}_{\text {Solid Organic }}\right)\right] \\
& +\lambda_{\beta}\left[(1.0)\left(\mathrm{G}_{\text {Solid Organic }}\right)\right] \\
& +\lambda_{\gamma}\left[\left(\mathrm{F}_{\text {plastic } \gamma}\right)\left(G_{\text {Solid Organic }}\right)\right] .
\end{aligned}
$$

The effective $G$ value for Solid Organic Waste that contains radionuclides which are mainly alphaemitters (i.e. $\lambda_{\beta}=\lambda_{\gamma}=0$ ) is:

$$
\mathrm{G}_{\text {Solid Organic Waste, } \alpha}=(1.0)(\mathrm{G}(\text { solid organic })) \text {. }
$$

Therefore, using the $\mathrm{G}$ values of $\mathrm{G}\left(\mathrm{H}_{2}\right)=4.1$ (based on the radiolysis of polyethylene), $\mathrm{G}(\mathrm{HCl})=0.7$ (based on the radiolysis of polyvinylchloride), and $\mathrm{G}$ (net gas) $=10.2$ (based on the radiolysis of cellulose) for waste containing radionuclides that are predominantly alpha-emitters, the effective G-values for Solid Organic Waste are:

$$
\begin{aligned}
& \mathrm{G}\left(\mathrm{H}_{2}\right)=[(1.0)(4.1)](1.0)=4.1 \\
& \mathrm{G}(\mathrm{HCl})=[(1.0)(0.7)](1.0)=0.7 \\
& \mathrm{G}(\text { net gas })=[(1.0)(10.2)](1.0)=10.2 \text {. } \\
& \text { 3.3.5 Summary of the Effective G Values for Various Waste Types When the } \\
& \text { Radionuclides are Primarily Alpha-Emitters }
\end{aligned}
$$

\subsubsection{Summary of the Effective G Values for Various Waste Types When the Radionuclides are Primarily Alpha-Emitters}

Table 3.10 summarizes the radiolytic $\mathrm{G}$ values for hydrogen, hydrogen chloride, and net gas generation for the various waste types discussed above. 
The bounding $\mathrm{G}\left(\mathrm{H}_{2}\right)$ and $\mathrm{G}$ (net gas) values for Solid Aqueous Inorganic Waste are based on the radiolysis of water. For all waste types, polyvinylchloride is the bounding material for $\mathrm{G}(\mathrm{HCl})$. For Solid Inorganic Waste in Plastic, the bounding $\mathrm{G}\left(\mathrm{H}_{2}\right)$ and $\mathrm{G}$ (net gas) values are based on polyethylene. For Solid Organic Waste, the bounding $\mathrm{G}\left(\mathrm{H}_{2}\right)$ is based on polyethylene, and the bounding $\mathrm{G}$ (net gas) is based on cellulose.

To estimate the effective bounding radiolytic $\mathrm{G}$ values at a temperature higher than $298 \mathrm{~K}$, the $\mathrm{G}$ values first need to be adjusted for temperature using the procedure presented in Section 2.4.2. The materials used for the bounding $G$ values for the various waste types are listed in Table 3.11 along with their $G$ values and their corresponding activation energies.

Table 3.10 Effective Radiolytic G Values for the Various Waste Types at $298 \mathrm{~K}$ when the Waste Contains Radionuclides that are Predominantly Alpha-Emitting

\begin{tabular}{lccc}
\hline & $\mathbf{G}\left(\mathbf{H}_{2}\right)$ & $\mathbf{G}(\mathbf{H C l})$ & $\mathbf{G}($ net gas) \\
\cline { 2 - 5 } Waste Type & \multicolumn{3}{c}{ (molecules/100 eV) } \\
\hline Solidified Aqueous Inorganic Absorbed Waste, $\alpha$ & 1.6 & $\sim 0$ & 2.4 \\
Solidified Aqueous Inorganic Particulate Waste, $\alpha$ & 1.6 & $\sim 0$ & 2.4 \\
Solidified Aqueous Inorganic Concreted Waste, $\alpha$ & 0.5 & $\sim 0$ & 0.73 \\
Solid Inorganic Waste in Plastic, $\alpha$ & 2.1 & 0.35 & 2.1 \\
Solid Inorganic Waste in Cans, $\alpha$ & 0 & 0 & 0 \\
Solid Organic Waste, $\alpha$ & 4.1 & 0.7 & 10.2 \\
\hline
\end{tabular}

Table 3.11 Activation Energies for Bounding G Value Materials

\begin{tabular}{llc}
\hline Material & $\begin{array}{l}\text { Bounding G Value } \\
{[\text { molecules } / 100 \mathrm{eV}]}\end{array}$ & $\begin{array}{l}\text { Activation Energy } \\
{[\mathrm{kcal} / \mathrm{mole}]}\end{array}$ \\
\hline Water & $\mathrm{G}\left(\mathrm{H}_{2}\right)=1.6, \mathrm{G}($ net gas $)=2.4$ & 0 \\
Polyethylene & $\mathrm{G}($ flam gas $)=4.1$ & 0.8 \\
Polyvinylchloride & $\mathrm{G}(\mathrm{HCl})=0.7$ & 3.0 \\
Cellulose & $\mathrm{G}($ flam gas $)=3.2, \mathrm{G}($ net gas $)=10.2$ & 2.1 \\
\hline
\end{tabular}


3. Hydrogen Generation Rates in Transuranic Waste 


\section{CALCULATION OF HYDROGEN CONCENTRATION FOR VARIOUS PACKAGING CONFIGURATIONS}

\subsection{Modeling Hydrogen Concentration in TRU Waste Transportation Containers}

The predominant source of hydrogen in a TRU waste transportation package is typically from the radiolysis of the hydrogenous material(s) in the contents. For contents that include significant gammaemitting nuclides or for contents that are adjacent to hydrogenous confinement materials, radiolysis of the polymeric confinement layers can also contribute significantly to the total hydrogen generation rate.

As hydrogen is generated, it could potentially accumulate within a confinement region to form a flammable mixture. This accumulation will occur if the release rate of hydrogen from that barrier is less than the sum of the generation rate within the region and the rate of hydrogen entering the confinement barrier. Parameters that govern the release of hydrogen from the various confinement and containment barriers in TRU waste transportation containers include:

(a) Waste packaging configuration (i.e., the number and type of confinement and containment layers surrounding the waste),

(b) Rate of hydrogen generation within the waste and confinement layers,

(c) Release rates of hydrogen from each of the confinement and containment layers,

(d) Temperature of the waste and the confinement components,

(e) Void volume within the various product containers, confinement layers, and containment vessel(s), and

(f) Duration of the shipping period ( normally assumed to be a maximum of one year).

The release rate of hydrogen through a given confinement barrier is a combination of the rate of hydrogen diffusion through any opening(s) or leakage path(s) in the barrier and the rate of hydrogen permeation through the barrier material. Some confinement materials, such as metal product cans (food pack cans) and glass containers, do not allow significant hydrogen permeation and any release of hydrogen is due to gas escaping through leakage paths. However, for other confinement materials, such as polymeric bags and polymeric drum liners, the hydrogen permeation rate can be significant. The hydrogen permeation rate through plastic bags is often on the order of the hydrogen diffusion rate through the small leakage paths in the twist-and-tape or fold-and-tape closures of plastic bags (NRC Docket No. 71-9218, Aug. 11, 1999). In general, the number of confinement layers should be minimized and the hydrogen permeability of the confinement layers should be maximized to limit the rate of hydrogen accumulation in the innermost confinement barrier, which is typically the region of highest hydrogen concentration.

The most common confinement barrier materials in a TRU waste transportation package are polymeric bags and metal cans. Some TRU wastes are placed in metal product cans and then "bagged out" by placing the metal can in a plastic bag. This bagged can may then be placed in one or more bags or in a second can that is bagged. Other TRU wastes may be placed directly in plastic bags.

\subsubsection{Diffusion of Hydrogen Through Leak Paths}

Hydrogen (and other gases) can escape from confinement barriers by diffusion through small openings or leakage paths. For metal can confinement barriers, the gas can diffuse through any small leakage paths 
that exist (e.g., in the lid crimp region), and in plastic bag confinement layers the gas can escape by diffusing through the bag closure (or filter vent). The diffusion rate of a gas through an opening depends on the geometry of the opening, type of gas, temperature, and the concentration gradient across the opening. The diffusion coefficient varies with temperature to the 1.75 power, with decreasing temperature causing a slight decrease in the coefficient. When estimating the diffusion rate of hydrogen in air, it is conservative for purposes of TRU waste transportation to use the diffusion coefficient for hydrogen in air at $-29^{\circ} \mathrm{C}$, which is $0.511 \mathrm{~cm}^{2} / \mathrm{s}$. However, unless the geometry of the leakage path is known, which is not usually the case for the leakage path(s) that might exist in metal cans or closure region of plastic bags, testing must be performed (or relevant tests) to determine the appropriate diffusion rate for modeling purposes. These tests need to be performed on the same types of metal cans and/or plastic bags that will be used as confinement barriers in the packaging. Similarly, if filter vents are used in the plastic bag or drum liner confinement layers, measurements (or referenced to published results) should be performed on the filters to determine the effective hydrogen diffusion rate.

For cases where the leakage path geometry is known, the effective hydrogen diffusion rate can be estimated. The product of the diffusion coefficient $\left(\mathrm{cm}^{2} / \mathrm{s}\right)$, the cross-sectional area of the leakage hole $\left(\mathrm{cm}^{2}\right)$, and the concentration gradient (mole/ $\mathrm{cm}^{4} \cdot \mathrm{mole}$ fraction) gives the effective hydrogen diffusion rate:

$$
\mathrm{T}_{\mathrm{D}}=D_{\mathrm{H}_{2}} \mathrm{~A}_{\mathrm{S}} \frac{\mathrm{dC}_{\mathrm{H}_{2}}}{\mathrm{dx}}
$$

where: $\mathrm{T}_{\mathrm{D}}$ is the effective hydrogen transport rate due to diffusion [mole $\mathrm{H}_{2} / \mathrm{s}$.mole fraction];

$\mathrm{D}_{\mathrm{H} 2}$ is the coefficient for hydrogen diffusion through air $\left[\mathrm{cm}^{2} / \mathrm{s}\right]$;

$A_{S}=\left(\pi d^{2}\right) / 4$ is cross-sectional area of the leakage hole $\left[\mathrm{cm}^{2}\right]$;

$\mathrm{d}$ is the effective diameter of the leakage hole $[\mathrm{cm}]$; and

$\mathrm{dC}_{\mathrm{H} 2} / \mathrm{dx}$ is the hydrogen concentration gradient [mole $\mathrm{H}_{2} / \mathrm{cm}^{4}$ ].

The hydrogen concentration gradient is the product of the gas concentration and the hydrogen mole fraction. The gas concentration is estimated with the ideal gas law: $C_{\text {gas }}=n / V=P / R T$. Then, the hydrogen concentration is $\mathrm{C}_{\mathrm{H} 2}=\mathrm{C}_{\mathrm{gas}} \mathrm{x}_{\mathrm{H} 2}$, and the hydrogen concentration gradient is:

$$
\frac{\mathrm{dC}_{\mathrm{H}_{2}}}{\mathrm{dx}}=\frac{\mathrm{C}_{\mathrm{H}_{2}, \text { in }}-\mathrm{C}_{\mathrm{H}_{2} \text {,out }}}{\mathrm{x}_{\mathrm{in}}-\mathrm{x}_{\text {out }}}=\frac{\mathrm{C}_{\mathrm{gus}}\left(\mathrm{x}_{\mathrm{H}_{2} \text {,in }}-\mathrm{x}_{\mathrm{H}_{2}, \text { out }}\right)}{\mathrm{t}}=\frac{\mathrm{P}\left(\mathrm{x}_{\mathrm{H}_{2} \text {,in }}-\mathrm{x}_{\mathrm{H}_{2} \text {,out }}\right)}{\mathrm{tR} \mathrm{T}}
$$

where: $\mathrm{C}_{\mathrm{H} 2 \text {,in }}$ is the hydrogen concentration inside the confinement barrier [ $\mathrm{mole}_{2} / \mathrm{cm}^{3}$ ];

$\mathrm{C}_{\mathrm{H} 2 \text {,out }}$ is the hydrogen concentration outside the confinement barrier [mole $\mathrm{H}_{2} / \mathrm{cm}^{3}$ ];

$\mathrm{x}_{\mathrm{H} 2 \text {,in }}$ is the hydrogen mole fraction inside the confinement barrier;

$\mathrm{x}_{112 \text {,out }}$ is the hydrogen mole fraction outside the confinement barrier;

$\mathrm{R}$ is the gas law constant $\left[82.05 \mathrm{~atm} \cdot \mathrm{cm}^{3} / \mathrm{gmol} \cdot \mathrm{K}\right]$;

$\mathrm{T}$ is the gas temperature $[\mathrm{K}]$;

$P$ is the gas pressure [atm]; and 
$t$ is the thickness of the confinement barrier [cm].

Substituting for the hydrogen concentration gradient into the Equation 4.1 gives:

$\mathrm{T}_{\mathrm{D}}=\left[\frac{D_{\mathrm{H}_{2}} \pi \mathrm{d}^{2} \mathrm{P}\left(\mathrm{x}_{\mathrm{H}_{2}, \text { in }}-\mathrm{x}_{\mathrm{H}_{2}, \text { out }}\right)}{4 \mathrm{tR} \mathrm{T}}\right]$.

To obtain conservative estimates of the effective hydrogen transport rate due to diffusion, the above equation should be calculated using: (1) the minimum leakage path cross-sectional area, (2) the coefficient for hydrogen diffusion in air at the minimum temperature, and (3) a pressure of one atmosphere.

\subsubsection{Permeation of Hydrogen Through Packaging Materials}

The permeability of a material to hydrogen is quantified as the material's hydrogen permeability coefficient. Permeability may be defined as the number of moles of gas passing per unit time through a material of unit area, which is of unit thickness under a unit partial pressure gradient at a specified temperature. Typical units for permeability are $(\mathrm{mole} \cdot \mathrm{cm}) /\left(\mathrm{s} \cdot \mathrm{cm}^{2} \cdot \mathrm{mmHg}\right)$. The permeability rate depends on the material type, material thickness, the material's history (i.e., absorbed dose), the concentration driving force, and temperature.

Two materials that are commonly used as polymeric confinement barriers (plastic bags) in TRU waste transportation packagings are polyvinyl chloride (PVC) and polyethylene (PE). In addition to material type, permeability also depends on the additives in the materials.

The dose absorbed by a polymeric confinement material may influence its permeability to gases. Although gamma doses up to $800 \mathrm{krad}$ seem to have no effect of the permeability of PE and PVC to $\mathrm{N}_{2}$, $\mathrm{O}_{2}, \mathrm{CO}_{2}$ and $\mathrm{H}_{2} \mathrm{O}$, and the crosslinking in the polymers caused by gamma ray absorption has been shown to not cause significant changes in the permeability (NRC Docket No. 71-9218, Aug. 11, 1999), preliminary tests performed on waste drums that had been stored for fifteen years indicate that the hydrogen permeability rates through both PE and PVC were higher than the rates through new plastic samples (Varsanyi 1975). For TRU waste materials that were placed in polymeric confinement layers recently or when the polymeric confinement layers have not absorbed a significant dose, the permeability rate of new confinement materials may be used for modeling purposes. For TRU waste materials that have been in particular confinement layers for a significant period of time or for cases where the confinement materials have absorbed a significant dose, measurements can be performed on the radiation-damaged confinement material to obtain the appropriate permeability coefficient for modeling purposes. However, if it is known that the confinement barriers in a package have a higher permeability than new material, modeling the hydrogen release with the properties of the new material should yield conservative results for the hydrogen concentration within the inner-most confinement layer.

Permeabilities are highly temperature dependent and this dependence can be represented with an exponential Arrhenius-type equation (Varsanyi 1975):

$\mathrm{P}=\exp \left(-\mathrm{E}_{\mathrm{p}} / \mathrm{RT}\right)$

where: $\mathrm{P}$ is the permeability $\left[(\right.$ mole $\left.\cdot \mathrm{cm}) /\left(\mathrm{s} \cdot \mathrm{cm}^{2} \cdot \mathrm{mmHg}\right)\right]$;

$E_{p}$ is the activation energy for permeation [ $\left.\mathrm{kcal} / \mathrm{gmol}\right]$;

$\mathrm{R}$ is the gas law constant $\left[1.987 \times 10^{-3} \mathrm{kcal} / \mathrm{gmol} \mathrm{K}\right]$; and 
$\mathrm{T}$ is the temperature [K].

Typically, for polymeric membranes the activation energies for hydrogen permeation are between 1 and $10 \mathrm{kcal} / \mathrm{gmol}$ (NRC Docket No. 71-9218, Aug. 11, 1999). The estimated activation energies for hydrogen permeation through PE and PVC membranes are $8.2 \mathrm{kcal} / \mathrm{gmol}$ and $1.9 \mathrm{kcal} / \mathrm{gmol}$, respectively (NRC Docket No. 71-9218, Aug. 11, 1999). Therefore, the hydrogen permeation rate through PE is much more sensitive to temperature than the rate through PVC. If a permeability $P_{1}$ is given at a temperature $T_{1}$, then the permeability at a temperature $T_{2}$ is given by:

$\mathrm{P}_{2}=\mathrm{P}_{1} \exp \left[\left(\mathrm{E}_{\mathrm{p}}\left(\mathrm{T}_{1}-\mathrm{T}_{2}\right)\right) / \mathrm{RT}_{2} \mathrm{~T}_{1}\right]$.

The hydrogen permeation rate through small plastic bags with a surface area about $0.6 \mathrm{~m}^{2}$ (not large drum liner bags), such as those used to bag-out solid inorganics and organics, is about $2 \times 10^{-6}$ mole/sec/mole fraction (NRC Docket No. 71-9218, Aug. 11, 1999). For larger bags with larger surface areas, permeation may be more important. When performing a conservative estimation of the total hydrogen transport through a plastic bag, the hydrogen permeation may be neglected and only the hydrogen diffusion through the bag closure (or bag filter vent if the bag is heat sealed) considered.

\subsection{Hydrogen Gas Concentration for Various Packaging Configurations}

This section details representative analytical approaches that can be used to determine the hydrogen concentration as a function of time in example TRU waste transportation packages. Various packaging configurations are analyzed starting with simple single enclosures and then adding confinement and/or containment layers to obtain more complex configurations of nested enclosures.

\subsubsection{Single Enclosures}

This section develops representative analytical approaches to model the hydrogen concentration as a function of time in single enclosures. Models are developed for leaking, non-leaking, and semi-open enclosures.

\subsubsection{Hydrogen Gas Concentration in a Single Rigid Non-Leaking Enclosure}

Consider a single non-leaking rigid enclosure holding radioactive material and other materials capable of radiolysis where the effective radiolytic $G$ value for net gas production is $G(n e t$ gas). Since some of the gas produced by radiolysis is often hydrogen, the radiolytic $G$ value for hydrogen gas generation can be described as $\mathrm{G}\left(\mathrm{H}_{2}\right)=\alpha \mathrm{G}$ (net gas), where $\alpha$ is less than or equal to one.

The number of moles of gas generated in the enclosure as a function of time due to radiolysis is:

$$
\mathrm{n}_{\text {net gas }}=\left(\frac{\mathrm{D}_{\mathrm{H}}}{100}\right)\left(\frac{\mathrm{G}(\text { net gas })}{\mathrm{A}_{\mathrm{N}}}\right)(\mathrm{t})
$$

and the number of moles of hydrogen gas generated as a function of time is:

$$
\mathrm{n}_{\mathrm{H}_{2}}=\left(\frac{\mathrm{D}_{\mathrm{H}}}{100}\right)\left(\frac{\mathrm{G}\left(\mathrm{H}_{2}\right)}{\mathrm{A}_{\mathrm{N}}}\right)(\mathrm{t})=\left(\frac{\mathrm{D}_{\mathrm{H}}}{100}\right)\left(\frac{\alpha \mathrm{G} \text { (net gas })}{\mathrm{A}_{\mathrm{N}}}\right)(\mathrm{t})
$$

where: $\mathrm{n}_{\text {net gas }}$ is the number of moles of gas generated [gmol]; 
$D_{\mathrm{H}} \quad$ is the decay heat that is absorbed by the radiolytic materials $[\mathrm{eV} / \mathrm{s}]$;

$\mathrm{G}$ (flam gas) is the radiolytic $\mathrm{G}$ value for flammable gas [molecules $/ 100 \mathrm{eV}$ ];

$\mathrm{G}$ (net gas) is the radiolytic $\mathrm{G}$ value for net gas generation [molecules $/ 100 \mathrm{eV}$ ];

$\mathrm{t} \quad$ is the time that the container has been sealed [s];

$\mathrm{A}_{\mathrm{N}} \quad$ is Avagadro's number [6.023 $\left.10^{23} \mathrm{molecules} / \mathrm{gmol}\right]$; and

$\alpha \quad$ is the fraction of $\mathrm{G}_{\mathrm{R}}$ (net gas) that is equivalent to $\mathrm{G}_{\mathrm{R}}$ (flam gas).

Using the above expressions, the mole fraction hydrogen, $\mathrm{X}_{\mathrm{H} 2}$, as a function of time is:

$$
X_{\mathrm{H}_{2}}(\mathrm{t})=\frac{\mathrm{n}_{\mathrm{H}_{2}}}{\mathrm{n}_{0}+\mathrm{n}_{\text {net gas }}}=\frac{\left(\frac{\mathrm{D}_{\mathrm{H}}}{100}\right)\left(\frac{\alpha \mathrm{G}(\text { netgas })}{\mathrm{A}_{\mathrm{N}}}\right)(\mathrm{t})}{\left(\frac{\mathrm{P}_{0} \mathrm{~V}}{\mathrm{R}_{\mathrm{g}} \mathrm{T}_{0}}\right)+\left(\frac{\mathrm{D}_{\mathrm{H}}}{100}\right)\left(\frac{\mathrm{G}(\text { netgas })}{\mathrm{A}_{\mathrm{N}}}\right)(\mathrm{t})}
$$

where: $P_{0}$ is the pressure when the container was sealed [atm];

$\mathrm{T}_{0} \quad$ is the temperature when the container was sealed $[\mathrm{K}]$;

$\mathrm{V} \quad$ is the container void volume $\left[\mathrm{cm}^{3}\right]$;

$\mathrm{R}_{\mathrm{g}} \quad$ is the gas law constant $\left[82.05 \mathrm{~cm}^{3} \cdot \mathrm{atm} / \mathrm{gmol} \cdot \mathrm{K}\right]$; and

$\mathrm{n}_{0} \quad$ is the initial number of gas moles in the container when the vessel was closed [gmol].

\subsubsection{Hydrogen Gas Concentration in a Single Rigid Leaking Enclosure}

An analysis is made of the hydrogen mole fraction as a function of time for an enclosure wherein hydrogen is being generated and the escape of hydrogen from the enclosure occurs by diffusion. The hydrogen mole balance for this case is:

$\frac{\mathrm{d}(\mathrm{Xn})}{\mathrm{dt}}=\mathrm{R}_{\mathrm{M}}-\mathrm{T}\left(\mathrm{X}-\mathrm{X}_{\mathrm{a}}\right)$

where: $\mathrm{n}$ is the total number of gas moles within the enclosure [gmol];

$\mathrm{X}$ is the hydrogen gas mole fraction;

$\mathrm{R}_{\mathrm{M}}$ is the molar hydrogen generation rate $\left[\mathrm{gmol} \mathrm{H}_{2} / \mathrm{s}\right.$ ];

$\mathrm{T}$ is the effective transport rate of hydrogen from the enclosure [gmol $\mathrm{H}_{2} / \mathrm{s} \cdot$ mole fraction];

$\mathrm{t}$ is the time $[\mathrm{s}]$; and

$\mathrm{X}_{\mathrm{a}}$ is the ambient hydrogen mole fraction.

In terms of hydrogen concentration, it is conservative to assume that the total gas moles, $\mathrm{n}$, remains unchanged. The approximation that the total gas moles are quasi-steady is conservative (tends to overestimate the hydrogen mole fraction) for the following reasons: (1) no radiolysis-produced dilutent gases 
are considered, and (2) there are no pressure gradients produced between enclosures due to increased gas density that could lead to convective flow. With the quasi-steady approximation that the total gas moles, $\mathrm{n}$, remains unchanged, and the differential equation can be simplified:

$$
\mathrm{n} \frac{\mathrm{dX}}{\mathrm{dt}}=\mathrm{R}_{\mathrm{M}}-\mathrm{T}\left(\mathrm{X}-\mathrm{X}_{\mathrm{a}}\right)
$$

where: $\mathrm{n}$ is the initial number of gas moles present in the enclosure when it is sealed.

The general solution to Equation 4.10 is:

$$
X(t)=\left(\frac{R_{m}}{T}+X_{a}\right)+\left[e^{\frac{-T}{n}}\left(X_{0}-X_{a}-\frac{R_{m}}{T}\right)\right]
$$

If it is assumed that $X_{a}=0$ and that the initial hydrogen mole fraction within the enclosure is zero (i.e., $\mathrm{X}_{0}=0$ ), then the solution to the above ordinary differential equation is:

$$
X(t)=\frac{R_{M}}{T}\left\{1-\exp \left(\frac{-T t}{n}\right)\right\} .
$$

This solution is valid only for cases where $R_{M}>T X(t)$, i.e., when the hydrogen generation rate is greater than the effective rate of hydrogen transport across the enclosure wall. Since $X(t)$ is less than or equal to 1.0 , the inequality $R_{M}>T X(t)$ is satisfied as long as $R_{M}>T$. The hydrogen mole fraction calculated with the above equation will have a higher degree of conservatism for larger values of the hydrogen mole fraction, and will tend to accurately predict, with a relatively small degree of conservatism, hydrogen mole fractions less than 0.1 . For an example calculation of the hydrogen gas concentration in a single rigid leaking enclosure, see Example \#1 in Appendix $F$.

\subsubsection{Hydrogen Gas Concentration in a Single Rigid Semi-Open Enclosure}

An analysis is made of the hydrogen gas concentration as a function of time for a semi-open rigid enclosure that contains material which is generating gas radiolytically. A "semi-open" enclosure is defined as a enclosure that has a significant leakage path where gas can easily escape (but no gas can enter) the enclosure and the pressure in the enclosure does not increase above ambient. In this analysis, it is assumed that the gases in the enclosure are well-mixed and that no outside gases can enter the enclosure. A mole balance over the enclosure (in terms of concentrations) can be expressed as:

$$
\mathrm{QC}_{\mathrm{A} 0}=\mathrm{QC}_{\mathrm{A}}+\mathrm{V} \frac{\mathrm{dC}_{\mathrm{A}}}{\mathrm{dt}}
$$

where: $Q$ is the volumetric rate of radiolytically-generated gas $\left[\mathrm{cm}^{3 /} / \mathrm{s}\right]$;

$\mathrm{C}_{\mathrm{AO}}$ is the concentration of flammable gas in the radiolytically-generated gases $\left[\mathrm{gmol} / \mathrm{cm}^{3}\right]$;

$\mathrm{C}_{\mathrm{A}}$ is the flammable gas concentration of the gas escaping the container $\left[\mathrm{gmol} / \mathrm{cm}^{3}\right]$;

$\mathrm{V}$ is the void volume in the container $\left[\mathrm{cm}^{3}\right]$; and

$t$ is the time $[s]$.

Separating variables and integrating yield: 


$$
C_{A}=C_{A 0}\left[1-\exp \left(\frac{-t Q}{V}\right)\right]
$$

For an example calculation of the hydrogen concentration in a single semi-open rigid container with its contents undergoing radiolysis, see Example \#2, Appendix F.

\subsubsection{Simple Nested Enclosures}

This section develops representative methods for modeling the hydrogen concentration as a function of time for various numbers of nested enclosures used to represent nested confinement layers (e.g., plastic bags, plastic drum liners, food product cans) and containment layers.

\subsubsection{Hydrogen Gas Concentration in a Rigid Leaking Enclosure Nested Within a Rigid Non-Leaking Enclosure}

Consider a rigid leaking enclosure holding radioactive material that is nested within a second rigid nonleaking enclosure. The radioactive material within the inner enclosure is radiolytically generating hydrogen. If the hydrogen escapes the inner enclosures only by diffusion, the hydrogen mole balance can be formed as follows:

$$
\begin{aligned}
& \frac{d\left(n_{1} X_{1}\right)}{d t}=R_{M}-T_{1}\left(X_{1}-X_{2}\right) \\
& \frac{d\left(n_{2} X_{2}\right)}{d t}=T_{1}\left(X_{1}-X_{2}\right)
\end{aligned}
$$

where: $\mathrm{n}_{1}$ is the number of gas moles within enclosure \#1 (inner enclosure) as a function of time

$$
\left(=\mathrm{n}_{0,1}+\mathrm{n}_{\mathrm{H} 2,1}\right) \text { [gmol]; }
$$

$\mathrm{n}_{2}$ is the number of gas moles within enclosure \#2 (outer enclosure) as a function of time $\left(=n_{0,2}+n_{H 2,2}\right)$, (not including gas within enclosure \#1) [gmol];

$\mathrm{n}_{0,1}$ is the initial number of gas moles within enclosure \#1 [gmol];

$\mathrm{n}_{0,2}$ is the initial number of gas moles within enclosure \#2 [gmol];

$n_{H 2,1}$ is the number of hydrogen gas moles within enclosure \#1 as a function of time [gmol];

$\mathrm{n}_{\mathrm{H} 2,2}$ is the number of hydrogen gas moles within enclosure \#2 as a function of time [gmol];

$X_{1}$ is the hydrogen gas mole fraction within enclosure \#1;

$\mathrm{X}_{2}$ is the hydrogen gas mole fraction within enclosure \#2;

$\mathrm{R}_{\mathrm{M}}$ is the molar hydrogen generation rate $\left[\mathrm{gmol} \mathrm{H}_{2} / \mathrm{s}\right]$;

$T_{1}$ is the effective rate of hydrogen transport through the wall of enclosure $\# 1$ [ $\mathrm{gmol} \mathrm{H}_{2} / \mathrm{s} \cdot \mathrm{mole}$ fraction];

$\mathrm{T}_{2}$ is the effective rate of hydrogen transport through the wall of enclosure \#2 [gmol $\mathrm{H}_{2} / \mathrm{s} \cdot \mathrm{mole}$ fraction]; and 
$\mathrm{t}$ is the time [seconds].

To facilitate an analytical solution to the above set of coupled differential equations, it is useful to consider the conservative quasi-steady assumption that the total number of gas moles within the enclosures does not change with time:

$\mathrm{n}_{1}=\mathrm{n}_{1,0}$
$\mathrm{n}_{2}=\mathrm{n}_{2,0}$.

Using this assumption, the mole fractions $\mathrm{X}_{1}$ and $\mathrm{X}_{2}$ are defined as:

$$
\begin{aligned}
& X_{1}=\frac{n_{H 2,1}}{n_{1,0}} \\
& X_{2}=\frac{n_{H 2,2}}{n_{2,0}},
\end{aligned}
$$

which results in mole fraction values that are about $4.76 \%$ conservative when the hydrogen gas is 5 volume percent. Additionally, since the total gas moles in each enclosure is assumed to be constant, there is no pressure increase or corresponding pressure-driven flow, which is an additional conservatism.

Therefore, using the quasi-steady assumption that the total gas moles in each enclosure remain relatively unchanged, $n_{1}$ and $n_{2}$ are constants that can be moved outside the derivative resulting in the set of coupled differential equations:

$$
\begin{aligned}
& \mathrm{n}_{1} \frac{\mathrm{dX}}{\mathrm{dt}}=\mathrm{R}_{\mathrm{M}}-\mathrm{T}_{1}\left(\mathrm{X}_{1}-\mathrm{X}_{2}\right) \\
& \mathrm{n}_{2} \frac{\mathrm{dX} \mathrm{X}_{2}}{\mathrm{dt}}=\mathrm{T}_{1}\left(\mathrm{X}_{1}-\mathrm{X}_{2}\right)
\end{aligned}
$$

If the initial hydrogen mole fraction in the enclosures are zero (i.e., $X_{1}(0)=0$ and $\left.X_{2}(0)=0\right)$, then the solutions to the above coupled ordinary differential equations is:

$$
\begin{aligned}
& X_{1}(t)=\frac{A S}{(A+B)^{2}}-\frac{A S \exp [-t(A+B)]}{(A+B)^{2}}+\frac{B S t}{(A+B)} \\
& X_{2}(t)=\frac{-B S}{(A+B)^{2}}+\frac{B S \exp [-t(A+B)]}{(A+B)^{2}}+\frac{B S t}{(A+B)}
\end{aligned}
$$

where: $S=\left(R_{M} / n_{1}\right) ; A=\left(T_{1} / n_{1}\right) ;$ and $B=\left(T_{1} / n_{2}\right)$.

For the check that Equations 4.19 and 4.20 are the solutions to the differential Equations $4.18 \mathrm{a}$ and 4.18b, see Example \#3, Appendix F. For an example calculation of the hydrogen gas concentration in a rigid leaking enclosure nested within a rigid non-leaking enclosure, see Example \#4, Appendix F.

\subsubsection{Hydrogen Gas Concentration in Two Nested Rigid Leaking Enclosures}

Consider a rigid leaking enclosure holding radioactive material that is nested within a second rigid leaking enclosure. The radioactive material within the inner enclosure is radiolytically generating 
hydrogen. If the hydrogen escapes the inner enclosures only by diffusion, and the quasi-steady assumption that the total gas moles in each enclosure remain relatively unchanged is used, the hydrogen mole balance can be formed as follows:

$\mathrm{n}_{1} \frac{\mathrm{dX}}{\mathrm{dt}}=\mathrm{R}_{\mathrm{M}}-\mathrm{T}_{1}\left(\mathrm{X}_{1}-\mathrm{X}_{2}\right)$
$\mathrm{n}_{2} \frac{\mathrm{dX}}{\mathrm{dt}}=\mathrm{T}_{1}\left(\mathrm{X}_{1}-\mathrm{X}_{2}\right)-\mathrm{T}_{2}\left(\mathrm{X}_{2}-\mathrm{X}_{\mathrm{a}}\right)$

or

$$
\begin{aligned}
& \frac{d X_{1}}{d t}=S-A\left(X_{1}-X_{2}\right) \\
& \frac{d X_{2}}{d t}=B\left(X_{1}-X_{2}\right)-C\left(X_{2}-X_{a}\right)
\end{aligned}
$$

where: $S=R_{M} / n_{1} ; A=T_{1} / n_{1} ; B=T_{1} / n_{2} ; C=T_{2} / n_{2}$;

$\mathrm{n}_{1}$ is the number of gas moles within enclosure \#1 (inner enclosure) when the enclosure was sealed [gmol];

$\mathrm{n}_{2}$ is the number of gas moles within enclosure $\# 2$ (outer enclosure) when the enclosure was sealed [gmol];

$\mathrm{X}_{1}$ is the hydrogen gas mole fraction within enclosure \#1;

$\mathrm{X}_{2}$ is the hydrogen gas mole fraction within enclosure \#2;

$\mathrm{T}_{1}$ is the effective rate of hydrogen transport through the wall of enclosure $\# 1$ [ $\mathrm{gmol} \mathrm{H}_{2} / \mathrm{s} \cdot \mathrm{mole}$ fraction];

$\mathrm{T}_{2}$ is the effective rate of hydrogen transport through the wall of enclosure $\# 2$ [ $\mathrm{gmol} \mathrm{H}_{2} / \mathrm{s} \cdot \mathrm{mole}$ fraction];

$\mathrm{t}$ is the time [seconds]; and

$\mathrm{X}_{\mathrm{a}}$ is the hydrogen mole fraction in the ambient environment (outside enclosure \#2).

For an outer enclosure leaking to an ambient environment that contains no hydrogen, then $X_{a}=0$ and the equations reduce to:

$$
\begin{aligned}
& \frac{\mathrm{dX}_{1}}{\mathrm{dt}}=\mathrm{S}-\mathrm{A}\left(\mathrm{X}_{1}-\mathrm{X}_{2}\right) \\
& \frac{\mathrm{dX}}{\mathrm{dt}}=\mathrm{B}\left(\mathrm{X}_{1}-\mathrm{X}_{2}\right)-\mathrm{C}\left(\mathrm{X}_{2}\right)
\end{aligned}
$$

where the initial conditions are $\mathrm{X}_{1}(0)=0$ and $\mathrm{X}_{2}(0)=0$ for the case when there is no hydrogen in the enclosures when they are sealed.

Using Mathematica (Wolfram, 1991) to solve the above set of coupled differential equations with the indicated initial conditions the results for the hydrogen mole fractions as a function of time are: 


$$
\begin{aligned}
X_{1}(t) & =\left[(0.25)(Z+W)\left(\frac{S(2 A-W-Z)}{A C W}\right) \exp \left(\frac{t}{2}(W-Z)\right)\right] \\
& +\left[(0.25)(Z-W)\left(\frac{S(Z-W-2 A)}{A C W}\right) \exp \left(\frac{-t}{2}(W+Z)\right)\right] \\
& +\left[\frac{4 S(A-Z)}{(W+Z)(W-Z)}\right]
\end{aligned}
$$

and

$$
\begin{aligned}
\mathrm{X}_{2}(\mathrm{t}) & =-\left[0.5 \exp \left(\frac{\mathrm{t}(\mathrm{W}-\mathrm{Z})}{2}\right)\right]\left(\frac{\mathrm{BS}}{\mathrm{ACW}}\right)(\mathrm{Z}+\mathrm{W}) \\
& +\left[0.5 \exp \left(\frac{-\mathrm{t}(\mathrm{W}+\mathrm{Z})}{2}\right)\right]\left(\frac{\mathrm{BS}}{\mathrm{ACW}}\right)(\mathrm{Z}-\mathrm{W}) \\
& -\left[\frac{4 \mathrm{BS}}{(\mathrm{W}-\mathrm{Z})(\mathrm{W}+\mathrm{Z})}\right]
\end{aligned}
$$

where: $Z=A+B+C$ and $W=\left[A^{2}+2 A B+B^{2}-2 A C+2 B C+C^{2}\right]^{0.5}$.

For an example calculation of the hydrogen concentration in two rigid leaking containers, see Example \#5, Appendix F.

\subsubsection{Hydrogen Gas Concentration in Two Nested Rigid Leaking Enclosures Nested Within a Rigid Non-Leaking Enclosure}

Consider a rigid leaking enclosure holding radioactive material that is nested within a second rigid leaking enclosure, which is in turn nested within a third rigid non-leaking enclosure. The radioactive material within the inner enclosure is radiolytically generating hydrogen. If the hydrogen escapes the inner and secondary enclosures only by diffusion, and the quasi-steady assumption that the total gas moles in each enclosure remain relatively unchanged is used, the hydrogen mole balance can be formed as follows:

$$
\begin{aligned}
& \mathrm{n}_{1} \frac{\mathrm{dX}}{\mathrm{dt}}=\mathrm{R}_{\mathrm{M}}-\mathrm{T}_{1}\left(\mathrm{X}_{1}-\mathrm{X}_{2}\right) \\
& \mathrm{n}_{2} \frac{\mathrm{dX}}{\mathrm{dt}}=\mathrm{T}_{1}\left(\mathrm{X}_{1}-\mathrm{X}_{2}\right)-\mathrm{T}_{2}\left(\mathrm{X}_{2}-\mathrm{X}_{3}\right) \\
& \mathrm{n}_{3} \frac{\mathrm{dX}}{\mathrm{dt}}=\mathrm{T}_{2}\left(\mathrm{X}_{2}-\mathrm{X}_{3}\right)
\end{aligned}
$$

or 


$$
\begin{aligned}
& \frac{d X_{1}}{d t}=S-A\left(X_{1}-X_{2}\right) \\
& \frac{d X_{2}}{d t}=B\left(X_{1}-X_{2}\right)-C\left(X_{2}-X_{3}\right) \\
& \frac{d X_{3}}{d t}=D\left(X_{2}-X_{3}\right)
\end{aligned}
$$

where: $\mathrm{S}=\mathrm{R}_{\mathrm{M}} / \mathrm{n}_{1} ; \mathrm{A}=\mathrm{T}_{1} / \mathrm{n}_{1} ; \mathrm{B}=\mathrm{T}_{1} / \mathrm{n}_{2} ; \mathrm{C}=\mathrm{T}_{2} / \mathrm{n}_{2} ; \mathrm{D}=\mathrm{T}_{2} / \mathrm{n}_{3}$;

$\mathrm{n}_{1}$ is the number of gas moles within enclosure \#1 (inner enclosure) when the enclosure was sealed [gmol];

$\mathrm{n}_{2}$ is the number of gas moles within enclosure \#2 (secondary enclosure) when the enclosure was sealed [gmol];

$\mathrm{n}_{3}$ is the number of gas moles within enclosure \#3 (outer enclosure) when the enclosure was sealed [gmol];

$\mathrm{X}_{1}$ is the hydrogen gas mole fraction within enclosure \#1;

$\mathrm{X}_{2}$ is the hydrogen gas mole fraction within enclosure \#2;

$X_{3}$ is the hydrogen gas mole fraction within enclosure \#3;

$\mathrm{T}_{1}$ is the effective rate of hydrogen transport through the wall of enclosure $\# 1$ [ $\mathrm{gmol} \mathrm{H}_{2} / \mathrm{s} \cdot \mathrm{mole}$ fraction];

$\mathrm{T}_{2}$ is the effective rate of hydrogen transport through the wall of enclosure $\# 2$ [ $\mathrm{gmol} \mathrm{H}_{2} / \mathrm{s} \cdot \mathrm{mole}$ fraction]; and

$\mathrm{t}$ is the time [seconds].

The initial conditions for the above three coupled ordinary differential equations are: $X_{1}(0)=0 ; X_{2}(0)=0$; and $\mathrm{X}_{3}(0)=0$.

\subsubsection{Hydrogen Gas Concentration in Three Nested Rigid Leaking Enclosures}

Consider a rigid leaking enclosure holding radioactive material that is nested within a second rigid leaking enclosure, which is in turn nested within a third rigid leaking enclosure. The radioactive material within the inner enclosure is radiolytically generating hydrogen. If the hydrogen escapes the inner and secondary enclosures only by diffusion, and the quasi-steady assumption that the total gas moles in each enclosure remain relatively unchanged is used, the hydrogen mole balance can be formed as follows:

$$
\begin{aligned}
& \mathrm{n}_{1} \frac{\mathrm{dX}}{\mathrm{dt}}=\mathrm{R}_{\mathrm{M}}-\mathrm{T}_{1}\left(\mathrm{X}_{1}-\mathrm{X}_{2}\right) \\
& \mathrm{n}_{2} \frac{\mathrm{dX}}{\mathrm{dt}}=\mathrm{T}_{1}\left(\mathrm{X}_{1}-\mathrm{X}_{2}\right)-\mathrm{T}_{2}\left(\mathrm{X}_{2}-\mathrm{X}_{3}\right) \\
& \mathrm{n}_{3} \frac{\mathrm{dX}}{\mathrm{dt}}=\mathrm{T}_{2}\left(\mathrm{X}_{2}-\mathrm{X}_{3}\right)-\mathrm{T}_{3}\left(\mathrm{X}_{3}-\mathrm{X}_{3}\right),
\end{aligned}
$$


or

$$
\begin{aligned}
& \frac{\mathrm{dX}_{1}}{\mathrm{dt}}=S-A\left(X_{1}-X_{2}\right) \\
& \frac{d X_{2}}{d t}=B\left(X_{1}-X_{2}\right)-C\left(X_{2}-X_{3}\right) \\
& \frac{d X_{3}}{d t}=D\left(X_{2}-X_{3}\right)-E\left(X_{3}-X_{a}\right),
\end{aligned}
$$

where: $\mathrm{S}=\mathrm{R}_{\mathrm{M}} / \mathrm{n}_{1} ; \mathrm{A}=\mathrm{T}_{1} / \mathrm{n}_{1} ; \mathrm{B}=\mathrm{T}_{1} / \mathrm{n}_{2} ; \mathrm{C}=\mathrm{T}_{2} / \mathrm{n}_{2} ; \mathrm{D}=\mathrm{T}_{2} / \mathrm{n}_{3} ; \mathrm{E}=\mathrm{T}_{3} / \mathrm{n}_{3}$

$\mathrm{n}_{1}$ is the number of gas moles within enclosure \#1 (inner enclosure) when the enclosure was sealed [gmol];

$\mathrm{n}_{2}$ is the number of gas moles within enclosure \#2 (secondary enclosure) when the enclosure was sealed [gmol];

$n_{3}$ is the number of gas moles within enclosure \#3 (outer enclosure) when the enclosure was sealed [gmol];

$\mathrm{X}_{1}$ is the hydrogen gas mole fraction within enclosure \#1;

$\mathrm{X}_{2}$ is the hydrogen gas mole fraction within enclosure \#2;

$\mathrm{X}_{3}$ is the hydrogen gas mole fraction within enclosure \#3;

$T_{1}$ is the effective rate of hydrogen transport through the wall of enclosure $\# 1$ [gmol H$/ \mathrm{s} / \mathrm{mole}$ fraction];

$\mathrm{T}_{2}$ is the effective rate of hydrogen transport through the wall of enclosure $\# 2$ [gmol H$/ \mathrm{s} \cdot \mathrm{mole}$ fraction];

$\mathrm{T}_{3}$ is the effective rate of hydrogen transport through the wall of enclosure $\# 3$ [ $\mathrm{gmol} \mathrm{H}_{2} / \mathrm{s} \cdot \mathrm{mole}$ fraction]; and

$\mathrm{t}$ is the time [seconds].

For the typical case when the ambient hydrogen concentration is zero, $X_{a}=0$, then the above equations simplify to:

$$
\begin{aligned}
& \frac{\mathrm{dX}_{1}}{\mathrm{dt}}=\mathrm{S}-\mathrm{A}\left(\mathrm{X}_{1}-\mathrm{X}_{2}\right) \\
& \frac{\mathrm{dX}}{\mathrm{dt}}=\mathrm{B}\left(\mathrm{X}_{1}-\mathrm{X}_{2}\right)-\mathrm{C}\left(\mathrm{X}_{2}-\mathrm{X}_{3}\right) \\
& \frac{\mathrm{dX}}{\mathrm{dt}}=\mathrm{D}\left(\mathrm{X}_{2}-\mathrm{X}_{3}\right)-\mathrm{E}\left(\mathrm{X}_{3}\right) .
\end{aligned}
$$




\subsubsection{Hydrogen Gas Concentration in Multiple Nested Enclosures: Generalized Approach}

\section{Generalized Approach for a Single Contents}

Consider radioactive material that is nested within multiple enclosures. Although differential equations can be developed and solved numerically to determine the hydrogen concentration in all void spaces between the various confinement and containment layers, the hydrogen gas concentration within the inner-most confinement layer is typically limiting (bounding). It is convenient (and yields bounding results for the hydrogen concentration within the inner-most confinement layer) to group the various confinement layers together to obtain an effective resistance to hydrogen flow that represents the sum of the resistances due to all the confinement layers. Using such an approach, the effective rate of hydrogen transport through the four confinement layers is:

$$
T_{e i f}=\frac{T_{1} T_{2} T_{3} T_{4}}{T_{1}+T_{2}+T_{3}+T_{4}}
$$

Similarly, for $\mathrm{N}$ confinement layers, the effect rate of hydrogen transport through the $\mathrm{N}$ layers is:

$$
\mathrm{T}_{\text {eff }}=\frac{\prod_{i=1}^{\mathrm{N}} \mathrm{T}_{\mathrm{i}}}{\sum_{\mathrm{i}=1}^{\mathrm{N}} \mathrm{T}_{\mathrm{i}}} \text {. }
$$

Using this effective rate of hydrogen transport, the hydrogen concentrations associated with a contents nested within $\mathrm{N}$ confinement layers and then placed in a containment vessel (surrounded by an atmosphere that contains no hydrogen) have the form of Equations $4.23 \mathrm{a}, \mathrm{b}$ :

$$
\begin{aligned}
& \frac{d X_{1}}{d t}=S-A\left(X_{1}-X_{2}\right) \\
& \frac{d X_{2}}{d t}=B\left(X_{1}-X_{2}\right)-C\left(X_{2}\right),
\end{aligned}
$$

where: $\mathrm{S}=\mathrm{R}_{\mathrm{M}} / \mathrm{n}_{1} ; \mathrm{A}=\mathrm{T}_{\mathrm{eff}} / \mathrm{n}_{1} ; \mathrm{B}=\mathrm{T}_{\mathrm{eff}} / \mathrm{n}_{2} ; \mathrm{C}=\mathrm{T}_{2} / \mathrm{n}_{2}$;

$\mathrm{n}_{1}$ is the number of gas moles within the inner-most confinement layer [gmol];

$\mathrm{n}_{2}$ is the number of gas moles between the outer-most confinement layer and the containment vessel (it is assumed that the volume between the $\mathrm{N}$ confinement layers is zero) [gmol];

$\mathrm{X}_{1}$ is the hydrogen gas mole fraction within the inner-most confinement layer (the $\mathrm{N}$ confinement layers);

$\mathrm{X}_{2}$ is the hydrogen gas mole fraction within enclosure \#2;

$\mathrm{T}_{\text {eff }}$ is the effective rate of hydrogen transport through the $\mathrm{N}$ confinement layers given by Equation 4.31 [gmol $\mathrm{H}_{2} / \mathrm{s}$-mole fraction];

$\mathrm{T}_{2}$ is the effective rate of hydrogen transport through the containment vessel [ $\mathrm{gmol} \mathrm{H}_{2} / \mathrm{s} \cdot \mathrm{mole}$ fraction]; and 
$\mathrm{t}$ is the time [seconds].

For the case in which there is no hydrogen in the enclosures (within the confinement layers or within the containment vessel) when they are sealed, the initial conditions are $X_{1}(0)=0$ and $X_{2}(0)=0$, and the solutions to Equations $4.33 \mathrm{a}$ and $4.33 \mathrm{~b}$ are given by Equations 4.24 and 4.25 , with $\mathrm{A}, \mathrm{B}$ and $\mathrm{S}$ defined as for Equations 4.33a and 4.33b.

If the containment vessel is assumed not to leak, the resulting equation for the hydrogen concentration within the $\mathrm{N}$ confinement layers (the inner-most confinement layer) is straight forward and yields conservative (bounding) results for the hydrogen concentration as a function of time. For the case of a contents nested within $\mathrm{N}$ confinement layers and then placed in a non-leaking containment vessel, the differential equations describing the hydrogen concentration are the same form as Equations $4.18 \mathrm{a}$ and 4.18b:

$$
\begin{aligned}
& \mathrm{n}_{1} \frac{\mathrm{dX}}{\mathrm{dt}}=\mathrm{R}_{\mathrm{M}}-\mathrm{T}_{\mathrm{eff}}\left(\mathrm{X}_{1}-\mathrm{X}_{\mathrm{C}}\right) \\
& \mathrm{n}_{\mathrm{C}} \frac{\mathrm{dX}}{\mathrm{dt}}=\mathrm{T}_{\mathrm{eff}}\left(\mathrm{X}_{1}-\mathrm{X}_{\mathrm{C}}\right)
\end{aligned}
$$

where: $\mathrm{n}_{1}$ is the number of gas moles within the inner-most confinement layer [gmol];

$\mathrm{n}_{\mathrm{C}}$ is the number of gas moles between the $\mathrm{N}$ confinement layers and the containment vessel (the volume between the $\mathrm{N}$ confinement layers is assumed to be zero) [gmol];

$\mathrm{R}_{\mathrm{M}}$ is the molar hydrogen generation rate $[\mathrm{gmol} \mathrm{H} / \mathrm{s}]$;

$\mathrm{X}_{1}$ is the hydrogen gas mole fraction within the inner-most confinement layer;

$\mathrm{X}_{C}$ is the hydrogen gas mole fraction in the volume between the outer-most confinement layer and the containment vessel; and

$\mathrm{T}_{\text {eff }}$ is the effective rate of hydrogen transport through the $\mathrm{N}$ confinement layers [ $\mathrm{gmol} \mathrm{H}_{2} / \mathrm{s} \cdot \mathrm{mole}$ fraction].

If the initial hydrogen mole fraction within the inner-most confinement layer and containment vessel are zero (i.e., $X_{1}(0)=0 \& X_{C}(0)=0$ ), then the solution to Equations $4.34 \mathrm{a}$ and $4.34 \mathrm{~b}$ for the hydrogen concentration as a functions of time within the inner-most confinement layer is:

$$
X_{1}(t)=\frac{A S}{(A+B)^{2}}-\frac{A S \exp [-t(A+B)]}{(A+B)^{2}}+\frac{B S t}{(A+B)}
$$

and the solution for the hydrogen concentration as a function of time for the volume between the outermost confinement layer and the containment vessel is:

$$
X_{C}(t)=\frac{-B S}{(A+B)^{2}}+\frac{B S \exp [-t(A+B)]}{(A+B)^{2}}+\frac{B S t}{(A+B)}
$$

where: $\mathrm{S}=\left(\mathrm{R}_{\mathrm{M}} / \mathrm{n}_{1}\right) ; \mathrm{A}=\left(\mathrm{T}_{\mathrm{eff}} / \mathrm{n}_{1}\right) ;$ and $\mathrm{B}=\left(\mathrm{T}_{\mathrm{eff}} / \mathrm{n}_{\mathrm{C}}\right)$. 


\section{Generalized Approach for Multiple Contents}

For a non-leaking containment vessel holding $\mathrm{N}$ contents each with multiple layers of confinement, the differential equations describing the hydrogen concentration are:

$\mathrm{n}_{1} \frac{\mathrm{dX}_{1}}{\mathrm{dt}}=\mathrm{R}_{\mathrm{M}, 1}-\mathrm{T}_{\mathrm{eff}, 1}\left(\mathrm{X}_{1}-\mathrm{X}_{\mathrm{C}}\right)$,

$\mathrm{n}_{2} \frac{\mathrm{dX}}{\mathrm{dt}}=\mathrm{R}_{\mathrm{M}, 2}-\mathrm{T}_{\mathrm{eff}, 2}\left(\mathrm{X}_{2}-\mathrm{X}_{\mathrm{C}}\right)$

$\mathrm{n}_{3} \frac{\mathrm{dX}}{\mathrm{dt}}=\mathrm{R}_{\mathrm{M}, 3}-\mathrm{T}_{\mathrm{eft}, 3}\left(\mathrm{X}_{3}-\mathrm{X}_{\mathrm{C}}\right)$

$\ldots \ldots . . \mathrm{n}_{\mathrm{N}} \frac{\mathrm{dX}_{\mathrm{N}}}{\mathrm{dt}}=\mathrm{R}_{\mathrm{M}, \mathrm{N}}-\mathrm{T}_{\mathrm{eff}, \mathrm{N}}\left(\mathrm{X}_{\mathrm{N}}-\mathrm{X}_{\mathrm{C}}\right)$, and

$\mathrm{n}_{\mathrm{C}} \frac{\mathrm{dX} \mathrm{C}}{\mathrm{dt}}=\mathrm{T}_{\text {eff }, 1}\left(\mathrm{X}_{1}-\mathrm{X}_{\mathrm{C}}\right)+\mathrm{T}_{\mathrm{eff}, 2}\left(\mathrm{X}_{2}-\mathrm{X}_{\mathrm{C}}\right)+\mathrm{T}_{\mathrm{eff}, 3}\left(\mathrm{X}_{3}-\mathrm{X}_{\mathrm{C}}\right)+\ldots . .+\mathrm{T}_{\text {eff }, \mathrm{N}}\left(\mathrm{X}_{\mathrm{N}}-\mathrm{X}_{\mathrm{C}}\right)$

where: $n_{i}$ is the number of gas moles initially in the multiple confinement layers around payload $i$

[gmol];

$\mathrm{n}_{\mathrm{C}}$ is the number of gas moles initially in the volume between the outer confinement layers around each payload and the containment vessel [gmol];

$\mathrm{X}_{\mathrm{i}}$ is the hydrogen mole fraction within the inner-most confinement layer surrounding payload $\mathrm{i}$;

$\mathrm{X}_{\mathrm{C}}$ is the hydrogen mole fraction between the outer-most confinement layer of each payload and the containment vessel; and

$\mathrm{T}_{\mathrm{eff}, \mathrm{i}} \quad$ is the effective rate of hydrogen transport across the multiple confinement layers around payload i [gmol $\mathrm{H}_{2} / \mathrm{s}$-mole fraction].

If it can be assumed that: (a) all the contents are essentially identical, (b) that the hydrogen generation rate from each of the contents is the same (i.e., $R_{M, 1}=R_{M, 2}=R_{M, 3}=\ldots=R_{M, N}=R_{M}$ ), (c) that the number and type of confinement layers around the $\mathrm{N}$ contents are the same (i.e., $\mathrm{T}_{\text {eff, } 1}=\mathrm{T}_{\text {eff, } 2}=\mathrm{T}_{\text {eff, } 3}=\ldots=\mathrm{T}_{\text {eff, }}$ $\mathrm{N}=\mathrm{T}_{\text {eff }}$ and $\mathrm{n}_{1}=\mathrm{n}_{2}=\mathrm{n}_{3}=\ldots=\mathrm{n}_{\mathrm{N}}$ ), then the set of differential equations in $3.2 .37 \mathrm{n}$ reduces to:

$\mathrm{n}_{1} \frac{\mathrm{dX}}{\mathrm{dt}}=\mathrm{R}_{\mathrm{M}}-\mathrm{T}_{\mathrm{eff}}\left(\mathrm{X}_{1}-\mathrm{X}_{\mathrm{C}}\right)$

$\mathrm{n}_{\mathrm{C}} \frac{\mathrm{dX}}{\mathrm{dt}}=\mathrm{NT}_{\mathrm{eff}}\left(\mathrm{X}_{1}-\mathrm{X}_{\mathrm{C}}\right)$

which have the form:

$$
\begin{aligned}
& \frac{d X_{1}}{d t}=S-A\left(X_{1}-X_{C}\right) \\
& \frac{d X_{C}}{d t}=B\left(X_{1}-X_{C}\right),
\end{aligned}
$$

where: $\mathrm{S}=\mathrm{R}_{\mathrm{M}} / \mathrm{n}_{1} ; \mathrm{A}=\mathrm{T}_{\mathrm{eff}} / \mathrm{n}_{1} ;$ and $\mathrm{B}=\mathrm{NT} \mathrm{T}_{\mathrm{eff}} / \mathrm{n}_{\mathrm{C}}$. 


\section{Calculation of Hydrogen Concentration}

If it is assumed that the confinement layers are initially hydrogen-free (i.e., $\left.X_{1}(0)=0\right)$, then the solution to Equations $4.39 \mathrm{a}$ and $4.39 \mathrm{~b}$ for the hydrogen concentration within the inner-most confinement layer of each payload is:

$$
X_{1}(t)=\frac{A S}{(A+B)^{2}}-\frac{A S \exp [-t(A+B)]}{(A+B)^{2}}+\frac{B S t}{(A+B)}
$$

or substituting for $\mathrm{A}, \mathrm{B}$, and $\mathrm{S}$ :

$$
X_{1}(t)=\left(\frac{n_{C}{ }^{2} R_{M}}{\left(n_{C}+N n_{1}\right)^{2} T}\right)\left\{1-\exp \left[-t T\left(\frac{n_{C}+N n_{1}}{n_{1} n_{C}}\right)\right]\right\}+\left(\frac{N R_{M} t}{n_{C}+N n_{1}}\right) .
$$

The solution for Equations $4.39 \mathrm{a}$ and $4.39 \mathrm{~b}$ for the hydrogen concentration as a function of time for the volume between the multiple confinement layers around each contents and the containment vessel is:

$$
X_{C}(t)=\frac{-B S}{(A+B)^{2}}+\frac{B S \exp [-t(A+B)]}{(A+B)^{2}}+\frac{B S t}{(A+B)} \text {, }
$$

or substituting for $\mathrm{A}, \mathrm{B}$, and $\mathrm{S}$ :

$$
X_{c}(t)=\left(\frac{N R_{M} n_{1} n_{C}}{\left(n_{C}+N n_{1}\right)^{2} T_{\text {eff }}}\right)\left\{-1+\exp \left[-t T\left(\frac{n_{C}+N n_{1}}{n_{1} n_{C}}\right)\right]\right\}+\left(\frac{N R_{M} t}{n_{C}+N n_{1}}\right) .
$$

\subsection{Pressures in Transuranic Waste Transportation Packages}

In this section, methods are developed to model the pressure increase in TRU waste transportation packages due to radiolytic gas generation. The analysis presented includes the pressure increase due to temperature and radiolytic gas generation. The analysis does not include other sources of gas generation, such as helium from radioactive decay, gas due to thermal degradation, gas due to chemical reaction, or gas due to biological metabolism.

\subsubsection{Pressure in a Single Rigid Non-Leaking Enclosure}

Consider a single enclosure containing radioactive material and other materials capable of radiolysis. If the decay heat of the radioactive contents absorbed by the radiolysis materials is $\mathrm{D}_{\mathrm{H}}$, and the effective radiolytic $\mathrm{G}$ value for net gas production is $\mathrm{G}$ (net gas), then the rate of gas production is:

$$
R_{M}=\left(\frac{D_{H}}{100}\right)\left(\frac{G(\text { net gas })}{A_{N}}\right)
$$

where: $\mathrm{R}_{\mathrm{M}}$

is the molar radiolytic gas generation rate $[\mathrm{gmol} / \mathrm{s}]$;

$\mathrm{D}_{\mathrm{H}} \quad$ is the contents decay heat $[\mathrm{eV}]$;

$\mathrm{G}$ (net gas) is the effective radiolytic net gas $\mathrm{G}_{\mathrm{R}}$ value [molecules gas $/ 100 \mathrm{eV}$ ]; and

$\mathrm{A}_{\mathrm{N}} \quad$ is Avagadro's number $\left[6.023 \times 10^{23} \mathrm{molecules} / \mathrm{gmol}\right]$. 
Using the radiolytic gas production rate, the ideal gas law can be used to describe the container pressure as a function of time:

$$
P_{u}(t)=\frac{\left(n_{o}+R_{M} t\right) R_{g} T}{V}
$$

where: $\quad P_{u}(t)$ is the container pressure as a function of time [atm];

$\mathbf{n}_{0} \quad$ is the initial number of moles of gas inside the container [gmol];

$\mathrm{t}$ is the time that the container has been sealed [s];

$\mathrm{R}_{\mathrm{g}}$ is the gas law constant [82.05 $\left.\mathrm{cm}^{3} \cdot \mathrm{atm} / \mathrm{gmol} \cdot \mathrm{K}\right]$;

$\mathrm{T} \quad$ is the container temperature $[\mathrm{K}]$; and

$\mathrm{V}$ is the container void volume $\left[\mathrm{cm}^{3}\right]$.

If the container was initially sealed at a pressure $P_{0}$ and a temperature $T_{0}$, then the initial number of gas moles, $\mathrm{n}_{0}$, is:

$$
\mathrm{n}_{0}=\frac{\mathrm{P}_{0} \mathrm{~V}}{\mathrm{R}_{\mathrm{g}} \mathrm{T}_{0}}
$$

Substituting the expression for the initial number of gas moles and for the radiolytic gas production rate, the pressure in a single non-leaking enclosure is:

$$
\mathrm{P}(\mathrm{t})=\left[\mathrm{P}_{0}\left(\frac{\mathrm{T}}{\mathrm{T}_{0}}\right)\right]+\left[\left(\frac{\mathrm{D}_{\mathrm{H}}}{100}\right)\left(\frac{\mathrm{G}(\text { net gas })}{\mathrm{A}_{\mathrm{N}}}\right)\left(\frac{\mathrm{R}_{\mathrm{g}} \mathrm{T}}{\mathrm{V}}\right) \mathrm{t}\right] \text {. }
$$

For an example calculation of the pressure in a single rigid non-leaking container with its contents undergoing radiolysis, see Example \#6, Appendix F.

\subsubsection{Pressure in a Single Rigid Leaking Enclosure}

Consider a container holding radioactive contents that has a void volume, $\mathrm{V}$, where gas is generated at a rate, $R_{M}$, which is the rate of radiolytic gas generation. The container has a small leak hole with a diameter, $\mathrm{D}$, through which gas leaks out to the environment at a rate dependent on the gas pressure within the container.

As shown above, the decay heat, $D_{\mathrm{H}}$, that is absorbed by the radiolytic material and the effective radiolytic $\mathrm{G}$-value of the material determines the gas generation rate:

$$
\mathrm{R}_{\mathrm{M}}=\left(\frac{\mathrm{D}_{\mathrm{H}}}{100}\right)\left(\frac{\mathrm{G} \text { (net gas })}{\mathrm{A}_{\mathrm{N}}}\right) \text {. }
$$

The leakage rate of gas out the container is dependent on the pressure driving force. Considering continuum flow (laminar flow) and molecular flow, the volumetric leakage rate at the upstream conditions can be given by: 
4. Calculation of Hydrogen Concentration

$$
L_{u}=\left(F_{C}+F_{M}\right)\left(P_{u}-P_{d}\right)\left(\frac{P_{a}}{P_{u}}\right)=\left(F_{C}+F_{M}\right)\left(P_{u}-P_{d}\right)\left[\frac{P_{u}+P_{d}}{2 P_{u}}\right]
$$

where: $\mathrm{L}_{\mathrm{u}}$ is the upstream volumetric leakage rate $\left[\mathrm{cm}^{3} / \mathrm{s}\right]$;

$F_{C}$ is the coefficient for continuum flow $\left[\mathrm{cm}^{3} / \mathrm{s} \cdot \mathrm{atm}\right]$;

$F_{M}$ is the coefficient for molecular flow $\left[\mathrm{cm}^{3} / \mathrm{s} \cdot \mathrm{atm}\right]$;

$P_{u}$ is the upstream pressure [atm];

$P_{d}$ is the down stream pressure [atm]; and

$\mathrm{P}_{\mathrm{a}}$ is the average pressure $=\left[\left(\mathrm{P}_{\mathrm{u}}+\mathrm{P}_{\mathrm{d}}\right) / 2\right][\mathrm{atm}]$.

A mole balance over the container yields the expression:

$$
\mathrm{dn}=\left[\mathrm{R}_{\mathrm{M}}-\left(\mathrm{L}_{\mathrm{u}} \rho_{\mathrm{M}}\right)\right] \text {, }
$$

where: $\mathrm{dn}$ is the change in the number of moles of gas inside the container [gmol];

$R_{M}$ is the rate of radiolytic gas generation [gmol/s];

$\mathrm{L}_{\mathrm{u}}$ is the volumetric upstream flow rate $\left[\mathrm{cm}^{3 /} / \mathrm{s}\right]$

$\rho_{\mathrm{M}} \quad$ is the gas molar density at $\mathrm{P}_{\mathrm{u}}\left[\mathrm{gmol} / \mathrm{cm}^{3}\right]$; and

$\mathrm{dt} \quad$ is the time differential [s].

Using the ideal gas law to describe the gas molar density, the above expression becomes:

$$
\frac{\mathrm{dn}}{\mathrm{dt}}=\mathrm{R}_{\mathrm{M}}-\left[\mathrm{L}_{\mathrm{u}}\left(\frac{\mathrm{P}_{\mathrm{u}}}{\mathrm{R}_{\mathrm{g}} \mathrm{T}}\right)\right]
$$

where: $\mathrm{R}_{\mathrm{g}}$ is the gas law constant $\left[82.05 \mathrm{~cm}^{3} \cdot \mathrm{atm} / \mathrm{gmol} \cdot \mathrm{K}\right]$; and

$\mathrm{T}$ is the gas temperature $[\mathrm{K}]$.

The differential equation for the upstream pressure is then:

$$
\frac{\mathrm{dP}}{\mathrm{dt}}=\frac{\mathrm{d}}{\mathrm{dt}}\left(\frac{\mathrm{nR} \mathrm{g}}{\mathrm{V}}\right)=\left(\frac{\mathrm{R}_{\mathrm{g}} \mathrm{T}}{\mathrm{V}}\right) \frac{\mathrm{dn}}{\mathrm{dt}}=\left(\frac{\mathrm{R}_{\mathrm{g}} \mathrm{TR}_{\mathrm{M}}}{\mathrm{V}}\right)-\left(\frac{\mathrm{L}_{\mathrm{u}} \mathrm{P}_{\mathrm{u}}}{\mathrm{V}}\right) .
$$

Substituting the expression for $\mathrm{L}_{\mathrm{u}}$ gives:

$$
\frac{d P_{u}}{d t}=\left(\frac{R_{g} T R_{M}}{V}\right)-\left[\left(F_{C}+F_{M}\right)\left(P_{u}-P_{d}\right)\left(\frac{P_{u}+P_{d}}{2 P_{u}}\right)\left(\frac{P_{u}}{V}\right)\right]
$$

or after rearranging: 


$$
\frac{d P_{u}}{d t}=\left(\frac{R_{g} T R_{M}}{V}\right)+\left[\left(\frac{F_{C}+F_{M}}{2 V}\right) P_{d}^{2}\right]-\left[\left(\frac{F_{C}+F_{M}}{2 V}\right) P_{u}^{2}\right]
$$

This equation has the form:

$\frac{\mathrm{dP}_{\mathrm{u}}}{\mathrm{dt}}+\Omega \mathrm{P}_{\mathrm{u}}^{2}=\Phi$

where: $\Omega=\left[\frac{\left(F_{C}+F_{M}\right)}{2 V}\right]$ and $\Phi=\left(\frac{R_{g} T_{M}}{V}\right)+\left(\frac{\left(F_{C}+F_{M}\right) P_{d}^{2}}{2 V}\right)$,

and $F_{m}$ is treated as a constant even though it is a function of the average pressure $\left[\left(\mathrm{P}_{u}+P_{d}\right) / 2\right]$. Since the average pressure is greater than or equal to one atmosphere (for $P_{d}=1 \mathrm{~atm}$ ), using an average pressure of 1 atm for the calculation of $F_{m}$ would bound the rate of gas release from a container. On the other hand, neglecting the contribution of molecular flow to the total flow from a container would bound the pressure in the container.

Separating variables in the above differential equation gives:

$\frac{\mathrm{dP}_{\mathrm{u}}}{\left(\frac{\Phi}{\Omega}\right)-\mathrm{P}_{\mathrm{u}}^{2}}=\frac{\mathrm{dP}_{\mathrm{u}}}{\Psi-\mathrm{P}_{\mathrm{u}}^{2}}=\Omega \mathrm{dt}$

where: $\Psi=\frac{\Phi}{\Omega}=\frac{\left(\frac{\mathrm{R} \mathrm{TR}_{\mathrm{M}}}{\mathrm{V}}\right)+\left(\frac{\left(\mathrm{F}_{\mathrm{C}}+\mathrm{F}_{\mathrm{M}}\right) \mathrm{P}_{\mathrm{d}}{ }^{2}}{2 \mathrm{~V}}\right)}{\frac{\left(\mathrm{F}_{\mathrm{C}}+\mathrm{F}_{\mathrm{M}}\right)}{2 \mathrm{~V}}}=\left(\frac{2 \mathrm{R}_{\mathrm{g}} \mathrm{TR}_{\mathrm{M}}}{\mathrm{F}_{\mathrm{C}}+\mathrm{F}_{\mathrm{M}}}\right)+\mathrm{P}_{\mathrm{d}}{ }^{2}$.

Integrating the above equation and rearranging gives:

$\tanh ^{-1}\left(\frac{P_{u}}{\sqrt{\Psi}}\right)=(\Omega \sqrt{\Psi}) t+C$, where $\Omega, \Psi$, and $C$ can be considered constants

Applying the initial condition that $\mathrm{P}_{\mathrm{u}}=\mathrm{P}_{\mathrm{u}, 0}$ at $\mathrm{t}=0, \mathrm{C}$ is determined:

$\mathrm{C}=\tanh ^{-1}\left(\frac{\mathrm{P}_{\mathrm{u}, 0}}{\sqrt{\Psi}}\right)$.

After substituting for $\mathrm{C}$ and rearranging, the gas pressure inside the container as a function of time is:

$\mathrm{P}_{\mathrm{u}}(\mathrm{t})=\sqrt{\Psi} \tanh \left[(\Omega \sqrt{\Psi}) \mathrm{t}+\tanh ^{-1}\left(\frac{\mathrm{P}_{\mathrm{u}, 0}}{\sqrt{\Psi}}\right)\right]$

If the container is closed at a pressure $\mathrm{P}_{0}$ and a temperature $\mathrm{T}_{0}$ and once sealed the container temperature is $\mathrm{T}$, then the initial gas pressure is: 
4. Calculation of Hydrogen Concentration

$$
\mathrm{P}_{\mathrm{u}, 0}=\mathrm{P}_{\mathrm{o}}\left(\frac{\mathrm{T}}{\mathrm{T}_{0}}\right)
$$

After substitution of the expressions for $\Omega$ and $\Psi$, the expression for the upstream pressure as a function of time becomes:

$$
P_{u}(t)=\sqrt{\left(\frac{2 R_{g} T R_{M}}{\left(F_{C}+F_{M}\right)}+P_{d}^{2}\right)} \tanh \left\{\left[t\left(\frac{F_{C}+F_{M}}{2 V}\right) \sqrt{\left(\frac{2 R_{g} T_{M}}{\left(F_{C}+F_{M}\right)}+P_{d}^{2}\right)}\right]+\tanh ^{-1}\left[\frac{T P_{0}}{T_{0} \sqrt{\left[\left(\frac{2 R_{g} R_{M}}{\left(F_{c}+F_{m}\right)}\right)+P_{d}^{2}\right]}}\right]\right\}
$$

Since $\tanh (\mathrm{x})$ approaches 1 as $\mathrm{x}$ approaches $\cdot$, the steady state container pressure is:

$$
P_{u}(t \rightarrow \infty)=P_{s s}=\sqrt{\left(\frac{2 R_{g} T_{M}}{\left(F_{C}+F_{M}\right)}+P_{d}{ }^{2}\right)}
$$

Under steady state conditions the flow of gas out of the container must be the same as the radiolytic gas generation rate. Therefore, the steady state pressure can be determined directly by equating the molar flow rate from the container to the rate of radiolytic gas generation:

$$
R_{M=}=\left(\frac{D_{H}}{100}\right)\left(\frac{G}{A_{N}}\right)=L_{u} \rho_{M}=\left(F_{c}+F_{m}\right)\left(P_{s s}-P_{d}\right)\left(\frac{P_{s s}+P_{d}}{2 P_{s s}}\right)\left(\frac{P_{s s}}{R_{g} T}\right)
$$

or

$$
P_{s s}=\sqrt{\left[\left(\frac{2 R_{g} T R_{M}}{F_{c}+F_{m}}\right)+P_{d}^{2}\right]}
$$

where: $\mathrm{P}_{\mathrm{ss}}$ is the steady state container pressure [atm]. For an example calculation of the pressure in a single rigid leaking container, see Example \#7, Appendix F.

\subsection{Time to Reach the Lower Flammability Limit for Hydrogen in Transuranic Waste Transportation Packages}

This section addresses representative methods for determining the potential flammability of gaseous mixtures that may be present in TRU waste transportation packages. After a general discussion of flammability limits, methods are presented to predict the time for reaching the lower flammability limit, particularly for hydrogen, within various layers of confinement of TRU waste transportation packages. The methods are based on limiting hydrogen to a concentration below its lower flammability limit in air during the shipping period. Typically the shipping period is a maximum of one year, which is consistent with the time period for determining the maximum normal operating pressure. For special cases, 
however, alternative shipping periods may be justified. For such justified cases, the shipping period may be defined as equal to one-half the time it takes the hydrogen to reach its lower flammability limit.

\subsubsection{Flammability Limits}

The flammability limit of a gas mixture comprised of a flammable gas and a gaseous oxidant represents a borderline composition; a slight change in one direction produces a flammable mixture, in the other direction a nonflammable mixture. There are two limits of flammability, a lower and a higher, for each fuel/oxidant pair. The lower limit corresponds to the minimum amount of combustible gas and the higher or upper limit to the maximum amount of combustible gas capable of conferring flammability on the mixture. Mixtures within these limits liberate enough energy on combustion of any one layer to ignite the neighboring layer of unburned gas and are therefore capable of self-propagation of flame; others mixtures are not.

\subsubsection{Hydrogen Flammability Limits}

Flames in mixtures of hydrogen and air are exceedingly pale; the flame in a limit mixture is almost invisible, even in a completely darkened room. Many experiments have been performed to determine the lower and upper flammability limits for hydrogen in air (Coward, 1952). A variety of geometrical configurations and ignition methods have been used for the reaction chamber. When using a verticallyoriented cylindrically-shaped reaction chamber, it was found that ignition at the top of the chamber (downward flame propagation) resulted in different results for the flammability limits compared with igniting the gases from the bottom of the chamber (upward flame propagation). A lower flammability limit of 4.1 volume percent hydrogen in air was measured for upward flame propagation in cylindrical tubes with diameters larger than about 2 inches. However, when the tube diameter was decreased to 0.8 inches, the lower flammability limit was 5.1 volume percent hydrogen. For horizontal flame propagation, the lower flammability limit for hydrogen in air was about 6.7 volume percent hydrogen, and for downward flame propagation the lower flammability was about 9 volume percent hydrogen.

For purposes of this document, the lower flammability limit for hydrogen in air is taken as 5 volume percent hydrogen. This value is considered appropriate based on the methods presented here, which are intended to provide a simplified analytical approach that is adequately conservative.

Increasing the pressure has only a marginal effect of the lower flammability limit for hydrogen in air. Some experiments have shown a slight increase ( $\sim 2$ volume percent) in the lower flammability limit as the pressure is increased from 1 to 5 atmospheres, however, other experiments have observed no change in the lower limit for pressures from 0.5 to 4 atmospheres.

An increase in temperature causes the lower limit to approach its lower bounding value, whereas an increase in temperature causes the upper limit to increase (i.e., at $540^{\circ} \mathrm{C}$ a 90.45 volume percent hydrogen mixture was ignited).

\subsubsection{Flammability Limits of Other Gases and Vapors}

Appendix D summarizes the lower and upper flammability limits for single gases and vapors in air (Coward and Jones 1952). Many of the higher limits and some of the lower limits could only be determined by raising the temperature sufficiently to raise the vapor pressure to the extent necessary to reach the limit composition. The limits for these cases, therefore, apply to the experimental temperature (see references to original sources in Coward and Jones 1952). 


\section{Calculation of Hydrogen Concentration}

\subsubsection{Mixtures of Gases or Vapors}

The flammability limit for a mixture of gases or vapors in air can be calculated if the flammability limits for the individual gases or vapors in air are known and if the mixture composition is known. The flammability limit for a mixture of gases or vapors is:

$$
F_{L, M I X}=\frac{100}{\frac{p_{1}}{F_{L, 1}}+\frac{p_{2}}{F_{L, 2}}+\frac{p_{3}}{F_{L, 3}}+\cdots}
$$

where: $F_{L, M I X}$ is the flammability limit of the mixture in air [volume percent flammable gas];

$\mathrm{p}_{\mathrm{i}} \quad$ is the proportion of combustible gas $\mathrm{i}$ in the original mixture, free from air and inert gases so that $p_{1}+p_{2}+\ldots=100$.

An example calculation of the effective lower flammability limit for a mixture of flammable gases is provided in Example \#8, Appendix F.

\subsubsection{Single Enclosures}

This section provides methods for estimating the time required to reach the lower flammability limit for hydrogen in air for single enclosures containing radioactive alpha-emitting material with hydrogenous material capable of undergoing radiolysis. For purposes of this document, the lower flammability limit for hydrogen in air is taken as 5.0 volume percent.

\subsubsection{Single Non-Leaking Rigid Enclosures}

For a single non-leaking rigid enclosure, the hydrogen mole fraction as a function of time is given by Equation 4.8. The time to reach 5 volume percent hydrogen by volume is obtained by setting the hydrogen mole fraction, $\mathrm{X}_{\mathrm{H}_{2}}$, equal to 0.05 (For gases, volume percent is equal to mole percent.) and solving for the time:

$$
\mathrm{t}_{5 \%}=\frac{5 \mathrm{~A}_{\mathrm{N}} \mathrm{P}_{0} \mathrm{~V}}{\mathrm{D}_{\mathrm{H}} \mathrm{G}(\text { net gas }) \mathrm{R}_{\mathrm{g}} \mathrm{T}_{0}(\alpha-0.05)}
$$

where: $t_{5 \%}$ is the time to reach 5 volume percent hydrogen [s];

$A_{N}$ is Avagadro's number [6.023×1023 molecules/gmol];

$\mathrm{P}_{0}$ is the pressure when the container was sealed [atm];

$\mathrm{V}$ is the void volume of the container $\left[\mathrm{cm}^{3}\right]$;

$\mathrm{D}_{\mathrm{H}}$ is the decay heat that is absorbed by the radiolytic materials [eV/s];

$\mathrm{G}$ (net gas) is the radiolytic $\mathrm{G}$ value for net gas generation [molecules $/ 100 \mathrm{eV}$;

$\mathrm{R}_{\mathrm{g}}$ is the gas law constant $\left[82.05 \mathrm{~cm}^{3} \cdot \mathrm{atm} / \mathrm{gmol} \cdot \mathrm{K}\right]$;

$\mathrm{T}_{0}$ is the temperature when the container was sealed [K]; and

$\alpha$ is the mole fraction of the gas generated by radiolysis that is hydrogen. 
From Equation 4.66 , it is clear that $\alpha$ must be greater than 0.05 to yield reasonable results. From a physical perspective, if $\alpha$ is less than 0.05 , a mixture of 5 volume percent hydrogen will never exist inside the container. Conservative estimates of the time to reach 5 volume percent hydrogen in the container can be obtained by setting $\alpha$ equal to 1.0 .

\subsubsection{Single Rigid Leaking Enclosures}

For single rigid leaking enclosures, the hydrogen mole fraction as a function of time is given by Equation 4.71. Setting the hydrogen mole fraction in this equation to 0.05 (the lower flammability limit) and solving for time yields the time necessary for the gas mixture inside the vessel to reach 5 volume percent hydrogen:

$$
\mathrm{t}_{5_{\mathrm{s}}}=\frac{-\mathrm{n}}{\mathrm{T}} \ln \left(1-\frac{0.05 \mathrm{~T}}{\mathrm{R}_{\mathrm{M}}}\right)
$$

where: $\mathrm{n}$ is the initial number of moles of gas inside the container [gmol];

$\mathrm{T}$ is the rate of hydrogen transport from the enclosure [gmol $\mathrm{H}_{2} / \mathrm{s}$. mole fraction]; and

$\mathrm{R}_{\mathrm{M}}$ is the molar hydrogen generation rate [gmol $\mathrm{H}_{2} / \mathrm{s}$ ].

Equation 4.67 is valid only for cases where $(0.05 \mathrm{~T})<\mathrm{R}_{\mathrm{M}}$. The initial number of gas mole inside the container when it is sealed, $n$, is calculated using the ideal gas equation along with the (i.e., $\mathrm{n}=\left(\mathrm{P}_{0} \mathrm{~V}\right) /\left(\mathrm{R}_{\mathrm{g}} \mathrm{T}_{0}\right)$.

\subsubsection{Simple Nested Enclosures}

The governing equations for the hydrogen mole fraction for simple nested enclosures are described in Section 4.2.2. The closed-form solutions giving the hydrogen mole fraction as a function of time for a rigid leaking enclosure nested within a rigid non-leaking enclosure are given by Equations 4.19 and 4.20. The closed-form solutions given the hydrogen mole fraction as a function of time for two nested rigid leaking enclosures are given by Equations 4.2.24 and 4.25. Since these equation cannot be solved explicitly for time, it is necessary to use a graphical approach, a trial-and-error, or a numerical iterative approach to determine the time necessary to reach a given hydrogen mole fraction. The simplest approach is to plot the solution for the hydrogen mole fraction as a function of time for the region of interest and to graphically determine the time that corresponds to the hydrogen mole fraction of interest. For an example calculation of the hydrogen gas concentration in a package containing radioactive material nested with three confinement layers and a containment vessel, see Example \#9 in Appendix F. 
4. Calculation of Hydrogen Concentration 


\section{CONTROL OF HYDROGEN IN TRANSURANIC WASTE TRANSPORTATION PACKAGES}

The gases generated in the contents, particularly hydrogen, should be controlled to prevent the occurrence of potentially flammable concentrations of gases within the contents confinement layers and in the void volume of the inner containment vessel cavity. In addition, the gases generated in the payload and released into the inner containment vessel cavity should be controlled to maintain the pressure within the acceptable design pressure of the vessel.

Hydrogen gas generation and pressures due to radiolysis can be controlled by:

- Restricting the materials that can be present in each payload shipping category,

- Limiting the number of internal layers of confinement within each payload container,

- Maximizing the gas permeability of the confinement material used,

- Limiting the decay heat within each payload container, and

- Limiting the time that the container is closed and sealed.

Restricting the materials in a package is an effective way of limiting the hydrogen produced by radiolysis. The amount of hydrogenous materials may be limited and/or the G-values of the hydrogenous materials may be limited. In addition, materials should be limited to ensure that there are no significant chemical, thermal or biological reactions that could generated gas.

Limiting the number of confinement layers allows the hydrogen to diffuse more rapidly from the innermost confinement layer to surrounding layers. Since the inner-most confinement layer encloses the region that typically has the highest hydrogen concentration for any given time, any arrangement of confinement layers that allows higher hydrogen fluxes from this region is useful in limiting the hydrogen concentration. In addition to limiting the number of confinement layers, the materials chosen for the confinement layers should be chosen to maximize the hydrogen diffusion through the material. Installation of filter vents on plastic bag or metal can confinement layers also limits the hydrogen concentration by allowing hydrogen to diffuse more rapidly through confinement layer.

Another control that leads to lower radiolytic hydrogen production rates is to limit the decay heat of the radioactive contents. Since the decay energy of the radioactive isotopes in the contents is the energy driving force for radiolysis (and for thermal effects and possibly for chemical and biological gas generation), limiting the energy flux from the contents will also reduce the hydrogen production rate proportionally.

Although the shipping period is typically defined as one-year (consistent with the time period for determination of the maximum normal operating pressure), for special cases alternative shipping periods may be justilied. For such justified cases, the shipping period may be defined as one-half the time it takes for hydrogen to accumulate in the package to a concentration equivalent to the lower flammability limit. 
5. Control of Hydrogen Generation 


\section{SUMMARY}

This document addresses hydrogen generation in TRU waste transportation packages. Four general hydrogen-generating mechanisms are considered: (1) chemical reaction, (2) thermal degradation, (3) biological metabolism, and (4) radiolysis. General information and guidelines are given for the first three mechanisms, with the focus of the report on hydrogen generation due to radiolysis.

The report provides methodologies for estimating the hydrogen generation in TRU waste due to radiolysis. Bounding $\mathrm{G}\left(\mathrm{H}_{2}\right)$-values are determined for common types of TRU waste. Equations are developed that allow prediction of hydrogen concentration as a function of time for various TRU waste content types and packaging configurations. Also, equations are developed that allow prediction of the time required to reach a given hydrogen concentration for simple packaging configurations.

General guidelines are provides for limiting the hydrogen generation and accumulation in TRU waste transportation packages. 
6. Summary 


\section{REFERENCES}

Alfassi, Z. B. and H. Heusinger, "The Radiation Chemistry of $\mathrm{CF} 2 \mathrm{Cl} 2$ in the Liquid Phase," Radiat. Phys. Chem., 22(1983)995-1000.

Alfassi, Z. B., "The Radiation Chemistry of $\mathrm{CFCl}_{3}$ in the Liquid Phase," Radiochem. Radioanal. Letters, 56(1982)333-342.

Amamiya, A. and S. Sekigawa, "Irradiation Effects on Polycarbonates," in Annual Report of the Japanese Assn. for Radiation Research on Polymers, 1(1959)469-476.

Arakawa, K. et al., "Radiation-Induced Gas Evolution from Commercial Lubricant Base Oil," Nuclear Technology, 61(1983)533-539.

Arakawa, K. et al., "Radiation-Induced Gas Evolution in Chloride-Containing Polymer. Poly (Vinyl Chloride), Chloroprene Rubber, and Chlorosulfonated-Polyethylene," Radiat. Phys. Chem., 27(1986)157- 163.

Arthur, J. C. Jr., "Graft Polymerization onto Polysaccharides," in Advances in Macromolecular Chemistry 2, ed. by W.M. Pasika, Academic Press, London, pp. 1-87, 1970.

Barney, G. S. and D. G. Bouse, "Alpha Radiolysis of Tributyl-Phosphate-Effects of Diluents," Atlantic Richfield Hanford Co., ARH-ST-153, April 1977.

Bersch, C. F. et al., "Effect of Radiation on Plastic Films," Modern Packaging, 32(1959)117-168.

Bibler, N. E. and E. G. Orebaugh, "Radiolytic Gas Production from Tritiated Waste Forms, Gamma and Alpha Radiolysis Studies," E.I. DuPont de Nemours and Company, Savannah River Laboratory, DP1464, Jan. 1978.

Bibler, N. E. "Curium-244 alpha Radiolysis of Nitric Acid. Oxygen Production from Direct Radiolysis of Nitrate Ions," J. Phys. Chem., 78(1974)211-215.

Bibler, N. E. "Gas Production from Alpha Radiolysis of Concrete Containing TRU Incinerator Ash, Progress Report 2, August 1, 1978-November 30, 1978," E.I. DuPont de Nemours and Company, Savannah River Laboratory, DPST-78-150-2, April 1979.

Bibler, N. E. "Radiolysis of 0.4 M Sulfuric Acid Solutions with Fission Fragments from Dissolved Californium-252. Estimated Yields of Radical and Molecular Products that Escape Reactions in Fission Fragment Tracks," J. Phys. Chem., 79(1975)1991-1995.

Bibler, N. E., "Radiolytic Gas Generation in Concrete Made with Incinerator Ash Containing Transuranium Nuclides," in Scientific Basis for Nuclear Waste Management, Vol. 2 pp. 585-592, 1980.

Bibler, N. E. "Radiolytic Gas Production During Long-Term Storage of Nuclear Wastes," E.I. DuPont de Nemours and Company, Savannah River Laboratory, DP-MS-76-51, American Chemical Society Meeting (preprint), October 27-29, 1976.

Bibler, N. E. "Radiolytic Gas Production from Concrete Containing Savannah River Plant Waste," E.I. DuPont de Nemours and Company, Savannah River Laboratory, DP-1464, January 1978.

Bockhorn, H. et al., "Investigation of the Kinetics of Thermal Degradation of Commodity Plastics," Combust. Sci. and Tech., 116-117(1996)129-151. 
Bohm, G. G. A. "Radiation Chemistry of Elastomers," in The Radiation Chemistry of Macromolecules, Vol. II, ed. M. Dole, Academic Press, New York, 1973.

Bohm, G. "Radiation Chemistry," Rubber Chem. Tech., 55(1982)575-666.

Bolt, R. O. and J. G. Carroll, Radiation Effects on Organic Materials, Academic Press, New York, 1963.

Bonzon, L. L. et al., "Status report on Equipment Qualification Issues-Research and Resolution," Sandia National Laboratories, NUREG/CR-4301, SAND85-1309, November 1986.

Burnay, S. G. "Comparative Evaluation of $\alpha$ and $\gamma$ Radiation Effects in a Bitumenisate," Nuclear and Chemical Waste Management, 7(1987)107-127.

Burns, W. G. and H. E. Sims, "Effect of Radiation Type in Water Radiolysis," J. Chem. Soc. Faraday Trans, I 77(1981)2809-2813.

Busfield, W. K. et al., "Radiation Degradation of Poly(styrene-co-Methylmethacrylate). 2. Protective Effects of Styrene on Volatile Products, Chain Scission and Flexural Strength," Polymer, 23(1982)431434.

Carniti, P. et al., "Polystyrene Thermodegredation. 2. Kinetics of Formation of Volatile Products," Ind. Eng. Chem. Res., 30(1991)1624-1629.

Cember, H., Introduction to Health Physics, Pergamon Press, New York, 1978.

Chapiro, A., Radiation Chemistry of Polymeric Systems, Interscience, Publishers, New York, 1962.

Characklis, W. G., "Bacterial Regrowth in Distribution Systems," American Water Works Assoc. Research Foundation Research Rep., American Water Works Assoc., Denver, CO, 1988.

Chen, T. H. et al., "Radiolysis of Chloroform and Carbon Tetrachloride," J. Phys. Chem., 64(1960) 1023- 1025.

Coward, H. F. and G. W. Jones, "Limits of Flammability of Gases and Vapors," Bulletin 503, Bureau of

Cowell, W. R. Sources and Development of Mathematical Software, Prentice Hall, New York, 1984.

Dalton, F. L. et al., "Gas Yields from Electron-Irradiated Cotton Cellulose," Nature, 200, pp. 862-864, 1963.

Deanin, R. D. Polymer Structure, Properties and Applications, Chaners Books, Boston, 1972.

Dole, L. R. and H. A. Friedman, "Radiolytic Gas Generation from Cement-Based Waste Hosts for DOE Low-Level Radioactive Wastes," preprint of a presentation at the Symposium on the Effects of Radiation on Materials, Seattle, Washington, June 1986.

Dole, M., "Effects of Radiation Environments on Plastics," in The Effects of Hostile Environments on Coatings and Plastics, ed. D.P. Garner, American Chemical Society, Washington D.C., 1983, pp. 17 24.

Dole, M., "Polyoxymethylene," in The Radiation Chemistry of Macromolecules, Vol. II, ed. M. Dole, Academic Press, New York, 1973.

Ershov, B. G. et al., "Mechanism of the Radiation Chemical Conversions of Cellulose," translated from Khimiya Vysokikh Energii, 20(1986)142-147. 
Fares, M. M. et al., "Analysis of Polymers Using Evolved-gas and Direct-pyrolysis Techniques," Analyst, 119(1994)693-696.

Fransolet, G. G., G. Villers, and W.J. Masschelein, "Influence of temperature on bacterial development in waters," Ozone Sci. Eng., 7:205(1985).

Garibov, A. A., "Water Radiolysis in the Presence of Oxides," in Proceedings of the Fifth Tihany Symposium on Radiation Chemistry, Akademiai Kiado, Budapest, 1983, pp. 377-384.

Georgia Institute of Technology, "Radiation Effects on Organic Materials in Nuclear Plants," Electric Power Research Institute, EPRI NP-2129, November 1981.

Getoff, N. and W. Lutz, "Radiation Induced Decomposition of Hydrocarbons in Water Resources," Radiat. Phys. Chem., 25(1985)21-26.

Geymer, D. O., "Radiation Chemistry of Substituted Vinyl Polymers. Polypropylene," in The Radiation Chemistry of Macromolecules, Vol. II, ed. M. Doles, Academic Press, New York, 1973.

Geymer, D. O., "Radiation Chemistry of Substituted Vinyl Polymers. Polypropylene," in The Radiation Chemistry of Macromolecules, Vol. II, ed. M. Dole, Academic Press, New York, 1973.

Gillen, K. T., R.L. Clough, and L.H. Jones, "Investigation of Cable Deterioration in the Containment Building of the Savannah River Nuclear Reactor," NUREG/CR-2877, SAND81-2613, August 1982.

Giori, C. and T. Yamauchi, "Effects of Ultraviolet and Electron Radiations on Graphite-Reinforced Polysulfone and Epoxy Resins," J. Appl. Polym. Sci., 29(1984)237-249.

Graessley, W. W. "Polyvinyl Acetate," in The Radiation Chemistry of Macromolecules, Vol. II, ed. M. Dole, Academic Press, New York, 1973.

Hall, K. L. et al., "Radiation Chemistry of Pure Compounds, " in Radiation Effects on Organic Materials, eds. R.O. Bolt and J.G. Carroll, Academic Press, New York, 1963.

Hartel, U. and W. Buckel, "Sodium ion-dependent hydrogen production in Acidaminococcus fermentans," Arch Microbiol, 166(1996)350-356.

Hegazy, E. A. et al., "Radiation Effects on Stabilized Polypropylene," Radiat. Phys. Chem., 27(1986)139-144.

Hegazy, E. A. et al., "Radiation-Induced Oxidative Degradation of Poly (Vinyl Chloride)," J. Appl. Polymer Sci., 26(1981)2947-2957.

Hegazy, E. A. et al., "Radiation-Induced Oxidative Degradation of Isotactic Polypropylene," J. Appl. Polym. Sci, 26(1981)1361-1372.

Holland, J. P. et al., "The Radiolysis of Dodecane-Tributylphosphate Solutions," Nuclear Instruments and Methods, 153(1978)589-593.

Hopkins, J. D., "Criteria for Flammable Gas Watch List Tanks," Westinghouse Hanford Co., WHC-EP0702, Rev. 0, August 1994.

Institute of Electrical and Electronics Engineers, Inc., "Radiation Effects Handbook," S-146, June 1963.

Jastrzebski, Z. D. The Nature and Properties of Engineering Materials, 2nd Ed., John Wiley \& Sons, New York, 1976. 
Johnson, E. R. The Radiation-Induced Decomposition of Inorganic Molecular Ions, Gordon and Breach Science Publishers, New York, 1970.

Joret, J. C., Y. Levi, T. Dupin, and M. Gilbert, "Rapid Method for Estimating Bioliminable Organic Carbon in Water," Proc. Annu. Conf. American Water Works Assoc., Denver, CO, 1988.

Kalia, V. C. and A. P. Joshi, "Conversion of Waste Biomass (Pea-Shells) into Hydrogen and Methane Through Anaerobic-Digestion," Bioresources Technology, 53:2(1995)165-168.

Kazanjian, A. R. and A. K. Brown, "Radiation Chemistry of Materials Used in Plutonium Processing," The Dow Chemical Company, Rocky Flats Division, RFP-1376, December 1969.

Kazanjian, A. R. and D.R. Horrell, "The Radiation-Induced Oxidation of Trichloroethlyene," J. Phys. Chem., 75(1971)613-616.

Kazanjian, A. R. and M. E. Killion, Results of experiments on radiolytic gas generation from sludge, Rockwell International, Rocky Flats Plant, personal communication reference in Tru-PACT Safety Analysis Report, 1981.

Kazanjian, A. R. "Radiolytic Gas Generation in Plutonium Contaminated Waste Materials," Rockwell International, Rocky Flats Plant, RFP-2469, October 1976.

Kosiewicz, S. T. "Gas Generation from the Alpha Radiolysis of Bitumen," Nuclear and Chemical Waste Management, 1(1980)139-141.

Kosiewicz, S. T. "Gas Generation from the Organic Transuranic Wastes. I. Alpha Radiolysis at Atmospheric Pressure," Nuclear Technology, 54(1981)92-99.

Kosiewicz, S. T. et al., "Studies of Transuranic Waste Storage Under Conditions Expected in the Waste Isolation Pilot Plant (WIPP), Interim Summary Report October 1, 1977-June 15, 1979," Los Alamos National Laboratory, LA-7931-PR.

Krasnansky, V. J. et al., "Effect of Gamma Radiation on Chemical Structure of Plastics," SPE (Society of Plastics Eng.) Trans., 1(1961)133-138.

Ladrielle, et al., "Alpha and Gamma Induced Radiolysis of Tributyl-Phosphate," Radiochem. Radioanal. Letters, 59(1983)355-364.

Le Chevallier, M. W., C. D. Caethon, and R. G. Lee, "Factors promoting survival of bacteria in chlorinated water supplies," Appl. Environ. Microbiol., 54:649(1988).

Lewis, E. L. "TRU Waste Certification: Experimental Data and Results," Monsanto Research Corp., Mound Laboratory, MLM-3096, Sept. 1983.

Liverhant, S. E., "Elementary Introduction to Nuclear Reactor Physics," John Wiley \& Sons, New York, 1960.

Ludowise, J. D. "Report on Plutonium Mining Activities at 216-Z-9 Enclosed Trench," Rockwell International, Rockwell Hanford Operations, RHO-ST-21, September 1978.

Makhlis, F. A. Radiation Plysics and Chemistry of Polymers, John Wiley \& Sons, New York, 1975, translated from the Russian.

Mandelkern, L. "Radiation Chemistry of Linear Polyethylene," in Radiation Chemistry of Macromolecules, Vol. I, ed. M. Dole, Academic Press, New York, 1972. 
Maul, A., A. H. El-Shaarawi, and J. C. Block, "Wetrotropic Bacteria in Water Distribution Systems. I. Spatial and Temporal Variation," Sci. Total Environ., 44:201(1985).

McDuffie, N. G., "Flammable Gas Tank Safety Program: Data Requirements for the Flammable Gas Tank Safety Issue Development Through the Data Quality Objectives (DQO) Process," Westinghouse Hanford Co., WHC-SD-WM-DQO-OO4, Rev. 0, May 6, 1994.

Miller, A. A. "Radiation Chemistry of Polyvinyl Chloride," J. Phys. Chem., 63(1959)1755-1759.

Mines, U.S. Government Printing Office, Washington, 1952.

Mirichi, R. et al., "Selected Problems of Radiation Stability of Some Solvents and Amines Used in the Reprocessing of Nuclear Fuel," Nukleonika, 26(1981)827-848.

Morrison, R. T. and R.N. Boyd, Organic Chemistry. 3rd Ed., Allyn and Bacon, Inc., Boston, 1973.

Nakamura, M., H. Kanbe, and J. Matsumoto, "Fundamental Studies on Hydrogen Production in the Acid- Forming Phase and its Bacteria in Anaerobic Treatment Processes-The Effects of Solids Retention Time," Wat. Sci. Tech., 28:7(1993)81-88.

Neufeldt, V. ed., Webster's New World Dictionary of American English, Simon \& Schuster, Inc., 1988.

Newton, A. S. "Chemical Effects of Ionizing Radiation," in Radiation Effects on Organic Materials, eds. R.O. Bolt and J.G. Carroll, Academic Press, New York, 1963.

Nitta, I. et al., "Effect of Radiation on Polyethlyene Glycol," in Annual Report of the Japanese Assn. for Radiation Research on Polymers, AEC-tr-6372, 3(1961)445-453.

Nitta, I. et al., "Effect of Radiation on Polyoxymethylene," in Annual Report of the Japanese Assn. for Radiation Research on Polymers, AEC-tr-6372, 3(1961)437-443.

Nuclear Regulatory Commission, "Minimization of Methane Gas in Plant Systems and Radwaste Shipping Containers," Information Notice No. 90-50, August 8, 1990.

Nuclear Regulatory Commission, "Safety Analysis Report for the TRUPACT-II Shipping Package," Rev. 14, NRC Docket No. 9218, U.S. Department of Energy, Washington, D.C., October 1994.

O'Donnell, J. H. and D. F. Sangster, Principles of Radiation Chemistry, American Elsevier Publishing Company, Inc., New York, 1970.

Ogura, N. "Further Studies on Decomposition of Dissolved Organic Matter in Coastal Seawater," Mar Biol., 31:101(1975).

Okada, T. "Radiolysis of Poly (Vinyl Alcohol)," in Annual Report of the Japanese Assn. for Radiation Research on Polymers, 8(1967)33-43.

Ottolenghi, M. and G. Stein, "The Radiation Chemistry of Chloroform," Radiation Research, 14(1961) 281- 290.

Pacakova, V. and P.A. Leclercq, "Gas Chromatography-Mass Spectrometry and High-Performance Liquid Chromatography Analysis of Thermal Degradation Products of Common Plastics," J. of Chromatography, 555(1991)229-237.

Pajunen, A. O. "Radiolytic Evolution of Gases from Z-9 Soils," Rockwell Hanford Operations, RHOCD-13, July, 1977. 
Parker Seals, Parker O-Ring Handbook, Lexington, KY, 1992.

Parkinson, W. W. and R. M. Keyser, "Radiation Chemistry of Substituted Vinyl Polymers. Polystyrene and Related Polymers," in The Radiation Chemistry of Macromolecules, Vol. II, ed. M. Dole, Academic Press, New York, 1973.

Pillay, K. K. S., "The Effects of Ionizing Radiation on Synthetic Organic Ion Exchangers," J. Radioanaly. Nuc. Chem., 97/1(1986)135-210.

Rowbottom, R. S., "Risks of Bacterial Hydrogen Generation in White Water Systems," Tappi Journal, 76:1(1993)97-98.

Schnabel, W., Polymer Degradation—Principles and Practical Applications, Macmillan Publishing Company, Inc., New York, 1981.

Smith, J. M., Chemical Engineering Kinetics, McGraw-Hill Book Co., New York, 1981.

Sobashima, S. et al., "Irradiation Effects on Polyoxymethylene," in Annual Report on the Japanese Assn. for Radiation Research on Polymers, AEC-tr-6231, 1(1959)329-338.

Spinks, J. W. T. and R. J. Woods, An Introduction to Radiation Chemistry, John Wiley \& Sons, New York 1976.

Sullivan, J. C. "Reactions of Plutonium Ions with the Products of Water Radiolysis," in Plutonium Chemistry, W.T. Carnal (Ed.), American Chem, Soc. ACS Symp., 216(1983)241.

Szymanski, W. et al., "Increase of Poly (Vinyl Chloride) Stability Towards Ionizing Radiation. II. Effects of Epidian Addition in PVC Films. III. Effects of the Addition of Ethylene Glycol Bis- betaAminocrotonate in PVC Foils," Nukeonika, 21(1976)277-283.

Turner, D. T., "Radiation Chemistry of Some Miscellaneous Polymers. Polyethylene Terephthalate," The Radiation Chemistry of Macromolecules, Vol. II, ed. M. Dole, Academic Press, New York, 1973.

U. S. Department of Energy, "Radioactive Waste Management," DOE Order 5820.2A, September 26, 1988.

U. S. Environmental Protection Agency, "Environmental Standards for the Management and Disposal of Spent Nuclear Fuel, High-Level and Transuranic Radioactive Waste, Final Rule," 40 CFR Part 191, Federal Register, Vol. 50, No. 182, 1985.

Van der Kooij, D., A. Visser, and W. A. M. Hijnen, "Determining the concentration of easily assimilable organic carbon in drinking water," J. Amer. Water Works Assoc., 74:540(1982).

VanDevender, W. H., "Slatec Mathematical Subprogram Library Version 2.0," Sandia National Laboratories, SAND84-0281, April 1984.

Varsanyi, "Investigations into the Permeability of Polymer Membranes of Food Packaging quality to Gases and Water Vapor after Radiation Treatments with Radurizing Doses," Acta Alimentaria, 4(1975)169-251.

Wang, R., F.P. Healey, and J. Meyers, "Amoerometric measurement of hydrogen evolution in Chlamydomonas," Plant Physiol., 48(1971)108-110.

Weast, R. C., ed., CRC Handbook of Chemistry and Physics, CRC Press, Inc., Boca Raton, FL, 1979.

Wetzel, R. G. and B. A. Manny, "Decomposition of Dissolved Organic Carbon and Nitrogen Compounds from Lleaves in an Experimental Hard-Water Stream," Limnol. Oceanogr., 17:927(1972). 
Xue, T. J., M. A. McKinney, and C. A. Wilkie, "The Thermal Degradation of Polyacrylonitrile," Polymer Degradation and Stability, 58(1997)193-202.

Zahran, A. H., et al., "Radiation Effects of Poly (Vinyl Chloride)-I. Gas Evolution and Physical Properties of Rigid PVC Films," Radiat. Phys. Chem., 26(1985)25-32.

Zerwekh, A. "Gas Generation from Radiolytic Attack of TRU-Contaminated Hydrogenous Waste," Los Alamos National Laboratory, LA-7674-MS, June 1979.

Ziegler, J. F., J. P. Biersack, and U. Littmark, The Stopping and Range of Ions in Solids, Vol. I, Perfamon Press, New York, 1985.

Zimmerman, J. "Radiation Chemistry of Some Miscellaneous Polymers. Polyamides," The Radiation Chemistry of Macromolecules, Vol. II, ed. M. Dole, Academic Press, New York, 1973. 
7. References 


\section{APPENDIX A. CHEMICAL REACTIONS}

Many chemical reactions that produce hydrogen gas involve a change in the valance of metal atoms or ions and the formation of hydrogen from the combination of hydrogen ions or from the dissociation of water. Additionally, hydrogen is produced when a metal hydride is converted to a metal oxide or to a metal hydroxide by reaction with oxygen-containing species, such as hydroxide ions, oxygen, or water.

Metals that are more electropositive than hydrogen (above hydrogen in the electromotive force series) will liberate hydrogen gas upon reaction with dilute acid solutions or in some cases water. These metals include: $\mathrm{Sn}, \mathrm{Ni}, \mathrm{Tl}, \mathrm{Cd}, \mathrm{Fe}, \mathrm{Zn}, \mathrm{Al}, \mathrm{Be}, \mathrm{Mg}, \mathrm{Na}, \mathrm{Ca}, \mathrm{Sr}, \mathrm{Ba}, \mathrm{Rb}, \mathrm{K}$, and $\mathrm{Li}$.

Example reactions between hydrogen ions and metals include:

$\mathrm{Fe}(\mathrm{s})+2 \mathrm{H}+(\mathrm{aq}) \Rightarrow \mathrm{H}_{2}(\mathrm{~g})+\mathrm{Fe}^{2+}(\mathrm{aq})$, and

$\mathrm{Zn}(\mathrm{s})+2 \mathrm{H}^{+}(\mathrm{aq}) \Rightarrow \mathrm{H}_{2}(\mathrm{~g})+\mathrm{Zn}^{2}+(\mathrm{aq})$.

The reaction between metallic sodium and water is:

$2 \mathrm{Na}+2 \mathrm{H}_{2} \mathrm{O} \Rightarrow 2 \mathrm{NaOH}+\mathrm{H}_{2}$.

Calcium hydride will also react with water to give hydrogen gas:

$\mathrm{CaH}_{2}+2 \mathrm{H}_{2} \mathrm{O} \Rightarrow \mathrm{Ca}(\mathrm{OH})_{2}+2 \mathrm{H}_{2}$

The dissolution of aluminum or silicon in alkali solution produces hydrogen according to the reactions:

$2 \mathrm{Al}+2 \mathrm{NaOH}+6 \mathrm{H}_{2} \mathrm{O} \Rightarrow 2 \mathrm{NaAl}(\mathrm{OH})_{4}+3 \mathrm{H}_{2}$, and

$\mathrm{Si}+4 \mathrm{NaOH} \Rightarrow \mathrm{Na}_{4} \mathrm{SiO}_{4}+2 \mathrm{H}_{2}$

Corrosion of metal comprising the packaging (including inner containers) is a phenomenon which can appear either generalized or local. Corrosion depends on the following parameters: (1) type of metal or alloy, (2) chemical properties of the surrounding water or vapor ( $\mathrm{pH}$, oxidant concentration, etc.), and (3) temperature and pressure of the surrounding medium. In addition to influencing the corrosion rate, these parameters affect the type and quantity of the corrosion products.

The following mechanisms describe the corrosion reaction between iron and water:

$3 \mathrm{Fe}+4 \mathrm{H}_{2} \mathrm{O} \Rightarrow \mathrm{Fe}_{3} \mathrm{O}_{4}+4 \mathrm{H}_{2}$, and

$\mathrm{Fe}+2 \mathrm{H}_{2} \mathrm{O} \Rightarrow \mathrm{Fe}(\mathrm{OH})_{2}+\mathrm{H}_{2}$

These two reactions will dominate over other iron corrosion reactions if the medium surrounding the wastes is anaerobic. If no consideration is given to consumption of hydrogen after its formation, then the volume of hydrogen produced will be directly related to the quantity of iron corroded.

In complex mixtures of transuranic isotopes, water, inorganics, and organics (e.g., lubricants, oils, solvents, resins), predicting all possible reactions that lead to hydrogen evolution may be difficult even if all the mixture constituents are known. In some radioactive liquid and sludge wastes, the hydrogen (and other flammable gas) generation rate has been found to be greater than that predicted from radiolysis (McDuffie 1994; Hopkins 1994). The discrepancy has been attributed to hydrogen produced by chemical 
degradation of organic compounds. At least for some radioactive liquids and sludges, the conditions and constituents that influence the degradation reactions are apparently basic $\mathrm{pH}$ (high hydroxide ion concentrations), as well as the presence of aluminate and nitrate. Since predicting the reactions that may lead to hydrogen evolution when a waste mixture includes many compounds is difficult, it may be necessary to perform tests to determine the rate of hydrogen evolution due to chemical interactions. In the absence of known chemical mechanisms, it may be necessary to determine empirical formulations involving the concentration of some of the key constituents to predict the flammable gas evolution rate. These non-radiolytic organic degradation reactions that lead to flammable gas evolution are believed to be less important when the waste is dewatered or solidified.

The rate of a homogeneous reaction is defined as the change in moles (due to reaction) of a reactant, or product, per unit time per unit volume of the reaction mixture. The rate of production of species "i" may be expressed as (Smith 1981):

$\mathrm{R}_{\mathrm{i}}=\frac{1}{\mathrm{~V}} \frac{\mathrm{dn}_{\mathrm{i}}}{\mathrm{dt}}=\frac{\mathrm{dC}_{\mathrm{i}}}{\mathrm{dt}}$

where: $\mathrm{V}$ is the reaction mixture volume [liters];

$\mathrm{n}_{\mathrm{i}}$ is the number of moles of species $\mathrm{i}$ [moles]; and

$\mathrm{C}_{\mathrm{i}}$ is the concentration of species $\mathbf{i}$ [moles/liter].

Considering the general homogeneous reaction:

$\mathrm{aA}+\mathrm{bB} \Rightarrow \mathrm{cC}+\mathrm{dD}$

the rate of change of moles of one chemical species is related to that of any other by the stoichiometry of the reaction according to the relationship:

$-\frac{1}{\mathrm{a}} \frac{\mathrm{dn}_{\mathrm{A}}}{\mathrm{dt}}=-\frac{1}{\mathrm{~b}} \frac{\mathrm{dn}_{\mathrm{B}}}{\mathrm{dt}}=\frac{1}{\mathrm{c}} \frac{\mathrm{dn}_{\mathrm{C}}}{\mathrm{dt}}=\frac{1}{\mathrm{~d}} \frac{\mathrm{dn}_{\mathrm{D}}}{\mathrm{dt}}$.

An empirical expression for the reaction rate is:

$\mathrm{R}_{\mathrm{A}}=-\frac{\mathrm{dC} \mathrm{A}}{\mathrm{dt}}=\mathrm{k}\left(\mathrm{C}_{\mathrm{A}}\right)^{\alpha}\left(\mathrm{C}_{\mathrm{B}}\right)^{\beta}$

where: $\alpha$ is the order of the reaction with respect to $A$;

$\beta$ is the order of the reaction with respect to $B$; and

$\mathrm{k}$ is the reaction rate constant.

The reaction rate constant, $k$, is independent of concentrations but temperature dependent. The dependency of $k$ on temperature for an elementary process follows the Arrhenius equation:

$\mathrm{k}=\mathrm{Ae} \mathrm{e}^{-\mathrm{F} / \mathrm{RT}}$

where: $\mathrm{A}$ is the frequency (or pre-exponential factor);

$E$ is the reaction activation energy [J]; 
$\mathrm{R}$ is the gas law constant $[8.314 \mathrm{~J} / \mathrm{mol} \cdot \mathrm{K}]$; and

$\mathrm{T}$ is the reaction temperature $[\mathrm{K}]$.

Although 10 CFR 71.43 (d) requires that a package be made of materials and construction that assures that there will be no significant chemical, galvanic, or other reaction among the packaging components, among package contents, or between the packaging components and the package contents, for certain contents such as non-solidified radioactive liquid and sludge waste mixtures, there may be some hydrogen evolution due to chemical reactions among the constituents in the contents. For waste mixtures where the chemical generation of hydrogen is unavoidable, the appropriate activation energy and waste temperature should be used to estimate the rate of hydrogen evolution. 
Appendix A 


\section{APPENDIX B. THERMAL DEGRADATION}

Pyrolysis is the chemical decomposition of a substance by heat (Neufeldt 1988). Thermal decomposition of many substances in a transportation package could potentially result in the generation of flammable gaseous species. Additionally, some materials may also release small amounts of gases well below a temperature that would cause thermal decomposition of the bulk material. Materials that outgas from a polymer may include unreacted monomers, trapped solvents, air, plasticizers, and initiators. Although typically only a small fraction of the gases released due to thermal decomposition is flammable and the amount of gases released due to outgassing is generally small, each contents and its packaging should be analyzed independently for the potential for hydrogen (and other flammable gas) generation by thermal outgassing and thermal degradation of materials.

Materials in radioactive material packages that should be analyzed for possible gas generation by thermal outgassing and thermal decomposition include elastomers, plastics, foams, glues, resins, cellulosic materials, and inorganic materials with absorbed water or volatile organics. The heating of these materials can cause spontaneous outgassing of volatile constituents in the form of vapors or gasses. The amount of outgassing and the degree of thermal decomposition depends on the temperature and other conditions within the containment vessel (i.e., gas pressure and gas composition).

When performing pressure and hydrogen concentration calculations, it may be important to include gases released from materials due to outgassing or thermal decomposition. The relative amount of outgassing under moderately elevated temperatures below the melting point and the thermal decomposition temperature may be estimated from room temperature vacuum outgassing experiments. Table B.1 lists the percent weight loss for some common polymers after two weeks at a gas pressure of $1.3 \times 10^{-4} \mathrm{~Pa}$ $\left(1.93 \times 10^{-8} \mathrm{lbf} / \mathrm{in}^{2}\right)$. As can be seen from Table B.1, the percent weight loss for vacuum outgassing was generally $1 \%$ or less. Therefore, for $28.3 \mathrm{~g}(0.062 \mathrm{lbm})$ of polymer, $1 \%$ outgassing results in about $0.28 \mathrm{~g}$ $\left.6.17 \times 10^{-4} \mathrm{lbm}\right)$ of released gas, which would have a volume of approximately $280 \mathrm{~cm}^{3}\left(9.9 \times 10^{-3} \mathrm{ft}^{3}\right)$ at one atmosphere. Therefore, an analysis of the contribution of flammable vapors outgassed from polymers in a containment vessel should address the types of polymers present, the operating temperature, the containment vessel void volume, and the flammability of the outgassed materials.

At sustained temperatures above the maximum continuous service temperature, thermal decomposition will occur. The thermal decomposition (incineration) of plastics can release dioxins, furans, and hydrochloric acid. Consideration of hydrochloric acid generation may be important for analyzing metal corrosion and the corresponding gas generation. During high temperature (i.e., 873-1173 K) thermal decomposition (oxygen-free pyrolysis) of polyethylene, polypropylene, polystyrene, and polyvinylchloride, the main gaseous products include hydrogen, methane, acetylene, ethene, ethane, propene, propane, butene and butane. The maximum continuous service temperatures and relative burning rates for some common plastics are listed in Table B.2. In general, the presence of aromatic rings improves the thermal stability of a polymer (Jastrzebski 1976).

Although thermal outgassing is not considered an important mechanism for hydrogen generation in transportation packages, it may contribute to the inventory of other flammable gases. Therefore, it may be important to determine the degree to which the resulting gas mixture approaches the lower flammability limit. In general, thermal decomposition of polymeric materials in radioactive material packages should be avoided. Flammable gases generated via thermal decomposition of polymeric (and other) materials in radioactive material transportation packages can be minimized by the choice of heatresistant polymeric confinement materials and limits on the contents decay heat. If thermal decomposition of polymeric materials within a radioactive material package is unavoidable, performance 
of thermal tests (in the absence of experimental data) on the polymeric materials by subjecting them to simulated transport conditions to determine the generation rate of hydrogen (and other flammable gases) and any potentially corrosive products may be necessary. When a transportation package contains a mixture of polymeric materials, experimental data concerning the thermal degradation of individual polymeric materials should be used with caution since it has been demonstrated that mixtures of polymers can have different (larger) thermally generated amounts of gases than the simple sum of the individual polymer contributions.

Some experimental results of polymer degradation studies for selected polymers are presented in Table B.3. From Table B.3, it is clear that significant thermal degradation should be expected for many polymers if the temperature is greater than about $473 \mathrm{~K}\left(392^{\circ} \mathrm{F}\right)$. However, for essentially all TRU waste transportation containers, the waste does not experience temperatures greater than about $393 \mathrm{~K}\left(248^{\circ} \mathrm{F}\right)$ as a result of the relatively low decay heats. Although most polymeric materials will not undergo significant thermal degradation at a temperature of $393 \mathrm{~K}\left(248^{\circ} \mathrm{F}\right)$, this temperature is above the maximum continuous service temperature (MCST) for some polymeric materials and a limited amount of thermal degradation may be expected to occur. The MCST is based on the polymer maintaining its required structural properties. Above the MCST, the material could be expected to soften (except for thermosetting resins) as it approaches its glass transition temperature and may release some trapped solvents, plasticizers, and other low-volatility materials and may also undergo some limited thermal degradation. Based on a maximum contents temperature of about $393 \mathrm{~K}\left(248^{\circ} \mathrm{F}\right)$, the polymers typically in TRU waste that should be examined as to their thermal degradation gas emission rate include (but are not limited to) nylon, polyethylene, polystyrene, polyvinylchloride, and epoxy.

Thermal degradation experiments performed on some common waste materials (such as cellulosics, plastics, and rubbers) at temperatures as high as $373 \mathrm{~K}\left(212^{\circ} \mathrm{F}\right)$ indicate that the moles of gas generated per kilogram of material would be $1.23 \times 10^{-3} \mathrm{moles} / \mathrm{kg}\left(2.7 \times 10^{-3} \mathrm{moles} / \mathrm{lbm}\right)$ waste material (Kosiewicz 1979). In addition, carbon dioxide and carbon monoxide are the common thermal degradation products and, although these gases would contribute to the total containment vessel gas pressure, they would not contribute to the inventory of flammable gases.

A second-order effect that may be important to consider is the release of $\mathrm{HCl}$ from the thermal degradation of polyvinylchloride. It is possible that thermally liberated hydrogen ions could undergo corrosion reactions with metals present, which would result in a release of hydrogen gas as a corrosion product.

Table B.1 Vacuum Outgassing of Some Common Polymers at 298 K (Parker Seals 1992)

\begin{tabular}{llcllc}
\hline Polymer & Compound \# & \% Wgt. Loss & Polymer & Compound \# & \% Wgt. Loss \\
\hline Butyl & B612-70 & 0.18 & Nitrile & N674-70 & 1.06 \\
Neoprene & C873-70 & 0.13 & Polyurethane & P648-90 & 0.129 \\
Ethylene Propylene & E515-80 & 0.39 & Silicone & S455-70 & 0.03 \\
Ethylene Propylene & E529-60 & 0.92 & Silicone & S604-70 & 0.31 \\
Ethylene Propylene & E692-75 & 0.76 & Fluorocarbon & V747-75 & 0.09 \\
Fluorosilicone & L449-65 & 0.28 & Fluorocarbon & V884-75 & 0.07 \\
Fluorosilicone & L677-70 & 0.25 & Fluorocarbon & V894-90 & 0.07 \\
Nitrile & N406-60 & 3.45 & & & \\
\hline
\end{tabular}


Table B.2 Maximum Continuous Service Temperatures (MCST) for Common Plastics (Weast 1979)

\begin{tabular}{|c|c|c|c|c|}
\hline Type of Plastic & $\begin{array}{l}\text { Resin } \\
\text { Type }\end{array}$ & Subclass & $\operatorname{MCST}\left[\mathrm{K},\left({ }^{\circ} \mathbf{F}\right)\right]$ & Relative Burning Rate \\
\hline Cellulose Acetate & $\mathrm{TP} *$ & Soft & -- & Medium \\
\hline Cellulose Acetate & $\mathrm{TP}$ & Hard & -- & Medium \\
\hline Cellulose Acetate Butyrate & $\mathrm{TP}$ & Soft & -- & Medium \\
\hline Cellulose Acetate Butyrate & $\mathrm{TP}$ & Hard & -- & Medium \\
\hline Nylon & $\mathrm{TP}$ & $6 / 6$ & $353-423(176-302)$ & Self Extinguishing \\
\hline Polycarbonates & $\mathrm{TP}$ & Unfilled & $411-416(280-289)$ & Self Extinguishing \\
\hline Polyethylene & $\mathrm{TP}$ & Low Density & $333-350(140-171)$ & Very Slow \\
\hline Polyethylene & $\mathrm{TP}$ & Medium Density & $344-366(160-199)$ & Slow \\
\hline Polyethylene & $\mathrm{TP}$ & High Density & $365-473(198-392)$ & Slow \\
\hline Methylmethacrylate & $\mathrm{TP}$ & Unmodified & $333-366(140-199)$ & Slow \\
\hline Polypropylene & $\mathrm{TP}$ & Unmodified & -- & Medium \\
\hline Polypropylene & $\mathrm{TP}$ & Copolymer & $463-513(374-464)$ & Medium \\
\hline Polystyrene & $\mathrm{TP}$ & Unmodified & $339-355(151-180)$ & Medium to Slow \\
\hline Polystyrene-acrylonitrile & $\mathrm{TP}$ & Unmodified & $350-361(171-190)$ & Slow \\
\hline Polytetrafluoro ethylene & $\mathrm{TP}$ & Unmodified & $533(500)$ & Self Extinguishing \\
\hline Polytrifluorochloro ethylene & $\mathrm{TP}$ & Unmodified & $473(392)$ & Self Extinguishing \\
\hline $\begin{array}{l}\text { Polyvinylchloride \& } \\
\text { Vinylchloride acetate }\end{array}$ & $\mathrm{TP}$ & Unmodified, rigid & $343-347(158-165)$ & Self Extinguishing \\
\hline $\begin{array}{l}\text { Polyvinylchloride \& } \\
\text { Vinylchloride acetate }\end{array}$ & $\mathrm{TP}$ & $\begin{array}{l}\text { Plasticized } \\
\text { (non rigid) }\end{array}$ & $353-375(176-221)$ & $\begin{array}{l}\text { Slow to Self } \\
\text { Extinguishing }\end{array}$ \\
\hline Epoxy & $\mathrm{TS} * *$ & Unfilled & $353(176)$ & Slow \\
\hline Melamine-Formaldehyde & $\mathrm{TS}$ & $\alpha$-cellulose filled & $372(210)$ & Self Extinguishing \\
\hline Melamine-Formaldehyde & TS & Mineral filled & $422(300)$ & Self Extinguishing \\
\hline Phenol-Formaldehyde & TS & Cordfilled & $394(250)$ & Self Extinguishing \\
\hline Phenol-Formaldehyde & $\mathrm{TS}$ & Cellulose filled & $422-450(300-351)$ & Self Extinguishing \\
\hline Phenol-Formaldehyde & $\mathrm{TS}$ & Unfilled & -- & Self Extinguishing \\
\hline Polyester (Styrene-Alkyd) & TS & $\begin{array}{l}\text { Glass fiber mat } \\
\text { reinforced }\end{array}$ & $394-477(250-399)$ & Self Extinguishing \\
\hline Silicones & TS & Mineral filled & $561(550)$ & Self Extinguishing \\
\hline Urea Formaldehyde & $\mathrm{TP}$ & $\alpha$-cellulose filled & $350(171)$ & Self Extinguishing \\
\hline $\begin{array}{l}\text { Acrylonitrile-Butadiene- } \\
\text { Styrene (ABS) }\end{array}$ & $\mathrm{TP}$ & $\begin{array}{l}\text { High Heat } \\
\text { Resistant }\end{array}$ & $361-383(190-230)$ & Slow \\
\hline Acetal & $\mathrm{TP}$ & Homopolymer & $357(183)$ & Slow \\
\hline Alkyd Resins & $\mathrm{TP}$ & $\begin{array}{l}\text { Synthetic, fiber } \\
\text { filled }\end{array}$ & $422-493(300-428)$ & Self Extinguishing \\
\hline
\end{tabular}

* TP=thermoplastic

** TS=thermosetting 
Appendix B

Table B.3 Various Thermal Degradation Results for Polymers

\begin{tabular}{|c|c|c|}
\hline Compound & Experimental Results & References \\
\hline Polystyrene & $\begin{array}{l}\text { When polystyrene is subject to temperatures in the range of } 633-693 \mathrm{~K} \\
\left(680-788^{\circ} \mathrm{F}\right) \text {, many volatile flammable products are released, including } \\
\text { benzene, toluene, ethylbenzene, and diphenylpropanes. }\end{array}$ & Carniti 1991 \\
\hline $\begin{array}{l}\text { Polypropylene } \\
\text { (filled) }\end{array}$ & $\begin{array}{l}\text { When filled polypropylene (Taboren) was heated for } 35 \text { minutes at } 533 \mathrm{~K} \\
\left(500^{\circ} \mathrm{F}\right) \text {, many low molecular weight volatile products were released, } \\
\text { including methane, ethane, ethene, propene, butene, } 1.3 \text {-butadiene, acetone, } \\
\text { pentane, etc. }\end{array}$ & $\begin{array}{l}\text { Pacakova and } \\
\text { Leclercq } 1991\end{array}$ \\
\hline Polyethylene & $\begin{array}{l}\text { Thermal oxidation of polyethylene shows gradual energy absorption until } \\
\text { melting at about } 383 \mathrm{~K}\left(230^{\circ} \mathrm{F}\right) \text {, and then combustion occurs at about } 523 \mathrm{~K} \\
\left(482^{\circ} \mathrm{F}\right) \text {. Polyethylene will release only minimum amounts of toxic or } \\
\text { flammable gases at } 343 \mathrm{~K}\left(158^{\circ} \mathrm{F}\right) \text {. Under air at } 773 \mathrm{~K}\left(932^{\circ} \mathrm{F}\right) \text { in flameless } \\
\text { conditions, compounds typical of the thermal degradation of polyethylene } \\
\text { included: } 1 \text {-alkenes (present in the largest amounts), and the corresponding } \\
\alpha, \omega-\text { alkadienes and n-alkanes. The only other substance present was } \\
\text { triethylphenol. }\end{array}$ & $\begin{array}{l}\text { Pacakova and } \\
\text { Leclercq } 1991\end{array}$ \\
\hline $\begin{array}{l}\text { Polyethylene- } \\
\text { Coated Paper }\end{array}$ & $\begin{array}{l}\text { When subject to a flameless temperature of } 773 \mathrm{~K}\left(932^{\circ} \mathrm{F}\right) \text { in air, } \\
\text { polyethylene-coated paper released acetone alcohol, trimethoxymethane, and } \\
\text { other higher molecular weight substances. }\end{array}$ & $\begin{array}{l}\text { Pacakova and } \\
\text { Leclercq } 1991\end{array}$ \\
\hline Milk Package & $\begin{array}{l}\text { When the milk package material was subject to } 773 \mathrm{~K}\left(932^{\circ} \mathrm{F}\right) \text { air in } \\
\text { flameless conditions, the characteristic products of burning polyethylene } \\
\text { were formed, i.e. the 1-alkenes, } \alpha, \omega \text {-alkadienes and n-alkanes. In addition, } \\
\text { the corresponding alkylaldehydes and derivatives of furals were present. }\end{array}$ & $\begin{array}{l}\text { Pacakova and } \\
\text { Leclercq } 1991\end{array}$ \\
\hline Polyamide 6 & $\begin{array}{l}\text { The experimentally obtained thermogravametric curve for polyamide } 6 \text {, when } \\
\text { heated at a rate of } 2 \mathrm{~K} / \text { min under helium, shows that significant volatile } \\
\text { products are released when the temperature reaches about } 553 \mathrm{~K}\left(536^{\circ} \mathrm{F}\right) \text { and } \\
\text { that the highest release rate of volatile products occurs when the temperature } \\
\text { is about } 688 \mathrm{~K}\left(779^{\circ} \mathrm{F}\right) \text {. Although the polymer decomposes quantitatively } \\
\text { producing a high amount of the monomer } \varepsilon \text {-caprolactame }(\cdot 90 \%) \text {, a } \\
\text { significant amount of volatile materials are released with molecular weights } \\
\text { between } 15 \text { and } 30 . \text { For decomposition of a } 2 \times 10^{-5} \mathrm{~kg}\left(4.4 \times 10^{-5} \mathrm{lbm}\right) \text { sample, } \\
\text { the apparent activation energy was about } 200 \mathrm{~kJ} / \mathrm{mole} \text {, the pre-exponential } \\
\text { factor was } \log _{10}(\mathrm{~A})=14.2 \text {, and the calculated apparent reaction order was } \\
0.82 \text {. For this material, there was no effect on the apparent activation energy } \\
\text { due to the initial sample size. }\end{array}$ & Bockhorn 1996 \\
\hline
\end{tabular}




\begin{tabular}{|c|c|c|}
\hline Compound & Experimental Results & References \\
\hline $\begin{array}{l}\text { Polyvinylchloride } \\
\text { (PVC) }\end{array}$ & $\begin{array}{l}\text { The experimentally obtained thermogravametric curve for PVC, when heated } \\
\text { at a rate of } 2 \mathrm{~K} / \text { min under helium, shows two decomposition steps between } \\
\text { ambient temperature and } 823 \mathrm{~K}\left(1022^{\circ} \mathrm{F}\right) \text {. The first weight loss, which occurs } \\
\text { in the temperature range of } 503-548 \mathrm{~K}\left(446-527^{\circ} \mathrm{F}\right) \text {, is caused by the } \\
\text { evolution of hydrogen chloride and a small amount of benzene. The reaction } \\
\text { rate of this first step is strongly dependent on the initial sample weight. Using } \\
\text { samples of low initial mass of PVC }\left(2 \times 10^{-5} \mathrm{~kg} \text { ), the reaction rate is given by }\right. \\
\text { a single peak, whereas a sample of } 10 \mathrm{mg} \text { initial mass causes a large } \\
\text { shouldered peak in the reaction rate. In the second decomposition step, which } \\
\text { occurs around a temperature of } 494 \mathrm{~K}\left(430^{\circ} \mathrm{C}\right) \text {, the remaining residue is } \\
\text { decomposed into aromatic hydrocarbons. After heating to } 823 \mathrm{~K}\left(1022^{\circ} \mathrm{F}\right) \\
\text { under helium, an undegradable residue ("carbon residue") of approximately } \\
7.5 \% \text { of the initial weight remains. For the } 2 \mathrm{mg} \text { initial weight samples, the } \\
\text { calculated apparent activation energy was about } 140 \mathrm{~kJ} / \text { mol, the pre- } \\
\text { exponential factor was } \log _{10}(\mathrm{~A})=13.0 \text {, and the calculated apparent reaction } \\
\text { order was about } 1.5 \text {. }\end{array}$ & Bockhorn 1996 \\
\hline $\begin{array}{l}\text { Polystyrene and } \\
\text { Poly } \\
\text { ( } \alpha \text {-methylstyrene) } \\
\text { and poly } \\
\text { (p-methylstyrene) }\end{array}$ & $\begin{array}{l}\text { Using a pyrolysis chamber at a pressure of } 0.01 \mathrm{~Pa} \text {, an evolved-gas analysis } \\
\text { on poly (a-methylstyrene) and poly (p-methylstyrene) was performed. After } \\
\text { the cell was evacuated to } 0.01 \mathrm{~Pa} \text {, the cell was heated to } 323 \mathrm{~K}\left(122^{\circ} \mathrm{F}\right) \text { to dry } \\
\text { the solvent and the unreacted monomer. The evolved gases were recorded at } \\
10 \mathrm{~K}\left(18^{\circ} \mathrm{F}\right) \text { intervals with a } 10 \mathrm{~K} / \mathrm{min}\left(18^{\circ} \mathrm{F} / \mathrm{min}\right) \text { heating rate. Using mass } \\
\text { spectroscopy analysis, none of the polymers under investigation produced ion } \\
\text { peaks at higher } \mathrm{m} / \mathrm{z} \text { than the monomer peaks. Intense peaks below } \mathrm{m} / \mathrm{z} 40 \\
\text { were observed during the initial stages of pyrolysis below } 623 \mathrm{~K}\left(662^{\circ} \mathrm{F}\right) \\
\text { indicating the formation of low relative molecular mass volatile compounds } \\
\text { such as ethylene and acetylene. The main decomposition started above } 673 \mathrm{~K} \\
\left(752^{\circ} \mathrm{F}\right) \text { resulting in mainly the monomer units. }\end{array}$ & $\begin{array}{l}\text { Fares et al. } \\
1994\end{array}$ \\
\hline Polyacrylonitrile & $\begin{array}{l}\text { The volatiles that evolve during thermolysis of polyacrylonitrile have been } \\
\text { studied using thermogravimetric analysis (TGA) infrared spectroscopy } \\
\text { (FTIR). Significant thermodegradation of polyacrylonitrile is somewhat } \\
\text { molecular weight dependent, but typically starts at a temperature of } 573 \mathrm{~K} \\
\left(572^{\circ} \mathrm{F}\right) \text {. For polyacrylonitrile samples that were polymerized with hydrogen } \\
\text { peroxide as the initiator, the thermodegradation commences with the } \\
\text { evolution of ammonia, hydrogen, cyanide, methane, water and carbon } \\
\text { monoxide. For commercial polyacrylonitrile, the water and carbon monoxide } \\
\text { products were not detected. }\end{array}$ & Xue et al. 1997 \\
\hline
\end{tabular}


Appendix B 


\section{APPENDIX C. BIOLOGICAL ACTIVITY}

Biological activity within TRU waste can be a source of gas generation. Although most TRU wastes lack sufficient substrate to support biological growth and do not provide an environment conducive to biological activity, some wastes that contain soils or other potentially biologically contaminated materials need to be evaluated for their potential to generate gases. The primary concern is the possible release of gases from biological systems within the waste that may cause an increase in containment vessel flammable gas concentration.

Growth of biological systems results when viable organisms utilize nutrients in the medium in which they are contained to sustain growth (Characklis 1988). Not all organic compounds are equally susceptible to microbial decomposition; the fraction that provides energy and carbon for bacterial growth has been called labile dissolved organic carbon (Wetzel and Manny 1972; Ogura 1975), biodegradable organic carbon (Joret et al. 1988), or assimilable organic carbon (Van der Kooij et al. 1982). Some forms of TRU waste and many of the packaging materials inside the containment vessel (plastics) are organic materials. The potential for microbial activity may exist if there is a suitable environment for the degradation of the organic substrates. Factors other than nutrients that influence growth or regrowth of bacteria in transportation packages include temperature (Fransolet et al. 1985), residence time in packaging (Maul 1985), and the efficacy of disinfecting techniques (Le Chevallier et al. 1988).

Many types of microorganisms should be considered in the degradation of TRU waste. Aerobic microorganisms, which produce carbon dioxide and water, require oxygen for growth. Aerobic organisms do not generate any flammable gases; any increase in pressure due to the carbon dioxide and water generated is somewhat offset by the oxygen consumed, especially if the conditions permit condensation of the water vapor. Anaerobic microorganisms, which can produce carbon dioxide, hydrogen, methane, and other products, degrade materials in oxygen-free environments (Hartel and Buckel 1996; Wang et al. 1971; Rowbottom 1993; Nakamura et al 1993; Kalia and Joshi 1995). Anaerobic microorganisms include facultative anaerobics, which can live with or without oxygen, and obligate anaerobics, which cannot tolerate any oxygen. Microorganisms most likely to be found in TRU waste products include bacteria and fungi. Bacteria utilize only the surface of the materials, whereas fungi can access the matrix of the material and are generally found in aerobic environments.

Of the various waste forms in TRU waste, only cellulosic materials are generally important in terms of the potential for gas generation via biological-induced degradation. Rubber or plastic materials are more resistant to microbial actions. The contribution of these compounds to the total gas generation will be negligible because of their inert nature. Sampling programs, where drums of TRU waste (in retrievable storage up to 15 years) were opened and examined for degradation, found little or no degradation of the packaging materials (NRC Docket No. 71-9218, Aug. 11, 1999). Even under conditions designed to promote microbial proliferation, rubber and plastic degrade very slowly, if at all. Similarly, solidified inorganic sludges, which have high alkalinity $(\mathrm{pH}=10-12)$ that is hostile for most common microorganisms, should not exhibit any significant microbial gas generation.

Examples of cellulosic materials that could be present in TRU waste are cotton and paper products. Biodegredation of cellulose, which is a polymer composed of chains of glucose monomers, requires hydrolysis of the polymer into monomer units. Biological depolymerization is a slow process. Wood is also present in TRU waste, but degrades at a much slower rate than cellulose alone because of the microbial-resistance of the lignin in wood. Since bacterial action is a strong function of surface area and substrate availability, TRU waste is typically not very conducive to high microbial activity as a result of 
its bulk material forms and the segregated nature of the materials (NRC Docket No. 71-9218, Aug. 11, 1999).

In addition, the availability of nutrients necessary for microbial growth is typically lacking in TRU waste transportation packages. Phosphorus levels are typically very low, and for cases where nitrogen is present, there is typically a lack of carbon substrate.

In summary, the environmental factors important to microbial growth, such as temperature, $\mathrm{pH}$, oxygen, moisture, and water availability, are sub-optimal or hostile in essentially all TRU waste transportation packages. These sub-optimal environmental conditions and the associated nutrient limitations will limit microbial activity to minimal levels; therefore, biological activity will contribute a minimal amount of gas during a shipment period of up to two years.

If the waste contains significant amounts of soil or other organic materials that may have been significantly inoculated with microbes, tests may be needed to determine the potential extent of biological gas production. An example of a case in which a TRU waste transportation package was shown to have significant amounts of biologically generated gas is documented in NRC Information Notice 90-50 (1990). In this case, the contents was demineralizer-filter resin that had been placed into liners, dewatered, and dried. It is believed that bacteria originating in a nearby heat exchanger were washed into a floor drain and became trapped in the demineralizer-filter. This example illustrates the need to evaluate TRU waste material to ascertain its potential for biological gas production. A possible test may include analyzing the waste for methane generation, which tends to be the most common flammable gas generated by biological activity. 


\section{APPENDIX D. RADIOLYTIC G-VALUES FOR VARIOUS MATERIALS \\ D.1 Radiolysis of Water}

The radiolysis of water has been studied more than that of any other compound. Using pulse radiolysis techniques, it has been shown (Sullivan 1983) that the primary decomposition products of pure water about $10^{-9}$ seconds after the irradiation pulse from a ${ }^{60} \mathrm{Co}$ gamma source are: $\mathrm{H}_{2} \mathrm{O} \rightarrow \mathrm{H}^{+}{ }_{\text {aq }}, \mathrm{OH}, \mathrm{e}^{-}, \mathrm{H}$, $\mathrm{H}_{2} \mathrm{O}_{2}, \mathrm{H}_{2}$, and $\mathrm{OH}^{-}$. The amounts of these products per $100 \mathrm{eV}$ absorbed $\left(\mathrm{G}_{\mathrm{R}}\right.$ values $)$ are respectively 2.9 , $2.75,2.65,0.65,0.70,0.45$, and 0.25 . Many of the water radiolysis decomposition products are reactive radicals and excited species (e.g., $\mathrm{e}^{-}{ }_{\mathrm{aq}}$ is a strong reducing agent, and $\mathrm{OH}^{-}$is a strong oxidizing agent) that undergo further reaction with each other and with the water molecules to give the final products. The $G$ values may vary slightly with energy and type of irradiation particle over a wide range of particles and energies (Sullivan 1983).

Experimental results for the radiolysis of water at room temperature show that $\mathrm{G}\left(\mathrm{H}_{2}\right)$ for water varies from 0.4 to 1.7 and that the bounding $\mathrm{G}\left(\mathrm{H}_{2}\right)$ for water subject to alpha radiation is 1.6. Representative results from studies on hydrogen generation from the radiolysis of water at room temperature are presented in Table D.1.

\section{D.2 Radiolysis of Unsubstituted Hydrocarbons}

\section{D.2.1 Saturated Hydrocarbons}

Saturated hydrocarbons contain only hydrogen and carbon atoms and single carbon-carbon bonds. As a group, saturated hydrocarbons include most common petroleum fuels, such as methane, propane, and octane. From experimental results on the radiolysis of saturated hydrocarbons, the bounding $\mathrm{G}\left(\mathrm{H}_{2}\right)$ value is 5.6 for saturated hydrocarbons in the liquid phase at room temperature in which the activity is due to alpha decay. Table D.2 lists experimental $G$ values for saturated hydrocarbons irradiated at room temperature in vacuum. The radiolytic $G$ values presented include $\mathrm{G}\left(\mathrm{H}_{2}\right), \mathrm{G}\left(\mathrm{CH}_{4}\right)$, and $\mathrm{G}$ (gas).

Some general observations have been noted concerning the radiolytic products from saturated hydrocarbons (Newton 1963). Normal saturated hydrocarbons yield principally hydrogen, with methane being produced only from the methyl end groups. Therefore, for normal hydrocarbons, the ratio of hydrogen to methane increases with increasing molecular weight. With branched-chain hydrocarbons, relatively more methane is produced, and the yield of methane increases with the number of methyl groups on the hydrocarbon chain. An activation energy for the $\mathrm{G}\left(\mathrm{H}_{2}\right)$ value for radiolysis of liquid neopentane and $n$-hexane, which is the energy required to initiate the reaction and is useful for calculating the temperature-dependence of the G-value, was measured to be approximately $3 \mathrm{kcal} / \mathrm{mole}$ (Hall 1963).

\section{D.2.2 Unsaturated Hydrocarbons}

Unsaturated hydrocarbons are hydrocarbons that have at least one double or triple carbon-carbon bond. Examples include acetylene, ethylene, 1-hexene, and cyclohexene. In general, for a given number of carbon atoms, unsaturated hydrocarbons exhibit lower radiolytic G-values than the corresponding saturated hydrocarbons. Table D.3 lists radiolytic $G$ values for several unsaturated hydrocarbons irradiated in vacuum at room temperature. 
Appendix D

\section{D.2.3 Aromatic Hydrocarbons}

Aromatic hydrocarbons have closed-ring structures with resonance-stabilized unsaturation of the carboncarbon bonds. The ability of the pi orbital systems in an aromatic molecule to dissipate energy throughout the system reduces the probability that excited or ionized aromatic molecules will dissociate. Examples of aromatic hydrocarbons include benzene, xylene, toluene, and discrete-ring polyphenyls.

Compared with normal hydrocarbons and unsaturated hydrocarbons, aromatic hydrocarbons have very low $\mathrm{G}$ values for hydrogen and total gas. As a result of the ability of aromatic compounds to absorb radiation energy and dissipate energy without molecular dissociation, aromatic compounds are good protective agents for a large number of chemicals (Newton 1963). For example, cyclohexene is protected from radiolytic decomposition by the addition of small amounts of benzene. Experimental radiolytic Gvalues for various aromatic hydrocarbons are presented in Table D.4. The bounding $G\left(H_{2}\right)$ value for aromatic hydrocarbons is about 0.6 .

\section{D.3 Radiolysis of Oxygenated Hydrocarbons}

\section{D.3.1 Alcohols}

Alcohols are compounds of the general formula $\mathrm{R}-\mathrm{OH}$, where $\mathrm{R}$ is any alkyl or substituted alkyl group. The group may be open-chain cyclic; it may contain a double bond, a halogen atom, or an aromatic ring. The functional group for alcohols is the hydroxyl group (-OH), which determines the general characteristics for this chemical family. Compounds in which the hydroxyl group is attached directly to an aromatic ring are called phenols, and their characteristics differ markedly from alcohols. Some experimental radiolytic $\mathrm{G}$ values for alcohols are listed in Table D.5. G-values for alcohols can be relatively high, with $\mathrm{G}\left(\mathrm{H}_{2}\right)$ for liquid methanol being about 5.4 .

\section{D.3.2 Ethers}

Ethers are compounds of the general formula $\mathrm{R}-\mathrm{O}-\mathrm{R}, \mathrm{Ar}-\mathrm{O}-\mathrm{R}$, or $\mathrm{Ar}-\mathrm{O}-\mathrm{Ar}$, where $\mathrm{R}$ is any alkyl or substituted alkyl group and $\mathrm{Ar}$ is any aromatic group. Table D.5 presents experimental $\mathrm{G}$ values for many ethers. The maximum $\mathrm{G}\left(\mathrm{H}_{2}\right)$ for the ethers listed is 3.6. Almost all radiolysis gases from ethers are flammable, and branching in the alkyl group tends to decrease hydrogen evolution but increase hydrocarbon yield (Hall 1963).

\section{D.3.3 Aldehydes \& Ketones}

Aldehydes are compounds of the general formula $\mathrm{RCHO}$; ketones are compounds of the general formula $R$ R'CO, with respective structures:

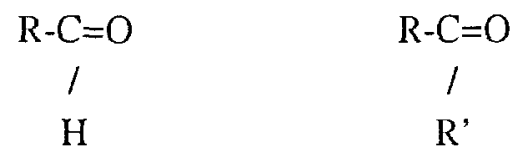

Aldehydes Ketones

Both aldehydes and ketones contain the carbonyl group, $\mathrm{C}=\mathrm{O}$, and are often referred to collectively as carbonyl compounds. Table D.5 presents experimental radiolytic $G$ values for several aldehydes and ketones. The maximum total $\mathrm{G}$ value for flammable gas production is 3.1 . 
Appendix D

\section{D.3.4 Carboxylic Acids}

Carboxylic acids contain the carboxyl group attached to either an alkyl group (RCOOH) or an aryl group $(\mathrm{ArCOOH})$, with respective structures:

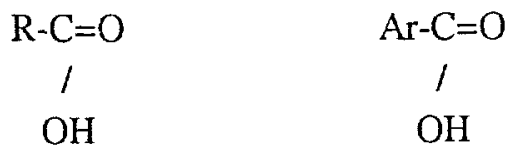

Table D.5 lists experimental radiolytic $\mathrm{G}$ values for two carboxylic acids that are liquids at room temperature.

\section{D.3.5 Esters}

Esters are functional derivatives of carboxylic acids in which the -OH of the carboxyl group is replaced by -OR'. (Phosphate esters are discussed separately.) The emulsifier for Envirostone, a gypsum-based material used to solidify organic and low $\mathrm{pH}$ aqueous sludges and liquid waste, has been identified as a polyethyl glycol ester. In addition, many plasticizers added to polymers to form commercial plastics are esters. Table D.5 presents experimental G-values for many esters. Benzyl acetate contains a benzene ring and has a much lower $\mathrm{G}\left(\mathrm{H}_{2}\right)$ value than the other esters.

\section{D.3.6 Phosphate Esters}

Phosphate esters have one of the following structures (Morrison and Boyd 1973):

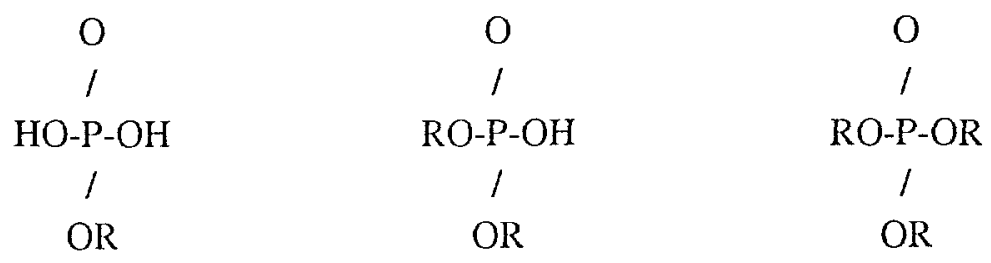

Tricresyl phosphate contains three benzene rings and has a much lower $\mathrm{G}\left(\mathrm{H}_{2}\right)$ value than either trioctyl or tributyl phosphate.

Tri-n-butyl phosphate (TBP), an organic ester of phosphoric acid, is used as an extractant in the reprocessing of nuclear fuel. Radiolysis experiments have been conducted to determine the decomposition products of TBP in different phases of the extraction system. The purex process uses a solution of TBP in dodecane (Ladrielle et al. 1983). Experiments were conducted using both gamma and alpha radiolysis of TBP and solutions of TBP in dodecane. The average alpha particle energy used in the radiolysis experiments was estimated to be $10.5 \mathrm{MeV}$ (alpha particles from a cyclotron). Radiolysis of pure TBP resulted in the formation of mono and dibutylphosphate, butanol, and saturated hydrocarbons (hydrocarbon chains from 5 to 11 carbon atoms long). Radiolysis of pure decane yielded saturated hydrocarbons. Holland (1978) performed gamma radiolysis experiments on TBP, dodecane, and mixtures of TBP and dodecane. The values of $\mathrm{G}\left(\mathrm{H}_{2}\right)=6.7$ and $\mathrm{G}\left(\mathrm{CH}_{4}\right)=0.05$ were determined for dodecane. Corresponding $G$ values for pure TBP were $\mathrm{G}\left(\mathrm{H}_{2}\right)=2.0$ and $\mathrm{G}\left(\mathrm{CH}_{4}\right)=0.3$. Radiolysis of mixtures of TBP and dodecane were found to yield less hydrogen than would be predicted by the mixture law, but the yield of acid was greater than that predicted by the mixture law.

Aromatic hydrocarbons, such as benzene, toluene, and cyclohexene protect TBP from radiolysis, while saturated hydrocarbons such as hexane, cyclohexane, and dodecane sensitize TBP to radiolytic degradation (Barney and Bouse 1977). Carbon tetrachloride has also been found to sensitize TBP 
radiolysis. Barney and Bouse (1977) found that chlorinated aromatic hydrocarbons also provide more protection to TBP for alpha radiolysis than did the chlorinated unsaturated hydrocarbons. Table D.5 presents radiolytic $G$ values for some common phosphate esters.

\section{D.4 Radiolysis of Halogenated Hydrocarbons}

Halogenated hydrocarbons are hydrocarbons in which at least one of the hydrogen atoms has been replaced by halogen atoms. Radiolysis of halogenated hydrocarbons can be strongly affected by the presence of oxygen or moisture, and chain reactions can occur involving $\mathrm{HCl}$ for chlorinated hydrocarbons. Experimental radiolysis G-values for some common halogenated hydrocarbons are given in Table D.6.

\section{D.4.1 Carbon Tetrachloride}

Radiolysis of carbon tetrachloride results in only two products: chlorine and hexachloroethane, which is not a gas. The observed $G$ value for both products are 0.65 and 0.75 for gamma radiation (Spinks and Woods 1976). When carbon tetrachloride is irradiated in the presence of oxygen, phosgene gas and chlorine are formed, each with a G value for gamma radiation of 4.3 (Spinks and Woods 1976).

\section{D.4.2 Aromatic Halides}

The aromatic halides chlorobenzene, bromobenzene, and idobenzene consist of a benzene ring with one hydrogen atom replaced by a chlorine, bromine, or iodine atom, respectively. Similar to the $\mathrm{G}\left(\mathrm{H}_{2}\right)$ values observed for the aromatic hydrocarbons, very low $\mathrm{G}\left(\mathrm{H}_{2}\right)$ values are found for the aromatic halides.

\section{D.4.3 Miscellaneous Halogenated Hydrocarbons}

Some of the halogenated hydrocarbons that may be present in TRU wastes are chloroform, methylene chloride, 1,1,1-trichloroethane, and 1,1,2-trichloro-1,2,2,-trifluoroethane (Freon-113). Measured values of $\mathrm{G}(\mathrm{HCl})$ of $\sim 5$ to 11 have been reported (Ottolenghi and Stein 1961; Chen et al. 1960) for pure chloroform at room temperature.

\section{D.5 Radiolysis of Organic Nitrogen Compounds}

Organic nitrogen compounds are basically hydrocarbons in which a functions group has been replaced by a $\mathrm{NO}_{2}, \mathrm{NH}_{2}$, or other group containing one or more nitrogen atoms. Experimental measured radiolytic $\mathrm{G}$ values for several organic nitrogen compounds subject to gamma radiation are presented in Table D.7. In addition to the radiolysis products listed in Table D.7, some of the compounds produced measurable quantities of ammonia (i.e., $\mathrm{G}\left(\mathrm{NH}_{3}\right)$ for aniline was 0.25 and $\mathrm{G}\left(\mathrm{NH}_{3}\right)$ for mono-n-butylamine was 4.0 ). Amines have the general formula $\mathrm{RNH}_{2}, \mathrm{R}_{2} \mathrm{NH}$, or $\mathrm{R}_{3} \mathrm{~N}$, where $\mathrm{R}$ is any alkyl or aryl group. In general, the radiolysis products of amines depend on the number of hydrogen atoms attached to the nitrogen atom. Similar to aromatic hydrocarbons, organic nitrogen compounds that have aromatic characteristics were found to have relatively low $\mathrm{G}$ values.

\section{D.6 Radiolysis of Commercial Lubricants}

Commercial lubricants are typically paraffinic, naphthenic, or aromatic hydrocarbons. G values have been measured for many commercial lubricants at room temperature using gamma and alpha radiation. Most experiments were conducted in vacuum, but some were conducted in air or oxygen environments. Some $\mathrm{G}$ values were observed to be essentially independent of adsorbed dose (Arakawa 1983). Some lubricants investigated included (1) Texaco Regal A motor oil, which is used in machining operations at 
the Rocky Flats Plant; (2) vacuum pump oil (DuoSeal); and (3) Rykon lubricating grease. A summary of the results of these radiolysis studies is provided in Table D.8.

\section{D.7 Radiolysis of Polymers}

Polymers, including polyethylene, PVC, and cellulose, are common organic solids found in TRU wastes. Other solids, such as solidified organic liquids, aqueous sludges, and bitumen are discussed in Section D.8. The controlling factor in the behavior of polymers under irradiation, as under most other environmental influences, is the chemical structure. This section provides both general information concerning the relative radiation resistance of polymers and experimental radiolysis results on various polymers. Generalized reasonable bounding values are then determined for classes of polymers based on functional groups.

Radiolysis of polymers generally results in two types of reactions: chain scission and crosslinking. Chain scission (degradation) is the term used for breaking of main-chain bonds in polymer molecules, which results in the formation of species of lower molecular weight. When scission of the polymer is predominate, structural strength and plasticity are rapidly lost. The polymer may eventually crumble to a powder. Crosslinking results in insoluble and infusible network structures because of increased molecular weight and size. Generally, competition occurs between the two reaction mechanisms.

Additives can be used to improve the aging properties of polymers subject to radiation. Commercial plastics and paper contain additives that modify the properties of the base polymer in the material. The additives generally improve the radiation stability of the commercial materials and reduce $G$ values for flammable gases. Organic additives can be subdivided into two categories: energy-sink materials, and chemical reactants. Energy sink materials are characterized by having aromatic characteristics and correspondingly low $\mathrm{G}$ values.

In the absence of oxygen, polymers can be divided into classes according to their tendency to degrade or crosslink. Polymers that predominantly crosslink when exposed to radiation have the following radiation resistance according to their functional groups and structure: aromatic $>$ unsaturated $>$ saturated. The radiation resistance of polymers that are borderline between crosslinking and scission generally follows: $S$-in main chain $>$ aromatic $>$ ester $>$ halogen $>$ saturated. For polymer that predominantly scission when exposed to radiation the radiation resistance ordering is: aromatic $>$ ester $>$ alcohol $>$ halogen $>$ saturated. Oxygen enhances the degradation of most polymers. Table D.9 summarizes some common polymers in order of their decreasing resistance when irradiated to net molecular-weight change for polymers that predominantly crosslink, are borderline between crosslinking and scission, or that predominantly undergo scission.

Polymers that are less radiation resistant tend to generate more flammable gas from radiolysis. Materials that have relatively high radiolytically-generated flammable gas production rates (i.e., G(flam gas) $=5-7$ ) include saturated hydrocarbons and polymers containing alcohol or ether functional groups. Materials that have moderate radiolytically-generated flammable gas production rates (i.e., $G($ flam gas) $=2-3$ ) include unsaturated hydrocarbons and polymers containing ester functional groups. Materials that have relatively low radiolytically-generated flammable gas production rates (i.e., G(flam gas)<1) include polymers with aromatic characteristics. A summary of the influence of chemical structure on flammable gas production rates is given in Table D.10. A summary of the maximum $G$ values observed for polymers containing only carbon, hydrogen, nitrogen, oxygen and halogens are listed in Table D.11. Relative $\mathrm{G}(\mathrm{gas})$ values for some miscellaneous commercial plastics are presented in Table D.12. 
Appendix D

The following sections provide brief descriptions of the results of radiolysis experiments at room temperature on selected polymers commonly found in TRU waste or used as confinement layers in TRU waste packages.

\section{D.7.1 Polyethylene}

Polyethylene is commonly found in TRU waste as shredded bottles and bags, and polyethylene bags and drum liners are commonly used as confinement layers in these packages. Polyethylene is made in two forms: low density polyethylene (LDPE) and high density polyethylene (HDPE). Unirradiated polyethylene melts to a viscous liquid at about 115 to $125^{\circ} \mathrm{C}\left(239\right.$ to $257^{\circ} \mathrm{F}$ ) (Spinks and Woods 1976). The $G$ values for gas species produced by the radiolysis of polyethylene depends on the presence or absence of oxygen.

When radiolysis experiments were performed on polyethylene in vacuum (using reactor radiation, electrons, gamma rays, or $\mathrm{x}$-rays), the bounding $\mathrm{G}\left(\mathrm{H}_{2}\right)$ value was generally 4.0 and the bounding $\mathrm{G}$ (flam gas) value was 4.1 (Chapiro 1962). One experiment performed in an oxygen-depleted gas atmosphere resulted in a $\mathrm{G}\left(\mathrm{H}_{2}\right)$ of 6.2 (Mandelkern 1972). This result seems to be an anomaly since all of the results by others indicate $\mathrm{G}\left(\mathrm{H}_{2}\right)$ values in the range of 2.0-4.0 (e.g., Zerwekh 1979; Kosiewicz 1981).

For the radiolysis of polyethylene in the presence of oxygen, almost all of the reported $\mathrm{G}\left(\mathrm{H}_{2}\right)$ values are less than 4.0. All $\mathrm{G}\left(\mathrm{H}_{2}\right)>4.0$ values reported in the literature are from experiments conducted prior to 1962. The credibility of the earlier experiments, in light of the large body of recent results that indicate lower $\mathrm{G}\left(\mathrm{H}_{2}\right)$ values, seems to be questionable. Many pre-1962 results are questionable because of difficulties in determining the absorbed dose when reactor radiation was used. Based on recent results for the radiolysis of polyethylene in vacuum, oxygen-present, and oxygen-depleted environments, reasonable bounding radiolytic $\mathrm{G}$ values for polyethylene are $\mathrm{G}\left(\mathrm{H}_{2}\right)=4.0$ and $\mathrm{G}($ flam gas $)=4.1$.

\section{D.7.2 Polypropylene}

Radiolysis experiments on polypropylene have been performed in oxygen and oxygen-depleted environments (Geymer 1973; Hegazy et al. 1981; Krasnansky et al. 1961; Hegazy 1986). The bounding radiolytic $\mathrm{G}$ values for these experiments were $\mathrm{G}\left(\mathrm{H}_{2}\right)=3.3, \mathrm{G}$ (flam gas)=3.4, and $\mathrm{G}$ (net gas)=3.4.

\section{D.7.3 Polyisobutylene}

A summary of several radiolysis experiments on polyisobutylene is given in Bohm's "Radiation Chemistry" (1982). These results indicate that bounding radiolytic $G$ values for polyisobutylene are $\mathrm{G}\left(\mathrm{H}_{2}\right)=1.6$ and $\mathrm{G}($ flam gas $)=2.4$.

\section{D.7.4 Polyvinylalcohol}

Gamma irradiation of polyvinyl alcohol indicated a bounding $\mathrm{G}\left(\mathrm{H}_{2}\right)$ value of 3.1, and $99 \%$ of the evolved gas was hydrogen (Okada 1967).

\section{D.7.5 Polyethylene Glycol}

Irradiation of polyethylene glycol, which has the commercial name of Carbowax, indicated a bounding $\mathrm{G}$ (flam gas) value of 3.5 , the gas consisting primarily of hydrogen and some methane, acetylene, and carbon monoxide (Nitta 1961). 


\section{D.7.6 Cellulose}

TRU waste may contain many different types of cellulose such as cotton cellulose, sulfite cellulose, wood cellulose, and they may have a wide range of crystallinity. In addition, many materials are made of or contain cellulose, such as paper, cloth, wood, Benelex, cellophane, cellulose acetate (rayon, molded items, paints, coatings), and ethyl cellulose (paints, molded items). Radiolysis experiments have been performed on many types of cellulose and on the various cellulose-containing products using gamma radiation, electrons, and alpha particles (Kosiewicz 1981; Zerwekh 1979; Ershov et al. 1986; Arthur 1970; Dalton et al. 1963). Based on the available experimental data, extremely conservative bounding G values for cellulose and cellulose products are estimated to be $\mathrm{G}\left(\mathrm{H}_{2}\right)=3.2, \mathrm{G}$ (flam gas) $=3.2$, and $\mathrm{G}$ (gas) $=10.2$. If sulfite cellulose and cotton cellulose are not present in the waste, reasonable bounding $\mathrm{G}$ values are estimated as $\mathrm{G}\left(\mathrm{H}_{2}\right)=1.4$ and $\mathrm{G}$ (flam gas) $=1.4$, and $\mathrm{G}$ (net gas)=6.2.

\section{D.7.7 Urea-Formaldehyde}

Urea-formaldehyde is a possible solidification medium for nuclear power reactor wastes. Although strongly dose dependent, the $\mathrm{G}$ values for doses corresponding to those seen in TRU waste packages during transportation are $\mathrm{G}\left(\mathrm{H}_{2}\right)=2.4, \mathrm{G}($ flam gas $)=2.4$, and $\mathrm{G}$ (net gas $)=2.8$.

\section{D.7.8 Polyoxymethylene}

A few authors have reported radiolysis results for polyoxymethylene (Krasnansky et al. 1961; Dole 1973; Sobashima et al. 1959; Nitta 1961). The radiolysis gases typically included about $15 \% \mathrm{H}_{2}, 67 \% \mathrm{CO}_{2}, 1 \%$ $\mathrm{CO}, 10 \% \mathrm{CH}_{4}, 1 \%$ methyl formate, $2 \%$ methyl ether, and $3 \%$ other gases (all volume percent). At room temperature, the bounding radiolytic $G$ values are estimated as $\mathrm{G}\left(\mathrm{H}_{2}\right)=2.1, \mathrm{G}$ (flam gas)=5.6, and $\mathrm{G}$ (net gas) $=14.1$.

\section{D.7.9 Polypropylene Oxide}

It has been determined (Geymer 1973) that polypropylene oxide is more susceptible to degradation under irradiation than polypropylene, and yields less hydrogen. The bounding $\mathrm{G}$ values for polypropylene oxide are $\mathrm{G}\left(\mathrm{H}_{2}\right)=1.0$, $\mathrm{G}(\mathrm{flam}$ gas $)=1.1$, and $\mathrm{G}($ net gas $) \cdot 1.4$. the bounding $\mathrm{G}$ values for polypropylene are $\mathrm{G}\left(\mathrm{H}_{2}\right)=1.1, \mathrm{G}(\mathrm{flam}$ gas $)=1.2$, and $\mathrm{G}($ net gas) 1.6 .

\section{D.7.10 Polyvinyl Formal}

From irradiation experiments in a graphite reactor, the $\mathrm{G}$ (gas) value for polyvinyl formal was found to be 1.4 times the value measured for polyethylene (NRC Docket No. 71-9218, Aug. 11, 1999).

\section{D.7.11 Polybutadiene and Polyisoprene}

Latex is the commercial name for polybutadiene and polyisoprene. The bounding $\mathrm{G}$ vales for Latex are estimated as $\mathrm{G}\left(\mathrm{H}_{2}\right)=0.7, \mathrm{G}($ flam gas $)=0.9$ and $\mathrm{G}$ (net gas)=0.9 (Kazanjian 1976; Zerwekh 1979; Bohm 1973).

\section{D.7.12 Polymethyl Methacrylate (PMMA)}

The main volatile products from the alpha radiolysis of PMMA are $\mathrm{H}_{2}, \mathrm{CO}_{2}, \mathrm{CO}, \mathrm{CH}_{4}$, propane and methyl methacrylate monomer (Kazanjian 1976; Zerwekh 1979; Chapiro 1962; Busfield et al. 1982; Bolt and Carroll 1963). Reasonable bounding $G$ values for the radiolysis of PMMA are estimated as $\mathrm{G}\left(\mathrm{H}_{2}\right)=0.4$, $\mathrm{G}$ (flam gas $)=2.0$, and $\mathrm{G}($ net gas $)=4.1$. 
Appendix D

\section{D.7.13 Polyvinyl Acetate}

The gamma radiolysis of polyvinyl acetate produced gaseous products with the following composition: $64 \% \mathrm{H}_{2}, 34 \% \mathrm{CH}_{4}$, and $2 \% \mathrm{CO}_{2}+\mathrm{CO}$ (Graessley 1973). The bounding $\mathrm{G}$ values for the radiolysis of polyvinyl acetate are estimated as $\mathrm{G}\left(\mathrm{H}_{2}\right)=0.9, \mathrm{G}$ (flam gas $)=1.4$, and $\mathrm{G}$ (net gas)=1.4.

\section{D.7.14 Polystyrene}

As a result of the aromatic rings in polystyrene, the $G$ values for the radiolysis of polystyrene are relatively low. The bounding $\mathrm{G}$ values for polystyrene are estimated as $\mathrm{G}\left(\mathrm{H}_{2}\right)=\mathrm{G}(\mathrm{flam}$ gas) $=0.2=\mathrm{G}$ (net gas) $=0.2$ (Busfield et al. 1982; Parkinson and Keyser 1973).

\section{D.7.15 Polysulfone}

Polysulfone subject to gamma and electron radiation indicated radiolytic $\mathrm{G}$ values of $\mathrm{G}\left(\mathrm{H}_{2}\right)=\mathrm{G}($ flam gas $)=\mathrm{G}$ (net gas) $=0.1$ (Giori and Yamauchi 1984)

\section{D.7.16 Polycarbonate}

When polycarbonate powder was exposed to gamma radiation in vacuum, the evolved gas was composed of carbon dioxide and carbon monoxide (Krasnansky et al. 1961; Amamiya and Sekigawa 1959). From these experiments, the bounding radiolytic $\mathrm{G}$ values are estimated as $\mathrm{G}\left(\mathrm{H}_{2}\right)=\mathrm{G}$ (flam gas)<0.1 and $\mathrm{G}$ (net gas) $=0.9$.

\section{D.7.17 Polyester}

Polyethylene terephthalate (PET) is the polymer upon which commercial polyesters, such as Dacron $\circledast$ and Mylar ${ }^{\circledR}$, are based. As a result of the aromatic character of PET, the $G$ values are relatively low. The bounding radiolytic $\mathrm{G}$ values are estimated as $\mathrm{G}\left(\mathrm{H}_{2}\right)=\mathrm{G}$ (flam gas) $=0.3$ and $\mathrm{G}$ (net gas) $<0.8$ (Krasnansky et al. 1961; Turner 1973; Bersch et al. 1959).

\section{D.7.18 Polyvinyl Chloride (PVC)}

PVC is often used as packaging material for TRU waste. In addition, various forms of PVC also appear in the waste itself. PVC and its copolymers are used in electrical components, in plastic tubing, and in gloves. Many radiolysis experiments have been performed on PVC in vacuum, in oxygen-depleted environments, and in the presence of oxygen (Kosiewicz 1981; Kazanjian 1976; Miller 1959; Szymanski et al. 1976; Hegazy et al. 1981; Arakawa et al 1986; Zahran et al. 1985). The highest value for $\mathrm{G}\left(\mathrm{H}_{2}\right)$ found for PVC was 0.7. Since $\mathrm{H}_{2}$ comprises almost all the flammable gases produced from the radiolysis of PVC, the bounding value for $\mathrm{G}$ (flam gas) is also 0.7. The value of $\mathrm{G}$ (net gas) obtained from the radiolysis of PVC depends strongly on whether the PVC is pure or commercial material and if oxygen is present. For commercial PVC, a reasonable bounding value for G(net gas) is estimated as 2.6.

The radiolysis of $\mathrm{PVC}$ generates relatively large amounts of $\mathrm{HCl}$, which is important in terms of potential corrosion of the packaging materials and the corresponding corrosion-related gas generation. In many experiments, the $\mathrm{G}(\mathrm{HCl})$ is not included in the $\mathrm{G}$ (net gas) as a result of the high reactivity of the $\mathrm{HCl}$ and the difficulty of extracting $\mathrm{HCl}$ gas from the test chamber before it reacts. The bounding value for $\mathrm{G}(\mathrm{HCl})$ for commercial PVC could be as high as 5.9 .

\section{D.7.19 Polychloroprene}

Neoprene rubber is composed of polychloroprene. Many gamma-radiolysis results of polychloroprene have been reported in the literature. The main gaseous products from the radiolysis of polychloroprene 
are $\mathrm{H}_{2}, \mathrm{HCl}, \mathrm{CO}, \mathrm{CO}_{2}$, and other miscellaneous short-chain hydrocarbons. The bounding radiolytic $\mathrm{G}$ values are estimated as $\mathrm{G}\left(\mathrm{H}_{2}\right)=\mathrm{G}(\mathrm{flam}$ gas $)=0.1$ and $\mathrm{G}$ (net gas) $=0.7$. The reasonable bounding $\mathrm{G}(\mathrm{HCl})$ for the radiolysis of polychloroprene is estimated as 0.06 .

\section{D.7.20 Chlorosulfonated Polyethylene}

Hapalon ${ }^{\circledR}$ gloves are composed of chlorosulfonated polyethylene. In addition lead oxide is often incorporated into the gloves to provide gamma shielding. Radiolysis experiments on commercial Hapalon ${ }^{\circledR}$ indicate that the bounding $\mathrm{G}$ values are $\mathrm{G}\left(\mathrm{H}_{2}\right)=\mathrm{G}($ flam gas) $=0.3$ and $\mathrm{G}$ (net gas) $=0.6$ (Kosiewicz 1981; Kazanjian 1976; Zerwekh 1979; Arakawa 1986).

\section{D.7.21 Polytetrafluoroethylene (PTFE) and Polychlorotrifluoroethylene}

Since both Polytetrafluoroethylene and Polychlorotrifluoroethylene contain no hydrogen in their base polymers, $\mathrm{G}\left(\mathrm{H}_{2}\right)$ and $\mathrm{G}$ (flam gas) for these materials is zero. Almost all the radiolysis gases produced by these compounds is $\mathrm{CO}_{2}$. The bounding $\mathrm{G}$ (net gas) value found was 1.1 (NRC Docket No. 71-9218, Aug. 11, 1999).

\section{D.7.22 Polyamides}

Polyamides are a class of compounds that include such commercial products as Nylon and Nomex. $\mathrm{G}$ values for polyamides can be bounded with $\mathrm{G}\left(\mathrm{H}_{2}\right)=1.1, \mathrm{G}$ (flam gas)=1.2, and $\mathrm{G}$ (net gas) $=1.5$ (Krasnansky et al. 1961; Dole 1983; Zimmerman 1973).

\section{D.7.23 Ion-Exchange Resins}

The $G$ values for synthetic organic resins, which comprise the vast majority of ion-exchange resins, depend on the resin and the ionic form of the resin (Pillay 1986). Of the many ion-exchange resins investigated, the bounding $G$ values were found to be $G\left(\mathrm{H}_{2}\right)=\mathrm{G}$ (flam gas)=1.7 and $\mathrm{G}$ (net gas)=2.1. Most $\mathrm{G}$ values for ion-exchange resins were much lower than the bounding values indicated. If an ionexchange resin is to compose a major portion of a waste shipment, determining the relevant $G$ values for that particular material may be useful.

\section{D.8 Radiolysis of Non-Polymer Solids}

Non-polymer solids include solidified liquid wastes, solid organic acids, asphalt, and miscellaneous inorganic solids.

\section{D.8.1 Radiolysis of Solidified Liquid Wastes}

Solidified liquid wastes include sludges, concretes, and gel-like or monolithic structures that bond liquid wastes so that free liquids are minimized.

\section{D.8.1.1 Aqueous Sludges}

Radiolysis experiments have been conducted (Kazanjian and Killion 1981) on a common sludge produced at the Rocky Flats Plant to determine the radiolytic gas yields as a function of water content and nitrate content. This sludge was produced by the neutralization of nitric acid solutions in the plutonium recovery process. The nitrate concentration in the material was determined to be $10.2 \mathrm{wgt} \%$, and the water content was 52 wgt. \%. The water content was varied by either drying or adding water to the as-received sludge, and the nitrate salts could be removed by washing the sludge with water. All experiments were conducted using gamma radiation (dose rate typically $4.45 \times 10^{5} \mathrm{rad} / \mathrm{hr}$ ) and a lowered pressure was used to permit accurate analysis of the evolved gases using mass spectroscopy. The results 
show that decreasing the water content of the sludge decreases the rate of gas generation. Small amounts of $\mathrm{CO}$ and $\mathrm{NO}_{\mathrm{x}}$ were also observed. Hydrogen evolution in sludge samples with depleted nitrate concentration and $65 \%$ water was up to three times greater than hydrogen evolution obtained from sludge samples containing nitrate. The measured value of $\mathrm{G}\left(\mathrm{H}_{2}\right)$ varied from 0.23 to 0.43 . (The largest $\mathrm{G}\left(\mathrm{H}_{2}\right)$ value observed (0.43) is very close to the value of 0.45 for $\mathrm{G}\left(\mathrm{H}_{2}\right)$ measured for gamma irradiation of liquid water at high pH.) A maximum value of $\mathrm{G}\left(\mathrm{O}_{2}\right)$ of 0.9 was found in the nitrate sludges from the radiolysis of nitrates. These findings are in agreement with other experiments on the radiolysis of nitric acid and solid inorganic nitrates.

Sludge from waste water processing at Mound Laboratory, composed primarily of carbon, iron, and calcium compounds immobilized in Portland cement, was contaminated with plutonium dioxide $(-20 \mu \mathrm{m}$ particle diameter) and the resulting radiolytic gas yields were analyzed. The $\mathrm{G}(\mathrm{gas})$ value measured was 0.21 , consisting almost entirely of hydrogen; the $\mathrm{G}\left(-\mathrm{O}_{2}\right)$ value was 0.13 (The $\mathrm{G}\left(-\mathrm{O}_{2}\right)$ value is the $\mathrm{G}$ value for the consumption of $\mathrm{O}_{2}$. (NRC Docket No. 71-9218, Aug. 11, 1999).

Gas generation from cemented caustic waste resulting from immobilization at Mound Laboratory of 1-N $\mathrm{NaOH}$ contaminated scrubber solution in Portland cement has been reported (Lewis 1983). The caustic waste was contaminated with plutonium dioxide (avg. particle size $\sim 20 \mu \mathrm{m}$ ). The caustic/cement waste form contained $22 \mathrm{wt} . \%$ water. The measured $\mathrm{G}$ (gas) value was 0.26 , consisting of about equal amounts of oxygen and hydrogen $\left[\mathrm{G}\left(\mathrm{O}_{2}\right)=0.11\right.$ and $\left.\mathrm{G}\left(\mathrm{H}_{2}\right)=0.13\right]$. A small amount of nitrogen was also generated.

\section{D.8.1.2 Cements}

The cement-based and other hydraulic binders used for immobilization of wastes require water in their curing reactions. Generally some excess water remains in the materials in a closed-pore system (e.g., Dole and Friedman 1986). Radiolysis of this unbound water results in gas generation in these solidified radioactive wastes. Experiments conducted in the temperature range of 70 to $100^{\circ} \mathrm{C}$ indicate that there is no temperature dependence on $\mathrm{G}\left(\mathrm{H}_{2}\right)$ for radiolysis of concrete, which is consistent with the temperature independence for the $\mathrm{G}\left(\mathrm{H}_{2}\right)$ of water (Bibler $1979 ; 1980$ ). The bounding $\mathrm{G}\left(\mathrm{H}_{2}\right)$ value for the alpha radiolysis of concrete was 0.6 , and the bounding $\mathrm{G}\left(\mathrm{H}_{2}\right)$ value for the gamma radiolysis of concrete was 0.03 . See Table D.13 for a summary of the radiolysis experiments on cements.

\section{D.8.1.3 Adsorbed or Absorbed Liquids}

During the radiolysis of adsorbed or absorbed liquids, the sorbing medium can either be inert to radiation or can transfer energy to the sorbed liquid. Unless experimental data demonstrate that the binding medium is radiolytically inert (e.g., vermiculite), for homogeneous mixtures all radiation energy should be assumed to interact with the sorbed liquid.

Radiolysis experiments conducted on octane sorbed onto vermiculite and commercial vacuum pump oil sorbed onto vermiculite indicate that the vermiculite acts as an inert diluent and that no energy transfer occurs between the vermiculite and the sorbed liquid (Bibler and Orebaugh 1978). $\mathrm{G}\left(\mathrm{H}_{2}\right)$ values were found to vary linearly with the mass fraction of organic material. The extrapolated $\mathrm{G}\left(\mathrm{H}_{2}\right)$ values for $100 \%$ liquid were 3.0 for octane and 1.6 for vacuum pump oil when high dose rates were used. At lower dose rates, the $\mathrm{G}\left(\mathrm{H}_{2}\right)$ values reported were 4.5 for octane and 2.0 for vacuum pump oil. The radiolysis gases were predominantly hydrogen and had the nominal ratio $\mathrm{H}_{2} / \mathrm{CO}_{2} / \mathrm{CH}_{4}=1.0 / 0.03 / 0.01$.

Studies of water adsorbed onto inorganic oxides $\left(\mathrm{SiO}_{2}, \mathrm{SiO}_{2}-\mathrm{Al}, \mathrm{SiO}_{2}-\mathrm{Ca}, \mathrm{Er}_{2} \mathrm{O}_{3}, \mathrm{La}_{2} \mathrm{O}_{3}\right.$, and $\left.\mathrm{Al}_{2} \mathrm{O}_{3}\right)$ subject to gamma radiation indicate that energy transfer can occur from the oxide to the water molecules (Garibov 1983). Values of $\mathrm{G}\left(\mathrm{H}_{2}\right)$ measure indicate that the energy transferred from the oxide to the 
absorbed water can be 3-5 times the energy originally absorbed by the water (based on its mass fraction). For water-inorganic oxide systems, an increase in temperature led to a decrease in $\mathrm{G}\left(\mathrm{H}_{2}\right)$, which was attributed to a greater desorption rate of water molecules from the oxide surface at the higher temperatures and the corresponding decrease in effective energy transfer from the oxide to the absorbed water molecules.

\section{D.8.2 Radiolysis of Solid Organic Acids}

$\mathrm{G}\left(\mathrm{H}_{2}\right)$ values for some organic acids that are solid at room temperature have been reported in the range from 1.2 to 2.3 (Bolt and Carroll 1963). G(gas) values for the same materials range from 1.8 to 4.1 . The maximum $\mathrm{G}$ value for flammable gas was 2.6. A value of $\mathrm{G}\left(\mathrm{CO}_{2}\right)$ of 14 has been reported for one of the organic acids (isobutyric acid) (Spinks and Woods 1976).

\section{D.8.3 Radiolysis of Asphalt}

A value of $\mathrm{G}$ (gas) for bitumen (asphalt) for low absorbed dose was estimated to be 1.3, with hydrogen being the primary gas evolved (Kosiewicz 1980). No dependence on temperature was observed from 20 to $70^{\circ} \mathrm{C}$. Gamma radiolysis experiments reported by Burnay (1987) measured lower G values.

\section{D.8.4 Radiolysis of Soil}

Gas evolved from plutonium-contaminated soil has been reported (Pajunen 1977). The soil was removed from the Z-9 trench at the Hanford site, which had been used as a liquid waste disposal site for the Plutonium Finishing Plant. The waste solutions deposited in the trench were acidic and consisted of (1) aluminum, magnesium, calcium, and other metal nitrate salt wastes, (2) degraded solvents (15\% tributyl phosphate or dibutyl phosphate in $\mathrm{CCl}_{4}$ ), and (3) other organics, such as solvent washings, fabrication oil, and other waste materials from hood and equipment flushings (Ludowise 1978). The top $30 \mathrm{~cm}$ of soil was sampled from the trench. The soil moisture content ranged between 0.2 and $25.5 \mathrm{wt}$. \%, averaging approximately $5 \mathrm{wt}$. \%. Organic content averaged $7.1 \mathrm{wt}$. \% with a range of 0.2 to $46.4 \mathrm{wt}$. \%. The highest value of G(gas) calculated from Pajunen's data was 1.6, for a soil having a combined organic and moisture content of about $15 \mathrm{wt}$. \%. The typical composition of the gas generated by the soils was $50 \% \mathrm{~N}_{2}, 14 \% \mathrm{O}_{2}, 23 \% \mathrm{H}_{2}$, and $13 \% \mathrm{CO}_{2}$ (percents for gases are volumetric).

Soil samples from Mound Laboratory property were contaminated with plutonium dioxide (particles averaging $\sim 20 \mu \mathrm{m}$ ) and analyzed for radiolytic gas generation. Gas generation was measured from a soil sample that contained about 5 wt. \% water. The $\mathrm{G}(\mathrm{gas})$ value was 0.22 , with $\mathrm{G}\left(\mathrm{H}_{2}\right)=0.15$ and $\mathrm{G}\left(\mathrm{CO}_{2}\right)=0.07$. Oxygen was consumed, with $\mathrm{G}\left(-\mathrm{O}_{2}\right)=0.10$ (NRC Docket No. 71-9218, Aug. 11, 1999).

\section{D.8.5 Radiolysis of Dry, Solid Inorganic Materials}

Dry, solid inorganic materials do not generate hydrogen but may produce other gases (frequently oxygen).

Some common inorganic chemicals used in processing aqueous wastes include ferric sulfate, calcium chloride, and magnesium sulfate. A treatment process has been identified (Kazanjian and Killion 1981) that produces a precipitate of hydrated oxides of iron, magnesium, aluminum, silicon, etc. In addition, various nitrates and carbonates can be present in dry solid inorganic materials.

For stoichiometric decomposition of nitrates, a value of $\mathrm{G}\left(\mathrm{O}_{2}\right)$ should be one-half of the $\mathrm{G}\left(\mathrm{NO}_{2}{ }^{-}\right)$value. A value of $\mathrm{G}\left(\mathrm{O}_{2}\right)<1.3$ has been determined (Johnson 1970). $\mathrm{G}$ values measured for gamma radiolysis of barium, potassium, and sodium chlorates had $\mathrm{G}(\mathrm{Cl}-)<1.8$ and $\mathrm{G}\left(\mathrm{O}_{2}\right)<4.0$. 
Appendix D

For alkali and alkaline earth perchlorates, values of $\mathrm{G}(\mathrm{Cl}-)<1.1$ and $\mathrm{G}\left(\mathrm{O}_{2}\right)<5.3$ were measured. Neither ozone nor free chlorine were detected in radiolytic gas generation measurements on dry solid inorganic materials.

\section{D.9 Radiolysis of Gases}

Radiolysis of the nitrogen/oxygen mixture found in air produces a small amount of ozone, as well as oxides of nitrogen (Spinks and Woods 1976). In a closed system, back reactions lead to an equilibrium concentration of these gases of a few ppm for ozone to a few percent for $\mathrm{NO}_{2}$ and $\mathrm{N}_{2} \mathrm{O}$. The $\mathrm{NO}$ yields are much smaller (Kazanjian and Brown 1969). When moisture is present, the main product is nitric acid, which is formed until the water vapor is exhausted (Spinks and Woods 1976; Kazanjian and Brown 1969). $G$ values for nitric acid formation are about 1.0 , but vary with water concentration (Kazanjian and Brown 1969).

Gaseous carbon dioxide is almost unaffected by ionizing radiation (Spinks and Woods 1976), possibly due to a back reaction between $\mathrm{CO}$ ozone to form $\mathrm{CO}_{2}$ and $\mathrm{O}_{2}$. 
Table D.1 Radiolytic $\mathrm{G}\left(\mathrm{H}_{2}\right)$ Values for Water at $298 \mathrm{~K}$

\begin{tabular}{|c|c|c|c|}
\hline Phase & $\mathbf{G}\left(\mathbf{H}_{2}\right)$ & Comments & References \\
\hline gas & 0.5 & gamma, electron & Spinks and Woods 1976 \\
\hline liquid & 0.4 & gamma, electron, $\mathrm{pH}=0.5$ & $\begin{array}{l}\text { Spinks and Woods 1976; Burns and Sims } \\
1981\end{array}$ \\
\hline liquid & 0.45 & gamma, electron, $\mathrm{pH}=3-13$ & $\begin{array}{l}\text { Spinks and Woods 1976; Burns and Sims } \\
1981\end{array}$ \\
\hline liquid & 1.1 & $6.4 \mathrm{MeV} \mathrm{He}++$ & Burns and Sims 1981 \\
\hline liquid & 1.3 & Cm-244 alpha $(5.8 \mathrm{MeV})$ & Bibler 1974 \\
\hline liquid & 1.6 & $5.3 \mathrm{MeV}$ alpha $(\mathrm{Po}), \mathrm{pH}=0.5$ & Spinks and Woods 1976 \\
\hline liquid & 1.7 & $\begin{array}{l}\text { Cf- } 252 \text { alpha, beta, fission frags, } 0.4 \mathrm{M} \\
\mathrm{H}_{2} \mathrm{SO}_{4}\end{array}$ & Bibler 1975 \\
\hline
\end{tabular}


Table D.2 Radiolytic G Values for Saturated Hydrocarbons at $298 \mathrm{~K}$

\begin{tabular}{|c|c|c|c|c|c|c|}
\hline Compound & Phase & $\mathbf{G}\left(\mathbf{H}_{2}\right)$ & $\mathrm{G}\left(\mathrm{CH}_{4}\right)$ & $\mathbf{G}$ (gas) & $\begin{array}{l}\text { Experimental } \\
\text { Conditions } \\
\end{array}$ & References \\
\hline propane & gas & 8.2 & 0.4 & NA & alpha, vacuum & Spinks and Woods 1976 \\
\hline n-butane & gas & 9 & 1.2 & NA & alpha, vacuum & Spinks and Woods 1976 \\
\hline isobutane & gas & 7.4 & 2.7 & NA & alpha, vacuum & Spinks and Woods 1976 \\
\hline pentane & gas & 7.3 & 0.8 & NA & alpha, vacuum & Spinks and Woods 1976 \\
\hline neopentane & gas & 2 & 2 & NA & alpha, vacuum & Spinks and Woods 1976 \\
\hline hexane & gas & 5.6 & 0.8 & NA & alpha, vacuum & Spinks and Woods 1976 \\
\hline pentane & liquid & 4.2 & 0.4 & NA & electron, vacuum & Spinks and Woods 1976 \\
\hline " & liquid & 4.2 & 0.2 & 5.4 & electron, vacuum & Hall 1963 \\
\hline hexane & liquid & 5 & 0.2 & 5.2 & electron, vacuum & Spinks and Woods 1976 \\
\hline$"$ & liquid & 5 & 0.1 & 7.2 & electron, vacuum & Hall 1963 \\
\hline cyclohexane & liquid & 5.6 & 0.1 & 5.7 & electron, vacuum & Spinks and Woods 1976 \\
\hline$"$ & liquid & 5.3 & 0.0 & 5.3 & alpha, vacuum & Spinks and Woods 1976 \\
\hline " & liquid & 7.7 & NA & NA & $\begin{array}{l}\text { fission frags, } \\
\text { vac. }\end{array}$ & Gaumann 1968?? \\
\hline heptane & liquid & 4.7 & 0.1 & NA & electron, vacuum & Spinks and Woods 1976 \\
\hline octane & liquid & 4.8 & 0.1 & NA & electron, vacuum & Spinks and Woods 1976 \\
\hline$"$ & liquid & 4.6 & 0.1 & NA & gamma, air & $\begin{array}{l}\text { Bibler and Orebaugh } \\
1978\end{array}$ \\
\hline$"$ & liquid & 4.2 & NA & NA & alpha, air & $\begin{array}{l}\text { Bibler and Orebaugh } \\
1978\end{array}$ \\
\hline nonane & liquid & 5 & 0.1 & $\mathrm{NA}$ & electron, vacuum & $\begin{array}{l}\text { Spinks and Woods 1976; } \\
\text { Bibler and Orebaugh } \\
1978\end{array}$ \\
\hline decane & liquid & 5.2 & 0.1 & NA & electron, vacuum & Spinks and Woods 1976 \\
\hline docedane & liquid & 4.9 & 0.1 & NA & electron, vacuum & Spinks and Woods 1976 \\
\hline hexadecane & liquid & 4.8 & 0.0 & NA & electron, vacuum & Spinks and Woods 1976 \\
\hline 2-methylpentane & liquid & 4.0 & 0.5 & NA & electron, vacuum & Spinks and Woods 1976 \\
\hline $\begin{array}{l}\text { 2,2-dimethyl- } \\
\text { butane }\end{array}$ & liquid & 2.0 & 1.2 & NA & electron, vacuum & Spinks and Woods 1976 \\
\hline neopentane & liquid & 1.6 & 3.7 & 5.6 & gamma, vacuum & Hall 1963 \\
\hline
\end{tabular}


Table D.3 Radiolytic G Values for Unsaturated Hydrocarbons at $298 \mathrm{~K}$

\begin{tabular}{|c|c|c|c|c|c|c|}
\hline Compound & Phase & $\mathrm{G}\left(\mathbf{H}_{2}\right)$ & $\mathrm{G}\left(\mathrm{CH}_{4}\right)$ & G(gas) & $\begin{array}{l}\text { Experimental } \\
\text { Conditions }\end{array}$ & References \\
\hline ethylene & gas & 1.2 & 0.1 & 2.8 & electron, vacuum & Hall 1963 \\
\hline cyclohexene & liquid & 1.3 & 0.0 & 1.3 & gamma, vacuum & $\begin{array}{l}\text { Spinks and Woods } \\
1976\end{array}$ \\
\hline$"$ & liquid & 3.0 & 0.0 & 3.0 & alpha, vacuum & $\begin{array}{l}\text { Spinks and Woods } \\
1976\end{array}$ \\
\hline 1-hexene & liquid & 0.8 & 0.0 & 0.8 & electron, vacuum & Hall 1963 \\
\hline
\end{tabular}


Table D.4 Radiolytic G Values for Common Aromatic Hydrocarbons at $298 \mathrm{~K}$

\begin{tabular}{|c|c|c|c|c|c|c|}
\hline Compound & Phase & $\mathbf{G}\left(\mathrm{H}_{2}\right)$ & $\mathrm{G}\left(\mathrm{CH}_{4}\right)$ & $\mathbf{G}$ (gas) & $\begin{array}{l}\text { Experimental } \\
\text { Conditions } \\
\end{array}$ & References \\
\hline benzene & liquid & 0.6 & 0.0 & 0.8 & alpha, vacuum & Spinks and Woods 1976 \\
\hline$"$ & liquid & $<0.1$ & $<0.1$ & $<0.1$ & gamma, vacuum & Spinks and Woods 1976 \\
\hline$"$ & liquid & $<0.1$ & $<0.1$ & $<0.1$ & electron, vacuum & IEEE S-146 1963 \\
\hline toluene & liquid & 0.6 & 0.0 & 0.6 & alpha, vacuum & Spinks and Woods 1976 \\
\hline$"$ & liquid & 0.1 & $<0.1$ & 0.1 & gamma, vacuum & Spinks and Woods 1976 \\
\hline$"$ & liquid & 0.1 & $<0.1$ & 0.1 & electron, vacuum & Hall 1963 \\
\hline p-xylene & liquid & 0.2 & 0.0 & 0.2 & gamma, vacuum & Spinks and Woods 1976 \\
\hline ethyl benzene & liquid & 0.2 & $<0.1$ & 0.2 & electron, vacuum & $\begin{array}{l}\text { Hall 1963; IEEE S-146 } \\
1963\end{array}$ \\
\hline$"$ & liquid & 0.2 & $<0.1$ & 0.2 & gamma, vacuum & Spinks and Woods 1976 \\
\hline " & liquid & 0.2 & $<0.1$ & 0.2 & reactor, vacuum & Hall 1963 \\
\hline $\begin{array}{l}\text { isopropyl } \\
\text { benzene }\end{array}$ & liquid & 0.2 & 0.1 & 0.3 & gamma, vacuum & Spinks and Woods 1976 \\
\hline$"$ & liquid & 0.2 & 0.1 & 0.3 & electron, vacuum & $\begin{array}{l}\text { Hall 1963; IEEE S-146 } \\
1963\end{array}$ \\
\hline$"$ & liquid & 0.3 & 0.1 & 0.4 & alpha, vacuum & IEEE S-146 1963 \\
\hline$"$ & liquid & 0.2 & 0.1 & 0.3 & reactor, vacuum & Hall 1963 \\
\hline $\begin{array}{l}\text { tert-butyl } \\
\text { benzene }\end{array}$ & liquid & 0.1 & 0.1 & 0.2 & electron, vacuum & $\begin{array}{l}\text { Hall 1963; IEEE S-146 } \\
1963\end{array}$ \\
\hline$"$ & liquid & 0.2 & $<0.1$ & 0.2 & reactor, vacuum & Hall 1963 \\
\hline mesitylene & liquid & 0.2 & $<0.1$ & 0.2 & electron, vacuum & Newton 1963 \\
\hline biphenyl & liquid & NA & NA & $<0.1$ & electron, vacuum & Hall 1963 \\
\hline “ & liquid & NA & $\mathrm{NA}$ & 0.1 & reactor, vacuum & Hall 1963 \\
\hline p-terphenyl & liquid & $<0.1$ & $<0.1$ & $<0.1$ & electron, vacuum & Hall 1963 \\
\hline “ & liquid & $<0.1$ & $<0.1$ & $<0.1$ & reactor, vacuum & Hall 1963 \\
\hline
\end{tabular}


Table D.5a Radiolytic G Values for Various Oxygenated Compounds at $298 \mathrm{~K}$

\begin{tabular}{|c|c|c|c|c|c|c|c|}
\hline Compound & Phase & $\mathbf{G}\left(\mathbf{H}_{2}\right)$ & $\mathrm{G}(\mathrm{CO})$ & $\mathrm{G}\left(\mathrm{CH}_{4}\right)$ & G(gas) & $\begin{array}{l}\text { Experimental } \\
\text { Conditions }\end{array}$ & References \\
\hline $\begin{array}{l}\text { Alcohols: } \\
\text { methanol }\end{array}$ & gas & 10.8 & 1.0 & 0.3 & 12.1 & gamma, vacuum & $\begin{array}{l}\text { Spinks and Woods } \\
1976\end{array}$ \\
\hline ethanol & gas & 10.8 & 1.2 & 0.9 & 12.9 & electron, vacuum & $\begin{array}{l}\text { Spinks and Woods } \\
1976\end{array}$ \\
\hline methanol & liquid & 5.4 & 0.1 & 0.7 & 6.2 & gamma, vacuum & $\begin{array}{l}\text { Spinks and Woods } \\
1976\end{array}$ \\
\hline “ & liquid & 3.5 & 0.2 & 0.4 & 4.5 & alpha, vacuum & IEEE S-146 1963 \\
\hline$"$ & liquid & 4.0 & 0.2 & 0.2 & 4.4 & gamma, vacuum & Hall 1963 \\
\hline ethanol & liquid & 5.0 & 0.1 & 0.6 & 5.7 & gamma, vacuum & $\begin{array}{l}\text { Spinks and Woods } \\
1976\end{array}$ \\
\hline “ & liquid & 3.5 & 0.1 & 0.4 & 4.5 & alpha, vacuum & IEEE S-146 1963 \\
\hline “ & liquid & 4.1 & 0.1 & 0.4 & 4.6 & alpha, vacuum & Hall 1963 \\
\hline 1-propanol & liquid & 4.4 & & & 4.4 & gamma, vacuum & $\begin{array}{l}\text { Spinks and Woods } \\
1976\end{array}$ \\
\hline “ & liquid & 2.8 & 0.1 & 0.1 & 3.0 & alpha, vacuum & Hall 1963 \\
\hline 2-propanol & liquid & 3.7 & & 1.5 & 5.2 & gamma, vacuum & $\begin{array}{l}\text { Spinks and Woods } \\
1976\end{array}$ \\
\hline n-propanol & liquid & 2.8 & & 0.1 & 3.9 & alpha, vacuum & IEEE S-146 1963 \\
\hline 1-butanol & liquid & 4.6 & & & 4.6 & gamma, vacuum & $\begin{array}{l}\text { Spinks and Woods } \\
1976\end{array}$ \\
\hline “ & liquid & 3.6 & 0.1 & 0.1 & 4.3 & alpha, vacuum & Hall 1963 \\
\hline t-butanol & liquid & 1.0 & & 3.6 & 4.6 & gamma, vacuum & $\begin{array}{l}\text { Spinks and Woods } \\
1976\end{array}$ \\
\hline n-butanol & liquid & 3.6 & & 0.1 & 4.3 & alpha, vacuum & IEEE S-146 1963 \\
\hline 1-octanol & liquid & 3.5 & 0.1 & $<0.1$ & 3.7 & alpha, vacuum & Hall 1963 \\
\hline 1-decanol & liquid & 3.5 & $<0.1$ & $<0.1$ & 3.6 & alpha, vacuum & Hall 1963 \\
\hline
\end{tabular}


Table D.5b Radiolytic G Values for Various Oxygenated Compounds at $298 \mathrm{~K}$

\begin{tabular}{|c|c|c|c|c|c|c|c|}
\hline Compound & Phase & $\mathbf{G}\left(\mathrm{H}_{2}\right)$ & $\mathrm{G}(\mathrm{CO})$ & $\mathrm{G}\left(\mathrm{CH}_{4}\right)$ & G(gas) & $\begin{array}{l}\text { Experimental } \\
\text { Conditions }\end{array}$ & References \\
\hline \multicolumn{8}{|l|}{ Ethers: } \\
\hline ethyl ether & liquid & 3.4 & NA & 0.4 & 3.8 & gamma, vacuum & $\begin{array}{l}\text { Spinks and Woods } \\
1976\end{array}$ \\
\hline “ & liquid & 3.6 & 0.1 & 0.2 & 3.9 & alpha, vacuum & Hall 1963 \\
\hline $\begin{array}{l}\text { ethyl n-butyl } \\
\text { ether }\end{array}$ & liquid & 3.3 & 0.1 & 0.1 & 3.5 & alpha, vacuum & Hall 1963 \\
\hline dibutyl ether & liquid & 2.9 & NA & 0.1 & 3.0 & gamma, vacuum & $\begin{array}{l}\text { Spinks and Woods } \\
1976\end{array}$ \\
\hline n-butyl ether & liquid & 2.7 & 0.1 & 0.1 & 2.9 & alpha, vacuum & Hall 1963 \\
\hline $\begin{array}{l}\text { ethyl tertbutyl } \\
\text { ether }\end{array}$ & liquid & 2.0 & 0.1 & 0.8 & 2.9 & alpha, vacuum & Hall 1963 \\
\hline isopropyl ether & liquid & 2.2 & $<0.1$ & 1.5 & 8.4 & gamma, vacuum & Newton 1963 \\
\hline “ & liquid & 2.4 & 0.1 & 0.9 & 5.8 & alpha, vacuum & Newton 1963 \\
\hline $\begin{array}{l}\text { d-isopropyl } \\
\text { ether }\end{array}$ & liquid & 2.4 & NA & 1.7 & 4.1 & gamma, vacuum & $\begin{array}{l}\text { Spinks and Woods } \\
1976\end{array}$ \\
\hline dioxan & liquid & 2.1 & 0.3 & NA & 2.4 & gamma, vacuum & $\begin{array}{l}\text { Spinks and Woods } \\
1976\end{array}$ \\
\hline tetrahydrofuran & liquid & 2.6 & NA & NA & 2.6 & Gamma, vacuum & $\begin{array}{l}\text { Spinks and Woods } \\
1976\end{array}$ \\
\hline \multicolumn{8}{|l|}{$\begin{array}{l}\text { Aldehydes \& } \\
\text { Ketones: }\end{array}$} \\
\hline propion-aldehyde & liquid & 1.2 & 1.6 & 0.1 & 4.4 & electron, vacuum & Hall 1963 \\
\hline acetone & liquid & 0.96 & 0.56 & 1.76 & 3.62 & 60-Co-gamma & $\begin{array}{l}\text { Spinks and Woods } \\
1976\end{array}$ \\
\hline$"$ & liquid & 1.47 & 0.8 & 0.97 & 3.86 & $6.9 \mathrm{MeV}$ He ions & $\begin{array}{l}\text { Spinks and Woods } \\
1976\end{array}$ \\
\hline “ & liquid & 2.36 & 1.05 & 0.99 & 5.17 & $67 \mathrm{MeV}$ C-ions & $\begin{array}{l}\text { Spinks and Woods } \\
1976\end{array}$ \\
\hline “ & liquid & 2.71 & 1.22 & 0.96 & 5.77 & 65.7 MeV $\mathrm{N}$ ions & $\begin{array}{l}\text { Spinks and Woods } \\
1976\end{array}$ \\
\hline “ & liquid & 1.0 & 0.6 & 1.8 & 3.6 & gamma, vacuum & $\begin{array}{l}\text { Spinks and Woods } \\
1976\end{array}$ \\
\hline “ & liquid & 1.5 & 0.8 & 1.0 & 3.9 & alpha, vacuum & $\begin{array}{l}\text { Spinks and Woods } \\
1976\end{array}$ \\
\hline “ & liquid & 0.9 & 0.8 & 2.6 & 4.8 & gamma, vacuum & Hall 1963 \\
\hline $\begin{array}{l}\text { methyl ethyl } \\
\text { ketone }\end{array}$ & liquid & 1.2 & 0.8 & 0.9 & 6.8 & gamma, vacuum & Hall 1963 \\
\hline diethyl ketone & liquid & 1.2 & 1.5 & 0.1 & 7.7 & gamma, vacuum & Hall 1963 \\
\hline
\end{tabular}


Table D.5c Radiolytic G Values for Various Oxygenated Compounds at $298 \mathrm{~K}$

\begin{tabular}{|c|c|c|c|c|c|c|c|}
\hline Compound & Phase & $\mathbf{G}\left(\mathbf{H}_{2}\right)$ & $\mathrm{G}(\mathrm{CO})$ & $\mathrm{G}\left(\mathrm{CH}_{4}\right)$ & G(gas) & $\begin{array}{l}\text { Experimental } \\
\text { Conditions } \\
\end{array}$ & References \\
\hline \multicolumn{8}{|l|}{ Carboxylic Acids: } \\
\hline acetic acid & liquid & 0.5 & 0.2 & 3.9 & 10.5 & gamma, vacuum & $\begin{array}{l}\text { Spinks and Woods } \\
1976\end{array}$ \\
\hline$"$ & liquid & 0.5 & 0.4 & 1.4 & 7.2 & alpha, vacuum & $\begin{array}{l}\text { Spinks and Woods } \\
1976\end{array}$ \\
\hline propionic acid & liquid & 0.8 & 0.3 & 0.5 & 5.5 & alpha, vacuum & Hall 1963 \\
\hline \multicolumn{8}{|l|}{ Esters: } \\
\hline methyl acetate & liquid & 0.8 & 1.6 & 2.0 & 5.7 & gamma, vacuum & $\begin{array}{l}\text { Spinks and Woods } \\
1976\end{array}$ \\
\hline$"$ & liquid & 0.9 & 1.6 & 2.1 & 5.6 & gamma, vacuum & Hall 1963 \\
\hline$"$ & liquid & 0.6 & 1.2 & 0.8 & 3.4 & electron, vacuum & Hall 1963 \\
\hline ethyl acetate & liquid & 0.9 & 1.1 & 1.6 & 3.6 & gamma, vacuum & Hall 1963 \\
\hline isopropyl acetate & liquid & 0.9 & 1.2 & 0.9 & 5.6 & alpha, vacuum & Hall 1963 \\
\hline$"$ & liquid & 0.5 & 0.8 & 1.0 & 3.6 & electron, vacuum & Hall 1963 \\
\hline n-propyl acetate & liquid & 0.8 & 1.1 & 0.4 & 4.0 & electron, vacuum & Hall 1963 \\
\hline benzyl acetate & liquid & 0.1 & 0.2 & 0.8 & 2.7 & electron, vacuum & Hall 1963 \\
\hline $\begin{array}{l}\text { di(2-ethyl) hexyl } \\
\text { sebacate }\end{array}$ & liquid & 1.0 & 0.3 & $<0.1$ & 1.8 & electron, vacuum & IEEE S-146 1963 \\
\hline$"$ & liquid & 1.0 & 0.3 & $<0.1$ & 1.5 & gamma, vacuum & Arakawa et al. 1983 \\
\hline $\begin{array}{l}\text { di(2-ethyl- hexyl) } \\
\text { adipate }\end{array}$ & liquid & 0.9 & 0.5 & $<0.1$ & 1.7 & gamma, vacuum & Arakawa et al. 1983 \\
\hline $\begin{array}{l}\text { pentaerythritol } \\
\text { ester }\end{array}$ & liquid & 0.8 & 0.8 & $<0.1$ & 1.9 & gamma, vacuum & Arakawa et al. 1983 \\
\hline \multicolumn{8}{|l|}{ Phosphate Esters: } \\
\hline $\begin{array}{l}\text { tricresyl } \\
\text { phosphate }\end{array}$ & liquid & 0.05 & $<0.1$ & $<0.1$ & 0.06 & gamma, vacuum & Arakawa et al. 1983 \\
\hline tributyl phosphate & liquid & 2.0 & $\mathrm{NA}$ & 0.3 & 2.3 & gamma & Holland et al. 1978 \\
\hline
\end{tabular}


Table D.6 Radiolytic G Values for Halogenated Hydrocarbons at 298 K

\begin{tabular}{|c|c|c|c|c|c|c|c|}
\hline Compound & Phase & $\mathbf{G}\left(\mathbf{H}_{2}\right)$ & $\mathbf{G}(\mathrm{HCl})$ & $\mathbf{G}\left(\mathbf{F}_{2}\right)$ & G(gas) & $\begin{array}{l}\text { Experimental } \\
\text { Conditions } \\
\end{array}$ & References \\
\hline $\begin{array}{l}\text { carbon } \\
\text { tetrachloride }\end{array}$ & liquid & $0.7-0.8$ & $0.7-0.8$ & NA & NA & gamma, vacuum & $\begin{array}{l}\text { Spinks and Woods } \\
\text { 1976; IEEE S-146 } \\
1963\end{array}$ \\
\hline$"$ & liquid & NA & NA & NA & 8.6 & gamma, oxygen & $\begin{array}{l}\text { Spinks and Woods } \\
1976\end{array}$ \\
\hline$"$ & liquid & NA & NA & NA & 0.6 & alpha, air & Kazanjian 1976 \\
\hline chlorobenzene & liquid & $<0.1$ & 1.4 & $<0.1$ & 1.4 & gamma, vacuum & $\begin{array}{l}\text { Spinks and Woods } \\
1976\end{array}$ \\
\hline bromobenzene & liquid & $<0.1$ & 2.3 & 0.2 & 2.5 & gamma, vacuum & $\begin{array}{l}\text { Spinks and Woods } \\
1976\end{array}$ \\
\hline idobenzene & liquid & $<0.1$ & $<0.1$ & 2.0 & 2.0 & gamma, vacuum & $\begin{array}{l}\text { Spinks and Woods } \\
1976\end{array}$ \\
\hline $\begin{array}{l}111- \\
\text { trichloroethane }\end{array}$ & liquid & 0.2 & NA & NA & 0.7 & alpha & Kazanjian 1976 \\
\hline$"$ & liquid & NA & 0.4 & NA & NA & gamma & Getoff and Lutz 1985 \\
\hline Freons & liquid & NA & NA & NA & $2.6 \max$ & gamma & $\begin{array}{l}\text { Alfassi 1982; Alfassi } \\
\text { and Heusinger } 1983\end{array}$ \\
\hline chloroform & liquid & NA & $5-11$ & NA & NA & gamma, vacuum & $\begin{array}{l}\text { Ottolenghi and Stein } \\
\text { 1961; Chen et al. } \\
1960\end{array}$ \\
\hline $\begin{array}{l}\text { methylene } \\
\text { chloride }\end{array}$ & liquid & NA & 4.9 & NA & NA & gamma, vacuum & IEEE S-146 1963 \\
\hline trichloroethlyene & liquid & NA & 0.25 & NA & NA & gamma, vacuum & $\begin{array}{l}\text { Kazanjian and } \\
\text { Horrell 1971; } \\
\text { Kazanjian and Brown } \\
1969\end{array}$ \\
\hline$"$ & liquid & NA & $\begin{array}{l}\mathrm{G}\left(\mathrm{H}^{+}\right)= \\
4600\end{array}$ & $\mathrm{NA}$ & NA & gamma, $\mathrm{O}_{2}$ & $\begin{array}{l}\text { Kazanjian and Brown } \\
1969\end{array}$ \\
\hline
\end{tabular}


Table D.7 Radiolytic G values for Organic Nitrogen Compounds at $298 \mathrm{~K}$

\begin{tabular}{|c|c|c|c|c|c|}
\hline Compound & Phase & $\mathbf{G}\left(\mathbf{H}_{2}\right)$ & G(gas) & $\begin{array}{l}\text { Experimental } \\
\text { Conditions }\end{array}$ & References \\
\hline nitromethane & liquid & $\mathrm{NA}$ & 2.0 & gamma, vacuum & $\begin{array}{l}\text { Spinks and Woods } \\
1976\end{array}$ \\
\hline nitrobenzene & liquid & NA & 0.16 & gamma, vacuum & $\begin{array}{l}\text { Spinks and Woods } \\
1976\end{array}$ \\
\hline acetonitrile & liquid & 0.67 & 1.52 & gamma, vacuum & $\begin{array}{l}\text { Spinks and Woods } \\
1976\end{array}$ \\
\hline methylamine & liquid & 5.4 & 5.58 & gamma, vacuum & $\begin{array}{l}\text { Spinks and Woods } \\
1976\end{array}$ \\
\hline aniline & liquid & 0.12 & 0.41 & gamma, vacuum & $\begin{array}{l}\text { Spinks and Woods } \\
1976\end{array}$ \\
\hline propionamide & liquid & 0.14 & 3.67 & gamma, vacuum & $\begin{array}{l}\text { Spinks and Woods } \\
1976\end{array}$ \\
\hline pyrrole & liquid & 0.2 & $\mathrm{NA}$ & gamma, vacuum & $\begin{array}{l}\text { Spinks and Woods } \\
1976\end{array}$ \\
\hline 3-pyrroline & liquid & 2.34 & $\mathrm{NA}$ & gamma, vacuum & $\begin{array}{l}\text { Spinks and Woods } \\
1976\end{array}$ \\
\hline pyrollidine & liquid & 6.35 & $\mathrm{NA}$ & gamma, vacuum & $\begin{array}{l}\text { Spinks and Woods } \\
1976\end{array}$ \\
\hline pyrazole & liquid & 0.04 & 0.16 & gamma, vacuum & $\begin{array}{l}\text { Spinks and Woods } \\
1976\end{array}$ \\
\hline tetrazole & liq̣uid & trace & 0.96 & gamma, vacuum & $\begin{array}{l}\text { Spinks and Woods } \\
1976\end{array}$ \\
\hline pyridine & liquid & 0.025 & $\mathrm{NA}$ & gamma, vacuum & $\begin{array}{l}\text { Spinks and Woods } \\
1976\end{array}$ \\
\hline pyrimidine & liquid & 0.03 & $\mathrm{NA}$ & gamma, vacuum & $\begin{array}{l}\text { Spinks and Woods } \\
1976\end{array}$ \\
\hline $\begin{array}{l}\text { mono-n- } \\
\text { butylamine }\end{array}$ & liquuid & 5.6 & 10.1 & $\begin{array}{l}\operatorname{gamma}, \mathrm{G}(\mathrm{HC})=0.5^{*} \\
\mathrm{G}\left(\mathrm{NH}_{3}\right)=4.0\end{array}$ & Mirichi 1981 \\
\hline dibutylamine & liquid & 3.6 & NA & gamma, $\mathrm{G}(\mathrm{HC})=0.5$ & Mirichi 1981 \\
\hline tri-n-butyl amine & liquid & 2.7 & $\mathrm{NA}$ & gamma, $\mathrm{G}(\mathrm{HC})=0.5$, & Mirichi 1981 \\
\hline
\end{tabular}


Table D.8 Radiolytic G Values for Common Commercial Lubricants at $298 \mathrm{~K}$

\begin{tabular}{|c|c|c|c|c|}
\hline Lubricant & Radiation & G Values & $\begin{array}{l}\text { Experimental } \\
\text { Conditions } \\
\end{array}$ & References \\
\hline Silicones & gamma & $\begin{array}{l}\mathrm{G}(\mathrm{gas})=2.3 ; \mathrm{G}\left(\mathrm{H}_{2}\right)=0.6 ; \\
\mathrm{G}\left(\mathrm{CH}_{4}\right)=1.4 ; \mathrm{G}\left(\mathrm{C}_{2} \mathrm{H}_{6}\right)=0.3\end{array}$ & vacuum & $\begin{array}{l}\text { Arakawa et al. } \\
1983\end{array}$ \\
\hline $\begin{array}{l}\text { Texaco } \\
\text { Regal-A } \\
\text { motor oil }\end{array}$ & alpha & $\begin{array}{l}G(\text { gas })=2.9 ; G\left(H_{2}\right)=2.8 \\
G(H C)=0.1\end{array}$ & $\begin{array}{l}\text { air, mixed w/ calcium } \\
\text { silicate to form paste }\end{array}$ & $\begin{array}{l}\text { Kazanjian } \\
1976\end{array}$ \\
\hline$"$ & gamma & $\mathrm{G}\left(\mathrm{H}_{2}\right)=2.3$ & vacuum; $8.4 \mathrm{Mrad}$ & $\begin{array}{l}\text { Kazanjian and } \\
\text { Brown } 1969\end{array}$ \\
\hline " & gamma & $\mathrm{G}\left(\mathrm{H}_{2}\right)=1.8$ & 500 torr $\mathrm{O}_{2} ; 8.4 \mathrm{Mrad}$ & $\begin{array}{l}\text { Kazanjian and } \\
\text { Brown } 1969\end{array}$ \\
\hline$"$ & gamma & $\mathrm{G}\left(\mathrm{H}_{2}\right)=2.1$ & 500 torr $\mathrm{O}_{2} ; 1.4 \mathrm{Mrad}$ & $\begin{array}{l}\text { Kazanjian and } \\
\text { Brown } 1969\end{array}$ \\
\hline $\begin{array}{l}\text { DuoSeal } \\
\text { vacuum } \\
\text { pump oil }\end{array}$ & $\begin{array}{l}\text { alpha } \\
\text { (Pu-238) }\end{array}$ & $\mathrm{G}(\mathrm{gas})=1.7 ; \mathrm{G}\left(\mathrm{H}_{2}\right)=1.6$ & $\begin{array}{l}\text { air; sorbed on } \\
\text { vermiculite }\end{array}$ & Zerwekh 1979 \\
\hline$"$ & $\begin{array}{l}\text { alpha } \\
(\mathrm{Cm}-244)\end{array}$ & $\begin{array}{l}\mathrm{G}(\text { gas })=2.8 ; \mathrm{G}\left(\mathrm{H}_{2}\right)=2.7 \\
\mathrm{G}\left(\mathrm{CO}_{2}\right)=0.1\end{array}$ & air & $\begin{array}{l}\text { Bibler and } \\
\text { Orebaugh } \\
1978\end{array}$ \\
\hline$"$ & gamma & $\begin{array}{l}\mathrm{G}(\text { gas })=2.1 ; \mathrm{G}\left(\mathrm{H}_{2}\right)=2.0 \\
\mathrm{G}\left(\mathrm{CO}_{2}\right)=0.1\end{array}$ & air & $\begin{array}{l}\text { Bibler and } \\
\text { Orebaugh } \\
1978\end{array}$ \\
\hline $\begin{array}{l}\text { Rycon } \\
\text { lubricating } \\
\text { grease }\end{array}$ & $\begin{array}{l}\text { gamma } \\
(\text { Co-60) }\end{array}$ & $\mathrm{G}\left(\mathrm{H}_{2}\right)=1.0$ & vacuum \& air & $\begin{array}{l}\text { Kazanjian and } \\
\text { Brown } 1969\end{array}$ \\
\hline
\end{tabular}


Table D.9 Radiation Resistance of Some Common Polymers at $298 \mathrm{~K}$

\begin{tabular}{ll} 
(listed in order of decreasing resistance to net molecular-weight change) \\
\hline Radiation resistance of common polymers that predominately crosslink \\
\hline Polymer & Characteristics \\
\hline poly(vinyl carbazole) & aromatic, $\mathrm{N}$ in main chain \\
polystyrene & aromatic \\
analine-formaldehyde & aromatic, N in main chain \\
nylon & N in main chain (amide) \\
polymethyl acrylate & ester \\
polyacrylonitrile & C-N triple bond \\
styrene-butadiene rubber & aromatic, unsaturated \\
polybutadiene & unsaturated \\
polyisoprene & unsaturated \\
nitrile-butadiene rubber & $\mathrm{C}-\mathrm{N}$ triple bond, unsaturated \\
polyethylene oxide & ether \\
polyvinyl acetate & ester \\
polyvinyl methyl ether & ether \\
polyethylene & saturated \\
silicone & saturated \\
\hline Radiation resistance of common polymers that are borderline between predominant \\
crosslinking and scission
\end{tabular}


Table D.10 Expected Relative G(flam gas) Values for Structurally Related Polymers Containing Only Carbon, Hydrogen, Nitrogen, and Oxygen

\begin{tabular}{l}
\hline High [liquid G(flam gas) $=\mathbf{5}-\mathbf{7}$ ] \\
\hline hydrocarbon polymers containing only saturated C-C \\
bonds \\
Polymers containing alcohol functional groups \\
Polymers containing ether functional groups \\
\hline Medium [liquid G(flam gas) $=\mathbf{2}-\mathbf{3}$ ] \\
\hline Hydrocarbon polymers containing unsaturated C-C bonds \\
Polymers containing ester functional groups \\
\hline Low [liquid G(flam gas) < 1 \\
\hline Polymers with aromatic characteristics \\
\hline
\end{tabular}


Table D.11 Summary of Maximum G Values for Various Classes of Polymers at $298 \mathrm{Ka}$

\begin{tabular}{|c|c|c|c|c|}
\hline Group & Polymer & $\mathbf{G}\left(\mathbf{H}_{2}\right)$ & G(flam gas) & $\mathbf{G}(\text { net gas) })^{b}$ \\
\hline Saturated- & polyethylene & 4.0 & 4.1 & 4.1 \\
\hline \multirow[t]{3}{*}{ Hydrocarbons } & polypropylene & 3.3 & 3.4 & 3.4 \\
\hline & ethylene-propylene & c & c & $\mathbf{c}$ \\
\hline & polyisobutylene & 1.6 & 2.4 & 2.4 \\
\hline \multirow[t]{2}{*}{ Alcohols } & polyvinyl alcohol & 3.1 & 3.1 & 3.1 \\
\hline & polyethylene glycol & 3.5 & 3.5 & 3.5 \\
\hline \multirow[t]{6}{*}{ Ethers } & cellulose & 3.2 & 3.2 & 10.2 \\
\hline & cellulose nitrate & d & d & $6.0^{e}$ \\
\hline & urea formaldehyde & 2.4 & 2.8 & 2.8 \\
\hline & polyoxymeylene & 2.1 & 5.6 & 14.1 \\
\hline & polypropylene oxide & 1.1 & d & d \\
\hline & polyvinyl formal & d & d & $5.6^{\mathrm{e}}$ \\
\hline Unsaturated - & polybutadiene & 0.5 & 0.5 & 0.5 \\
\hline Hydrocarbons & polyisoprene & 0.7 & 0.9 & 0.9 \\
\hline \multirow[t]{2}{*}{ Esters } & polymethyl methacrylate & 0.4 & 2.0 & 4.1 \\
\hline & polyvinyl acetate & 0.9 & 1.4 & 1.4 \\
\hline \multirow[t]{5}{*}{ Aromatics } & polystyrene & 0.2 & 0.2 & 0.2 \\
\hline & polysulfone & 0.1 & 0.1 & 0.1 \\
\hline & polycarbonate & $<0.1$ & $<0.1$ & 0.9 \\
\hline & polyesters & 0.3 & 0.3 & $<0.8$ \\
\hline & polyphenyl methacrylate & $<0.1$ & $<0.1$ & 1.3 \\
\hline Halogen - & polyvinyl chloride & 0.7 & 0.7 & 2.6 \\
\hline Containing & polychloroprene & 0.1 & 0.1 & 0.7 \\
\hline \multirow[t]{6}{*}{ Polymers } & chlorosulfonated polyethylene & 0.3 & 0.3 & 0.6 \\
\hline & polychlorotrifluoroethylene & 0 & 0 & 1.1 \\
\hline & polytetrafluoroethylene & 0 & 0 & $<0.3$ \\
\hline & chlorinated polyether & 0.7 & 0.8 & 0.8 \\
\hline & rubber hydrochloride & 0 & 0 & $<2.1$ \\
\hline & polyvinylidene chloride & 0 & 0 & $<2.1$ \\
\hline \multirow[t]{2}{*}{ Miscellaneous } & polyamides & 1.1 & 1.2 & 1.5 \\
\hline & ion exchange resins & 1.7 & 1.7 & 2.1 \\
\hline
\end{tabular}

a Values listed are those most appropriate for TRU waste, i.e., above $10 \mathrm{Mrad}$ absorbed dose or for conmercial rather than for pure materials.

b $G$ (net gas) is the net $G$ value, and includes depletion of oxygen when applicable.

c Values are intermediate between those for polyethylene and those for polypropylene.

¿ Not reported.

e Calculated on the basis of $\mathrm{G}(\mathrm{gas})=[$ factor] $[\mathrm{G}(\mathrm{gas})] \mathrm{s}$ for polyethylene, factor $=1.5$ for cellulose nitrate and factor $=1.4$ for polyvinyl formal, and $\mathrm{G}(\mathrm{gas})=4.1$ for polyethylene. 
Table D.12 G(gas) Values for Miscellaneous Commercial Plastics

\begin{tabular}{lclc}
\hline Material & G(gas) & Material & G(gas) \\
\hline cellulose nitrate & 6.2 & $\begin{array}{l}\text { melamine formaldehyde w/ } \\
\text { cellulosic filler }\end{array}$ & 0.8 \\
polyvinyl formal & 5.7 & Selectron 5038 polyester & 0.8 \\
polyethylene & 4.1 & natural rubber w/ fillers & $<0.8$ \\
allyl diglycol carbonate & 2.6 & natural rubber & 0.4 \\
ethyl cellulose & 2.1 & Thiokol ST & 0.4 \\
methyl methacrylate & 2.1 & Neoprene & $<0.25$ \\
cellulose propionate & 2.1 & casein plastic & 0.2 \\
cellulose acetate & 1.6 & Mylar $\circledast$ film & 0.2 \\
butyrate & 1.6 & Plaskon alkyd & 0.12 \\
nylon & $<1.2$ & triallyl cyanurate & 0.12 \\
phenolics (no fillers) & 1.2 & aniline formaldehyde & 0.04 \\
urea formaldehyde $w /$ & & & $<0.04$ \\
cellulostic filler & 1.2 & furane resin (asbestos \& carbon & $<0.04$ \\
Silastic & 1.2 & filler) & $<0.04$ \\
cellulose acetate & 1.2 & polystyrene & \\
butyl rubber & $<1.2$ & & \\
natural rubber & & & \\
\hline
\end{tabular}


Table D.13 Summary of Radiolysis Experiments on Cements at $298 \mathrm{~K}$

\begin{tabular}{|c|c|c|c|}
\hline Cement Type & Source & Radiolysis Products / Comments & References \\
\hline $\begin{array}{l}\text { high-alumina } \\
\text { cement }\end{array}$ & $\begin{array}{l}\text { gamma } \\
(\mathrm{Co}-60)\end{array}$ & $\begin{array}{l}\text { Steady-state } \mathrm{H}_{2} \text { pressure was dose dependent, } \\
\mathrm{O}_{2} \text { partially consumed, equilibrium pressure in } \\
\text { descending order for: } \mathrm{Fe}_{2} \mathrm{O}_{3} \text { cement }>\text { neat } \\
\text { cement }>\mathrm{MnO}_{2} \text { cement }\end{array}$ & $\begin{array}{l}\text { Bibler } 1976 \text {; } \\
\text { Bibler } 1978\end{array}$ \\
\hline $\begin{array}{l}\text { high-alumina } \\
\text { cement }\end{array}$ & alpha & $\begin{array}{l}\mathrm{H}_{2} \text { and } \mathrm{O}_{2} \text { produced, } \mathrm{O}_{2} \text { was } 20-50 \% \text { of total } \\
\text { gas, no steady-state pressure up to } 200 \text { psi, } \\
\mathrm{G}\left(\mathrm{H}_{2}\right)_{\mathrm{avg}}=0.21\end{array}$ & Bibler 1978 \\
\hline $\begin{array}{l}\text { high-alumina } \\
\text { cement w/ } \mathrm{NO}_{3-}^{-} \\
\text {or } \mathrm{NO}_{2-}^{-}\end{array}$ & gamma & $\begin{array}{l}\text { No additional pressurization as compared to } \\
\text { high-alumina cement without the nitrates. At } \\
\text { low dose rates }(0.09 \mathrm{Mrad} / \mathrm{hr}) \mathrm{O}_{2} \text { was } \\
\text { consumed, and at high dose rates ( } 28 \mathrm{Mrad} / \mathrm{hr} \text { ) } \\
\mathrm{O}_{2} \text { was generated. No steady state pressure was } \\
\text { reached. }\end{array}$ & Bibler 1978 \\
\hline $\begin{array}{l}\text { Portland } \\
\text { cement/gypsum- } \\
\text { perlite plaster in } \\
\text { ratio } 1.7: 1.0 \text { with } \\
\text { water }\end{array}$ & gamma & $\begin{array}{l}\mathrm{G}\left(\mathrm{H}_{2}\right)=0.03 \text {, hydrogen was the only gas } \\
\text { produced, steady-state pressure was dose rate } \\
\text { dependent, } \mathrm{O}_{2} \text { in air was partially consumed, } \\
\text { and nitrogen was unaffected }\end{array}$ & $\begin{array}{l}\text { Bibler and } \\
\text { Orebaugh } \\
1978\end{array}$ \\
\hline $\begin{array}{l}\text { Portland cement } \\
\text { / gypsum-perlite } \\
\text { plaster in ratio } \\
1.7: 1.0 \text { with } \\
\text { water }\end{array}$ & $\begin{array}{l}\text { alpha: } \\
(\mathrm{Cm}-244)\end{array}$ & $\begin{array}{l}\mathrm{G}\left(\mathrm{H}_{2}\right)=0.6 \text {, hydrogen generation was not dose } \\
\text { rate dependent, oxygen was partially consumed, } \\
\text { nitrogen was unaffected, no steady state } \\
\text { pressure was obtained up to } 200 \text { psi. }\end{array}$ & $\begin{array}{l}\text { Bibler and } \\
\text { Orebaugh } \\
1978\end{array}$ \\
\hline concrete & incinerator ash & $\begin{array}{l}\text { With } 35 \% \text { water (by mass) } \mathrm{G}\left(\mathrm{H}_{2}\right)=0.38 \text {, after } \\
\text { drying at } 200^{\circ} \mathrm{C} \text { to obtain } 7.4 \% \text { water } \\
\mathrm{G}\left(\mathrm{H}_{2}\right)=0.0002 \text {. Conclusion was that water of } \\
\text { hydration is not nearly as easily degraded as } \\
\text { free water. }\end{array}$ & $\begin{array}{l}\text { Bibler and } \\
\text { Orebaugh } \\
1978\end{array}$ \\
\hline $\begin{array}{l}\text { cement-based } \\
\text { grouts }\end{array}$ & $\begin{array}{l}\text { alpha: } \\
\text { simulated } \\
\text { current acid } \\
\text { waste }\end{array}$ & $\begin{array}{l}\text { The simulated waste was acidic and contained } \\
\text { metal sulfates and nitrates. The cement was } \\
\text { low-alumina cement. } G \text { (gas) }=0.32-0.43 \text {. (After } \\
\text { samples were dried at an elevated temperature, } \\
\text { no radiolysis gases were evolved.) A portion of } \\
\text { the gas evolved was hydrogen. }\end{array}$ & $\begin{array}{l}\text { Dole and } \\
\text { Friedman } \\
1986\end{array}$ \\
\hline $\begin{array}{l}\text { cement-based } \\
\text { grouts }\end{array}$ & $\begin{array}{l}\text { alpha: } \\
\text { simulated } \\
\text { double-shell } \\
\text { slurry waste }\end{array}$ & $\begin{array}{l}\text { The simulated waste was acidic and contained } \\
\text { metal sulfates and nitrates. The cement was } \\
\text { low-alumina cement. G(gas)=0.04-0.15. A } \\
\text { portion of the gas evolved was hydrogen. }\end{array}$ & $\begin{array}{l}\text { Dole and } \\
\text { Friedman } \\
1986\end{array}$ \\
\hline $\begin{array}{l}\text { cement-based } \\
\text { grouts }\end{array}$ & $\begin{array}{l}\text { gamma: } \\
\text { simulated } \\
\text { souble-shell } \\
\text { slurry waste }\end{array}$ & $\begin{array}{l}\text { The simulated waste was acidic and contained } \\
\text { metal sulfates and nitrates. The cement was } \\
\text { low-alumina cement. } G \text { (gas) }=0.02 \text {. A portion of } \\
\text { the gas evolved was hydrogen. }\end{array}$ & $\begin{array}{l}\text { Dole and } \\
\text { Friedman } \\
1986\end{array}$ \\
\hline
\end{tabular}


Appendix D 


\section{APPENDIX E. FLAMMABILITY LIMITS}

Table E.1 Lower and Upper Flammability Limits for Common Gases and Vapors

\begin{tabular}{|c|c|c|}
\hline \multirow[b]{2}{*}{ Gas or vapor } & \multicolumn{2}{|c|}{ Limits in Air (\%) } \\
\hline & Lower & Higher \\
\hline \multicolumn{3}{|l|}{ Inorganic } \\
\hline Hydrogen & 4.1 & 75 \\
\hline Ammonia & 15 & 28 \\
\hline Hydrazine & 4.7 & 100 \\
\hline Hydrogen sulfide & 4.3 & 45 \\
\hline Hydrogen cyanide & 6 & 41 \\
\hline Cyanogen & 6 & 32 \\
\hline Carbon Disulfide & 1.2 & 50 \\
\hline Carbon Monoxide & 23.5 & 100 \\
\hline \multicolumn{3}{|l|}{ Hydrocarbons } \\
\hline Methane & 5.0 & 14 \\
\hline Ethane & 3.0 & 12.5 \\
\hline Propane & 2.2 & 9.5 \\
\hline Butane & 1.9 & 8.5 \\
\hline Isobutane & 1.8 & 8.4 \\
\hline Pentane & 1.4 & 7.8 \\
\hline Isopentane & 1.4 & 7.6 \\
\hline 2-2 Dimethylpropane & 1.4 & 7.5 \\
\hline Hexane & 1.2 & 7.5 \\
\hline Dimethyl butane & 1.2 & 7.0 \\
\hline 2-Methyl pentane & 1.2 & 7.0 \\
\hline Heptane & 1.1 & 6.7 \\
\hline 2-3 Dimethyl pentane & 1.1 & 6.7 \\
\hline Octane & 1.0 & - \\
\hline Iso-octane & 1.0 & 6.0 \\
\hline Methyl cyclohexane & 1.2 & - \\
\hline Ehtyl cyclohexane & 0.9 & 6.6 \\
\hline Nonane & 0.8 & - \\
\hline Tetramethyl pentane & 0.8 & 4.9 \\
\hline Diethyl pentane & - & 5.7 \\
\hline Decane & 0.8 & 5.4 \\
\hline Ethylene & 3.1 & 32 \\
\hline Proplyene & 2.4 & 10.3 \\
\hline Butylene & 2.0 & 9.6 \\
\hline Butene-1 & 1.6 & 9.3 \\
\hline Butene-2 & 1.8 & 9.7 \\
\hline Isobutylene & 1.8 & 8.8 \\
\hline
\end{tabular}


Appendix E

Table E.1. Lower and Upper Flammability Limits for Common Gases and Vapors, continued

\begin{tabular}{|c|c|c|}
\hline \multirow[b]{2}{*}{ Gas or vapor } & \multicolumn{2}{|c|}{ Limits in Air (\%) } \\
\hline & Lower & Higher \\
\hline b-n-Amylene & 1.5 & 8.7 \\
\hline Butadiene & 2.0 & 11.5 \\
\hline Acetylene & 2.5 & 81 \\
\hline Benzene & 1.4 & 7.1 \\
\hline Toluene & 1.4 & 6.7 \\
\hline o-Xylene & - & 6.0 \\
\hline Ethyl benzene & 1.0 & - \\
\hline Styrene & - & 6.1 \\
\hline Butyl benzene & - & 5.8 \\
\hline Naphthalene & - & 5.9 \\
\hline Cyclopropane & 2.4 & 10.4 \\
\hline Ethyl cyclobutane & 1.2 & 7.7 \\
\hline Ethyl cyclopentane & - & 6.7 \\
\hline Cyclohexane & - & 8 \\
\hline \multicolumn{3}{|l|}{ Alcohols } \\
\hline Methyl alcohol & 6.7 & 36 \\
\hline Ethyl alcohol & 3.3 & 19 \\
\hline n-Propyl alcohol & 2.1 & 13.5 \\
\hline Isopropyl alcohol & 2.0 & 12 \\
\hline n-Butyl alcohol & 1.4 & 11.2 \\
\hline Amyl alcohol & 1.2 & - \\
\hline Furfuryl alcohol & 1.8 & 16.3 \\
\hline Allyl alcohol & 2.5 & 18.0 \\
\hline Propylene glycol & 2.6 & 12.5 \\
\hline Triethylene glycol & 0.9 & 9.2 \\
\hline \multicolumn{3}{|l|}{ Ethers } \\
\hline Methyl ether & 3.4 & 18 \\
\hline Ethyl Ether & 1.7 & 48 \\
\hline Ethyl n-propyl ether & 1.9 & 24 \\
\hline Isopropyl ether & 1.3 & 21 \\
\hline Vinyl ether & 1.7 & 28 \\
\hline Ethylene Oxide & 3.6 & 80 \\
\hline Propylene oxide & 2.1 & 21.5 \\
\hline Dioxane & 2.0 & 22 \\
\hline
\end{tabular}


Table E.1. Lower and Upper Flammability Limits for Common Gases and Vapors, continued

\begin{tabular}{|c|c|c|}
\hline \multirow[b]{2}{*}{ Gas or vapor } & \multicolumn{2}{|c|}{ Limits in Air (\%) } \\
\hline & Lower & Higher \\
\hline Trioxane & 3.6 & 29 \\
\hline Acetal & 1.6 & 10.4 \\
\hline \multicolumn{3}{|l|}{ Acid; Anhydride } \\
\hline Acetic Acid & 5.4 & - \\
\hline Acetic anhydride & 2.7 & 10 \\
\hline Phthalic anhydride & 1.7 & 10 \\
\hline \multicolumn{3}{|l|}{ Esters } \\
\hline Methyl formate & 5.0 & 20 \\
\hline Ethyl formate & 2.7 & 13.5 \\
\hline Butyl formate & 1.7 & 8 \\
\hline Methyl acetate & 3.1 & 16 \\
\hline Ethyl acetate & 2.2 & 9 \\
\hline Vinyl acetate & 2.6 & 13.4 \\
\hline Propyl acetate & 1.8 & 8 \\
\hline Isopropyl acetate & 1.8 & 8 \\
\hline Butyl acetate & 1.4 & 7.6 \\
\hline Amyl acetate & 1.1 & - \\
\hline Methyl cellulose acetate & 1.7 & 8.2 \\
\hline Methyl propionate & 2.4 & 13 \\
\hline Ethyl propionate & 1.8 & 11 \\
\hline Methyl lactate & 2.2 & - \\
\hline Ethyl lactate & 1.5 & - \\
\hline Ethyl nitrate & 4.0 & - \\
\hline Ethyl nitrite & 3.0 & - \\
\hline \multicolumn{3}{|l|}{ Phenols } \\
\hline Cresol & 1.1 & - \\
\hline \multicolumn{3}{|l|}{ Amines and Imines } \\
\hline Methylamine & 4.9 & 20.7 \\
\hline Dimethylamine & 2.8 & 14.4 \\
\hline Trimethylaunine & 2.0 & 11.6 \\
\hline Ethylamine & 3.5 & 14.0 \\
\hline Diethylamine & 1.8 & 10.1 \\
\hline
\end{tabular}


Appendix E

Table E.1. Lower and Upper Flammability Limits for Common Gases and Vapors, continued

\begin{tabular}{|c|c|c|}
\hline \multirow[b]{2}{*}{ Gas or vapor } & \multicolumn{2}{|c|}{ Limits in Air (\%) } \\
\hline & Lower & Higher \\
\hline Triethylamine & 1.2 & 8.0 \\
\hline Propylamine & 2.0 & 10.4 \\
\hline n-Butyl amine & 1.7 & 9.8 \\
\hline Allylamine & 2.2 & 22 \\
\hline Ethylene imine & 3.6 & 46 \\
\hline Methyl cellulose & 2.5 & 19.8 \\
\hline Ethyl cellulose & 1.8 & 14.0 \\
\hline Butyl cellulose & 1.1 & 10.6 \\
\hline Diethyl peroxide & 2.3 & - \\
\hline \multicolumn{3}{|l|}{ Aldehydes } \\
\hline Acetaldehyde & 4.1 & 55 \\
\hline Paraldehyde & 1.3 & - \\
\hline Butyraldehyde & 2.5 & - \\
\hline Acrolein & 2.8 & 31 \\
\hline Croton aldehyde & 2.1 & 15.5 \\
\hline Furfural & 2.1 & - \\
\hline \multicolumn{3}{|l|}{ Ketones } \\
\hline Acetone & 2.5 & 11 \\
\hline Methyl ethyl ketone & 1.8 & 10 \\
\hline Methyl propyl ketone & 1.5 & 8 \\
\hline Methyl butyl ketone & 1.3 & 8 \\
\hline Methyl isobutyl ketone & 1.4 & 7.5 \\
\hline Cyclohexanone & 1.1 & - \\
\hline Isophorone & 0.8 & 3.8 \\
\hline \multicolumn{3}{|c|}{ Other N Compounds } \\
\hline Acrylonitrile & 3.0 & 17 \\
\hline Pyridine & 1.8 & 12.4 \\
\hline Nicotine & 0.7 & 4.0 \\
\hline \multicolumn{3}{|c|}{ Halogen Derivatives } \\
\hline Methyl chloride & 7.6 & 17.4 \\
\hline Methyl bromide & 13.5 & 14.5 \\
\hline Methylene chloride & - & - \\
\hline
\end{tabular}


Table E.1. Lower and Upper Flammability Limits for Common Gases and Vapors, continued

\begin{tabular}{lcc}
\hline \multicolumn{1}{c}{ Gas or vapor } & \multicolumn{2}{c}{ Limits in Air $(\%)$} \\
\hline Ethyl chloride & Lower & Higher \\
Ethyl bromide & 3.8 & 15.4 \\
Ethylene dichloride & 6.7 & 11.3 \\
Vinyl chloride & 6.2 & 16 \\
Dichloroethylene & 4.0 & 22 \\
Trichloroethylene & 9.7 & 12.8 \\
Ethylene chlorohydrin & - & - \\
Propyl chloride & 4.9 & 15.9 \\
Propylene dichloride & 2.6 & 11.1 \\
Allyl chloride & 3.4 & 14.5 \\
Allyl bromide & 3.3 & 11.1 \\
2-Chloropropene & 4.4 & 7.3 \\
n-Butyl chloride & 4.5 & 16.0 \\
Butyl bromide & 1.8 & 10.1 \\
Chlorobutene & 5.2 & 5.6 \\
Isocrotyl chloride & 2.2 & 9.3 \\
Isocrotyl bromide & 4.2 & 19 \\
n-Amyl chloride & 6.4 & 12 \\
tert.-Amyl chloride & 1.6 & 8.6 \\
Chlorobenzene & 1.5 & 7.4 \\
Dichlorobenzene & 1.3 & 7.1 \\
\hline \multicolumn{1}{c}{ Miscellaneous } & 2.2 & 9.2 \\
\hline Gasoline & & \\
Naphtha & 0.8 & 5.6 \\
Coal gas & 5.3 & 5 \\
Kerosine & 0.8 & \\
\hline
\end{tabular}


Appendix E 


\section{APPENDIX F. SAMPLE PROBLEMS}

\section{Example \#1: Calculation of hydrogen gas concentration in a single rigid leaking enclosure}

Problem: Consider a rigid container holding radioactive waste that is generating hydrogen gas at a rate of $4.2 \times 10^{-7} \mathrm{gmol} / \mathrm{s}$. Hydrogen gas escapes the container by diffusion through a small opening in the wall of the container. It has been determined experimentally that the effective hydrogen release rate through the opening is $4 \times 10^{-7} \mathrm{gmol} \mathrm{H} / 2 / \mathrm{s} \cdot$ mole fraction. The void volume in the container is $1000 \mathrm{~cm}^{3}$, the temperature is $298 \mathrm{~K}$, and the pressure is assumed to be 1 atmosphere. Calculate the hydrogen gas mole fraction as a function of time. How long does it take for the hydrogen mole fraction to reach 0.05 ( 5 mole percent hydrogen)? How long does it take to reach 19 volume percent hydrogen?

Solution: For this problem, $\mathrm{T}=4 \times 10^{-7} \mathrm{gmol} / \mathrm{s}$ and $\mathrm{R}_{\mathrm{M}}=4.2 \times 10^{-7} \mathrm{gmol} / \mathrm{s}$. Using the ideal gas law the initial number of gas moles is: $\mathrm{n}=(1 \mathrm{~atm})\left(1000 \mathrm{~cm}^{3}\right) /\left(82.05 \mathrm{~atm}^{3} \mathrm{~cm}^{3} / \mathrm{gmol} \cdot \mathrm{K}\right)(298 \mathrm{~K})=4.09 \times 10^{-2} \mathrm{gmol}$. Using Equation 4.12 with these values for $T, R_{M}$, and $n$, the mole fraction of hydrogen as a function of time, $X(t)$, is:

$X(t)=1.05\left[1-\exp \left(-9.78 \times 10^{-6} t\right)\right]$.

This equation can be rearranged to give the time as a function of the hydrogen mole fraction:

$$
t=\frac{-\ln \left(1-\frac{X(t)}{1.05}\right)}{9.78 \times 10^{-6}}
$$

From this equation it is determined that the hydrogen mole fraction reaches 0.05 after 4988.8 seconds ( $~ 83.1$ minutes), and the hydrogen mole fraction reaches 0.19 (19 volume percent) after $2.04 \times 10^{4}$ seconds $(\sim 5.67$ hours $)$.

\section{Example \#2: Single semi-open rigid container w/ contents undergoing radiolysis}

Problem: Consider a semi-open rigid container with a void volume of $1000 \mathrm{~cm}^{3}$ that contains material which radiolytically generates gases. The $\mathrm{G}$ (net gas) value is 1.5 molecules $/ 100 \mathrm{eV}$, the $\mathrm{G}$ (flam gas) value is 0.7 molecules $/ 100 \mathrm{eV}$, and the decay heat absorbed by the material radiolytically generating gas is $2 \mathrm{~W}$. Assume that the container initially has no flammable gas, that the temperature is steady at $313 \mathrm{~K}$, and that the pressure outside the container is 1.0 atmosphere. Determine an equation describing the hydrogen mole fraction as a function of time. What is the steady-state hydrogen mole fraction? How long does it take for the hydrogen mole fraction in the container to reach 0.05 ( 5 volume percent hydrogen)?

Solution: The molar rate of radiolytically generated gas is determined from Equation 4.6:

$$
\mathrm{R}_{\mathrm{M}} \text { (net gas) }=(2 \mathrm{~W})\left(\frac{\mathrm{J} / \mathrm{s}}{\mathrm{W}}\right)\left(\frac{\mathrm{eV}}{1.602 \times 10^{-19} \mathrm{~J}}\right)\left(\frac{1.5 \text { molecules } / 100 \mathrm{eV}}{6.023 \times 10^{23} \mathrm{molecules} / \mathrm{gmol}}\right)=3.11 \times 10^{-7} \mathrm{gmol} / \mathrm{s}
$$

The volumetric rate of gas generation is then determined by applying the ideal gas law: 


$$
\mathrm{Q}=\frac{\left.\mathrm{R}_{\mathrm{M}} \text { (net gas }\right)}{\rho_{\mathrm{M}}}=\frac{\mathrm{RTR}_{\mathrm{M}}(\text { net gas })}{\mathrm{P}}=\frac{\left(82.05 \frac{\mathrm{cm}^{3} \cdot \mathrm{atm}}{\mathrm{gmol} \cdot \mathrm{K}}\right)(313)\left(3.11 \times 10^{-7} \frac{\mathrm{gmol}}{\mathrm{s}}\right)}{1 \mathrm{~atm}}=7.99 \times 10^{-3} \frac{\mathrm{cm}^{3}}{\mathrm{~s}} .
$$

The concentration (or molar density) of flammable gas entering the container is determined from the Gvalues for net gas and for flammable gas along with the ideal gas law:

$$
\mathrm{C}_{\mathrm{A} 0}=\left(\frac{\mathrm{G}(\mathrm{flam} \text { gas })}{\mathrm{G}(\text { net gas })}\right)\left(\frac{\mathrm{P}}{\mathrm{RT}}\right)=\left(\frac{0.7}{1.5}\right)\left(\frac{1 \mathrm{~atm}}{\left(82.05 \mathrm{~cm}^{3} \cdot \mathrm{atm} / \mathrm{gmol} \cdot \mathrm{K}\right)(313)}\right)=1.817 \times 10^{-5} \frac{\text { mole flam Gas }}{\mathrm{cm}^{3}} .
$$

The equation describing the concentration of flammable gas (moles flammable gas per cubic centimeters) in the container as a function of time is determined using Equation 4.14:

$$
\mathrm{C}_{\mathrm{A}}=\left(1.817 \times 10^{-5} \mathrm{gmol} / \mathrm{cm}^{3}\right)\left[1-\exp \left(\frac{-(\mathrm{t})\left(7.99 \times 10^{-3} \mathrm{~cm}^{3} / \mathrm{s}\right.}{1000 \mathrm{~cm}^{3}}\right)\right] \text {. }
$$

It is useful to calculate the mole fraction of flammable gas as a function of time. At a pressure of $1 \mathrm{~atm}$ and a temperature of $313 \mathrm{~K}$, one cubic centimeter contains $n=\left[(1 \mathrm{~atm})(1 \mathrm{~cm} 3) /\left(82.05 \mathrm{~atm} \cdot \mathrm{cm}^{3} / \mathrm{gmol} \cdot \mathrm{K}\right)(313)\right]=$ $3.894 \times 10^{-5}$ gmoles gas. Therefore, the mole fraction of flammable gas as a function of time for this example is:

Mole Fraction Flammable $\operatorname{Gas}=\mathrm{X}(\mathrm{t})=\left(\frac{1.817 \times 10^{-5}}{3.894 \times 10^{-5}}\right)\left[1-\exp \left(\frac{-\mathrm{t}\left(7.99 \times 10^{-3} \mathrm{~cm}^{3} / \mathrm{s}\right)}{1000 \mathrm{~cm}^{3}}\right)\right]$.

For long times the exponential term gœes to zero and the steady-state flammable gas mole fraction is 0.467 .

The above equation can be rearranged to give the time as a function of the mole fraction flammable gas:

$$
t=(-125156.4) \ln (1-X(t) 2.143) \text {. }
$$

From this equation, the flammable gas reaches 5 mole \% (mole fraction of 0.05 or 5 volume percent) at a time of about $14.185 \times 10^{3}$ seconds (236.4 minutes).

\section{Example \#3: Check of solution to hydrogen gas concentration in a rigid leaking enclosure nested within a rigid non-leaking enclosure}

Problem: Prove that the expressions for $X_{1}$ and $X_{2}$ in Equations 4.19 and 4.20 satisfy the coupled differential equations in 4.2.18a and 4.19b.

Solution: From Equations 4.19 and $4.20, \mathrm{X}_{1}(\mathrm{t})$ is given by:

$$
X_{1}(t)=\frac{A S}{(A+B)^{2}}-\frac{A S \exp [-t(A+B)]}{(A+B)^{2}}+\frac{B S t}{(A+B)}
$$

and $X_{2}(t)$ is given by: 


$$
X_{2}(t)=\frac{-B S}{(A+B)^{2}}+\frac{B S \exp [-t(A+B)]}{(A+B)^{2}}+\frac{B S t}{(A+B)}
$$

Taking the derivative of $X_{1}$ :

$$
\frac{\mathrm{d}}{\mathrm{dt}}\left[\mathrm{X}_{1}(\mathrm{t})\right]=\frac{\mathrm{d}}{\mathrm{dt}}\left[\frac{\mathrm{AS}}{(\mathrm{A}+\mathrm{B})^{2}}-\frac{\mathrm{AS} \exp [-\mathrm{t}(\mathrm{A}+\mathrm{B})]}{(\mathrm{A}+\mathrm{B})^{2}}+\frac{\mathrm{BS} \mathrm{t}}{(\mathrm{A}+\mathrm{B})}\right]
$$

or

$$
\frac{d X_{1}}{d t}=\frac{A S}{(A+B)^{2}}(A+B) \exp [-t(A+B)]+\frac{S B}{(A+B)}=\frac{A S \exp [-t(A+B)]+S B}{(A+B)} .
$$

Substituting $\mathrm{X}_{1}(\mathrm{t}), \mathrm{X}_{2}(\mathrm{t})$, and the above expression for $\mathrm{dX}_{1} / \mathrm{dt}$ into Equation 4.18 a yields:

$$
\begin{aligned}
\frac{\mathrm{dX}_{1}}{\mathrm{dt}} & =S-A\left(X_{1}-X_{2}\right) \\
& =S-A\left\{\frac{A S(1-\exp [-t(A+B)])}{(A+B)^{2}}+\frac{S B t}{A+B}+\frac{B S(1-\exp [-t(A+B)]}{(A+B)^{2}}-\frac{S B t}{A+B}\right\} \\
& =S-A S\left\{\frac{(A+B)(1-\exp [-t(A+B)])}{(A+B)^{2}}\right\}=S-\frac{A S}{A+B}+\frac{A S \exp [-t(A+B)]}{A+B} \\
& =\frac{B S}{A+B}+\frac{A S \exp [-t(A+B)]}{A+B}=\frac{A S \exp [-t(A+B)]+S B}{A+B} .
\end{aligned}
$$

Therefore, with this check and the check that the initial condition on $X_{1}$ is satisfied (i.e., $\left.X_{1}(0)=0\right)$ by the solution, the solution for $X_{1}$ is proved valid.

Now, check the solution for $\mathrm{X}_{2}$ by substituting it into the differential equation for $\mathrm{dX} / \mathrm{dt}$.

The derivative of $\mathrm{X}_{2}$ is:

$$
\frac{d}{d t}\left[X_{2}(t)\right]=\frac{d}{d t}\left[\frac{-B S}{(A+B)^{2}}+\frac{B S \exp [-t(A+B)]}{(A+B)^{2}}+\frac{B S t}{(A+B)}\right]
$$

or

$$
\frac{d X_{2}}{d t}=\frac{-B S(A+B) \exp [-t(A+B)]}{(A+B)^{2}}+\frac{S B}{A+B}=\frac{S B[1-\exp [-t(A+B)]]]}{A+B} \text {. }
$$

Substituting $X_{1}, X_{2}$, and the above expression for $\mathrm{dX}_{2} / \mathrm{dt}$ into Equation $4.18 \mathrm{~b}$ : 


$$
\begin{aligned}
\frac{d X_{2}}{d t} & =B\left(X_{1}-X_{2}\right) \\
& =B\left\{\frac{A S(1-\exp [-t(A+B)])}{(A+B)^{2}}+\frac{S B t}{A+B}+\frac{B S(1-\exp [-t(A+B)]}{(A+B)^{2}}-\frac{S B t}{A+B}\right\} \\
& =B S\left\{\frac{(A+B)(1-\exp [-t(A+B)])}{(A+B)^{2}}\right\}=\frac{B S\{1-\exp [-t(A+B)]\}}{A+B}
\end{aligned}
$$

Therefore, with this check and the check that the initial condition on $X_{2}$ is satisfied (i.e., $\left.X_{2}(0)=0\right)$ by the solution, the solution for $\mathrm{X}_{2}$ is proved valid.

\section{Example \#4: Hydrogen gas concentration in a rigid leaking enclosure nested within a rigid non- leaking enclosure}

Problem: Consider a leaking container with contents that have a decay heat of $2.26 \mathrm{~W}\left(1.41 \times 10^{19} \mathrm{eV} / \mathrm{s}\right)$ and an effective radiolytic $\mathrm{G}$-value for hydrogen generation of 0.7 molecules $\mathrm{H}_{2} / 100 \mathrm{eV}$. The leak in the container has been determined to allow a flux of $\mathrm{T}_{1}=1.1 \times 10^{-7} \mathrm{gmol} \mathrm{H}_{2} / \mathrm{s}$-mole fraction. The leaking container is nested within a nonleaking container. The void volume of the inner container is 1.0 liter, and the void volume in the outer container (excluding the inner container) is 2.0 liters. Assume that the temperature of the system is constant at $330 \mathrm{~K}$ and that the only radiolysis gas produced is hydrogen. How long does it take for the inner container to reach 5 volume percent hydrogen if it is assumed that there is initially no hydrogen in either container.

Solution: Given a decay heat of $1.41 \times 10^{19} \mathrm{eV} / \mathrm{s}$ and a G-value of 0.7 molecules $\mathrm{H}_{2} / 100 \mathrm{eV}$, the hydrogen generation rate is $9.87 \times 10^{16}$ molecules $\mathrm{H}_{2} / \mathrm{s}$ or $\mathrm{R}_{\mathrm{M}}=1.64 \times 10^{-7} \mathrm{gmol} \mathrm{H}_{2} / \mathrm{s}$, which is calculated using Equation 4.6. If it is assumed that the containers were filled at 1 atmosphere and $298 \mathrm{~K}$, then the initial number of gas moles are: $n_{1}=4.09 \times 10^{-2}$ gmol and $n_{2}=8.18 \times 10^{-2}$ gmol, where $n_{1}$ is the original number of gas moles within the inner enclosure and $n_{2}$ is the initial number of gas moles in the void volume within the outer enclosure. Therefore, $S=R_{M} / n_{1}=4.01 \times 10^{-6}, A=T_{1} / n_{1}=2.69 \times 10^{-6}$, and $B=T_{1} / n_{2}=1.34 \times 10^{-6}$. Using these numerical inputs and the equation for $X_{1}(t)$ given by Equation 4.19 , the time to reach $X_{1}=0.05$ is determined implicitly to be approximately 211.3 minutes or about 3.5 hours. For this problem, the time to reach a given hydrogen mole fraction can be determined in various ways, including: (1) graphical techniques; (2) trial-and-error methods; or (3) iterative methods (Newton scheme).

\section{Example \#5: Hydrogen concentration in two nested rigid leaking containers}

Problem: Consider a leaking container with contents that have a decay heat of $2.26 \mathrm{~W}(1.41 \times 1019 \mathrm{eV} / \mathrm{s})$ and an effective radiolytic $\mathrm{G}$-value for hydrogen generation of 0.0131 molecules $\mathrm{H}_{2} / 100 \mathrm{eV}$ that is nested within a second leaking container. The leak in the inner container has been determined to allow a flux of $\mathrm{T}_{1}=1.1 \times 10^{-7} \mathrm{gmol} \mathrm{H}_{2} / \mathrm{s}$.mole fraction, and the outer container has been determined to allow a hydrogen flux of $\mathrm{T}_{2}=1.2 \times 10^{-7} \mathrm{gmol} \mathrm{H}_{2} / \mathrm{s}$.mole fraction. The void volume of the inner container is 1.5 liters, and the void volume in the outer container (excluding the inner container) is 2.5 liters. Assume that the temperature of the system is constant at $330 \mathrm{~K}$ and that the only radiolysis gas produced is hydrogen. How long does it take for the inner container to reach 4 volume percent hydrogen if it is assumed that there is initially no hydrogen in either container? What is the hydrogen percent by volume in the outer container (excluding the inner container) when the inner container has 5 volume percent hydrogen? 
Solution: The coupled differential equations describing the hydrogen concentration in two nested rigid leaking enclosures are given by Equations $4.23 \mathrm{a}$ and $4.23 \mathrm{~b}$. The solutions for Equations $4.23 \mathrm{a}$ and $4.23 \mathrm{~b}$ are given by Equation 4.24 and 4.250 . With a decay heat of $1.41 \times 10^{19} \mathrm{eV} / \mathrm{s}$ and a G-value for hydrogen generation of 0.0131 molecules $\mathrm{H}_{2} / 100 \mathrm{eV}$, the hydrogen generation rate is $\mathrm{R}_{\mathrm{M}}=3.0675 \times 10^{-9} \mathrm{gmol} \mathrm{H}_{2} / \mathrm{s}$. If it is assumed that the containers were filled at 1 atmosphere and $298 \mathrm{~K}$, then the initial number of gas moles within the two enclosures are: $\mathrm{n}_{1}=6.135 \times 10^{-2} \mathrm{gmol}$ and $\mathrm{n}_{2}=0.1022 \mathrm{gmol}$. Therefore, $\mathrm{S}=\mathrm{R}_{\mathrm{M}} / \mathrm{n}_{1}=5.0 \times 10^{-8}, \mathrm{~A}=\mathrm{T}_{1} / \mathrm{n}_{1}=1.79 \times 10^{-6}, \mathrm{~B}=\mathrm{T}_{1} / \mathrm{n}_{2}=1.076 \times 10^{-6}$, and $\mathrm{C}=\mathrm{T}_{2} / \mathrm{n}_{2}=1.174 \times 10^{-6}$. With these numerical inputs, $Z=4.043 \times 10^{-6}$, and $\mathrm{W}=2.815 \times 10^{-6}$. Then, using these inputs to Equation 4.24 for $\mathrm{X}_{1}(\mathrm{t})$ and Equation 4.25 for $\mathrm{X}_{2}(\mathrm{t})$, the hydrogen concentration for the two containers as a function of time can be determined. See Figure F.1 for the graphical results.

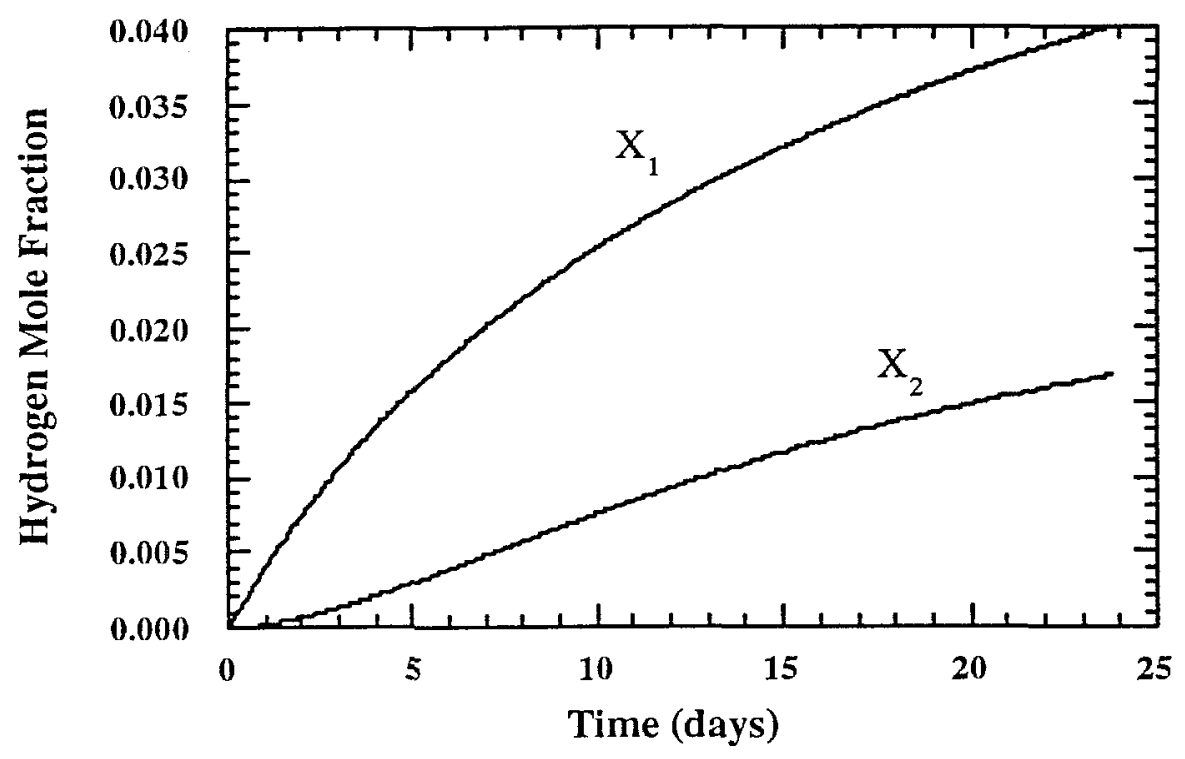

Figure F.1 Hydrogen concentration as a function of time

From the numerical results used to generate the above plot, it is determined than the inner container reaches 4 volume percent hydrogen (mole fraction hydrogen of 0.4 ) after about 23.8 days, and that at this time the outer container has about 1.7 volume percent hydrogen.

\section{Example \#6: Pressure in a single rigid non-leaking container with contents undergoing radiolysis}

Problem: Consider a case where the container was sealed at a pressure $P_{0}=1$ atm and a temperature $\mathrm{T}_{0}=25^{\circ} \mathrm{C}(298 \mathrm{~K})$. The decay heat absorbed by the material undergoing radiolysis is $\mathrm{D}_{\mathrm{H}}=6.24 \times 10^{20} \mathrm{eV} / \mathrm{s}$, the container temperature is $90^{\circ} \mathrm{C}(363 \mathrm{~K})$, the effective net gas radiolytic $\mathrm{G}$ values is $\mathrm{G}($ net gas $)=0.3$ molecules $/ 100 \mathrm{eV}$, and the container void volume is 5 liters $\left(5000 \mathrm{~cm}^{3}\right)$. Calculate the container pressure as a function of time. How long does it take for the container to reach a pressure of 2 atmospheres?

Solution: The pressure as a function of time (from Equation 4.47) is: 
$\left.\mathrm{P}(\mathrm{t})=\left[1 \mathrm{~atm}\left(\frac{363 \mathrm{~K}}{298 \mathrm{~K}}\right)\right]+\left(\frac{6.24 \times 10^{20} \frac{\mathrm{eV}}{\mathrm{s}}}{100}\right) \frac{0.3 \frac{\mathrm{molecules}}{100 \mathrm{eV}}}{6.023 \times 10^{23} \frac{\mathrm{molecules}}{\mathrm{gmol}}}\right)\left(\frac{\left(82.05 \frac{\mathrm{cm}^{3} \cdot \mathrm{atm}}{\mathrm{gmol} \cdot \mathrm{K}}\right)(363 \mathrm{~K})}{5000 \mathrm{~cm}^{3}}\right)(\mathrm{t})$

or after simplification:

$$
\mathrm{P}(\mathrm{t})=1.22 \mathrm{~atm}+\left(1.85 \times 10^{-5} \frac{\mathrm{atm}}{\mathrm{s}}\right)(\mathrm{t}) \text {. }
$$

From this equation, the pressure will reach 2 atm in $4.226 \times 10^{4}$ seconds or about 11.7 hours.

\section{Example \#7: Pressure in a Single Rigid Leaking Container with Contents Undergoing Radiolysis}

Problem: Consider an example of a single leaking enclosure that has a single leakage hole with a length of $0.5 \mathrm{~cm}$ and a diameter of $3.2 \times 10^{-3} \mathrm{~cm}$. The container was initially sealed at $25^{\circ} \mathrm{C}$, but has a steady state temperature of $80^{\circ} \mathrm{C}$. Assume that (1) the effective radiolytic $\mathrm{G}$ value is 0.8 molecules $/ 100 \mathrm{eV}$; (2) the contents decay heat is $2.5 \mathrm{~W}$ and all decay heat is absorbed by the material capable of undergoing radiolysis; (3) the void volume of the container is $1000 \mathrm{~cm}^{3}$; (4) the effective viscosity of the gas is 0.021 $\mathrm{cP}$, and (5) the effective molecular weight of the gas within the container at any time can be approximated by $26 \mathrm{~g} / \mathrm{gmol}$. Assuming the downstream pressure is one atmosphere, calculate the container pressure as a function of time and the maximum container pressure.

Solution: First it is useful to determine if the contribution to the flow from molecular flow can be neglected. Forming the ratio $\mathrm{F}_{\mathrm{c}} / \mathrm{F}_{\mathrm{m}}$ :

$$
\frac{F_{c}}{F_{m}}=\frac{654 D P_{a}}{m \sqrt{T / M_{w}}}=\frac{(654)\left(3.2 \times 10^{-3}\right)\left(P_{u}+1\right)}{(2)(0.021) \sqrt{353 / 26}}=13.5\left(\mathrm{P}_{u}+1\right),
$$

it is clear that for $\mathrm{P}_{\mathrm{u}} \cdot 1 \mathrm{~atm}$, then $\mathrm{F}_{\mathrm{m}} \cdot\left(\mathrm{F}_{\mathrm{c}} / 27\right)$ or $\mathrm{F}_{\mathrm{m}}$ is about $3.7 \%$ of $\mathrm{F}_{\mathrm{c}}$. Therefore, the contribution to the total flow rate from molecular flow can reasonably be neglected. By neglecting molecular flow, the calculated container pressure is conservative and bounding.

Neglecting molecular flow, the equation for the container pressure as a function of time (from Eqn. 4.61) is:

$$
P_{u}(t)=\sqrt{\left(\frac{2 R_{g} T R_{M}}{F_{C}}+P_{d}^{2}\right)} \tanh \left\{\left[t\left(\frac{F_{C}}{2 V}\right) \sqrt{\left(\frac{2 R_{g} T R_{M}}{F_{C}}+P_{d}^{2}\right)}\right]+\tanh ^{-1}\left(\frac{T P_{0}}{\left.T_{0} \sqrt{\left[\left(\frac{2 R_{g} T R_{M}}{F_{c}}\right)+P_{d}{ }^{2}\right.}\right]}\right)\right\} .
$$

Substituting $F_{c}=2.487 \times 10^{-2}, V=1000 \mathrm{~cm}^{3}, \mathrm{R}=82.05 \mathrm{~cm}^{3} \cdot \mathrm{atm} / \mathrm{gmol} \cdot \mathrm{K}, \mathrm{R}_{\mathrm{M}}=2.073 \times 10^{-7} \mathrm{gmol} / \mathrm{s}, \mathrm{T}_{0}=298 \mathrm{~K}$, $T=353 \mathrm{~K}, \mathrm{P}_{\mathrm{d}}=1 \mathrm{~atm}, \mathrm{P}_{0}=1$ atm into the above equation and plotting the results gives the curve in Figure F.2. 


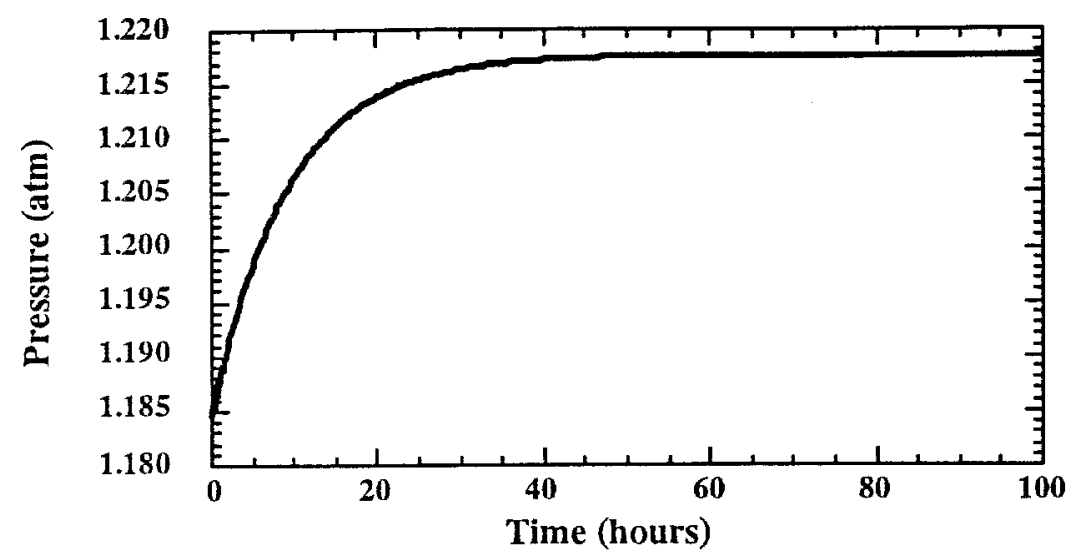

Figure F.2 Pressure as a function of time for example single leaking container

The results shown in Figure F.2 indicate that the container reaches its maximum pressure after about 50 hours and that the maximum pressure is a little less than $1.218 \mathrm{~atm}$. An exact calculation of the steady state pressure shows that $\mathrm{P}_{\mathrm{ss}}=1.2177$.

Example \#8: Lower flammability limit for natural gas in air

Problem: What is the lower flammability limit of natural gas in air?

Solution: Natural gas has an approximate composition of $80 \%$ methane (lower limit, $5.3 \%$ ), 15\% ethane (lower limit $3.22 \%$ ), $4 \%$ propane (lower limit $2.37 \%$ ), and $1 \%$ butane (lower limit $1.86 \%$ ). Using Equation 4.65, the lower limit of the natural gas mixture is:

$$
\mathrm{F}_{\mathrm{L}, \mathrm{MIX}}=\frac{100}{\frac{80}{5.3}+\frac{15}{3.22}+\frac{4}{2.37}+\frac{1}{1.86}}=4.55 \% \text {. }
$$

Example \#9: Time to reach 5 volume percent hydrogen in a package with radioactive material nested within three confinement layers and a non-leaking rigid containment vessel

Problem: Consider a mass of radioactive material that has a decay heat of $1 \times 10^{18} \mathrm{eV} / \mathrm{s}$ and a G-value for radiolysis of 0.5 molecules $/ 100 \mathrm{eV}$. The material is first placed in a metal "product can" that allows a

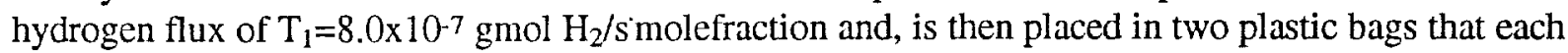
allow a hydrogen flux of $5.0 \times 10^{-7} \mathrm{gmol} \mathrm{H} / \mathrm{s}$ mole fraction. This "bagged-out" material is then placed in a rigid non-leaking containment vessel. If the material is sealed in the containment vessel at $298 \mathrm{~K}$, the void volume within the product can is 0.5 liters, the void volume between the outer bag and the containment vessel is 1.5 liters, and the temperature is constant at $330 \mathrm{~K}$, how long does it take for the hydrogen mole fraction within the product can to reach 0.05 ( 5 volume percent hydrogen)? Assume that the only gas produced is hydrogen.

Solution: For a decay heat of $1 \times 10^{18} \mathrm{eV} / \mathrm{s}$ and a G-value of 0.5 molecules $\mathrm{H}_{2} / 100 \mathrm{eV}$, the hydrogen generation rate is $\mathrm{R}_{\mathrm{M}}=8.3 \times 10^{-9}$ moles $\mathrm{H}_{2} / \mathrm{s}$. For the three confinement layers (metal can and two plastic bags), the effective hydrogen flux is $1 / \mathrm{T}_{\text {eff }}=\left(1 / 8.0 \times 10^{-7}\right)+\left(1 / 5 \times 10^{-7}\right)+\left(1 / 5 \times 10^{-7}\right)$, or $\mathrm{T}_{\text {eff }}=1.9 \times 10^{-7} \mathrm{gmol}$ $\mathrm{H}_{2} /$ s mole fraction. Using this effective allowable flux through the three confinement layers, the problem 
can be visualized as a radioactive mass within one confinement layer (representing the three confinement layers) that is within a non-leaking rigid containment vessel. The solution to this case is given by Equation 4.19, which gives the hydrogen mole fraction as a function of time for the inner-most confinement layer. The number of gas moles originally within the confinement volumes is calculated with the ideal gas equation as $n_{1}=2.05 \times 10^{-2}$ gmol, and the number of gas moles between the confinement layers and the containment vessel is $n_{2}=1.16 \times 10^{-2}$ gmol. Using these values, $S=\left(R_{M} / n_{1}\right)=8.1 \times 10^{-6}$, $\mathrm{A}=\left(\mathrm{T}_{\text {eff }} / \mathrm{n}_{1}\right)=9.3 \times 10^{-6}$, and $\mathrm{B}=\left(\mathrm{T}_{\text {eff }} / \mathrm{n}_{2}\right)=3.1 \times 10^{-6}$. Then, the hydrogen mole fraction as a function of time is as shown in Figure F.3.

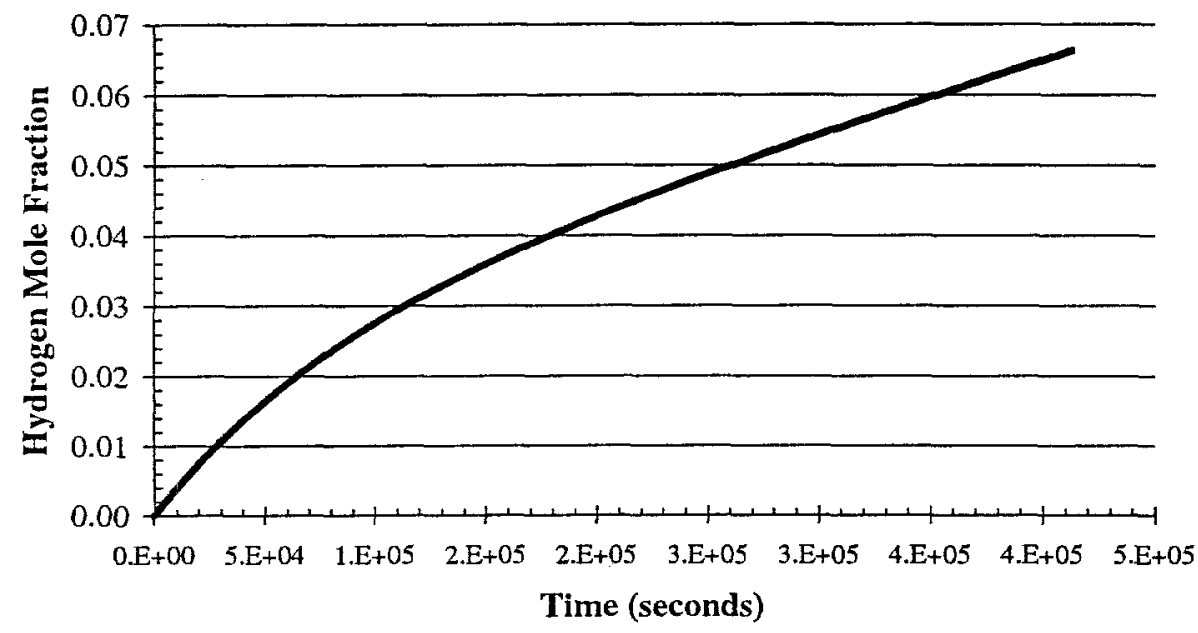

Figure F.3 Hydrogen mole fraction as a function of time

From the plot, the hydrogen mole fraction in the innermost confinement layer reaches 0.05 in about $2.6 \times 10^{5}$ seconds or about 72.2 hours. 